\title{
Investigation of Particle Measurement in Different Dilution Ratios with Gasoline Direct Injection and Port Fuel Injection
}

John Adam Phillips

West Virginia University, jophillips@mix.wvu.edu

Follow this and additional works at: https://researchrepository.wvu.edu/etd

Part of the Automotive Engineering Commons

\section{Recommended Citation}

Phillips, John Adam, "Investigation of Particle Measurement in Different Dilution Ratios with Gasoline Direct Injection and Port Fuel Injection" (2020). Graduate Theses, Dissertations, and Problem Reports. 7815.

https://researchrepository.wvu.edu/etd/7815

This Thesis is protected by copyright and/or related rights. It has been brought to you by the The Research Repository @ WVU with permission from the rights-holder(s). You are free to use this Thesis in any way that is permitted by the copyright and related rights legislation that applies to your use. For other uses you must obtain permission from the rights-holder(s) directly, unless additional rights are indicated by a Creative Commons license in the record and/ or on the work itself. This Thesis has been accepted for inclusion in WVU Graduate Theses, Dissertations, and Problem Reports collection by an authorized administrator of The Research Repository @ WVU. For more information, please contact researchrepository@mail.wvu.edu. 


\title{
INVESTIGATION OF PARTICLE MEASUREMENT IN DIFFERENT DILUTION RATIOS WITH A GASOLINE DIRECT INJECTION AND PORT FUEL INJECTION VEHICLE
}

\author{
John Adam Phillips \\ Thesis Submitted to the \\ Benjamin M. Statler College of Engineering and Mineral Resources at \\ West Virginia University \\ In partial fulfillment of the requirements for the degree of \\ Master of Science \\ in \\ Mechanical Engineering \\ Gregory Thompson, Ph. D., Chair \\ Arvind Thiruvengadam, Ph. D. \\ Derek Johnson, Ph. D.
}

Department of Mechanical and Aerospace Engineering

West Virginia University

Morgantown, West Virginia

2020

Keywords: Gasoline Direct Injection, Particle Measurement, Port Fuel Injection Copyright 2020 John Adam Phillips 


\title{
ABSTRACT \\ Investigation of Particle Measurement in Different Dilution Ratios with a Gasoline Direct Injection and Port Fuel Injection Vehicle
}

\begin{abstract}
John Adam Phillips
Ambient air quality has been a concern in the United States since the mid-1900's, forcing legislations like the Air Pollution Control Act and Clean Air Act necessary to bring focus on air pollution and quality. The Environmental Protection Agency (EPA) continues to update the requirements for more efficient vehicles and emissions sampling methods. Today the EPA has implemented regulations on modern spark ignited engines without any major focus on the type of injection technologies being used. While particle matter (PM) is a requirement to measure for a vehicle certification, more research should focus on the particle number (PN) measurements that are required for vehicle certification in the European Union. This study explores the results of an experimental setup that measures particle data within multiple simultaneous dilution ratio sampling environments. In addition to different dilution ratios, two types of injection strategies were examined and included gasoline direct injected (GDI) and port fuel injected (PFI). The emphasis of the study was the comparison of real time particle number and mass concentration to highlight injection technologies effect on particles. Furthermore, this research analyzed and compared the results in separate dilutions environments to evaluate sampling from a high dilution ratio and determine whether this was an acceptable sampling method. As engine technology, such as GDI, becomes the prominent method of injection and PFI continues to be utilized, methods of soot measurement should be improved to measure near $0.01 \mathrm{mg} / \mathrm{m}^{3}$. The PN measurements should be considered in addition to current PM regulation with PN concentrations measured above $1 \times 10^{7} \mathrm{~cm}^{-3}$ during transient test conditions.
\end{abstract}




\section{ACKNOWLEDGEMENTS}

I often felt the more I prepared and conducted my research, I had created more work for myself than when I initially started. With that being said, there are plenty of people that came along the way to help whether it was at work or not. I would like to thank Dr. Gregory Thompson for helping me to the completion of my research and for the initially opportunity to work for CAFEE years ago as an undergrad. I would also like to thank my committee members Dr. Arvind Thiruvengadam and Dr. Derek Johnson for their help during this process and guidance along my journey with CAFEE. I would like to thank my dad Jack Phillips, my mother Pam Morgan, my step-mom Mandy Phillips, my brother Ben Phillips, and my cousins Mikie and Travis Terry, my friends Dan and Karen Skinner for all the support during my time as a masters student. I would like to thank my close friends/co-workers Allen Duffy and Andrew Melcher as they both helped me in their own way tremendously during my time as a graduate student and I cannot thank them enough for it. I would also like to thank the staff of CAFEE: Dan Carder, Robert Cochran, Aaron Barnett, Ryan Barnett, Stephen Cummings, Marc Besch, and Aaron Leasor. With a special thanks to Jason England, Branson Tasker, Dylan Conelly, Matt Cummings, Sydnie Spencer, Marc Besch, Josh Matheny, Phil Korpeck, Saroj Pradhan, and Ross Ryskamp. 


\section{$\underline{\text { Table of Contents }}$}

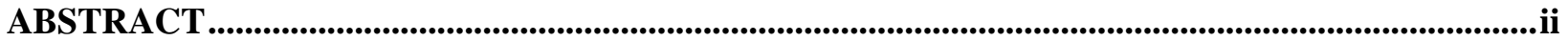

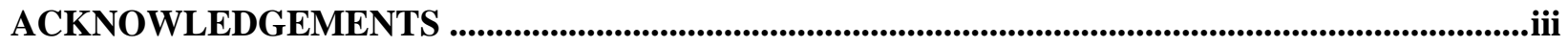

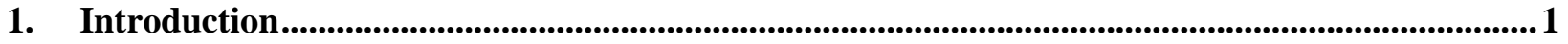

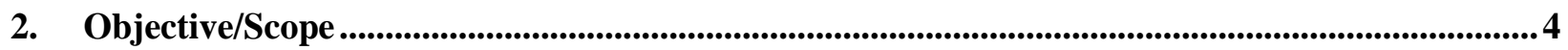

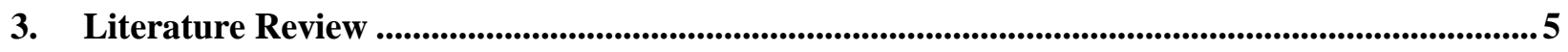

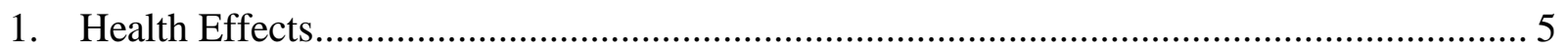

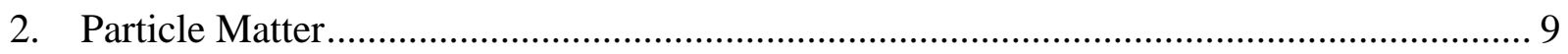

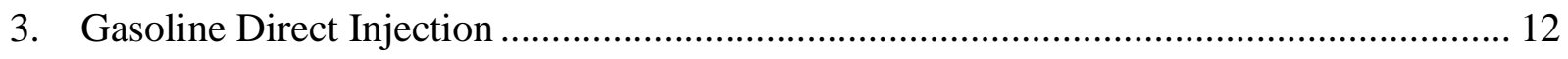

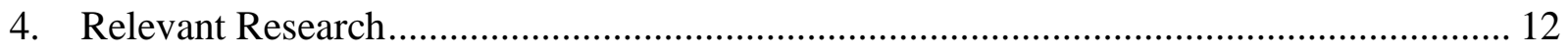

4. PM and Dilution Ratio Reduction ........................................................................................................ 16

5. Methods and Materials / Experimental Set Up ...........................................................................

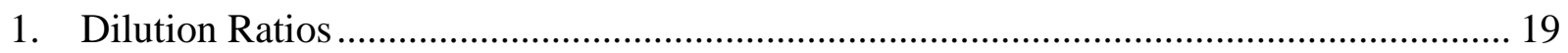

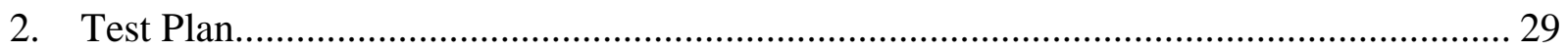

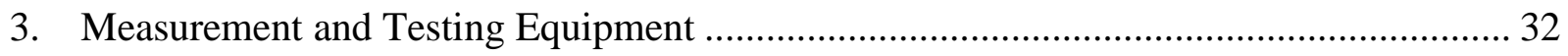

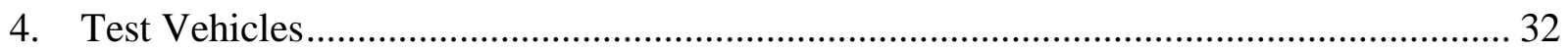

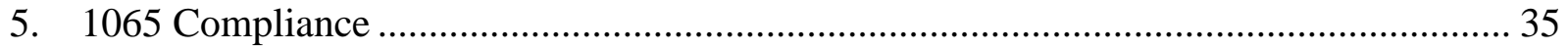

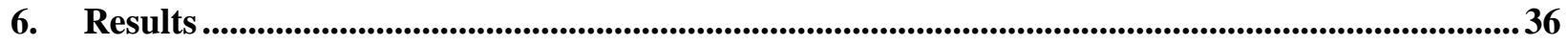

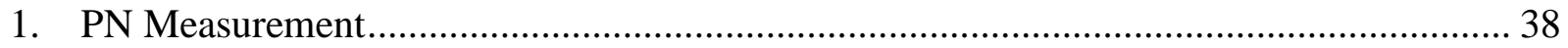

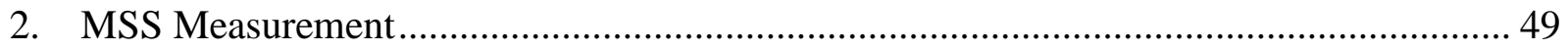

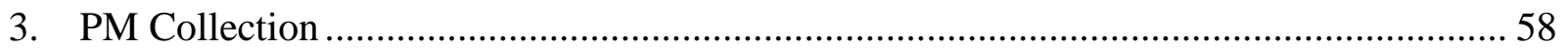

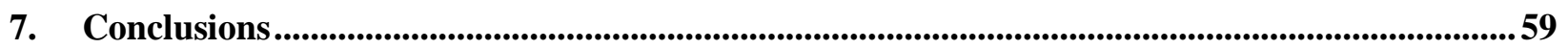

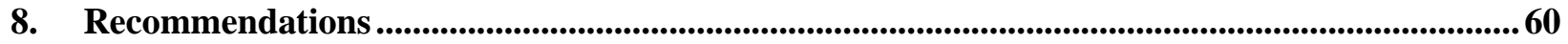

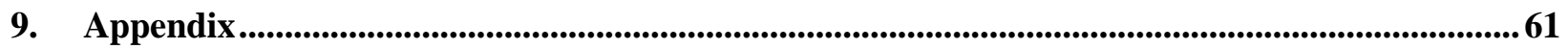




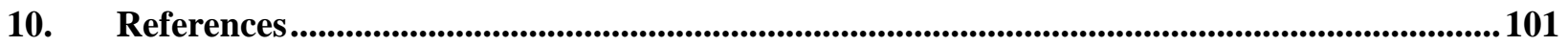




\section{Table of Figures}

FIGURE 1: ILLUSTRATION OF WALL-GUIDED DIRECT INJECTION (A) AND SPRAY-GUIDED DIRECT INJECTION (B) (GCC 2006).

\section{3}

FIGURE 2: RESULTS FROM (MCCAFFERY, ET AL. 2019) OF THE SOOT MASS (A) AND GRAVIMETRIC MASS

(B) FROM TEST VEHICLES OVER FOUR TEST ROUTES.

FIGURE 3: RESULTS FROM (MCCAFFERY, ET AL. 2019) OF THE PARTICLE NUMBER EMISSIONS OVER THE FOUR TEST ROUTES WITH GDI VEHICLES.

FIGURE 4: TYPICAL ENGINE EXHAUST PARTICLE SIZE DISTRIBUTION (BESCH 2016) VISUALIZING THE CONCENTRATION AND MASS WEIGHT OF PARTICLES IN THE DIFFERENT MODES

FigURE 5: GASEOUS RESULTS FROM (KARAVALAKIS, ET AL. 2015)THC (A), NMHC (B), $\mathrm{CO}_{2}$ (C), AND FUEL ECONOMY (D) FOR WG-DI AND SG-DI WITH SIX DIFFERENT FUELS OVER THE FTP AND UC CYCLE

FIGURE 6: AVERAGE PARTICLE SIZE DISTRIBUTION FROM (KARAVALAKIS, ET AL. 2015), OF AN WG-DI VEHICLE (A) AND AN SG-DI (B) FOR A FTP AND UC CYLE. SIX DIFFERENT FUELS WERE TESTED FOR

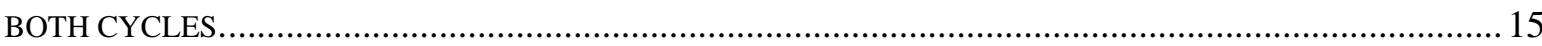

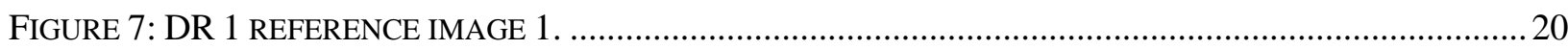

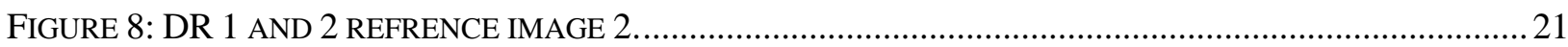

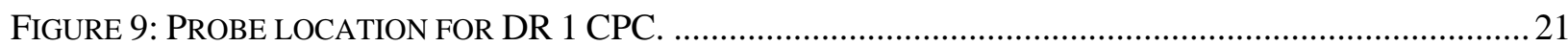

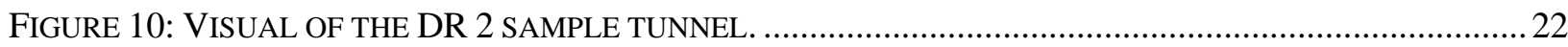

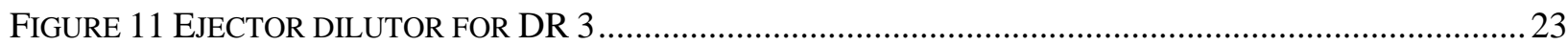

FIGURE 12: VISUAL AND DESCRIPTION OF EJECTOR DILUTOR OPERATION (AIR-VAC 2011)...................23

FIGURE 13: VISUAL OF THE TEST STAND THAT CONTAINS THE DR 3 SAMPLE TUNNEL............................24

FIGURE 14: INTRODUCTION OF THE DILUTION AIR INTO THE DR 2 SAMPLE........................................25

FIGURE 15: FLOW PATH OF DLMB DILUTED SAMPLE FROM THE CVS TUNNEL. .....................................26

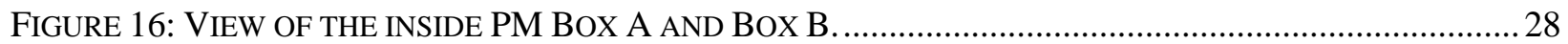

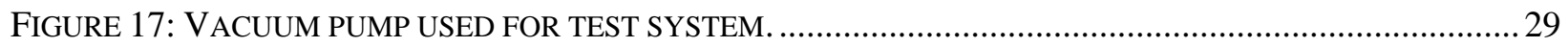

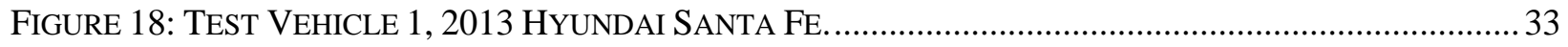

FIGURE 19: 2014 HYUNDAI SANTA FE EMISSION CONTROL INFORMATION LABEL ................................... 33

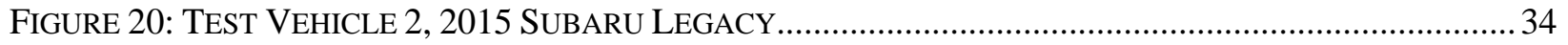

FIGURE 21: 2015 SUBARU LEGACY EMISSION CONTROL INFORMATION LABEL ...................................... 34

FIGURE 22: EMISSIONS STANDARD FOR EPA TIER 2 BIN 4 \& 5 ........................................................ 34

FIGURE 23: PM FILTER SPECIFICATIONS PER 40 CFR PART 1065.170 (C)(2) (EVIROMENTAL PROTECTION

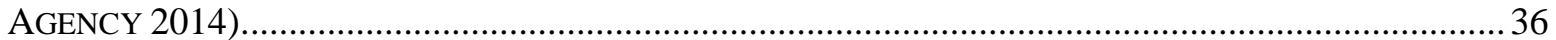

FIGURE 24: CPC CONCENTRATION AT DR 1 DURING CITY DRIVING CONDITIONS....................................... 39

FIGURE 25: CPC CONCENTRATION AT DR 2 DURING CITY DRIVING CONDITIONS. ...................................40

FIGURE 26: CPC CONCENTRATION AT DR 3 DURING CITY DRIVING CONDITIONS. ................................. 40

FIGURE 27: NORMALIZED VEHICLE SPEED AND CO2 AGAINST THE DR 1 CPC CONCENTRATION.............41

FIGURE 28: EXPLODED VIEW OF NORMALIZED AXIS OF FIGURE 27 .................................................. 42

FIGURE 29: CPC CONCENTRATION AT DR 1 DURING URBAN DRIVING CONDITIONS. ..............................43

FIGURE 30: CPC CONCENTRATION AT DR 2 DURING URBAN DRIVING CONDITIONS..............................4 44

FIGURE 31: CPC CONCENTRATION AT DR 3 DURING URBAN DRIVING CONDITIONS. ..............................4 44

FIGURE 32: CPC CONCENTRATION AT DR 1 DURING HIGHWAY DRIVING CONDITIONS............................46

FIGURE 33: CPC CONCENTRATION AT DR 2 DURING HIGHWAY DRIVING CONDITIONS............................46

FIGURE 34: CPC CONCENTRATION AT DR 3 DURING HIGHWAY DRIVING CONDITIONS.............................4 47

FIGURE 35: CPC CONCENTRATION AT DR 1 DURING LA92 DRIVING CYCLE. ...........................................48

FIGURE 36: CPC CONCENTRATION AT DR 2 DURING LA92 DRIVING CYCLE. ...........................................4 48

FIGURE 37: CPC CONCENTRATION AT DR 3 DURING LA92 DRIVING CYCLE.........................................49

FIGURE 38: MSS CONCENTRATION AT DR 1 DURING CITY DRIVING CONDITIONS. .................................50

FIGURE 39: MSS CONCENTRATION AT DR 2 DURING CITY DRIVING CONDITIONS. ..................................50 
FIGURE 40: MSS CONCENTRATION AT DR 3 DURING CITY DRIVING CONDITIONS. ................................51

FIGURE 41: MSS CONCENTRATION AT DR 1 DURING URBAN DRIVING CONDITIONS...............................51

FIGURE 42: MSS CONCENTRATION AT DR 2 DURING URBAN DRIVING CONDITIONS...............................52

FIGURE 43: MSS CONCENTRATION AT DR 3 DURING URBAN DRIVING CONDITIONS..............................52

FIGURE 44: MSS CONCENTRATION AT DR 1 DURING HIGHWAY DRIVING CONDITIONS...........................53

FIGURE 45: MSS CONCENTRATION AT DR 2 DURING HIGHWAY DRIVING CONDITIONS..........................54

FIGURE 46: MSS CONCENTRATION AT DR 3 DURING HIGHWAY DRIVING CONDITIONS..........................54

FIGURE 47: MSS CONCENTRATION AT DR 1 DURING THE FIRST HALF OF THE LA92 DRIVING CONDITIONS.

FIGURE 48: MSS CONCENTRATION AT DR 1 DURING THE SECOND HALF OF THE LA92 DRIVING

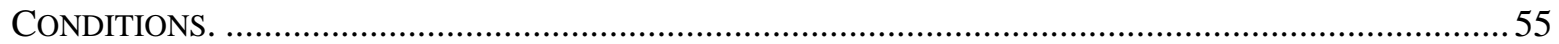

FIGURE 49: MSS CONCENTRATION AT DR 2 DURING THE LA92 DRIVING CONDITIONS.........................56

FIGURE 50: MSS CONCENTRATION AT DR 2 DURING THE FIRST HALF OF THE LA92 DRIVING CONDITIONS.

.56

FIGURE 51: MSS CONCENTRATION AT DR 2 DURING THE SECOND HALF OF THE LA92 DRIVING

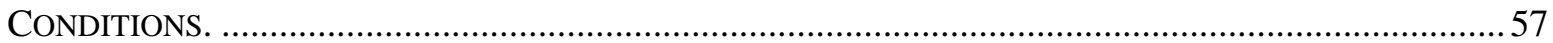

FIGURE 52: MSS CONCENTRATION AT DR 3 DURING THE LA92 DRIVING CONDITIONS. ........................57

FIGURE 53: SOOT PER MILE DURING THE LA92 TRANSIENT CYCLE> ...................................................58

Figure 54: O'KeEFE CONTROls Co. ORIFICE DATA SHEET FOR METAl ORIFICE AIR Flow IN SCFM...61

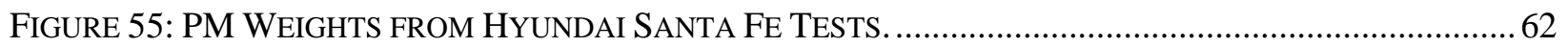

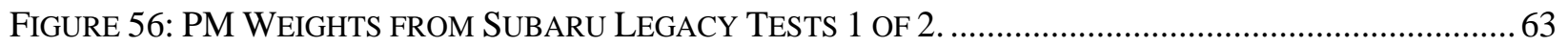

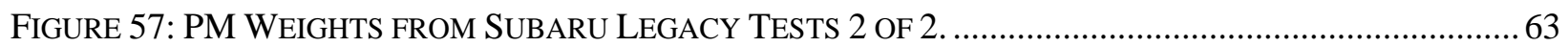

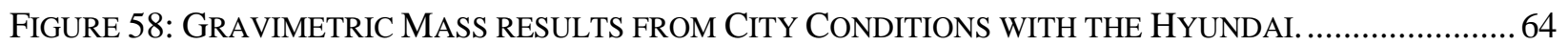

FIGURE 59: GRAVIMETRIC MASS RESULTS FROM CITY CONDITIONS WITH THE SUBARU..........................64

FIGURE 60: GRAVIMETRIC MASS RESULTS FROM URBAN CONDITIONS WITH THE HYUNDAI. .....................6 65

FIGURE 61: GRAVIMETRIC MASS RESULTS FROM URBAN CONDITIONS WITH THE SUBARU. .....................65

FIGURE 62: GRAVIMETRIC MASS RESULTS FROM HIGHWAY CONDITIONS WITH THE HYUNDAI. ................66

FIGURE 63: GRAVIMETRIC MASS RESULTS FROM HIGHWAY CONDITIONS WITH THE SUBARU...................66

FIGURE 64: GRAVIMETRIC MASS RESULTS FROM LA92 DRIVE CYCLE WITH THE HYUNDAI......................67

FIGURE 65: GRAVIMETRIC MASS RESULTS FROM LA92 DRIVE CYCLE WITH THE SUBARU........................67

FigURE 66: AERIAL VIEW EMPTY TEST CELL WITH MULTi-DiLUTION SETUP INSTALLED.........................68

FiguRE 67: SidE VIEW EMPTY TEST CELl with MUlti-Dilution SETUP INSTALLED \#1 .......................6 68

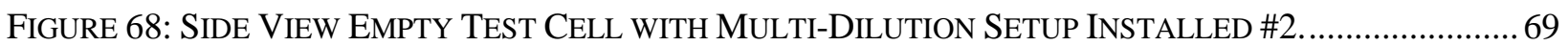

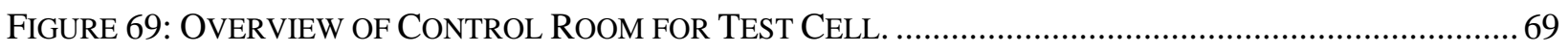

FIGURE 70: ZOOMED LEFT VIEW OF CONTROL ROOM FOR TEST CELL ................................................ 70

FIGURE 71: ZOOMED RIGHT VIEW OF CONTROL ROOM FOR TEST CELL................................................ 70

FIGURE 72: GAS BOTTLE RACK CONTAINING SPAN GASES FOR ANALYZERS ON TEST STAND..................71

Figure 73: UNCOVERED VIEW OF WALL-MOUNTED DAQ BOX WITH TEST CELl EDGETECH HuMIDITY

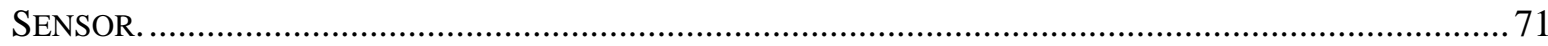

FIGURE 74: COVERED VIEW OF W ALL-MOUNTED DAQ BOX WITH TEST CELL EDGETECH HuMIDITY

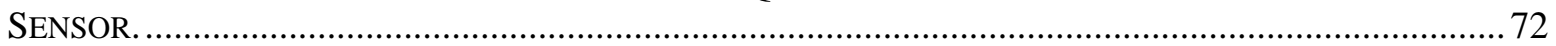

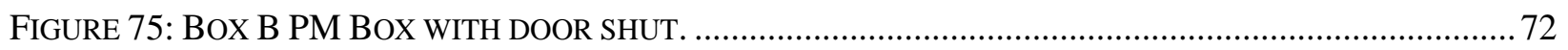

FIGURE 76: WIRING OF THE TEMPERATURE CONTROLLERS FOR PM BOX B. ...................................... 73

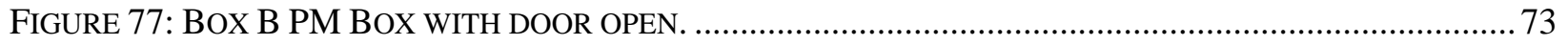

FIGURE 78: ZOOMED IN VIEW OF THE INTERNALS OF PM BOX B......................................................... 74

Figure 79: SidE VIEW OF THE THIRD DILUTION TUNNEL, DR 3 ANALYZER RACK TEST STAND, AND PM

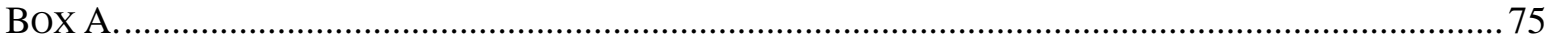

FIGURE 80: ZOOMED IN VIEW OF THE INTERNALS OF PM BOX A. ................................................... 76

FIGURE 81: CLOSER OF THE DR 3 DILUTION TUNNEL (MOST RIGHT TUNNEL).......................................... 77

FIGURE 82: ZOOMED FRONT LEFT VIEW OF THE ANALYZER RACK TEST STAND .................................... 78

FIGURE 83: FRONT VIEW OF THE ANALYZER RACK TEST STAND. .......................................................... 79 
FIGURE 84: ZOOMED VIEW OF THE DR 3 EJECTOR DILUTOR AND MASS FlOW CONTROLLER. 79 FIGURE 85: DR 3 AND RAW $\mathrm{CO}_{2}$ ANALYZERS WITH THE SWITCHBOARD TO ZERO/SPAN/SAMPLE ABOVE.

FIGURE 86: FID ANALYZER USED TO PERFORM PROPANE INJECTIONS FOR DR 3 DILUTION CONFIRMATION. 80

FIGURE 87: ISOTROPIC VIEW WITHOUT COVER OF THE DAQ BOX MOUNTED ON THE ANALYZER RACK TEST STAND.....

FIGURE 88: FRONT VIEW WITH COVER OF THE DAQ BOX MOUNTED ON THE ANALYZER RACK TEST STAND.

FIGURE 89: ICP-CON \#2 IN DAQ BOX MOUNTED ON ANALYZER RACK TEST STAND..... .81

FIGURE 90: ICP-CON \#1 IN DAQ BOX MOUNTED ON ANALYZER RACK TEST STAND...........................8 82

FIGURE 91: POWER SUPPLY FOR EQUIPMENT IN DAQ BOX ON ANALYZER RACK TEST STAND. .............. 83

FIGURE 92: STARTECH TO CONNECT CPC'S, MSS'S, AND MFC'S IN DAQ BOX ON ANALYZER RACK TEST

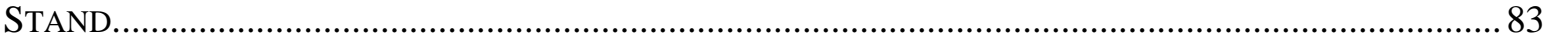

FIGURE 93: FRONT VIEW OF TEMPERATURE CONTROLLERS FOR EXPERIMENTAL SETUP (BOX \#1)..........8 84

FIGURE 94: BACK VIEW OF TEMPERATURE CONTROLLERS FOR EXPERIMENTAL SETUP (BOX \#1) ........... 84

FIGURE 95: UNCOVERED SIDE VIEW OF TEMPERATURE CONTROLLERS FOR EXPERIMENTAL SETUP (BOX $\# 1)$.

FIGURE 96: FRONT VIEW OF TEMPERATURE CONTROLLERS FOR EXPERIMENTAL SETUP (BOX \#2).......... 86

FIGURE 97: UNCOVERED SIDE VIEW OF TEMPERATURE CONTROLLERS FOR EXPERIMENTAL SETUP (BOX \#2).

FIGURE 98: DILUTION TUNNEL FOR DR 2 WITH THE DR 2 PM BOX (DLMB) IN THE BACK.....................8.87

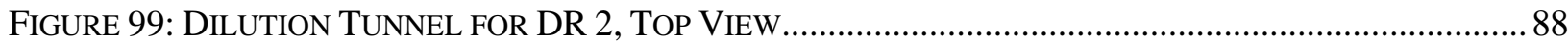

FIGURE 100: HORIBA OBS-ONE USED TO SAMPLE ON DR 2 WITH SPAN/ZERO CAL GASSES ON BOTTLE RACK. .88

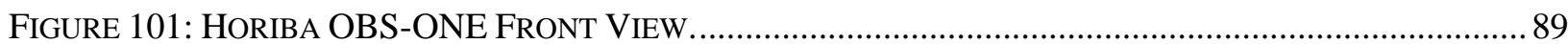

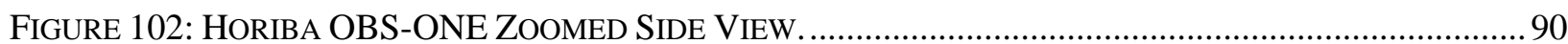

FIGURE 103: HORIBA OBS-ONE SOFTWARE COMPUTER................................................................. 91

FIGURE 104: OVERVIEW OF THE TEST CELL WITH THE HYUNDAI TEST VEHICLE....................................99

FIGURE 105: REAR VIEW OF THE TEST CELL WITH THE HYUNDAI TEST VEHICLE.................................. 92

FIGURE 106: SidE REAR VIEW OF THE TEST CELL WITH THE HYUNDAI TEST VEHICLE...........................93

FigURE 107: FRONT TOP VIEW OF THE TEST CELL WITH THE HYUNDAI TEST VEHICLE. .........................93

FIGURE 108: IMAGE \#1 OF ALL EQUIPMENT IN PLACE DURING THE HYUNDAI TESTING. ...........................94

FIGURE 109: IMAGE \#2 OF ALL EQUIPMENT IN PLACE DURING THE HYUNDAI TESTING. .............................95

FIGURE 110: IMAGE \#3 OF ALL EQUIPMENT IN PLACE DURING THE HYUNDAI TESTING. ..........................95

FIGURE 111: IMAGE \#4 OF ALL EQUIPMENT IN PLACE DURING THE HYUNDAI TESTING. ...........................96

FIGURE 112: IMAGE \#1 OF THE TEST CELL DURING THE SUBARU TESTING...........................................99

FIGURE 113: IMAGE \#2 OF THE TEST CELL DURING THE SUBARU TESTING.........................................98

FIGURE 114: IMAGE \#3 OF THE TEST CELl DURING THE SUBARU TESTING..........................................98

FIGURE 115: IMAGE \#4 OF THE TEST CELL DURING THE SUBARU TESTING.........................................99

FigURE 116: IMAGE \#5 OF THE TEST CELL DURING THE SUBARU TESTING............................................99

FIGURE 117: IMAGE \#6 OF THE TEST CELL DURING THE SUBARU TESTING.......................................... 100

FIGURE 118: IMAGE \#7 OF THE TEST CELL DURING THE SUBARU TESTING.......................................... 100 


\section{List of Tables}

TABLE 1: TEST VEHICLE SPECIFICATIONS (MCCAFFERY, ET AL. 2019) ................................................... 6

TABLE 2: TEST PLAN OF EQUIPMENT AND DESIGNATED DILUTION RATIO THE VEHICLE 1 (2013 HYUNDAI

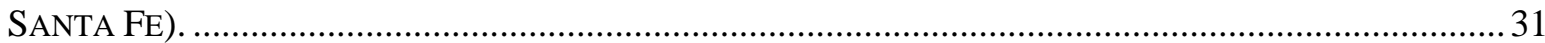

TABLE 3: TEST PLAN OF EQUIPMENT AND DESIGNATED DILUTION RATIO THE VEHICLE 2 (2015 SUBARU

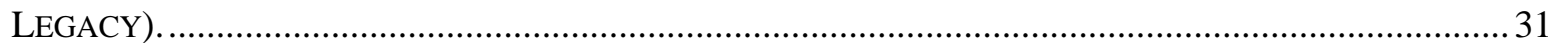

TABLE 4: OUTLINE OF TEST CYCLE NUMBERS WITH CORRESPONDING TESTING CONDITIONS AND TEST

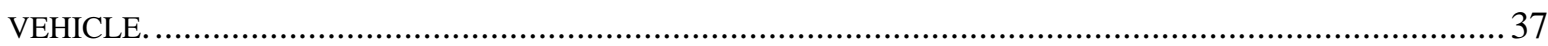

TABLE 5: EQUIPMENT TYPE, MEASURING LOCATION, AND MEASURING TRAITS......................................... 38 


\section{Introduction}

Ambient air quality has been a concern in the US since the mid 1900's and continues to be a concern. The 1955 Air Pollution Control Act was the first federal legislation in the United States to address air quality and the 1963 Clean Air Act was the first legislation to control air pollution (Shouse and Lattanzio 2020). Across the world, other countries are becoming more conscience of their role in air pollution and have passed ambient air regulations with goals to preserve local environmental health and welfare and global aspects like the ozone layer or reduce ambient carbon dioxide levels (EPA 2020, Shouse and Lattanzio 2020, Eviromental Protection Agency 2014, ECE/TRANS/505/Rev.7/Add.48 2015). In the United States, the Environmental Protection Agency (EPA) enforces the emissions regulations set in place. The primary local environmental health criteria air pollutants that are regulated include carbon monoxide, lead, nitrogen dioxide, ozone, particulate matter, and sulfur dioxide (Eviromental Protection Agency 2014).

Modern day internal combustion engines operating on the Otto cycle are restricted to the Tier 3 emissions levels set forth by the EPA. This emissions regulation was one of the last phases since January 1, 2000 with the implementation of the Tier 1 emissions requirements. Recent regulations have forced manufacturers to focus on improved efficiency and improved technologies to meet Tier 3 requirements (Eviromental Protection Agency 2014). Many manufacturers are now producing internal combustion engines with direct injection method of fuel injection for spark ignited engines (EPA 2020). This method of fuel injection is similar to the injection process of a compression ignition engine. Compression ignition relies on using the change in volume of the trapped air to pressurize the air and fuel in the cylinder, causing the temperature to rapidly increase. At the desired time, fuel is injected into the cylinder and the heat available within the trapped air ignites the fuel-air mixture. Gasoline direct injection (GDI) uses a similar injection strategy by injecting directly into the cylinder, allowing for more effective atomization of the fuel, and

achieving an improved mixing of the fuel compared to port fuel injection (PFI) strategies. The GDI process still requires a spark plug to ignite the air/fuel mixture. Increasing the compression ratio allows for a cylinder pressure which often leads to higher efficiency of the engine. Increasing the engine efficiency will lead to a more effective use of energy available and should reduce the emissions emitted (Heywood 1988, Awad, et al. 2020, Moon, et al. 2017). 
Using GDI technology may provide an improved injection method to increase engine efficiency but it also has downsides. When using GDI, particulate matter (PM) and particulate number (PN) levels significantly increase when compared to the PFI technology (Zhao 2009, Ko et al. 2018). Concerns over possible health risks of increased particulate levels could drive new regulations in the United States similar to Euro VI regulations on PN level in the European Union. Euro VI regulation requires that gasoline engines operating with direct injection produce a maximum of $0.005 \mathrm{~g} / \mathrm{km}$ of PM and $6.0 \times 10^{11}$ \#/km of PN (Besch 2016, ECE/TRANS/505/Rev.7/Add.48 2015). Direct injection has various forms but all with the same purpose: to inject fuel directly into the combustion chamber near the crankshafts top dead center (TDC) at a high pressure. Spray-guided and wall-guided are the most common forms of direct injection and combined have been reported to consist of more than 50\% of the model year (MY) 2019 vehicles (Zhao 2009, EPA 2020). Figure 1 presents an overview of GDI injection methods with wall-guided denoted "A)" and spray-guided "B)". 


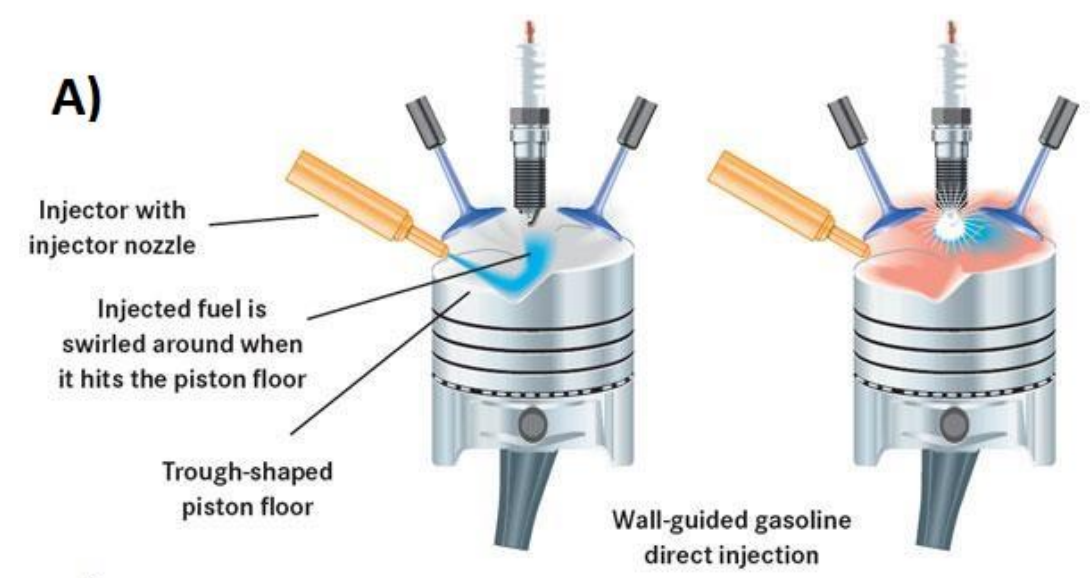

B)

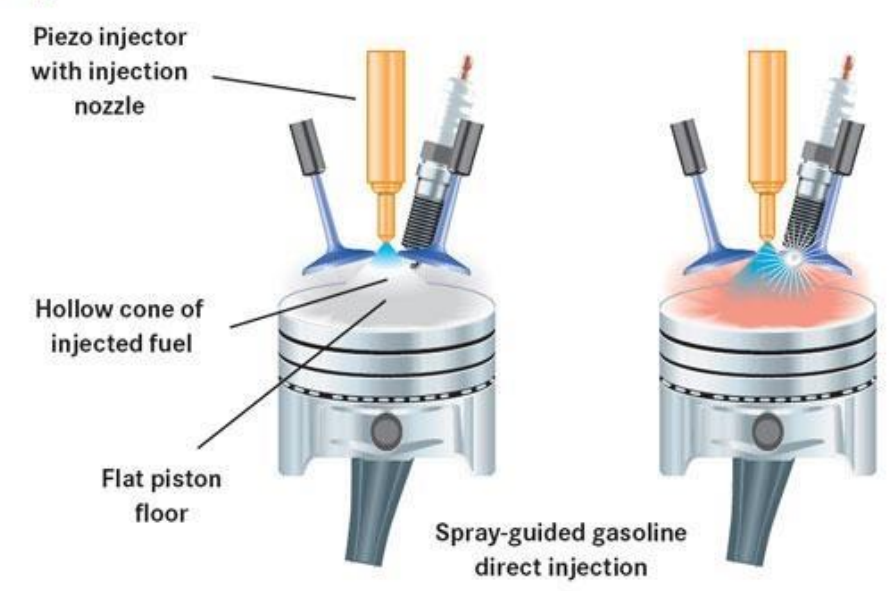

Figure 1: Illustration of wall-guided direct injection (A) and spray-guided direct injection (B) (GCC 2006).

Reducing particle mass and concentration in GDI vehicles is completed using a gasoline particulate filter (GPF). GPFs are comparable to the diesel particulate filters (DPF) used on diesel engines. A GPF will usually have lower filtration efficiency because the GDI engine lacks soot accumulation inside the GPF (Awad, et al. 2020, Saito, et al. 2011). Using a GPF with a three way catalyst (TWC) can result in a filtration efficiency above $90 \%$ in some cases (Awad, et al. 2020). Using a GPF may prevent potential negative health issues from inhaled particulates. However, PN regulations may need to be enacted to further reduce particle emissions, and their impact, being emitted from GDI vehicles. A review of the literature is provided as a basis to understand the health concerns, engine operation, particle formation, and particle measurement.

Presently, regulations in the United States only requires gravimetric-based PM measurements utilizing a chassis dynamometer system to quantify the particulate emissions emitted from light duty passenger vehicles. However, the PN may be equally important to human and environmental 
health and should be considered. In the vehicle certification, a chassis dynamometer is used to prescribe a load versus speed (time) that the vehicle must follow. Different speed versus time profiles are used to mimic different driving conditions to evaluate the vehicle's engine and aftertreatment system. The subsequent emissions generated in the engine and aftertreatment are then ducted to a dilution tunnel where the raw exhaust is mixed with conditioned air to form a dilute mixture. This dilute mixture is then sampled for the regulated gaseous species and particulate matter for gravimetric analysis. The dilution tunnel system can also be utilized for PN measurement. However, the dilution ratio, along with other conditions, affects the way in which the particulates form and hence will affect the PN. There is a need to understand the effects of the dilution process on $\mathrm{PN}$.

\section{Objective/Scope}

The overall objective of this work is to compare the particulate mass and concentration from a single GDI spray-guided engine to a PFI configuration engine. To meet this objective, the two vehicles were evaluated over three different steady state test cycle conditions and a LA92 transient cycle on a chassis dynamometer and emissions collection system. These cycles simulated a city route with the vehicle speed maintained at approximately $25 \mathrm{mph}$, an urban route with the speed maintained at $45 \mathrm{mph}$, and a highway route with the speed maintained at $65 \mathrm{mph}$. During these cycles, the carbon dioxide $\left(\mathrm{CO}_{2}\right)$ was measured in the emissions collection to monitor the dilution ratio. The focus was on particle emissions taken with AVL MicroSoot Sensors, TSI CPCs, and gravimetric particle mass. These tests were conducted on a chassis dynamometer with three separate dilution ratios. Dilution ratio 1 (DR 1) was measured from the constant volume sampling (CVS) tunnel with a ratio of 20:1, dilution ratio 2 (DR 2) was sampled with a dilution ratio of approximately 40:1, and dilution ratio 3 (DR 3 ) was sampled with a dilution ratio of approximately 80:1. These dilution ratios were all sampled simultaneously during a test cycle. By capturing these results, a comparison between the two separate methods of injection and the effects of a measurement environment on particle concentration were revealed. 


\section{Literature Review}

\section{Health Effects}

A primary motivation for emissions regulations is the health of humans and the surrounding environment. While the research discussed herein does not make any conclusion on the effects of light duty GDI internal combustion engine emissions on the health of individuals or ambient air quality, it is important to discuss the risk associated with the byproducts of an internal combustion engine using GDI technology and especially the particulates produced. For human health, the number of particles deposited on the lungs is dependent on the concentration of particles and their size. Different particle sizes are capable of reaching different areas of the lungs. Particles smaller than $5 \mu \mathrm{m}$ in diameter can reach the alveoli in a person's lungs while particles above $5 \mu \mathrm{m}$ are only capable of traveling to the proximal airways and are removed by the mucociliary clearance (Sydbom, et al. 2001). Due to the decreased time period of fuel atomization and fuel impingement, GDI engines are capable of producing up to twice the particle mass of a typical port fuel injection (PFI) engine (Raza, et al. 2018). In the United States, the Tier 3 emissions standard is the present regulation on light duty vehicles. This regulation holds no restriction on the particle number concentration of light duty vehicles but only particle mass per unit distance traveled (Eviromental Protection Agency 2014). In European regulation, a particle number concentration and mass are imposed (ECE/TRANS/505/Rev.7/Add.48 2015). While meeting the requirement for particle mass, it is possible that many of the nanoparticles can pass through the exhaust system and enter the surrounding environment. As later explained in the section "Particle Matter," nanoparticles are low density particles. This allows large concentrations to be collected whilst only colleting a small amount of mass (Besch 2016, Kittelson 1998). By restricting the particle number concentration along with particle mass, the particle concentration must be reduced. PM emissions created from gasoline spark ignited engines can be linked to lube oils and contribute nearly $25 \%$ of the overall PM measurements (Raza, et al. 2018). Using a GPF can reduce the particle number concentration, particle mass, and black carbon emissions. Studies have shown that a use of a catalyzed GPF can improve the conversion efficiency of $\mathrm{CO}$ and $\mathrm{NO}_{\mathrm{x}}$ emissions (McCaffery, et al. 2019). McCaffery, et al. 2019 conducted a study with three different GDI vehicles (two wall-guided and one sprayguided) equipped with the original equipment manufacturer three-way catalyst (OEM TWC) used 
to reduce the emissions for the Federal Tier 3 emissions standards. The technical specifications of the test vehicles are provided in Table 1 . The test routes performed are described later in the text.

Table 1: Test vehicle specifications (McCaffery, et al. 2019).

\begin{tabular}{|c|c|c|c|}
\hline \multicolumn{1}{|c|}{ GDI 1 } & GDI 2 & GDI 3 \\
\hline Vehicle Model Year & 2017 & 2017 & 2018 \\
\hline Cylinder number & 4, inline & 4, inline & V6 \\
\hline Displacement & $2.0 \mathrm{~L}$ & $1.5 \mathrm{~L}$ & 305 at $6800 \mathrm{rpm}$ \\
\hline Horsepower & 155 at $6000 \mathrm{rpm}$ & 181 at $63000 \mathrm{rpm}$ & $264 \mathrm{lb}$-ft at $5200 \mathrm{rpm}$ \\
\hline Torque & $150 \mathrm{lb}-\mathrm{ft}$ at 4000 rpm & $185 \mathrm{lb}$-ft at 4320 rpm & $11.5: 1$ \\
\hline Compression Ratio & $13.0: 1$ & $10.0: 1$ & Naturally Aspirated \\
\hline Air Intake & Naturally Aspirated & Turbocharged & Wall-guided \\
\hline Fuel Delivery & Wall-guided & Centrally-mounted & USEPA: T3 LDV, CA SULEV 30 \\
\hline Emissions Standards & USEPA: T3B30, CA SULEV 30 PZEV & USEPA: T3B30, CA SULEV 30 PZEV & \\
\hline
\end{tabular}

The OEM TWC was replaced with a GPF catalyst on GDI 1 and GDI 2 from Table 1 and the tests repeated. The test was performed on road which required the use of portable emissions measurement systems (PEMS). While gaseous species were measured, the focus of the current section is health effects, and this study was used to provide data to show the benefit of a GPF. Solid particle number emissions were measured using AVL's M.O.V.E. PN PEMS iS for the wallguided GDI vehicles and the spray-guided GDI vehicle was instrumented with the NTK NCEM. PN PEMS units used a corona diffusion charger type measurement system. The AVL M.O.V.E. PN PEMS iS measures solid PN in accordance to the Particle Measurement Programme (PMP) protocol while the NTK NCEM does not, due to measuring solid and volatile particles <23nm (McCaffery, et al. 2019). This may contribute to a higher reported particle mass and number concentration when compared to the wall guided vehicles. The three vehicles performed triplicate tests for each of the four routes around the city of Los Angeles and Southern California. The four routes were intended to embody traits of rural, urban, and highway driving conditions with varying altitude and ambient climatic conditions. Routes have been labeled as "Downtown LA," "Highway," "Mt Baldy," and "Downtown SD." "Downtown LA" was a 16-mile route of primarily urban driving conditions with an average speed of $15.7 \mathrm{mph}$. The "Highway" route was high speed driving over 43 miles with an average speed of $48.3 \mathrm{mph}$. The third route, "Mt Baldy," began near sea level and traveled up to an elevation of 1524 meters and back down to near sea level. The elevation change can be attributed to the route traveling up Mountain Baldy and involved steep grades up and downhill. This route maintained an average speed of $25.1 \mathrm{mph}$ over the 44.2 miles. The fourth route started and ended in downtown San Diego near the harbor. This route was 
considered to have high ambient temperatures and relative humidity while traveling 13.1 miles through mostly urban and some highway driving conditions. The tests were performed in order from route one to three and the fourth, "Downtown SD," was performed separately. Each test began after the vehicle and TWC were at operating temperature.

The results for the soot mass and gravimetric mass is presented in Figure 2. Vehicle GDI 1 experienced a reduction in PM emissions ranging from $12 \%-49 \%$ while the soot mass emissions were reduced by $44 \%-66 \%$ with the GPF catalyst installed. The GDI 2 vehicle reported a $60 \%$ 96\% reduction in PM emissions and 93\%-99\% reduction of soot mass emissions when installed with a GPF. These results showed higher GPF filtration efficiencies for urban test routes when compared to that of the Highway test route. While GDI 2 had much higher filtration efficiencies, this is likely due to the lower engine-out PM levels of GDI 1. 

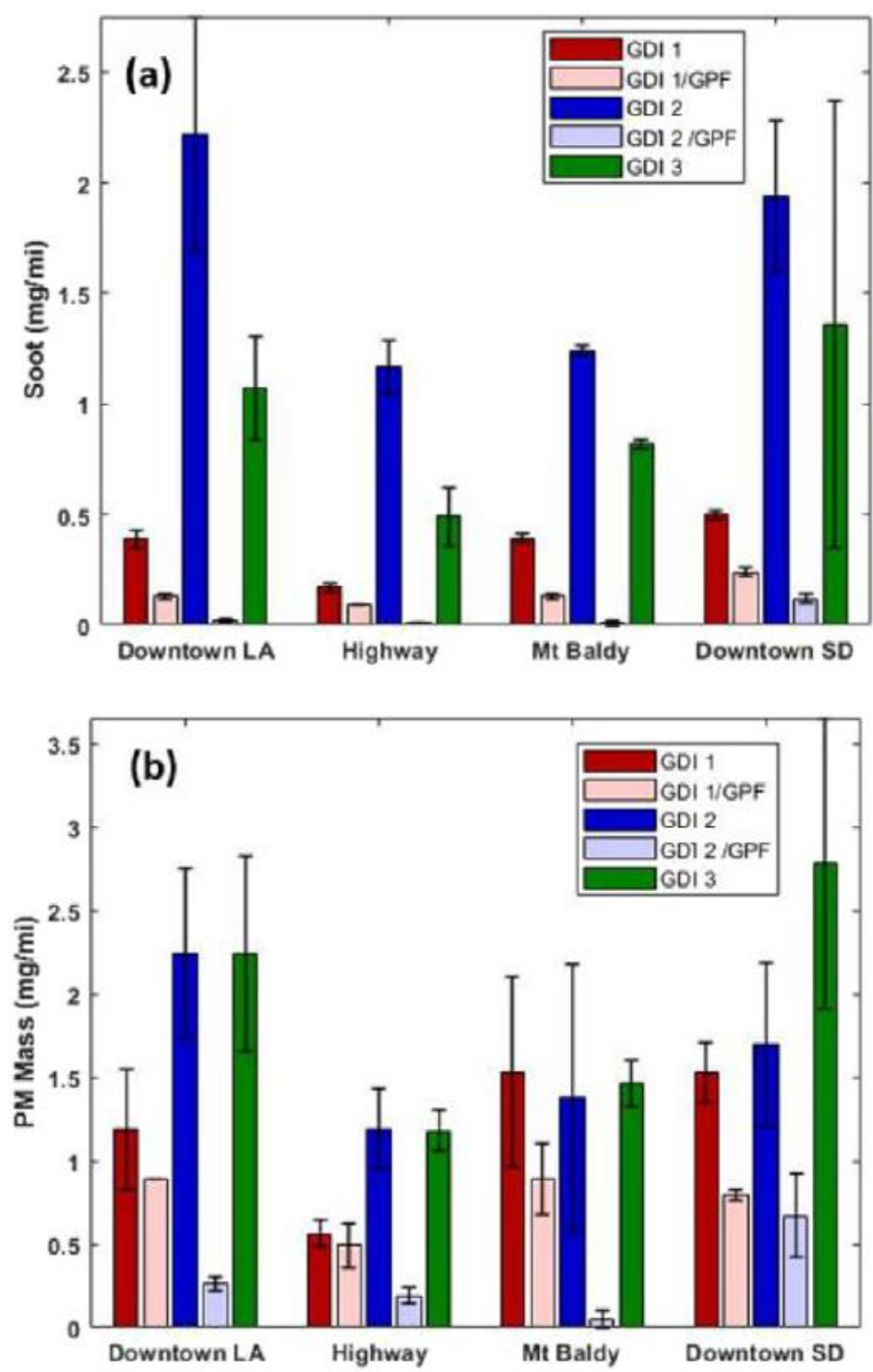

Figure 2: Results from (McCaffery, et al. 2019) of the Soot mass (a) and gravimetric mass (b) from test vehicles over four test routes.

Results of the particle number concentrations are presented in Figure 3. These results are similar to the soot and particle mass of Figure 2. The results show that the vehicles with the GPF developed a lower PN concentration over the different test routes. During the Mt. Baldy route, there was a large PN concentration with GDI 2 that the author contributed to the NTK NCEM diffusion charger method to measure particle concentrations. The NCEM infers a particle size distribution and assumes an average diameter for all particles. In the text of (McCaffery, et al. 2019), it is "hypothesized" that during higher engine loading, "small volatile or solid particles" formed in the exhaust that may have also been below the cutoff size of $23 \mathrm{~nm}$ from the equipment. This resulted 
in particles that normally would not be measured to increase the particle concentration for GDI 2. From this, it was determined that the GPF could potentially store semi-volatiles and later release them under certain driving conditions (McCaffery, et al. 2019).

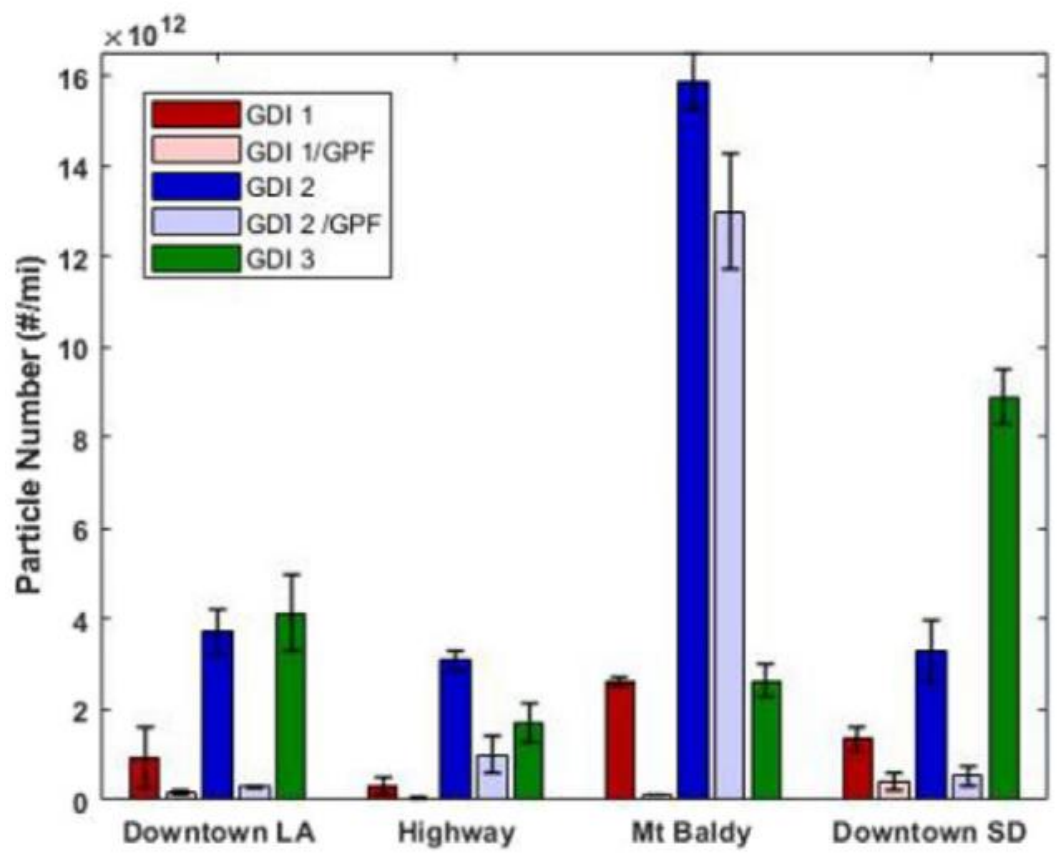

Figure 3: Results from (McCaffery, et al. 2019) of the particle number emissions over the four test routes with GDI vehicles.

Particle emissions are reduced in (McCaffery, et al. 2019), meaning measures could be taken to prevent these particles from being emitted. While this study is not focused on measuring the effect of different GDI engines on public health, it is important to understand why particle emissions from GDI engines are important to measure and control.

\section{Particle Matter}

PM in light duty internal combustion engines can be broken into three common sources: fuel composition, lubrication oil, and rich combustion. Within these sources, PM can be categorized into subgroups of solid, volatile, and semi-volatile. The subgroup is determined by whether the chemical composition is organic or inorganic and its physical state (Awad, et al. 2020). Aerosols are highly dependent on the environmental conditions the samples are collected from; for example, residence time, local temperature of the aerosol, and dilution rates can change the properties of aerosols and may cause them to be measured differently if the environmental conditions change. Methods of measuring particles size depends heavily on the concentrations, particle size 
distribution, and particle size measured (Besch 2016). PM emissions are formed as a product of fuel combustion in the engine or by nucleation and condensation in the exhaust when cooled or diluted during measurement (Awad, et al. 2020). From the particle distribution, the mode of the particle by the size can be inferred. The three modes of a particle are nucleation mode, accumulation mode, and coarse mode (Besch 2016). Nucleation mode is a range of particles characterized for their size in the range of 3-30 nm. The lower limit of $3 \mathrm{~nm}$ has been limited due to the lower detection limit of the equipment used at the time. Most particles in nucleation mode are formed from cooling and/or diluting of volatile and semi-volatile organic compounds (VOC/SVOC) from the engine exhaust. The VOC/SVOC are mainly made up of hydrocarbons and sulfur compounds but will contain some ash and elemental carbon. While in a typical diesel exhaust particle distribution, particles in nucleation mode will contain the most concentration of particles $(>90 \%)$, the mass of these particle size is relatively low $(<20 \%)$. Sampling particles in nucleation mode is the most challenging because of their sensitivity to the environment and collection methods. Conditions including sample temperature, relative humidity, dilution rates, and dilution ratios affect volatiles. The volatility of a particle can be defined by its evaporation temperature. Solid particles (non-volatile) must have an evaporation temperature above $350{ }^{\circ} \mathrm{C}$. Semi-volatile particles have an evaporation temperature of $100{ }^{\circ} \mathrm{C}$ to $350{ }^{\circ} \mathrm{C}$, while volatile particles must completely evaporate below $100{ }^{\circ} \mathrm{C}$ (Besch 2016, Kittelson 1998). Accumulation mode is defined by particles that are between $30-500 \mathrm{~nm}$ in diameter. While these particles are higher in particle mass, they do not account for much of the concentration. These particles are not significantly affected by dilution and sampling such as the particles in nucleation mode range. Particles in the accumulation mode may still be impacted by particles re-volatilizing. These particles are easily removed with particulate filters (Besch 2016). Particles in coarse mode are characterized as those with a diameter of $500 \mathrm{~nm}$ or greater. These particles account for 5-20\% of the total particle mass. Although these types of particles are measured during an engine or vehicle test, they are usually found to be deposits from cylinder walls or exhaust piping/systems (Besch 2016). These particles are of less interest for the purpose of this study. Figure 4 illustrates the different modes of a particle and how their concentrations and mass compared to other modes. 


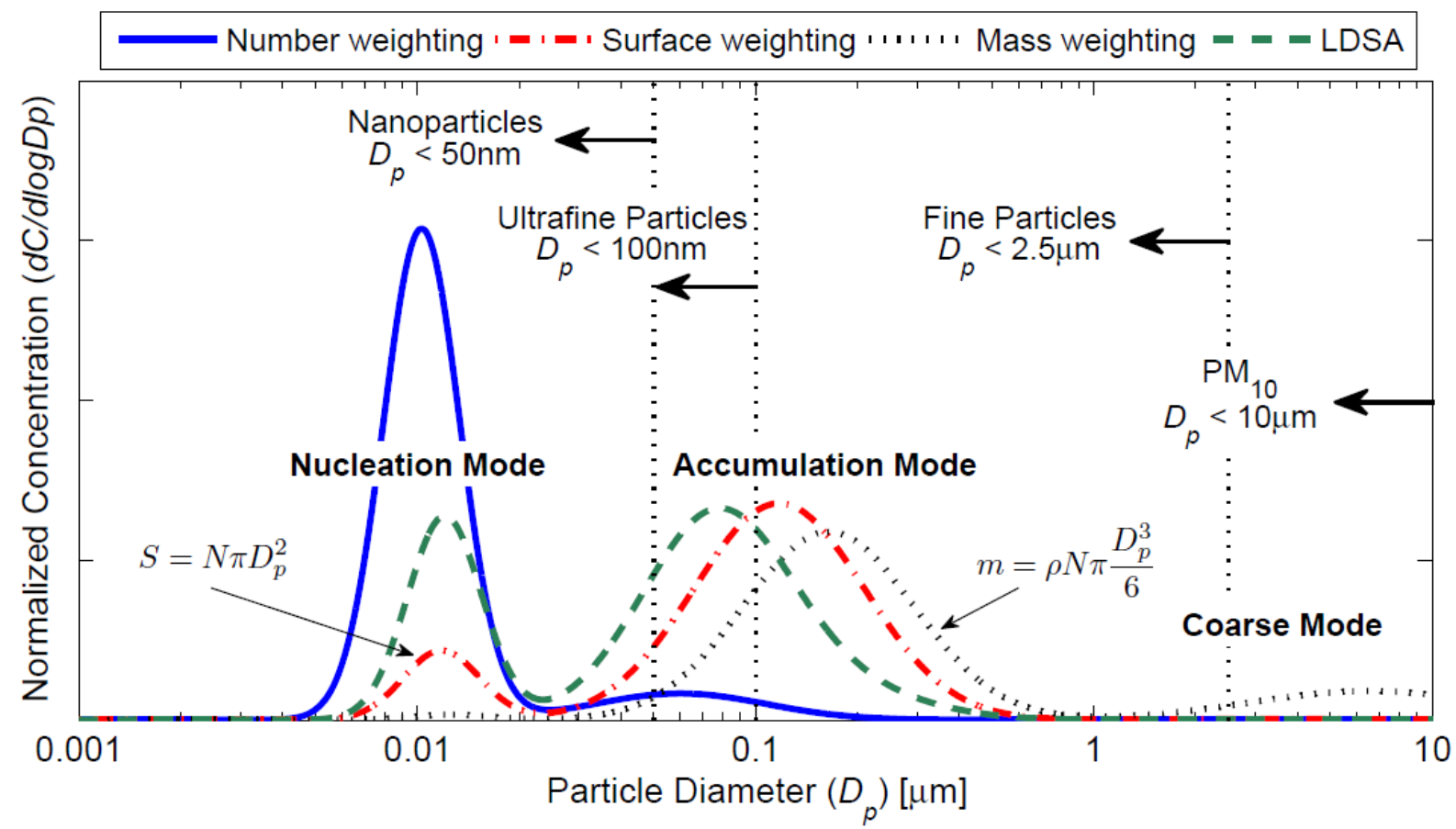

Figure 4: Typical engine exhaust particle size distribution (Besch 2016) visualizing the concentration and mass weight of particles in the different modes.

Europe uses the World Harmonized Light-duty Test Cycle (WLTC) to approve vehicles for its Euro VI emissions regulations. The WLTC contains higher loads and vehicle speeds when compared to the New European Driving Cycle (NEDC) that has been used for certification testing since 2000. The Euro 6 emissions regulations use the WLTC cycle to determine if light duty vehicles comply with the $6.0 \times 10^{11}$ \#/km PN requirement (Ko, Kim and Chung, et al. 2018). Particle number concentrations measured under these regulations are to be counted between $23 \mathrm{~nm}$ and $2.5 \mu \mathrm{m}$ in diameter (ECE/TRANS/505/Rev.7/Add.48 2015). Methods used to measure particle number can be broken into the two major groups and include condensation particle counters (CPC) and corona dischargers (Ko, Kim and Chung, et al. 2018). When measuring PN for certificatory requirements, the measurement must be of only solid particles (Besch 2016). When measuring for solid particles in a laboratory setting, typically a CPC will be integrated into the equipment to remove non-solid particles. A volatile particle remover (VPR) can be used but previous reporting has found that a VPR may not remove all non-volatile sub-23 $\mathrm{nm}$ particles so a catalyst stripper (CS) can be used in place rather than a VPR (Ko, Kim and Chung, et al. 2018). 


\section{Gasoline Direct Injection}

In light duty gasoline fueled internal combustion engines, GDI has seen increased implementation over the last 15 years. For example, model year 2008 vehicles had less than 3\% GDI technologies while model year 2019 projected 50\% of the vehicles were GDI (EPA 2020). The reason modern vehicles have been converting from PFI to GDI may be because the increased efficiency and fueling control results in lower $\mathrm{CO}_{2}$ emissions (Karavalakis, et al. 2015). Within GDI technology, there are two main methods of injection. Wall-guided DI (WG-DI) is a more common option for GDI engines, having an injector mounted on the side and spraying toward a contoured piston that projects the atomized fuel upward in the direction of the spark plug. While WG-DI engines may be more common, they experience higher levels of PM and total hydrocarbons (THC). During the combustion process, some of the fuel may contact the cylinder walls. If the fuel is quenched during mixing in the chamber, incomplete combustion occurs locally and soot is formed, along with other semi-volatiles (non-solid particles). THC is formed due to the incomplete evaporation and mixing with air and absorption and desorption of the fuel trapped in the piston crevices and dissolved into the lubrication oil. Spray guided DI (SG-DI) is an alternative method of injecting but less common in the US because the lean fueling strategy would require an emissions control strategy for oxides of nitrogen $\left(\mathrm{NO}_{\mathrm{x}}\right)$ (Karavalakis, et al. 2015).

\section{Relevant Research}

In the study performed by Karavalakis et al, both methods of injections in GDI engines were evaluated with different blends of ethanol and iso-butanol. The different fuels included a E10 (10\% ethanol and 90\% gasoline) for reference, an E15 ethanol blend, an E20 ethanol blend, and a gasoline, iso-butanol blend. The gasoline iso-butanol blend was combined at $16 \%, 24 \%$, and $32 \%$ butanol which were comparable to E10, E15, and E20 ethanol fuels, respectively. Oxygen and fuel volatility properties were matched, and the Reid vapor pressure (RVP) was retained within 6.47.2psi. The test vehicles were both 2012 model year passenger cars with TWC. One vehicle being a WG-DI with a 2.0 L engine and the other being SG-DI with 3.5 L engine. Each vehicle was tested over three repeat Federal Test Procedure (FTP) cycles and three Unified Cycles (UC) with each of the six fuels. Each vehicle completed all six tests with a single fuel type before multiple drain and fill procedures were conducted to prepare for a new fuel. Gaseous test measurements included $\mathrm{THC}, \mathrm{CO}, \mathrm{NO}_{\mathrm{x}}, \mathrm{NMHC}$, and $\mathrm{CO}_{2}$. DNPH cartridges were used for carbonyl analysis, 
carbotrap adsorption tubes for volatile organic compounds (VOC), and an Agilent 6890 GC with an FID maintained at $300{ }^{\circ} \mathrm{C}$ was used to measure the VOCs. Particle number measurement was measured with a TSI 3776 ultrafine-CPC for particle concentration, TSI EEPS for size distribution, and mass based measured was measured with a $47 \mathrm{~mm}$ Teflon ${ }^{\circledR}$ filter. A Code of Federal Regulation (CFR) Title 40 Part 1065 compliant microbalance measured the PM mass in a controlled clean chamber environment. In the review of this paper, the focus was a comparison of the spray-guided and wall-guided injection technologies rather than the different fuels. The fuel most relevant to this research was the E15 ethanol blend since it will be most comparable to the fuel being used in this research. The THC emissions were $0.012 \mathrm{~g} / \mathrm{mile}$ for the spray-guided (SGDI) and $0.095 \mathrm{~g} / \mathrm{mile}$ for the wall-guided (WG-DI) for the FTP cycle for the E15 blend. The THC emissions for the UC test cycle showed a similar $0.018 \mathrm{~g} / \mathrm{mile}$ for the SG-DI vehicle and the WGDI vehicle had a reduction of THC emissions resulting in $0.008 \mathrm{~g} / \mathrm{mile}$. It should be noted that in Figure 5, the graph representing the THC have different scales. The THC emissions were represented by the high concentrations seen in the first few hundred seconds, during the cold-start portion. It was reported that the hot-start portion of the test had near zero THC emissions due to the light off temperature being below the temperature of the TWC. THC emissions may have an increased effect due to fuel impingement, especially for spark ignited direct injection engines. It is also assumed that as the engine operates past the cold-start condition and the cylinder surface temperature increases, an improved environment for fuel vaporization and pool fires occurs, resulting in lower THC emissions (Karavalakis, et al. 2015). The $\mathrm{CO}_{2}$ emissions for the FTP cycle showed $350 \mathrm{~g} / \mathrm{mile}$ for the SG-DI and $250 \mathrm{~g} / \mathrm{mile}$ for the WG-DI. The masses of the vehicles may cause deviation due to the SG-DI vehicle using a 3.5 L engine compares to the $2.0 \mathrm{~L}$ WG-DI engine. Whereas the $\mathrm{CO}_{2}$ emissions for the UC cycle reveal the SG-DI to have $350 \mathrm{~g} / \mathrm{mile}$ and 280 g/mile for the WG-DI. The fuel economy results for the SG-DI for the FTP and the UC cycles were 24 miles/gallon. For the WG-DI the fuel economy for the FTP was 34 miles/gallon while the UC cycle implies the fuel economy was 30 miles/gallon. The results of these different vehicles indicate that the SG-DI vehicle sees little to no change between the FTP and the UC cycle while the WG-DI vehicles showed an increase of $20 \%$ in $\mathrm{CO}_{2}$ emissions and, subsequently, a $25 \%$ decrease in fuel economy. The THC emissions from the UC cycle indicate a $40 \%$ decline when compared to the FTP cycle. 

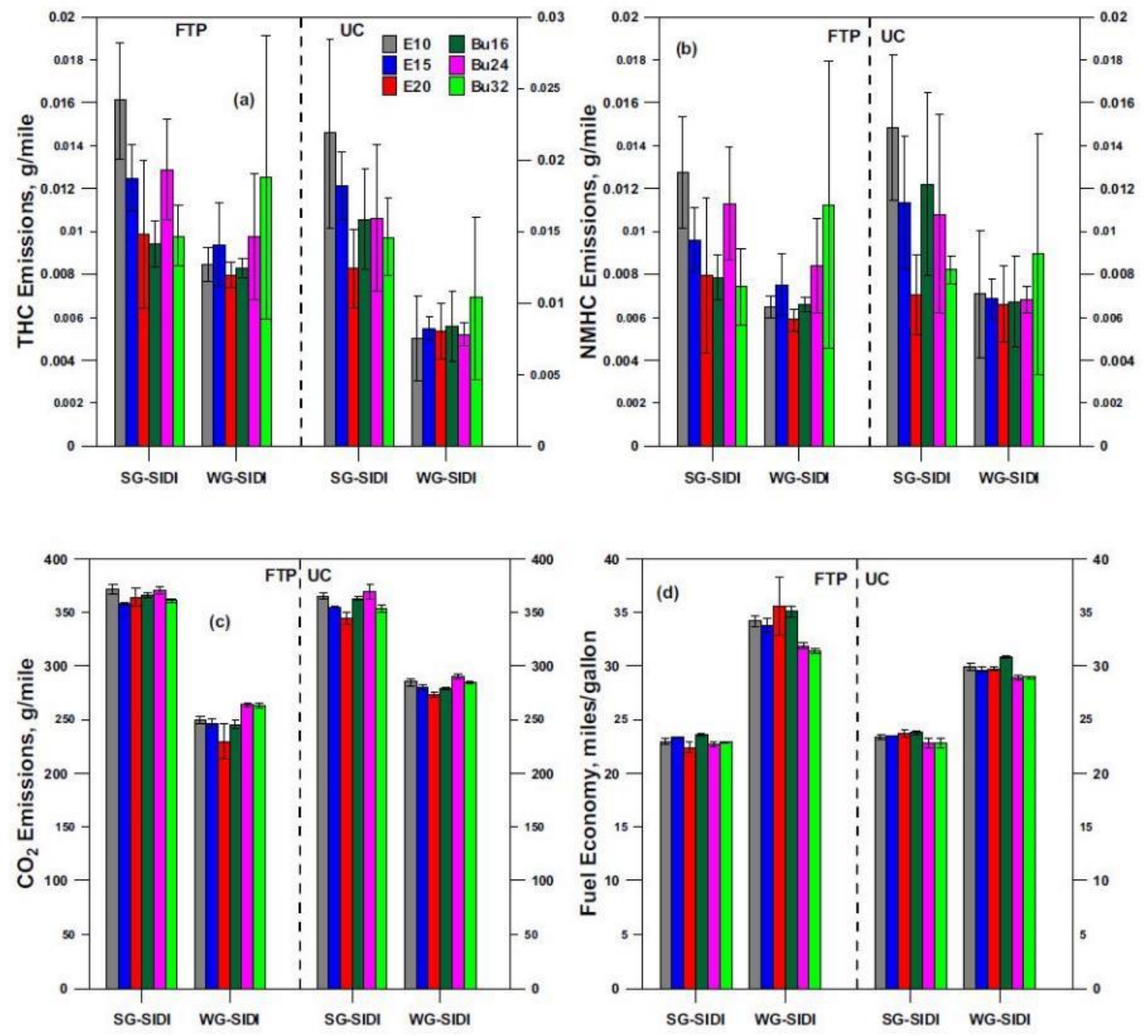

Figure 5: Gaseous Results from (Karavalakis, et al. 2015)THC (a), $\mathrm{NMHC}(b), \mathrm{CO}_{2}(c)$, and Fuel Economy (d) for WG-DI and SG-DI with six different fuels over the FTP and UC cycle.

Figure 6 presents the particle size distribution from the study. The top portion of the figure represents the WG-DI vehicle while the lower portion shows SG-DI particle size distribution. The blue lines represent the E15 fuel which is most comparable to the fuel used in this research discussed later and is the only particle distribution reviewed. The distributions are similar from cycle to cycle but when comparing the direct injection methods, the SG-DI concentration shows a decrease of approximately $1.0 \times 10^{5} \mathrm{~cm}^{-3}$ to the concentration of the WG-DI. Using the particle distribution in Figure 6, the distribution shows most of the particles in accumulation mode with the WG-DI engine. The WG-DI had a larger concentration of particles because of zones with rich air fuel ratio (AFR). This rich localization comes from the injection charge cloud and is attributed to the poor mixture preparation association with wall guided engine design. While it will not be 
tested in the following research, it is important to note the decrease in average particle concentrations when changing from ethanol fuel blends to iso-butanol blends. This highlights that other options are available to further lower particle emissions that could aid hardware such as a GPF to minimize particle concentration from tailpipe out emissions.
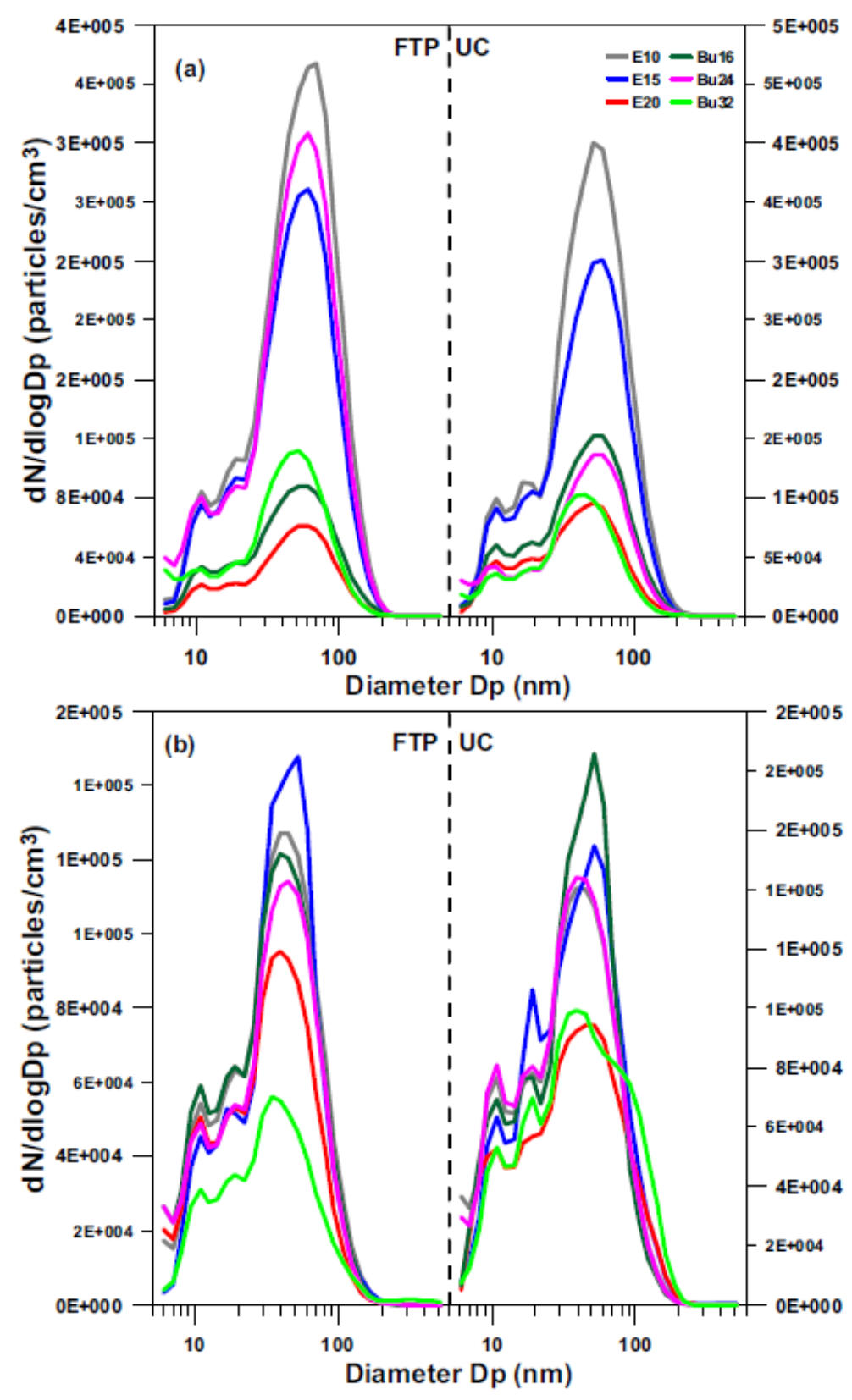

Figure 6: Average particle size distribution from (Karavalakis, et al. 2015), of an WG-DI vehicle (a) and an SG-DI (b) for a FTP and UC cyle. Six different fuels were tested for both cycles. 


\section{PM and Dilution Ratio Reduction}

In the United States, emissions testing falls under the CFR Title 40, Part 1065 umbrella. The specific requirements for emissions testing are included in this and other sections. For gravimetric $\mathrm{PM}$, a $47 \mathrm{~mm}$ filter is required to trap a sample of the dilute exhaust for mass measurement. The PM sampling requires a filter face velocity across a $38 \mathrm{~mm}$ diameter filter stain area to be 50 $\mathrm{cm} / \mathrm{sec}$ or to target filter loading of $400 \mu \mathrm{g}$. Due to the high dilution ratios, $400 \mu \mathrm{g}$ would require a higher filter flow velocity and thus require the filter face velocity target of $50 \mathrm{~cm} / \mathrm{sec}$. The 50 $\mathrm{cm} / \mathrm{s}$ filter face velocity can be translated into a flowrate of 2.3 SCFM using the dimensions for the equipment and flow paths. The methods for two of the three PM sampling systems utilized critical flow orifices to control the flowrate of the sample path.

With the dilute exhaust flow being predominately gas, there are multiple methods to measure and record the flow rate of the sample streams. For example, critical flow orifices (CFO) will achieve a constant velocity flow through them once a pressure ratio of the upstream and downstream pressures has been achieved. A high vacuum system can be used to pull the sample though the flow path and designed to provide an adequate pressure drop $(\Delta \mathrm{P})$ across the CFO unless there is a blockage or significant restriction, such as when the filters become overloaded with PM.

The CFO's used were provided from O'Keefe Controls Company and using their data sheets shown in Figure 54 in the Appendix, the orifice selected was Size Number 100. This size is important in reference to the flow value at critical flow. In a choked flow setting, the flow of this orifice is $59 \mathrm{SLPM}$. This value can be converted to $2.08 \mathrm{SCFM}$ using standard conditions $\left(70{ }^{\circ} \mathrm{F}\right.$ and $14.7 \mathrm{psia})$. For a CFO to achieve critical flow, upstream $\left(P_{\text {up-stream }}\right)$ and downstream $\left(P_{\text {down- }}\right.$ stream) pressure is compared to a pressure ratio. By dividing $P_{\text {up-stream }}$ by $P_{d o w n-s t r e a m}$ as shown below, the absolute pressure ratio $\left(P_{\text {ratio }}\right)$ can be determined.

$$
P_{\text {ratio }}=\frac{P_{\text {up-stream }}}{P_{\text {down-stream }}}
$$

For the flow to be critical, the $P_{\text {ratio }}$ must be at least 0.528 at standard conditions (O'Keefe Controls Co. 2011). Pressure ratios above this confirm a critical flow while ratios below do not. The pressures being used for the calculation must be an absolute pressure as well. 
The flowrate of the orifice will need correction factors for temperature $\left(\mathrm{T}_{\text {sample }}\right)$, pressure $\left(\mathrm{P}_{1}\right)$, viscosity $(\mu)$ and relative humidity $\left(\mathrm{RH}_{\text {sample }}\right)$. Equations for $\mathrm{RH}_{\text {sample }}$ and $\mu$ were found in a user manual from Meriam for Laminar Flow Elements (Meriam n.d.).

$$
R H_{\text {sample }}=\frac{\rho_{w e t}}{\rho_{d r y}}
$$

The correction factor $\mathrm{RH}_{\text {sample }}$ is calculated by dividing the density of wet air ( $\left.\rho_{\text {wet }}\right)$ at the sample condition by the density of dry air $\left(\rho_{\mathrm{dry}}\right)$ at the standard condition of the orifice.

$$
\mu_{\text {corr }}=\frac{\mu_{\text {std }}}{\mu_{\text {measured }}}
$$

The viscosity correction factor is the viscosity of air at standard temperature condition $\left(\mu_{\text {std }}\right)$ divided by the viscosity of the sampled air temperature condition ( $\left.\mu_{\text {measured }}\right)$.

Normally there is a $\mathrm{K}$ value for the geometry of the orifice, but this has already been factored into the given flow rate from O'Keefe Controls Co. The temperature and pressure values of the sample were recorded and the calculated real-time during the testing, while viscosity and humidity were considered constant due to humidity measurement capabilities and viscosity being determined by temperature which should remain constant with all heated sample paths. Humidity measurements at sample locations were recorded but for reference only as the equipment was not calibrated nor held a high measurement resolution. Heated lines were leak checked and temperature checked before use. The equation below was used to calculate a corrected flow rate for two of the critical flow orifices controlling sample flow for PM collection.

$$
Q_{\text {actual }}=Q_{\text {est }} * \frac{529.67}{\left(T_{\text {sample }}+459.67\right)} * \frac{P_{1}}{14.7} * R H_{\text {sample }} * \mu_{\text {corr }}
$$

The first part of the equation is the estimated flow from O'Keefe Co. Next is the correction factor for the temperature, the recorded temperature value $\left({ }^{\circ} \mathrm{F}\right)$ is converted to Rankine and divided into the temperature at the given standard condition, also in Rankine. Then the pressure is divided into the atmospheric pressure given at standard conditions, in PSIA. As previously stated, relative humidity and viscosity corrections were used by multiplying the correction factors by the estimated flow. 
Gravimetric PM is a mass measurement of the particles collected onto a filter during a test cycle. The weight of the filter is recorded before the cycle starts and after. The calculation of the net filter mass from a test cycle $\left(M_{c y c l e}\right)$ is the difference between the from the $M_{\text {post }}$ (post-mass) and $M_{\text {pre }}$ (pre-mass).

$$
M_{\text {cycle }}=M_{\text {post }}-M_{\text {pre }}
$$

For comparison amongst other filters, the $M_{\text {cycle }}$ will need to be equated to a normalized value to allow for an even comparison. During the filter sampling, the flow across the filter is measured. This flow measurement, with the time the sample valve is open during a test cycle allowed the calculation of the volume sampled. From the data provided from a single test cycle, the number of seconds the sample valve remained opened was summed $\left(T_{\text {sampled }}\right)$. The volumetric flowrate is taken and the mean flow rate from the moment the sample valve is opened, until it is closed, is determined. This value $\left(\dot{V}_{\text {avg }}\right.$ ) will represent the average flow from the beginning of filter sampling until the end. Due to the high vacuum system and large flowrate required, there is a bypass valve installed parallel to the sample valve. The bypass system flows the exhaust stream through the sampling system, but around the filter housing, to maintain constant sampling conditions at the beginning or end of test period and to maintain a consistent flow during a transition of sampling paths. The $\mathrm{V}_{\text {sampled, }}$, is the total volume sampled across the filter and is calculated as such.

$$
V_{\text {sampled }}=\dot{\mathrm{V}}_{\mathrm{avg}} * \mathrm{~T}_{\text {sampled }}
$$

Using $M_{\text {cycle }}$ and $V_{\text {sampled }}$, the mass per volume sampled can be calculated to compare the particles weights sampled at each dilution ratio.

$$
M_{\text {vol }}=M_{\text {cycle }} / V_{\text {sampled }}
$$

Mass per volume $\left(M_{v o l}\right)$ can be used to normalize the PM weights between cycles and dilution ratios for basic comparisons.

Dilution ratio calculation is used to confirm the proper sample cycle to cycle. DR 1 exist in the CVS tunnel of the test cell. Using the Horiba OBS-ONE, the exhaust flow rate (EFR) of the engine compared to the CVS tunnel EFR, the dilution ratio can be calculated. DR 1 used $\mathrm{CO}_{2}$, along with DR 2 and 3, to classify their dilution ratio. The methods for both are similar but with different 
sources. For the exhaust flow, the recorded data for the CVS tunnel ( Exh $\left._{\mathrm{cvs}}\right)$ and Horiba OBS-ONE (Exh $\left.\mathrm{Ebs}_{\text {ob }}\right)$ was time aligned and an average of the flows taken from the entire cycle time. This can be seen from the equation below.

$$
D i l_{D R 1}=\frac{E x h_{c v s}}{E x h_{o b s}}
$$

When using $\mathrm{CO}_{2}$, the process is similar. The $\mathrm{CO}_{2}$ traces were time aligned and an average of the concentrations taken for the duration of the cycle. The average of the lower diluted system (i.e. 20:1<40:1) was divided by higher diluted system to yield a relative dilution ratio of the two systems. Until the ratio is multiplied by the dilution ratio of the system it samples from, it is not the final dilution ratio.

$$
D i l_{D R X}=\frac{C O_{2_{\text {conc. } 1}}}{C O_{2_{\text {conc. } 2}}}
$$

Where $\mathrm{CO}_{2}$ conc. 1 is a lower dilution ratio system than $\mathrm{CO}_{2}$ conc. 2. The system used to conduct this research used three dilution systems. If the first dilution ratio $\left(\mathrm{CO}_{2}\right.$ conc. $\left.{ }_{1}\right)$ is divided by the last dilution ratio $\left(\mathrm{CO}_{2}\right.$ conc. 3), the result would be Dil final.

\section{Methods and Materials / Experimental Set Up}

Equations used for the PM boxes with CFOs will be presented in the following section along with the various equipment. All analyzers, pressure transducers, thermocouples, heated lines, and other test critical equipment was verified and calibrated prior to testing to ensure data integrity.

\section{Dilution Ratios}

The sampling system consisted of three separate dilution ratios. These dilution ratios are labeled as DR 1, DR 2, and DR 3. The DR 1 ratio is based on the CVS tunnel sampling system with a Horiba critical flow orifice (CFO) sampling system to maintain constant flow. For this testing, the flow rate of the tunnel was selected at $14.5 \mathrm{~m}^{3} / \mathrm{min}$ to achieve a dilution ratio of approximately 20:1. Figure 7 shows an overview of the test cell equipment. The Horiba cabinets in the background house the sample bags that are filled during the test cycle. The Horiba cabinet to the right of them is a MEXA 7000 that sampled all the gaseous species. At the right edge of Figure 7, the stainless- 
steel pipe is the CVS tunnel. The back side of the CVS tunnel has a second flange that is symmetric to the one shown by the blue arrow. This flange contains the probe for the DR 1 PM box (shown above the blue MircoSoot Sensor (MSS) in Figure 8), and the heated sample line transferred the sample to the Air-Vac ejector dilutor for DR 3. This flange is also where the MSS in Figure 8 measured. Further up the CVS tunnel by approximately 12 " is a separate probe for the CPC. This probe location can be seen circled in Figure 9.

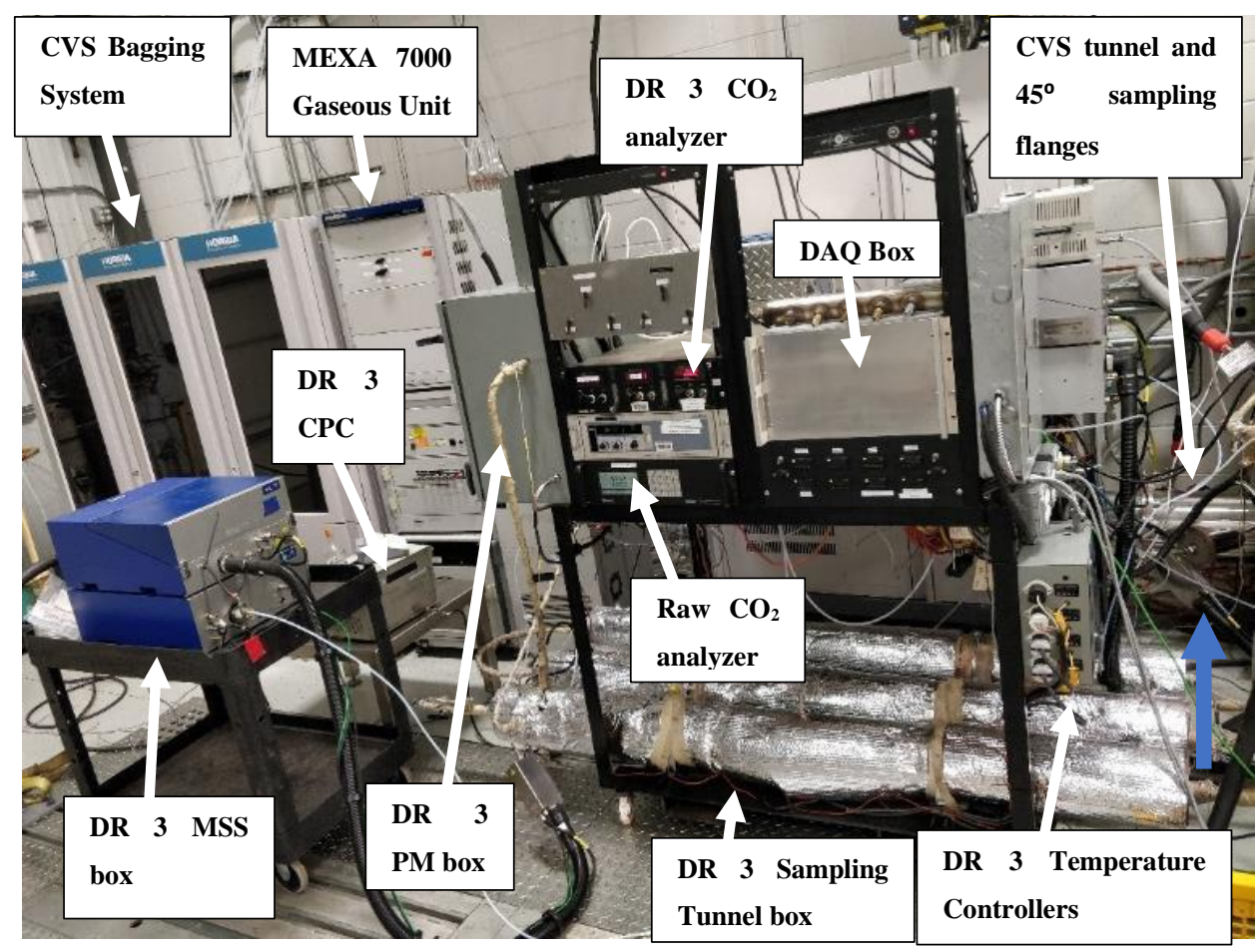

Figure 7: DR 1 reference image 1. 


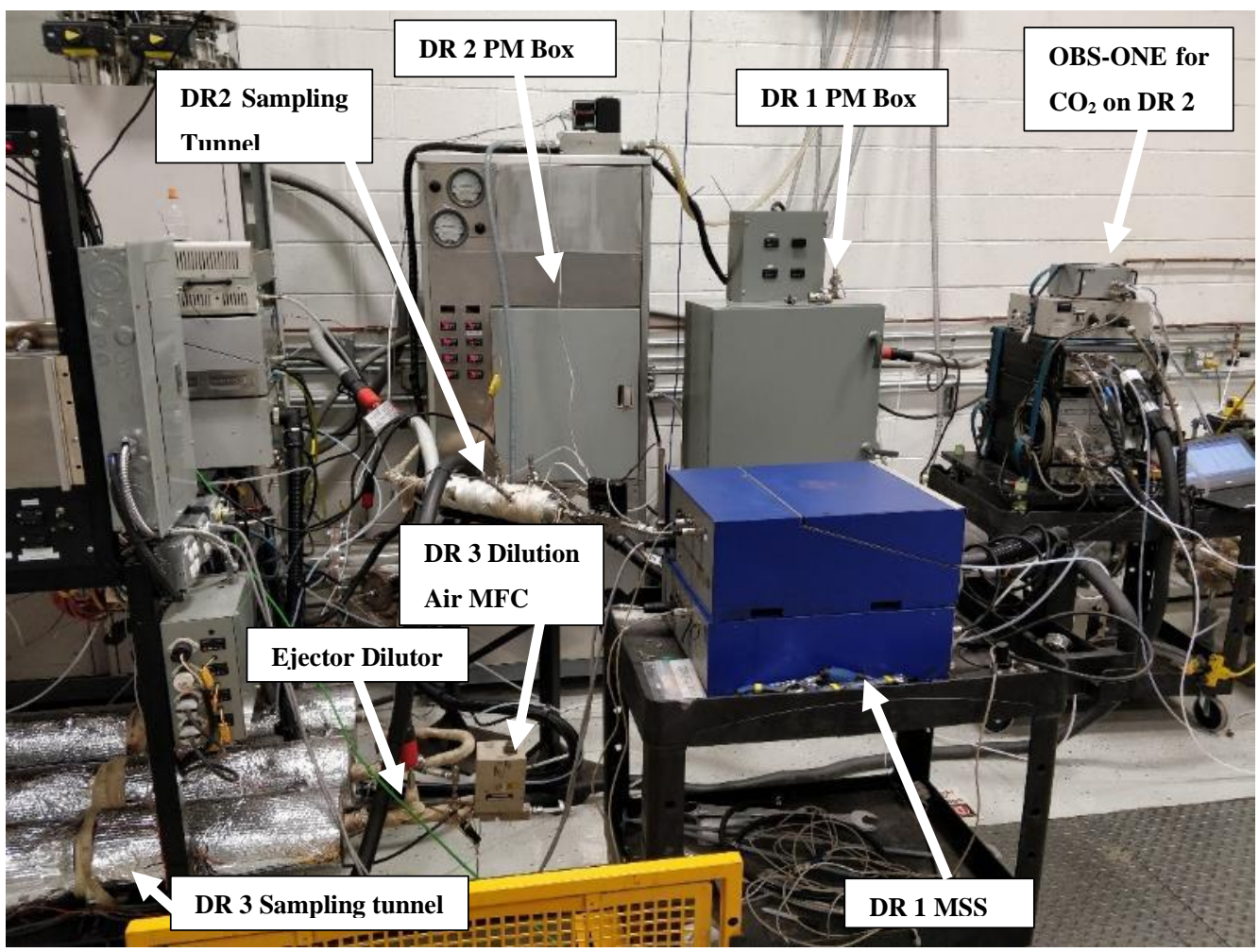

Figure 8: DR 1 and 2 refrence image 2.

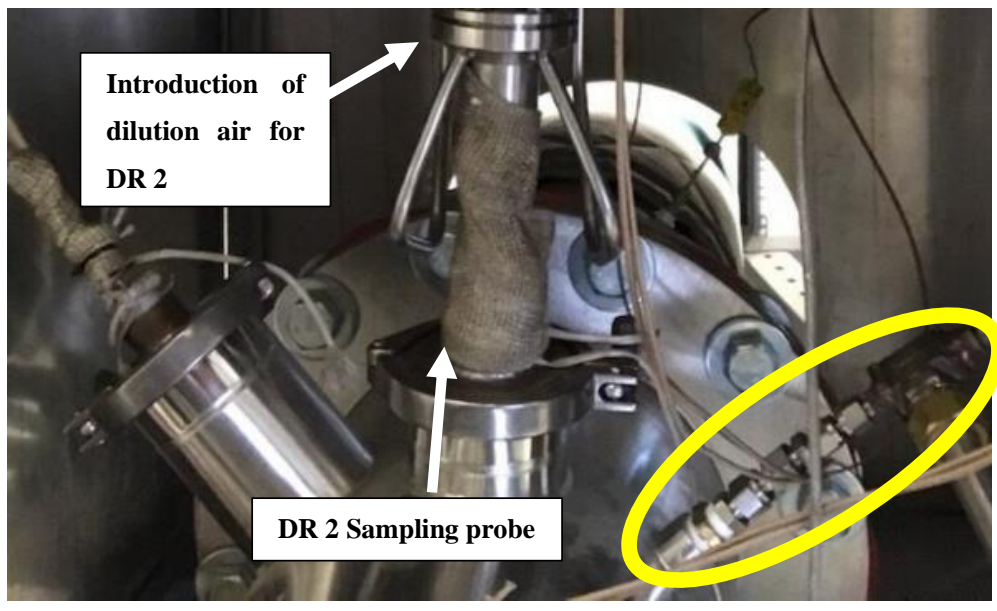

Figure 9: Probe location for DR 1 CPC.

For DR 2, the sample traveled into the existing PM box on the CVS tunnel and be introduced to a 2:1 dilution, for an overall dilution ratio of 40:1. After passing through this dilution stage, the sample traveled into a smaller, secondary tunnel that equipment measured from, shown in Figure 10. The filter loading took place in the grey box behind the small tunnel in Figure 10. The gaseous measurement was taken with a Horiba OBS-ONE. This unit can be seen previously in Figure 8 to the right. 


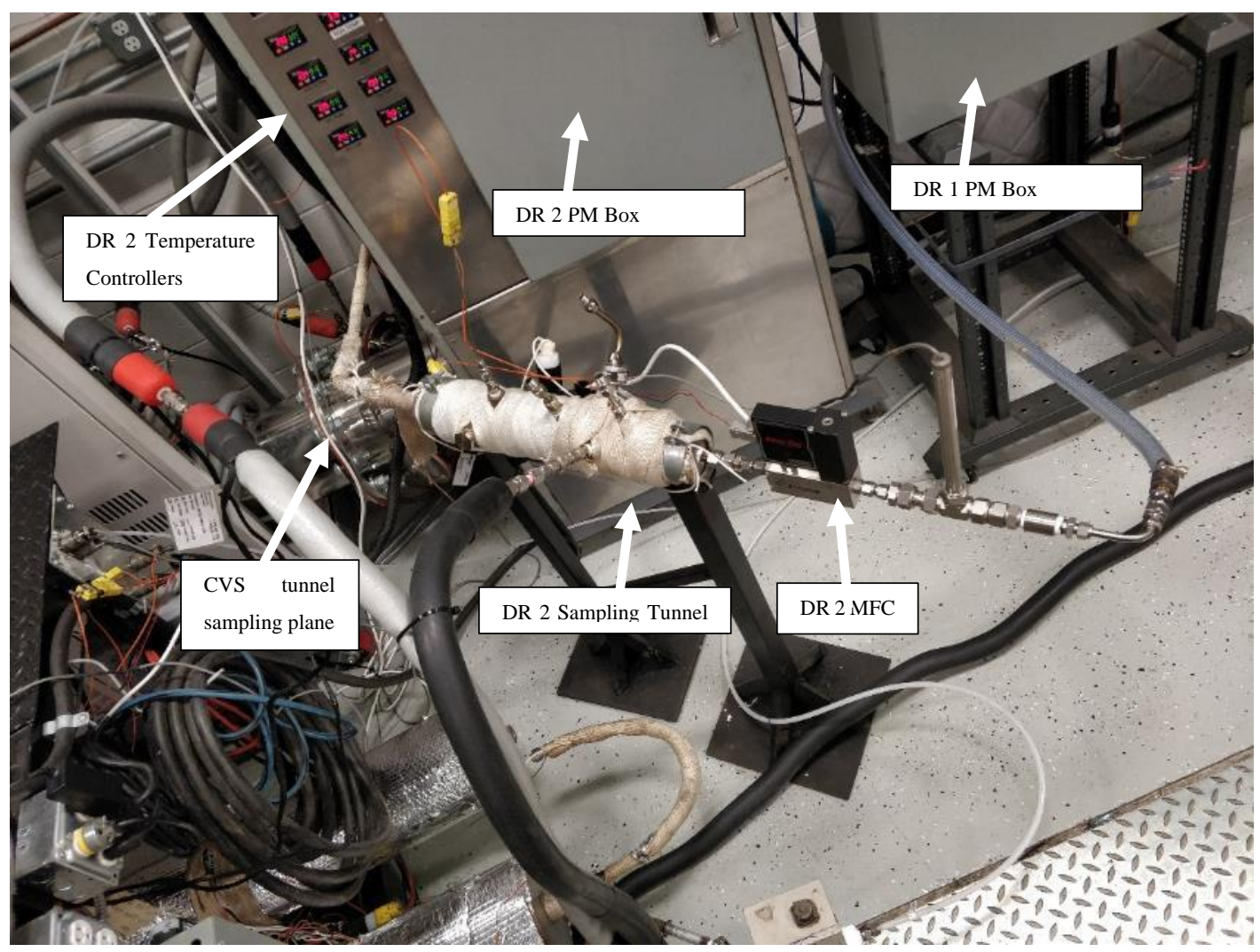

Figure 10: Visual of the DR 2 sample tunnel.

The DR 3 ratio pulled a sample from the sample plane in the CVS tunnel by the vacuum flow produced by a vacuum pump and an ejector dilutor shown in Figure 11. The ejector dilutor had a supply air line with a constant dilution air flow (blue arrow) into the ejector dilutor. This air flow into the ejector dilutor creates a vacuum on the sample port of the ejector dilutor. Upstream of the sample port was a critical flow orifice (CFO). The sample port with a CFO is of a certain diameter and the vacuum from the compressed air creates critical flow (constant) velocity of the sample line. This allows for a constant sample flow (yellow arrow) to be pulled from the CVS tunnel and diluted at a constant rate (Air-Vac 2011, O'Keefe Controls Co. 2003, O'Keefe Controls Co. 2011). Figure 12 provides a schematic of the flow for the Air-Vac ejector dilutor. The dilution air of the ejector dilutor has a mass flow controller to limit and measure the air flow in and also a pressure transducer to monitor pressure differences that could affect the mass flow controller performance or flowrate. The pressure transducers were verified and calibrated prior to use. 


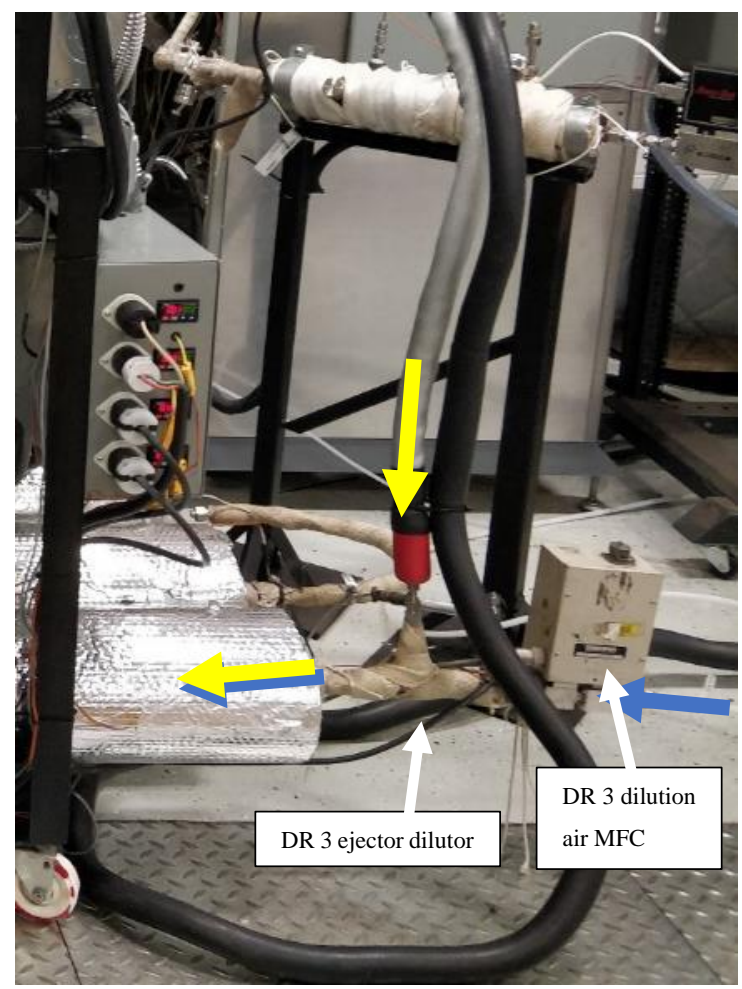

Figure 11 Ejector dilutor for DR 3

\section{How AV Series Works}

Compressed air flows through a small circular opening to generate a high velocity. This air expands, resulting in decreased pressure to provide vacuum levels up to $27.5^{\mathrm{H}} \mathrm{Hg}$. The vacuum port is perpendicular to the air supply.

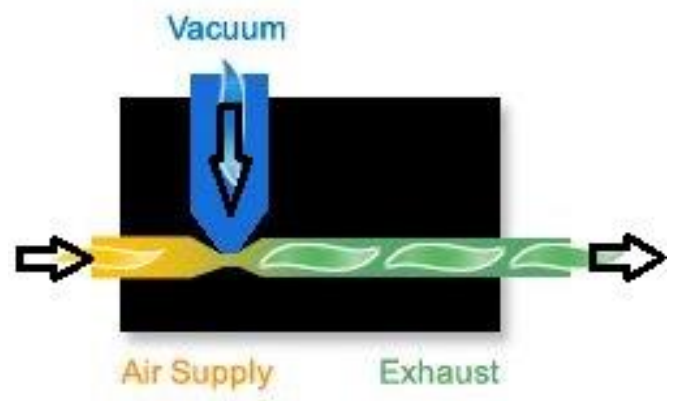

Figure 12: Visual and description of ejector dilutor operation (Air-Vac 2011).

This ejector dilutor flowed a sample into a separate secondary tunnel at a dilution ratio of 4:1, to achieve a final dilution ratio of 80:1. The DR 3 sample passed through the first tunnel in the set of three. This tunnel is shown in Figure 13 as having the grey heated sample line and tan colored box 
in line with the tunnel itself. The tunnels behind were used for a separate project and will not be included during this research. The $\mathrm{CO}_{2}, \mathrm{PM}$, and particle measurements were taken from the left end of the tunnel in Figure 13. All $\mathrm{CO}_{2}$ analyzers were used to measure $\mathrm{CO}_{2}$ to confirm dilution ratio. Each analyzer was equipped and linearized with its appropriate concentration of gas. The tunnel length was designed to incorporate a longer residence time for the particles in the sample for the purposes of another research project.

The tunnels were all wrapped with heating elements that were temperature controlled. The temperature controllers can be seen on the rack beside the $\mathrm{CO}_{2}$ analyzers and mounted on the side of the rack. There is also another box mounted behind the rack for the additional tunnels that were not needed for this work. The temperature controllers on the analyzer rack are responsible for controlling the heated sample lines, the tunnel heaters and the heat tape used to heat any surfaces that do not supply their own heat source. An example of this would be the ejector dilutor or the secondary sample tunnel for DR 2. All heated surfaces were covered with exhaust insulation wrap to maintain temperature. The tunnel on DR 3 was covered with HVAC insulation wrap to cover more area and insulation was used to cover the portions that were used to mount the tunnel to the test stand.

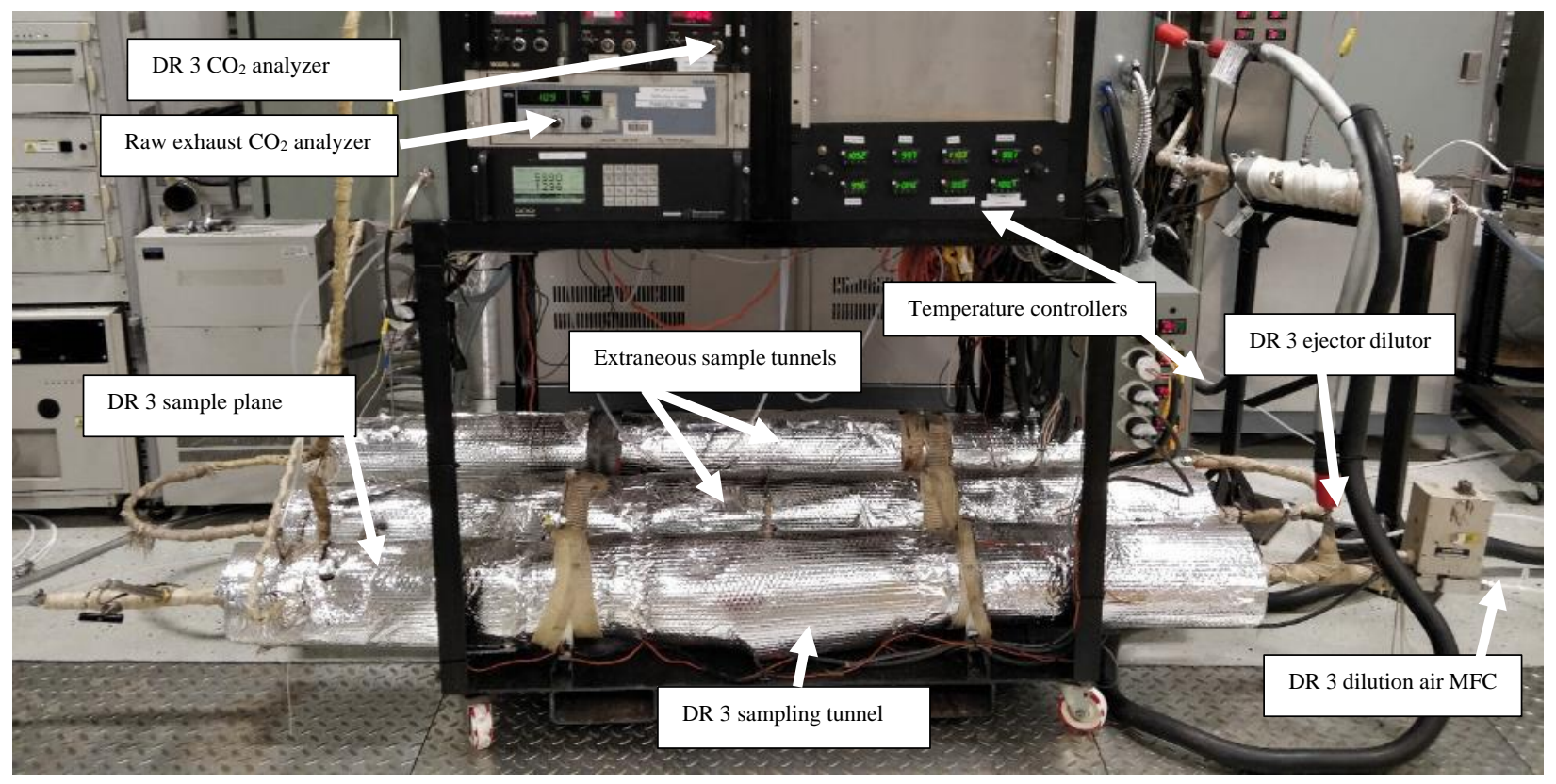

Figure 13: Visual of the test stand that contains the DR 3 sample tunnel. 
For PM, there are three different boxes being used to collect PM. The first box is located on the existing CVS tunnel and used during typical operation of the test cell. During the testing of this research, this box was referred to as the "DLMB." The DLMB was used to sample PM from DR 2. Figure 14 shows an image of how the dilution air is injected into the sample for DR 2. The dilution air (blue arrows) was introduced to the sample (yellow arrow) as the probe exits the CVS tunnel (large silver piping).

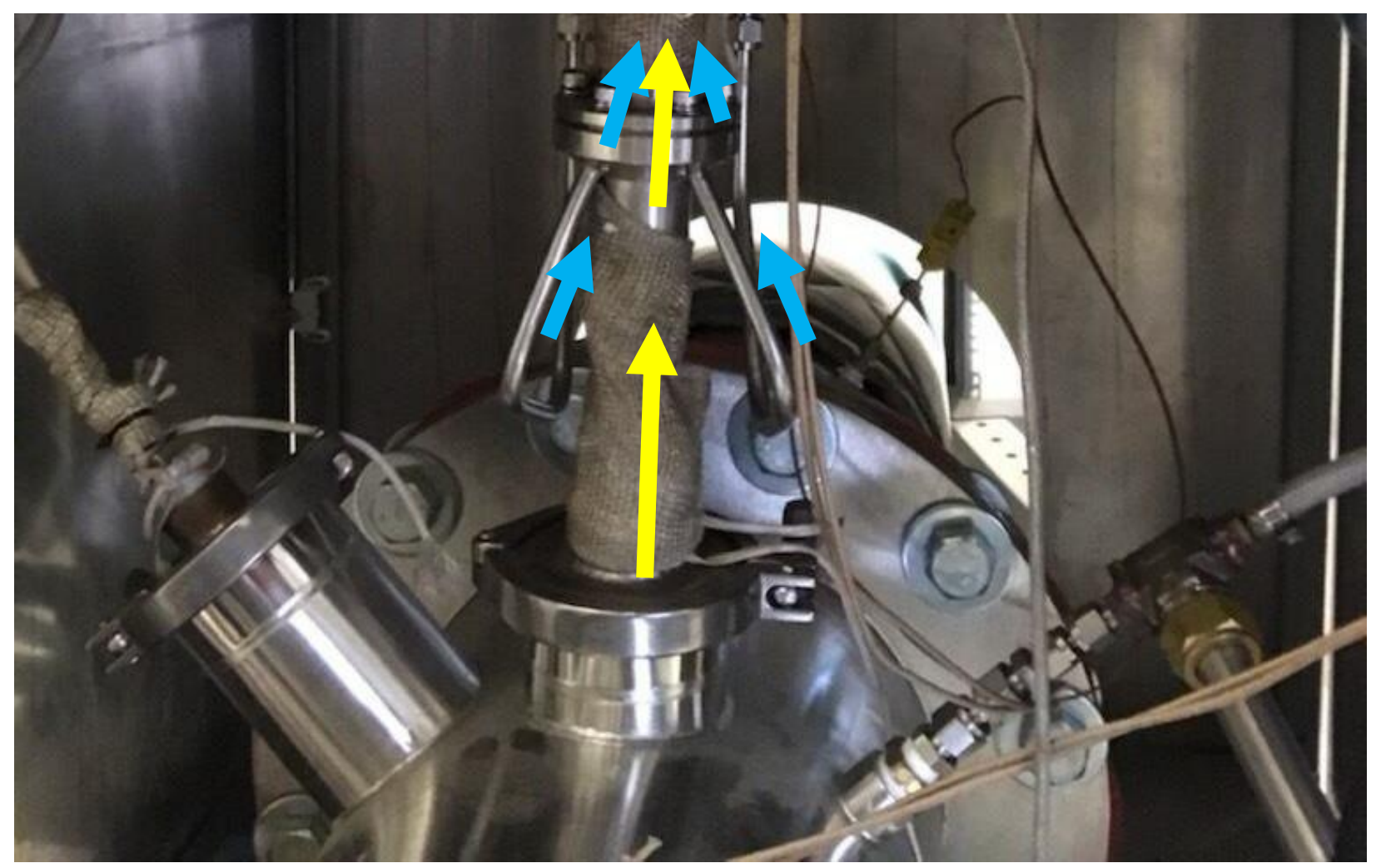

Figure 14: Introduction of the dilution air into the DR 2 sample.

The diluted sample of DR 2 traveled into a flow splitter, shown in Figure 15, that allowed flow to travel to the DLMB (the diluted sample path on the left that travels into the insulated box) and also to a small secondary tunnel for particle and gaseous measurement (diluted sample path on the right). The full path from the CVS tunnel, the introduction of the dilution air, and to the flow splitter can also be seen on the left of Figure 15 with the detailed view of the flow splitter in the detailed right portion. 


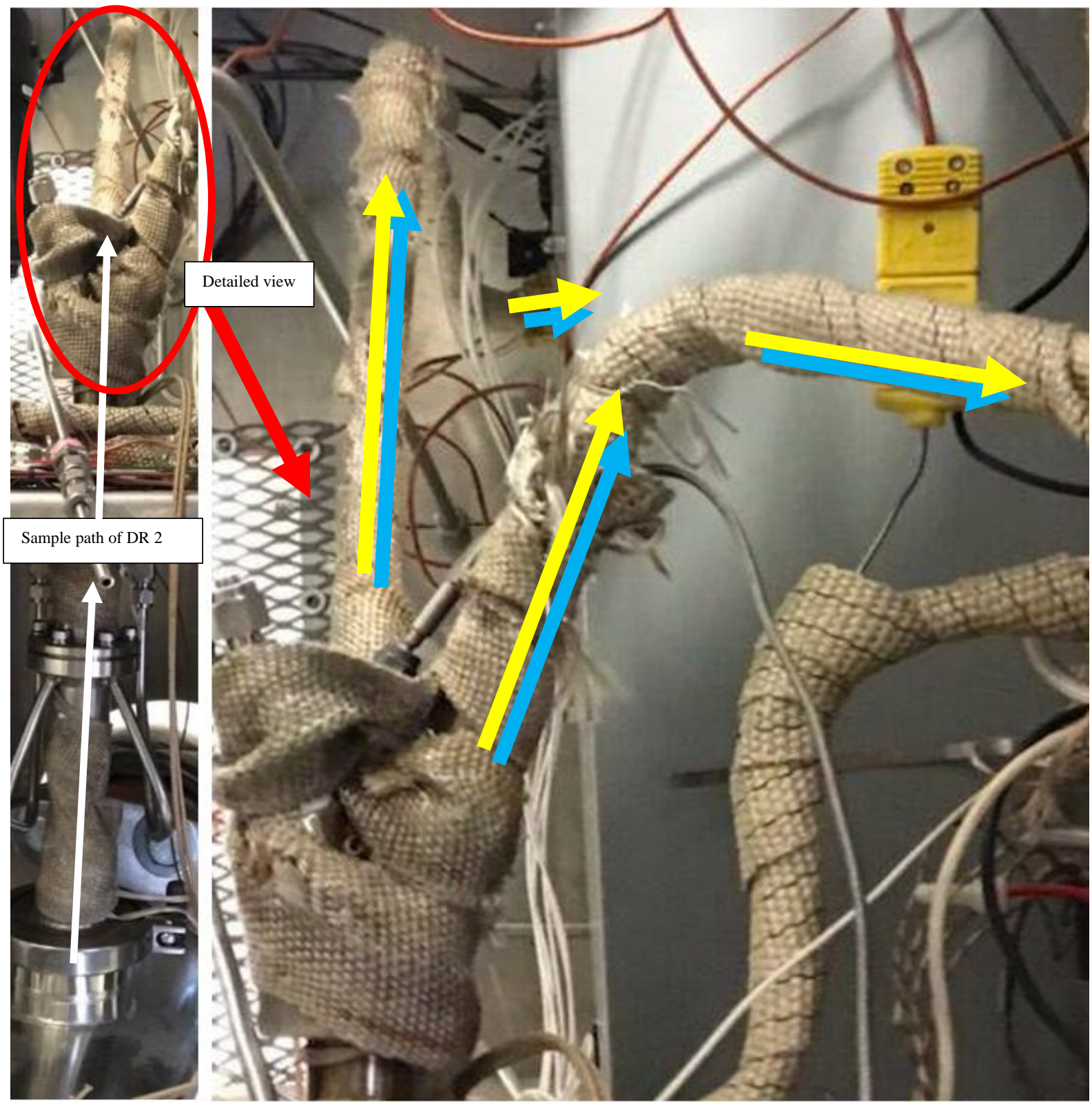

Figure 15: Flow path of DLMB diluted sample from the CVS tunnel.

Once the sample for DR 2 travels into the DLMB, the sample will travel into an identical path as the samples for DR 1 and DR 3, with the exception of flow measurement. For the DR2 DLMB PM measurement, the flow was measured using a Alicat Scientific MCR-100SLPM-D mass flow controller (MFC). The PM boxes for DR 1 and DR 2 were constructed prior to the beginning of the project with all new tubing and custom flow splitters but used cyclones and valves from prior projects. Figure 16 shows the components internal to PM Box A used to sample at DR 3 and PM Box B used to sample at DR 1. The box was designed for use on a project parallel to the research 
data collected and is the reason for the organization of the line routing. The blue lines indicate the flow of the sample up to the exit of the filter holder. Once the sample is through the filter holder, the lines change to green. The sample comes into the box, and immediately passes through the cyclone to remove large particles via vortex separation. The flow travels out of the cyclone and into a custom flow splitter designed to maintain isokinetic flow. The flow for this experiment only travelled through the left filter holder. During the experiment, the right filter holder was removed, and the exposed fittings were plugged. The sample passed over a single $47 \mathrm{~mm}$ TX40 filter, this is where the sample line changes from blue to green. The sample passes through to the critical flow orifice and the valve that opens/closes to introduce vacuum pressure to allow flow. In the sample path, there is a small brass object underneath the filter holder in Figure 16 (circled in yellow). This is the critical flow orifice (CFO) used to maintain a constant flow during the test cycles. The CFO has been machined to a particular diameter and corrected for pressure, temperature, and humidity. This equation of the flow can be seen in the PM and Dilution Ratio Reduction section. For the corrections, the temperature and absolute pressure upstream of the $\mathrm{CFO}$ around the $\mathrm{CFO}$ were recorded real time during the testing. Differential pressure was recorded across the CFO to confirm an adequate pressure ratio between the upstream and downstream pressure to host critical flow. The differential pressures were recorded using a Honeywell PPT010-1D-WW-2V-B. The absolute pressure transducers were Omega PX176-02A5V models. These pressure transducers were calibrated prior to installation and use in the research. The temperature measurement was measured in the flow block with a J-type thermocouple. The vacuum source used was a Busch Mink MM 1104 BV vacuum pump, shown in Figure 17. 


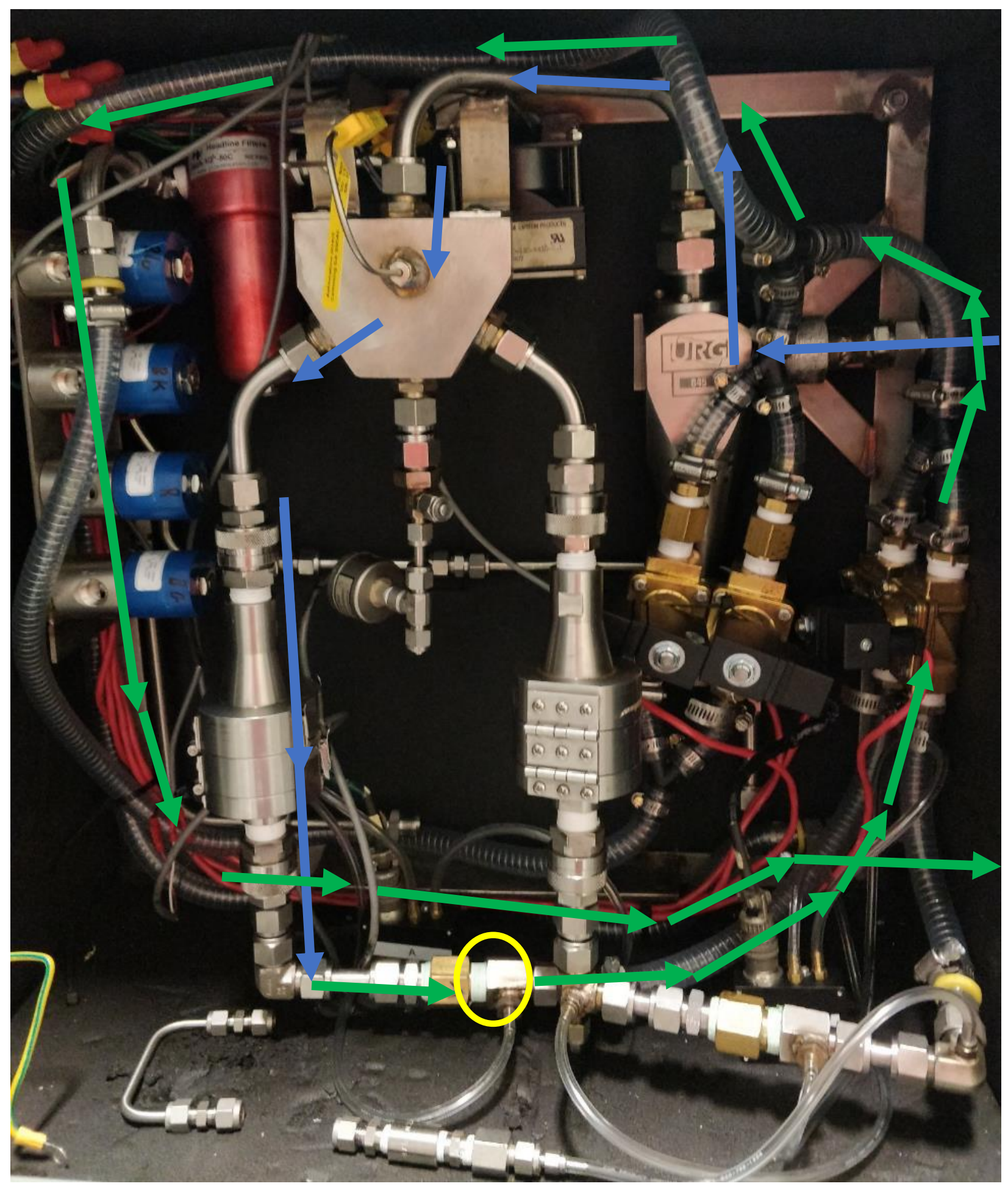

Figure 16: View of the inside PM Box A and Box B. 


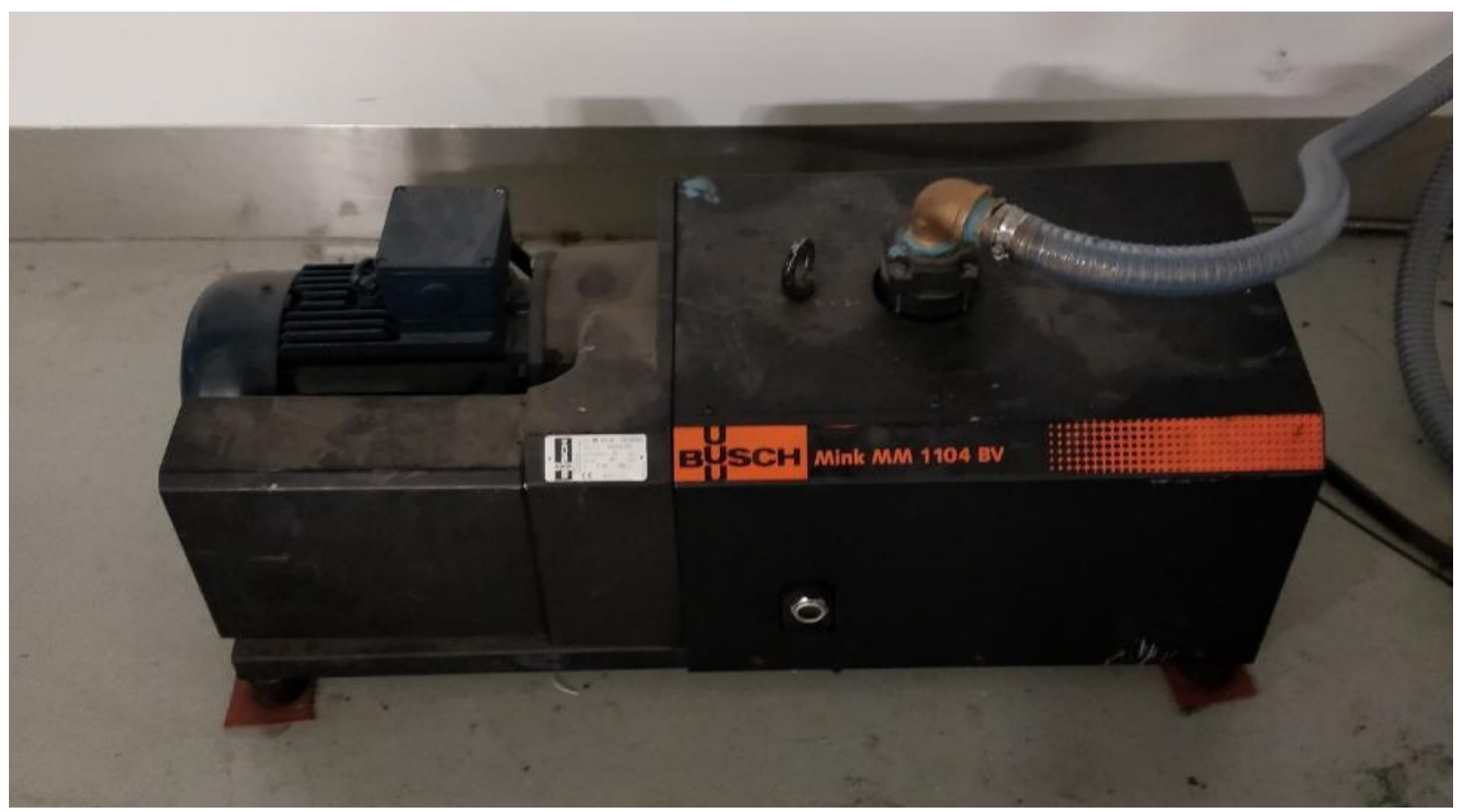

Figure 17: Vacuum pump used for test system.

For particle measurement, multiple MSS units and CPC units were used. Also, during the testing of the Subaru Legacy, one MSS unit was not available and the second MSS unit was moved between DR 2 and DR 3. This will all be explained in the text later for clarification. During the testing of the Sant Fe, each dilution ratio had their own MSS, CPC, $\mathrm{CO}_{2}$ analyzer, and PM measurement. The PM measurement details were explained in the previous section.

\section{Test Plan}

The test matrix is shown in Table 2 and Table 3. This overview of the tests shows there were three different steady state conditions: City, Urban, and Highway. The City conditions was driven on the chassis dynamometer at approximately $25 \mathrm{mph}$, the Urban at $45 \mathrm{mph}$, and the highway at $65 \mathrm{mph}$. Each of the driving conditions were performed by both vehicles for 5 minutes during a hot-start condition. The vehicle was operated over two consecutive 5-minute warm-up procedures to prepare it for the test cycles and allow the oil and coolant to reach operating temperature and confirm all measurement equipment was operating properly. Directly after the steady state testing the vehicle was evaluated using a warm start transient LA92 cycle. After the warm start, the vehicle was soaked for 5 minutes and then performed a hot start LA92. During the hot start, all equipment measured continuous signals and gravimetric PM was collected. While testing the 2013 Hyundai 
Santa Fe (GDI), three AVL MSS were available, one for DR 1, DR 2, and DR 3. Due to this, it allowed three tests per steady state condition without pausing to install MSS 2 on DR 3. During the 2015 Subaru Legacy testing, only two MSSs were available. This set of testing required a fourth test to allow for MSS 2 to show repeatability during test 1 and 2 on DR2 and when switched to DR 3 for test 3 and 4, it was used to show repeatability on DR 3. During this time, MSS 1 remained on DR 1 to show repeatability among all four tests. To confirm the first and second cycle produce repeatable data, both cycles were measured with an MSS, a TSI CPC, and $\mathrm{CO}_{2}$ analyzer on the CVS tunnel. While a MSS and TSI CPC measure from the desired dilution ratios DR 2 and DR 3, respectively. This data determined that each cycle had a repeatable soot concentration, particle number concentration, and the CVS tunnel maintained a close dilution ratio to allow for a comparison of continuous data. The particle concentration and soot concentration were compared at each of the testing conditions to determine different particle and soot characteristics for each injection methods and at different driving conditions. DR 1 was also selected as the baseline because it sampled in the lowest dilution ratio because this sample would allow for the highest measurement resolution within the three dilution ratios. Between each cycle there was a 5-minute soak. This was to allow time for filter media change, documentation, and any equipment sampling location change if needed.

Due to low staff availability, the drivers for the vehicles were not the same. The steady state condition testing was collected during a "Simple Capture" in the software and was used to record all data. This required that all filter sample and bypass valves to be manually opened and closed during these 5-minute periods leading to a slight variation in the sample time of each of the filters. The two PM boxes on DR 1 and DR 3 were constructed used critical flow orifices rather than mass flow controllers. These orifices were measured and calibrated using a flow calculation with the appropriate corrections in the data collection software to output the appropriate flow. 
Table 2: Test plan of equipment and designated dilution ratio the Vehicle 1 (2013 Hyundai Santa Fe).

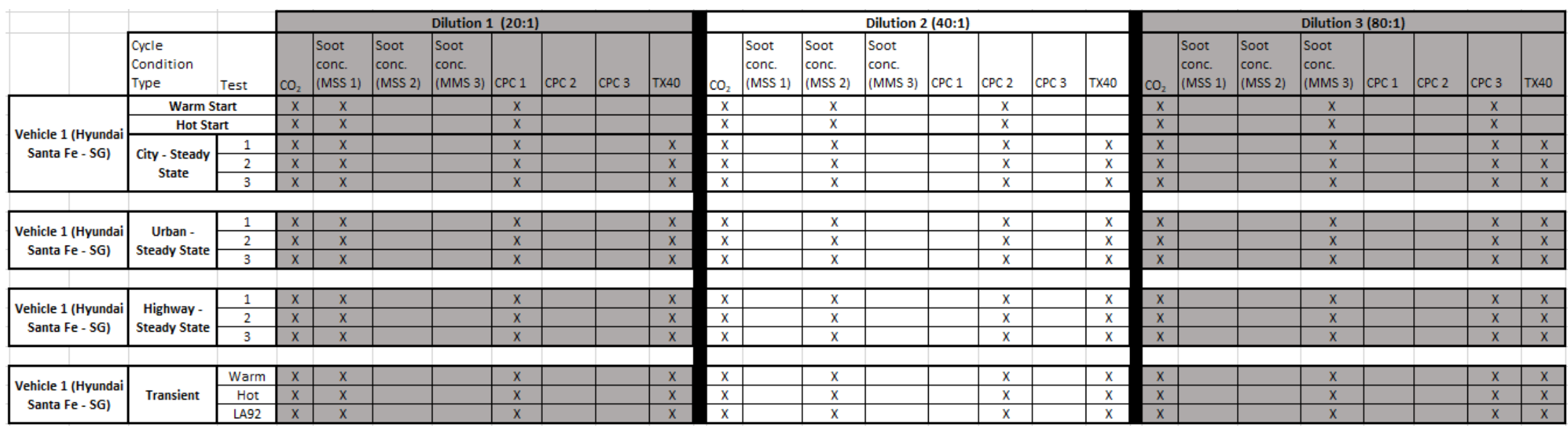

Table 3: Test plan of equipment and designated dilution ratio the Vehicle 2 (2015 Subaru Legacy).

\begin{tabular}{|c|c|c|c|c|c|c|c|c|c|c|c|c|c|c|c|c|c|c|c|c|c|c|c|c|c|c|}
\hline & & & \multicolumn{8}{|c|}{ Dilution 1 (20:1) } & \multicolumn{8}{|c|}{ Dilution $2(40: 1)$} & \multicolumn{8}{|c|}{ Dilution $3(80: 1)$} \\
\hline & \begin{tabular}{|l}
$\begin{array}{l}\text { cycle } \\
\text { Condition } \\
\text { Type }\end{array}$ \\
\end{tabular} & Test & $\mathrm{CO}_{2}$ & \begin{tabular}{|l|} 
Soot \\
conc. \\
(MSS 1) \\
\end{tabular} & \begin{tabular}{|l|} 
Soot \\
conc. \\
(MSS 2) \\
\end{tabular} & \begin{tabular}{|l|} 
Soot \\
conc. \\
(MMS 3) \\
\end{tabular} & CPC 1 & CPC 2 & CPC 3 & $T \times 40$ & $\mathrm{CO}_{2}$ & \begin{tabular}{|l|} 
Soot \\
conc. \\
(MSS 1)
\end{tabular} & \begin{tabular}{|l} 
Soot \\
conc. \\
(MSS 2) \\
\end{tabular} & \begin{tabular}{|l|} 
Soot \\
conc. \\
(MMS 3) \\
\end{tabular} & CPC 1 & CPC 2 & $\mathrm{CPC} 3$ & TX40 & $\mathrm{CO}_{2}$ & \begin{tabular}{|l|} 
Soot \\
conc. \\
(MSS 1) \\
\end{tabular} & \begin{tabular}{|l|} 
Soot \\
conc. \\
(MSS 2) \\
\end{tabular} & \begin{tabular}{|l|} 
Soot \\
conc. \\
(MMS 3) \\
\end{tabular} & CPC 1 & $\mathrm{CPC} 2$ & CPC 3 & $T \times 40$ \\
\hline \multirow{6}{*}{$\begin{array}{c}\text { Vehicle } 3 \text { (Subaru } \\
\text { Legacy - PFI) }\end{array}$} & \multirow{2}{*}{\multicolumn{2}{|c|}{$\begin{array}{c}\text { Warm Start } \\
\text { Hot Start }\end{array}$}} & $x$ & $x$ & & & $x$ & & & & $\mathrm{x}$ & & $x$ & & & $x$ & & & $x$ & & & & & & $x$ & \\
\hline & & & $\mathrm{x}$ & $\mathrm{x}$ & & & $\mathrm{x}$ & & & & $x$ & & $x$ & & & $x$ & & & $x$ & & & & & & $x$ & \\
\hline & \multirow{4}{*}{$\begin{array}{c}\text { City - Steady } \\
\text { State }\end{array}$} & 1 & $x$ & $x$ & & & $x$ & & & $x$ & $x$ & & $\mathrm{x}$ & & & $x$ & & $x$ & $x$ & & & & & & $x$ & $\mathrm{x}$ \\
\hline & & 2 & $\mathrm{x}$ & $\mathrm{x}$ & & & $\mathrm{x}$ & & & $\mathrm{x}$ & $\mathrm{x}$ & & $\mathrm{x}$ & & & $\mathrm{x}$ & & $\mathrm{x}$ & $\mathrm{x}$ & & & & & & $\mathrm{x}$ & $\mathrm{x}$ \\
\hline & & 3 & $\mathrm{x}$ & $\mathrm{x}$ & & & $\mathrm{x}$ & & & $\mathrm{x}$ & $\mathrm{x}$ & & & & & $\mathrm{x}$ & & $\mathrm{x}$ & $\mathrm{x}$ & & $\mathrm{x}$ & & & & $x$ & $\mathrm{x}$ \\
\hline & & 4 & $x$ & $x$ & & & $x$ & & & $\mathrm{x}$ & $\mathrm{x}$ & & & & & $x$ & & $\mathrm{x}$ & $x$ & & $x$ & & & & $x$ & $x$ \\
\hline & & & & & & & & & & & & & & & & & & & & & & & & & & \\
\hline \multirow{4}{*}{$\begin{array}{c}\text { Vehicle } 3 \text { (Subaru } \\
\text { Legacy - PFI) }\end{array}$} & \multirow{4}{*}{$\begin{array}{c}\text { Urban - } \\
\text { Steady State }\end{array}$} & 1 & $\mathrm{x}$ & $x$ & & & $\mathrm{x}$ & & & $x$ & $\mathrm{x}$ & & $\mathrm{x}$ & & & $x$ & & $\mathrm{x}$ & $\mathrm{x}$ & & & & & & $x$ & $\mathrm{x}$ \\
\hline & & 2 & $\mathrm{x}$ & $\mathrm{x}$ & & & $\mathrm{x}$ & & & $x$ & $\mathrm{x}$ & & $\mathrm{x}$ & & & $\mathrm{x}$ & & $\mathrm{x}$ & $\mathrm{x}$ & & & & & & $x$ & $\mathrm{x}$ \\
\hline & & 3 & $\mathrm{x}$ & $x$ & & & $x$ & & & $x$ & $\mathrm{x}$ & & & & & $x$ & & $\mathrm{x}$ & $\mathrm{x}$ & & $x$ & & & & $\mathrm{x}$ & $\mathrm{x}$ \\
\hline & & 4 & $x$ & $x$ & & & $x$ & & & $x$ & $\mathrm{x}$ & & & & & $x$ & & $x$ & $x$ & & $x$ & & & & $x$ & $x$ \\
\hline \multirow{4}{*}{$\begin{array}{l}\text { Vehicle } 3 \text { (Subaru } \\
\text { Legacy - PFI) }\end{array}$} & \multirow{4}{*}{$\begin{array}{l}\text { Highway - } \\
\text { Steady State }\end{array}$} & 1 & $x$ & $\bar{x}$ & & & $x$ & & & $x$ & $x$ & & $x$ & & & $x$ & & $\bar{x}$ & $\mathrm{x}$ & & & & & & $\bar{x}$ & $\bar{x}$ \\
\hline & & 2 & $\mathrm{x}$ & $x$ & & & $x$ & & & $x$ & $\mathrm{x}$ & & $\mathrm{x}$ & & & $\mathrm{x}$ & & $\mathrm{x}$ & $x$ & & & & & & $\mathrm{x}$ & $x$ \\
\hline & & 3 & $\mathrm{x}$ & $\mathrm{x}$ & & & $\mathrm{x}$ & & & $\mathrm{x}$ & $\mathrm{x}$ & & & & & $x$ & & $x$ & $x$ & & $x$ & & & & $\mathrm{x}$ & $x$ \\
\hline & & 4 & $x$ & $x$ & & & $x$ & & & $x$ & $\mathrm{x}$ & & & & & $x$ & & $x$ & $x$ & & $x$ & & & & $x$ & $x$ \\
\hline \multirow{4}{*}{$\begin{array}{l}\text { Vehicle } 3 \text { (Subaru } \\
\text { Legacy - PFI) }\end{array}$} & \multirow{4}{*}{ Transient } & Warm & $\bar{x}$ & $x$ & & & $x$ & & & $x$ & $x$ & & $x$ & & & $x$ & & $x$ & $x$ & & & & & & $x$ & $x$ \\
\hline & & Hot & $\mathrm{x}$ & $x$ & & & $x$ & & & $x$ & $x$ & & $x$ & & & $x$ & & $x$ & $x$ & & & & & & $x$ & $x$ \\
\hline & & LA92 & $x$ & $x$ & & & $x$ & & & $x$ & $\mathrm{X}$ & & & & & $x$ & & $x$ & $\mathrm{x}$ & & $x$ & & & & $x$ & $x$ \\
\hline & & LA92 & $x$ & $x$ & & & $x$ & & & $x$ & $\mathrm{x}$ & & $x$ & & & $x$ & & $x$ & $\mathrm{x}$ & & & & & & $x$ & $x$ \\
\hline
\end{tabular}


Each vehicle had an oil change and conditioning of 250 miles before the start of testing. The fuel purchased was pump grade, 87-octane supplied from a GoMart fuel station in Morgantown, WV and transferred to a 55-gallon barrel to allow the vehicles to be flushed and complete testing with the same batch of fuel. The fuel flush procedure was to empty the vehicles fuel tank, refill the tank to $40 \%$ with the test fuel, drain the tank again, and fill the vehicle back to $40 \%$ and begin testing.

\section{Measurement and Testing Equipment}

The testing equipment consisted of a Horiba Vulcan Chassis Dynamometer. This is a dual-roll CFR Title 40 Part 1066-compliant chassis dynamometer and capable of testing spark ignited and compression ignited vehicles, two and four wheel drive. For vehicle emissions measurement, there was a full Horiba emissions 7200 measurement bench for continuous gaseous data with a CFO to accommodate for various exhaust flowrates to maintain a compliant dilution factor or dilution ratio. The gaseous species that were measured consisted of $\mathrm{CO}_{2}, \mathrm{CO}, \mathrm{THC}, \mathrm{NMHC}, \mathrm{NO}$, and $\mathrm{NO}_{\mathrm{x}}$. Other equipment being added to the laboratory for the experiment setup included a Horiba Model 210A $\mathrm{CO}_{2}$ analyzer, AVL MicroSoot Sensor, AVL PM PEMS with MicroSoot measurement capability, AVL MicroSoot Plus, a TSI Model 3022a condensate particle counter (CPC), and TSI Model 3025a (CPC), TSI Model 3772 (CPC), and Horbia OBS-ONE.

\section{Test Vehicles}

The test vehicles selected for the testing were of separate injection technology, one being GDI while the other was PFI. The first test vehicle was an all-wheel drive 2013 Hyundai Santa Fe, equipped with a naturally aspirated 2.4L Spray Guided GDI engine shown in Figure 18 and meets the EPA's Tier 2 Bin 5 emissions, shown in Figure 22. The Vehicle Emission Control Information Tag shown in Figure 19. 


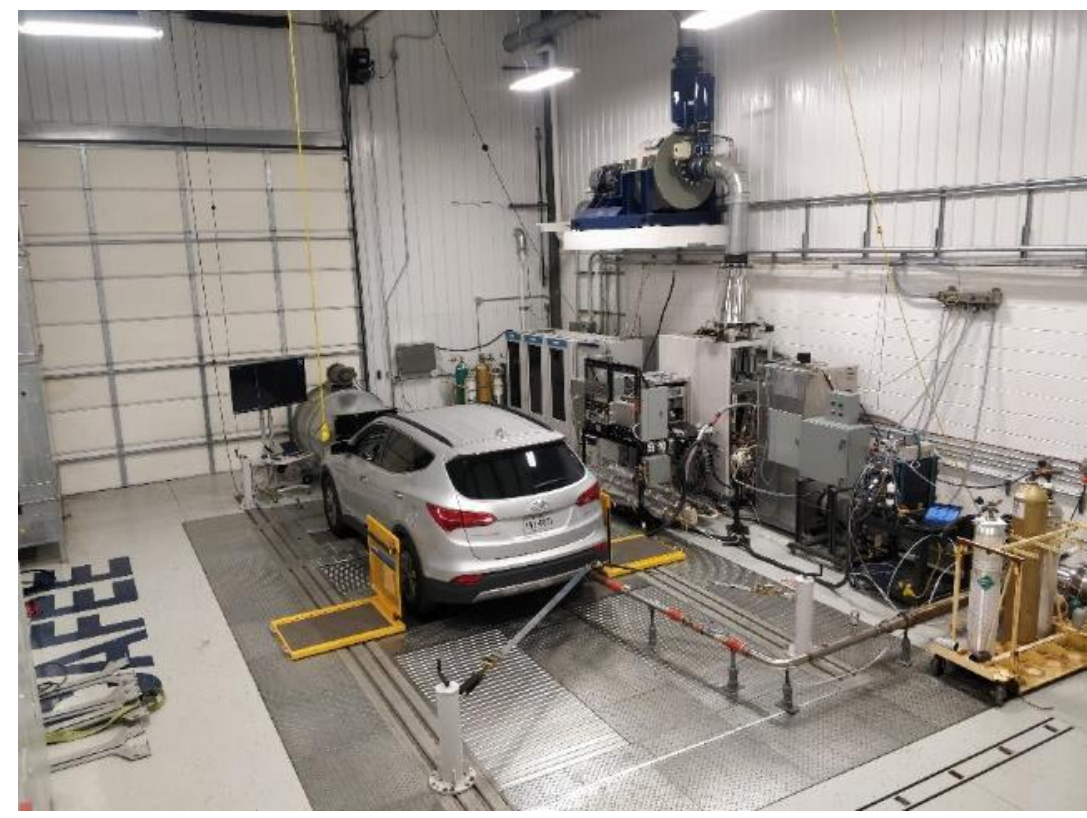

Figure 18: Test Vehicle 1, 2013 Hyundai Santa Fe.

\begin{tabular}{|l|l|l|}
\hline \multicolumn{3}{|c|}{ HYUNDAI MOTOR COMPANY } \\
\hline VEHICLE EMISSION CONTROL. INFORMATION
\end{tabular}

Figure 19: 2014 Hyundai Santa Fe Emission Control Information Label.

The other vehicle is an all-wheel drive 2015 Subaru Legacy, shown in Figure 20, equipped with a naturally aspirated 2.5L Port Fuel Injected engine compliant with EPA's Tier 2, Bin 4 emissions, shown in Figure 22. The Vehicle Emission Control Information tag shown in Figure 21. 


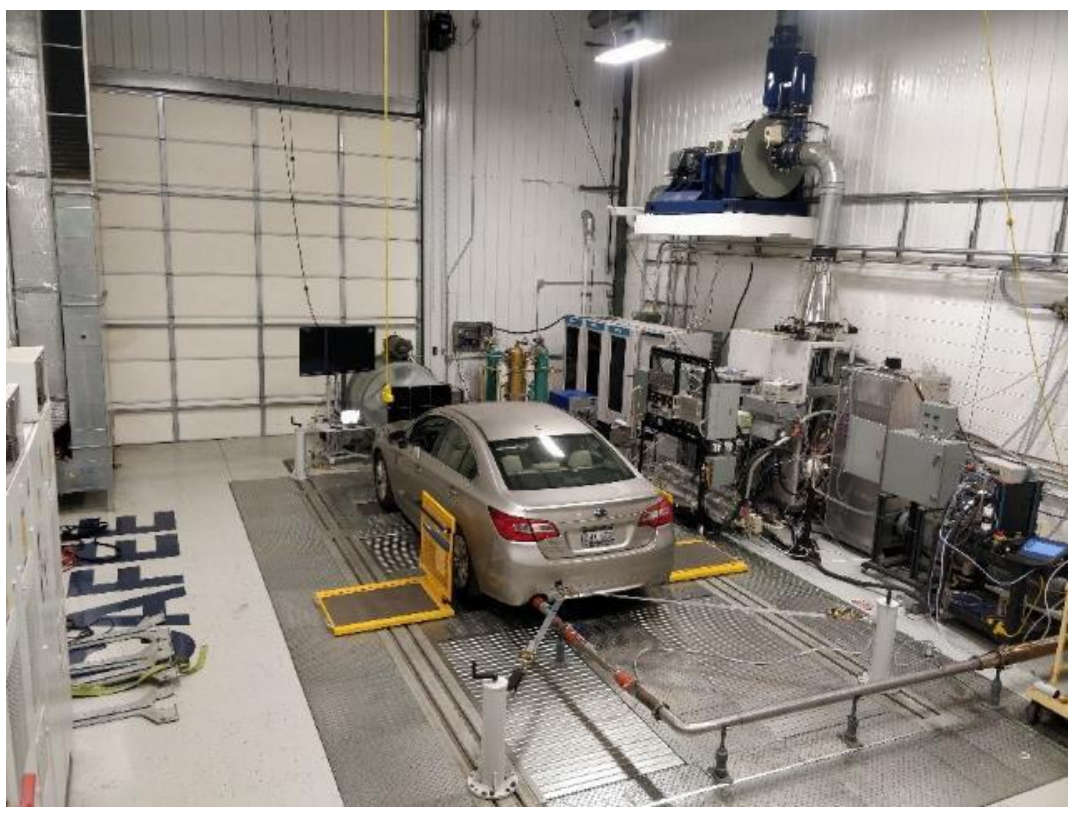

Figure 20: Test Vehicle 2, 2015 Subaru Legacy.

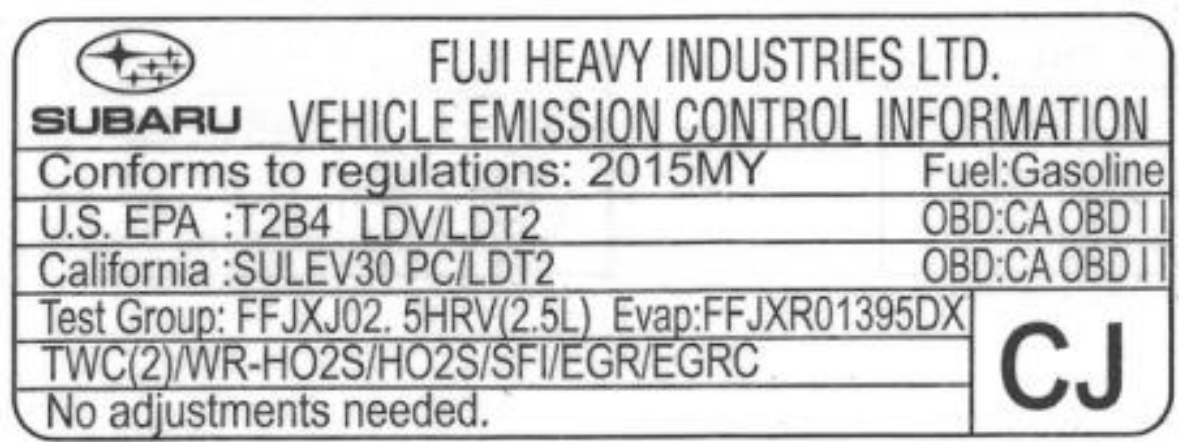

Figure 21: 2015 Subaru Legacy Emission Control Information Label.

Both vehicles used an automatic transmission.

\begin{tabular}{|l|l|c|c|c|c|c|}
\hline \multirow{3}{*}{ Standard } & \multirow{3}{*}{ Vehicles } & \multicolumn{5}{|c|}{$\begin{array}{c}\text { Emission Limits at Full Useful Life } \\
(100,000-120,000 \text { miles) }\end{array}$} \\
\cline { 3 - 7 } & & \multicolumn{5}{|c|}{ Maximum Allowed Grams per Mile } \\
\cline { 3 - 7 } & & Nitrous Oxide & $\begin{array}{c}\text { Non-Methane } \\
\text { Organic Gas }\end{array}$ & $\begin{array}{c}\text { Carbon } \\
\text { Monoxide }\end{array}$ & $\begin{array}{c}\text { Particulate } \\
\text { Matter }\end{array}$ & Formaldehyde \\
\cline { 3 - 7 } & & 0.04 & 0.070 & 2.1 & 0.01 & 0.011 \\
\hline Bin 4 & LDV, LLDT, HLDT, MDPV & 0.07 & 0.090 & 4.2 & 0.01 & 0.018 \\
\hline Bin 5 & LDV, LLDT, HLDT, MDPV & & & & & \\
\hline
\end{tabular}

Figure 22: Emissions Standard for EPA Tier 2 Bin 4 \& 5. 


\section{1065 Compliance}

For 40 CFR part 1065 compliance, in the construction of PM boxes, all sample paths used a 300 series stainless steel constructed tubing (40§1065.145(c)(1)) inside an insulated and temperaturecontrolled box. All sample lines were heated to the temperature of the sample plane being measured from to maintain the temperature of the sample (40§1065.145(d)(2)). Sample lines all used mandrel bends with a maximum possible radius within the constraints of the sample line $(40 \S 1065.145(d)(2))$. The probes used for particle sampling used a "J-probe." This probe uses a single open end that faces directly into the upstream flow (40§1065.145(c)(3)). Sample tunnels were maintained closely to atmospheric pressure to foster isokinetic flow during testing. Sampling systems were designed to maintain isokinetic sampling (40§1065.145(c)(3)). Isokinetic sampling is the uniform sampling of fluid where the fluid removed is withdrawn at the same velocity as the fluid traveling by the sample probe and not at a retarded or accelerated velocity. Along with isokinetic flow, the PM boxes must sample at a velocity of no more than $50 \mathrm{~cm} / \mathrm{sec}$ across the filter stain area $(40 \S 1065.170(\mathrm{a})(2))$. The stain area can be defined as the $38.86 \mathrm{~mm}$ portion shown in Figure 23. The $50 \mathrm{~cm} / \mathrm{sec}$ translates to $2.3 \mathrm{SCFM}$ for the existing set up and the critical flow orifice target flow rate was slightly below 2.3 SCFM in case of a machining tolerances. Dilution air introduced into the sample was completed so at $(25 \pm 5){ }^{\circ} \mathrm{C}$ as per CFR 40§1065.145(e)(1) and PM box temperatures were maintained at $(47 \pm 5){ }^{\circ} \mathrm{C}$ as per $40 \S 1065.145(\mathrm{e})(4)$. Overall dilution ratio of the CVS tunnel was determined by CFR 40§1066.110(b)(2)(iii)(B) to maintain a dilution factor of 7:1 to 20:1. Dilution ratio is not the same as dilution factor. The dilution factor is a comparison of total dilution air and exhaust sampled during a cycle while a dilution ratio is simply a ratio of two averages over the cycle of the same measurement in two different sampling environments (i.e. CVS tunnel and raw exhaust and using averaged $\mathrm{CO}_{2}$ traces or averaged flow rates over a cycle). For the CVS tunnel to achieve a compliant dilution factor, $14.5 \mathrm{~m}^{3} / \mathrm{min}$ was used as the CVS tunnel flowrate. This flowrate yielded a 20:1 dilution ratio during the LA92 drive cycle which was used as DR 1 for primary dilution. 


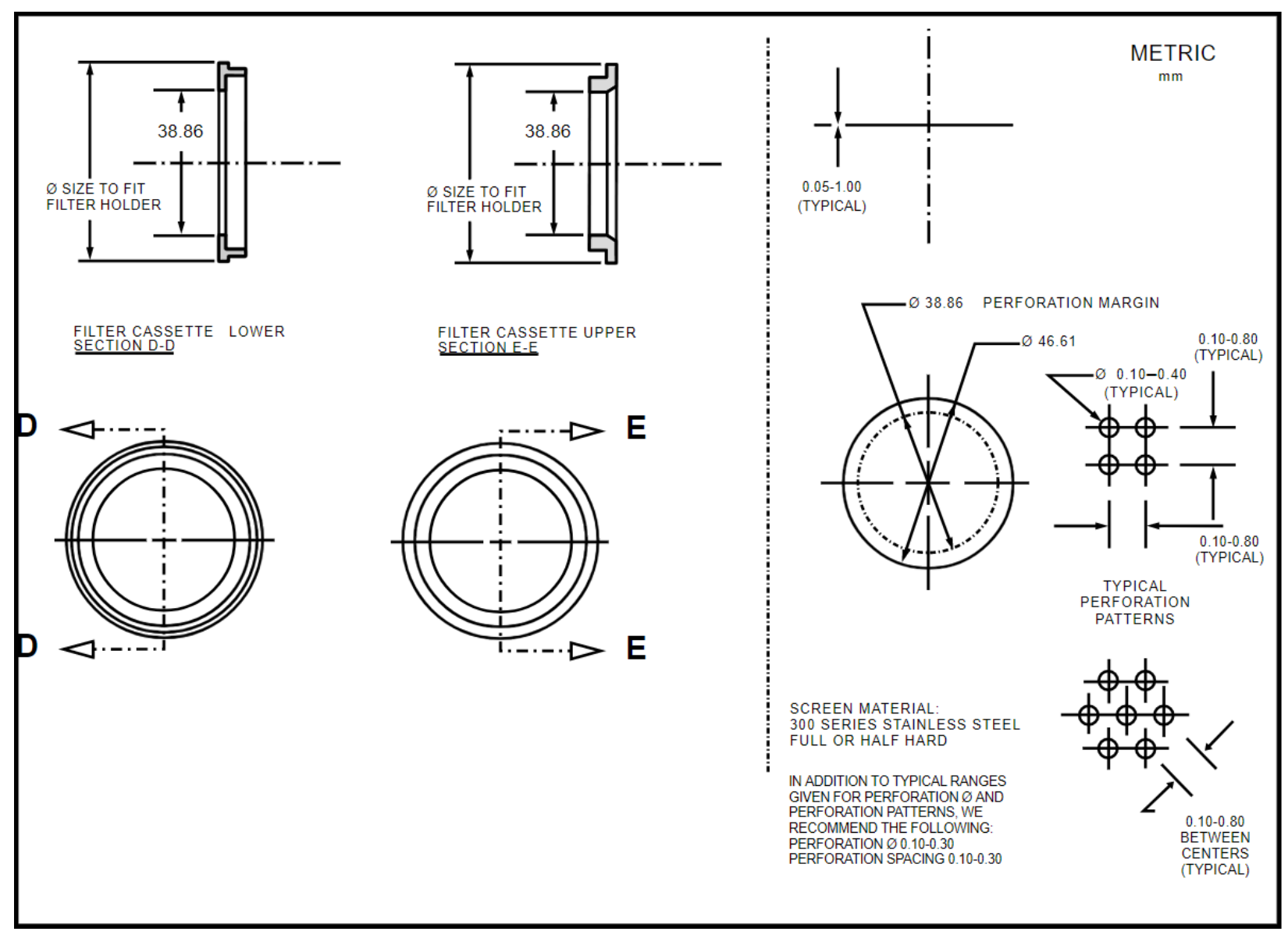

Figure 23: PM filter specifications per 40 CFR Part 1065.170 (c)(2) (Eviromental Protection Agency 2014).

\section{Results}

Table 4 shows the test cycle number for reference in the plots of the results as they will be labeled with the cycle number as the identifier. Each test cycle number is aligned with the planned test procedure (i.e. driving condition, vehicle, etc.). 
Table 4: Outline of test cycle numbers with corresponding testing conditions and test vehicle.

\begin{tabular}{|c|c|c|}
\hline Cycle \# & Driving Conition & Vehicle \\
\hline 178 & City Test 1 & Hyundai Santa Fe \\
\hline 179 & City Test 2 & Hyundai Santa Fe \\
\hline 180 & City Test 3 & Hyundai Santa Fe \\
\hline 183 & Urban Test 1 & Hyundai Santa Fe \\
\hline 184 & Urban Test 2 & Hyundai Santa Fe \\
\hline 185 & Urban Test 3 & Hyundai Santa Fe \\
\hline 186 & Highway Test 1 & Hyundai Santa Fe \\
\hline 187 & Highway Test 2 & Hyundai Santa Fe \\
\hline 188 & Highway Test 3 & Hyundai Santa Fe \\
\hline 191 & LA92 Transient & Hyundai Santa Fe \\
\hline 194 & City Test 1 & Subaru Legacy \\
\hline 195 & City Test 2 & Subaru Legacy \\
\hline 196 & City Test 3 & Subaru Legacy \\
\hline 197 & City Test 4 & Subaru Legacy \\
\hline 198 & Urban Test 1 & Subaru Legacy \\
\hline 199 & Urban Test 2 & Subaru Legacy \\
\hline 200 & Urban Test 3 & Subaru Legacy \\
\hline 201 & Urban test 4 & Subaru Legacy \\
\hline 202 & Highway Test 1 & Subaru Legacy \\
\hline 203 & Highway Test 2 & Subaru Legacy \\
\hline 204 & Highway Test 3 & Subaru Legacy \\
\hline 205 & Highway Test 4 & Subaru Legacy \\
\hline 208 & LA92 Transient Test 1 & Subaru Legacy \\
\hline 209 & LA92 Transient Test 2 & Subaru Legacy \\
\hline & & \\
\hline
\end{tabular}

Results are separated into PN measurement, MSS measurement, and PM collection. The sections displaying the PN and MSS measurements have all test cycles performed plotted in the same figure for that particle dilution ratio and the specific sampling system. The legend is displayed to the right or bottom of the figure and it correlates the color of the trace to the test number for that test condition. Table 4 can be used in conjunction with the figure titles and legend labels below to further relate back to a test cycle number. Dilution ratios should project a similar affect in particle concentrations with DR1 producing the highest concentration, followed by DR 2 which should have half of the DR 1 particle concentration. DR 3 should have half of DR 2's particle concentration. This can be hypothesized because the DR 1 is diluted 2:1 for DR 2, and similarly DR 1 is diluted 4:1 for DR 3. It can also be assumed that the dilution of DR 3 is twice that of DR 2. 
During the presentation of the results, portions may refer to the detectability of the sample, particularly for the MSS. There will be data presented with a CPC that over-ranged during testing. Technical specifications of the MSS and CPC equipment is presented in Table 5 along with the sampling location. Note that the GDI tested when all three MSSs were available and the PFI tested when only two were available. This required the use the AVL MicroSoot Sensor to measure on DR 2 and DR 3. As a reminder, the testing increased to four tests to accommodate for two hot starts with the AVL MicroSoot Sensor on DR 2 and two more hot starts with the AVL MicroSoot Sensor measuring DR 3. The AVL M.O.V.E. PM PEMS was always used to measure DR 1 for data correlation and repeatability.

Table 5: Equipment type, measuring location, and measuring traits.

\begin{tabular}{|l|c|c|c|c|}
\hline & $\begin{array}{l}\text { Detection } \\
\text { Limit }\end{array}$ & $\begin{array}{c}\text { Measuring } \\
\text { Resolution }\end{array}$ & Mearsuable Range & $\begin{array}{l}\text { Measuring } \\
\text { Location }\end{array}$ \\
\hline AVL MicroSoot Sensor & N/A & $1 \mu \mathrm{g} / \mathrm{m}^{3}$ & $0.001-50 \mathrm{mg} / \mathrm{m}^{3}$ & DR1/DR2 \\
\hline AVL MicroSoot Plus & N/A & $1 \mu \mathrm{g} / \mathrm{m}^{3}$ & $0.001-50 \mathrm{mg} / \mathrm{m}^{3}$ & DR2 \\
\hline AVL M.O.V.E. PM PEMS & N/A & $5 \mu \mathrm{g} / \mathrm{m}^{3}$ & $0.001-50 \mathrm{mg} / \mathrm{m}^{3}$ & DR1 \\
\hline TSI Model 3022a & $50 \% 7 \mathrm{~nm}$ & $\mathrm{~N} / \mathrm{A}$ & $0-9.99 \times 10^{6}$ & DR1 \\
\hline TSI Model 3025a & $50 \% 3 \mathrm{~nm}$ & N/A & $0-9.99 \times 10^{4}$ & DR2 \\
\hline TSI Model 3772 & $50 \% 10 \mathrm{~nm}$ & N/A & $0-9.99 \times 10^{4}$ & DR3 \\
\hline
\end{tabular}

\section{PN Measurement}

Figure 24, Figure 25, and Figure 26 show the testing of dilution ratios 1, 2, and 3, respectively, during the City driving conditions where the vehicle was maintained at $25 \mathrm{mph}$ for 5 minutes. The results show that the PFI Subaru Legacy did not emit a detectable amount of PN above ambient conditions at any dilution ratio while the GDI Hyundai Santa Fe did. The GDI PN concentration fluctuated around $20,000-25,000 \mathrm{~cm}^{-3}$ for the low speed steady state condition for DR1. For two cycles of the GDI, there is a spike that reached $65,000 \mathrm{~cm}^{-3}$. These spikes could be caused by the cruise control counteracting the deceleration of the vehicle after initially being set. They could also be engine controlling such as timing, fueling, or EGR. The significant detail is that they are seen in the GDI vehicle alone and also seen as soot with the MSS later in the results. These spikes can also be seen in DR 2 with the increases reaching $40,000 \mathrm{~cm}^{-3}$ and the steady state condition settles at $15,000 \mathrm{~cm}^{-3}$. DR 3 sampling location shows PN concentrations from 5,000 to $10,000 \mathrm{~cm}^{-3}$ with only hot start 1 from the GDI showing the spike as seen in DR 2 and 3. Figure 26 presents hot start 
3 of the GDI. During the cycle, the GDI loses a detectable amount particle concentration until the last minute of the cycle. From steady state low vehicle speed condition, it should be expected that particle concentrations would be lowest of the Urban, Highway, or LA92 transient cycle conditions. The concentration level should increase as the test conditions increase in vehicle speed. Due to the low concentrations, the resolution of the dilution ratios was not as clear with the PN measurement but are still seen dropping at each of the higher dilutions.

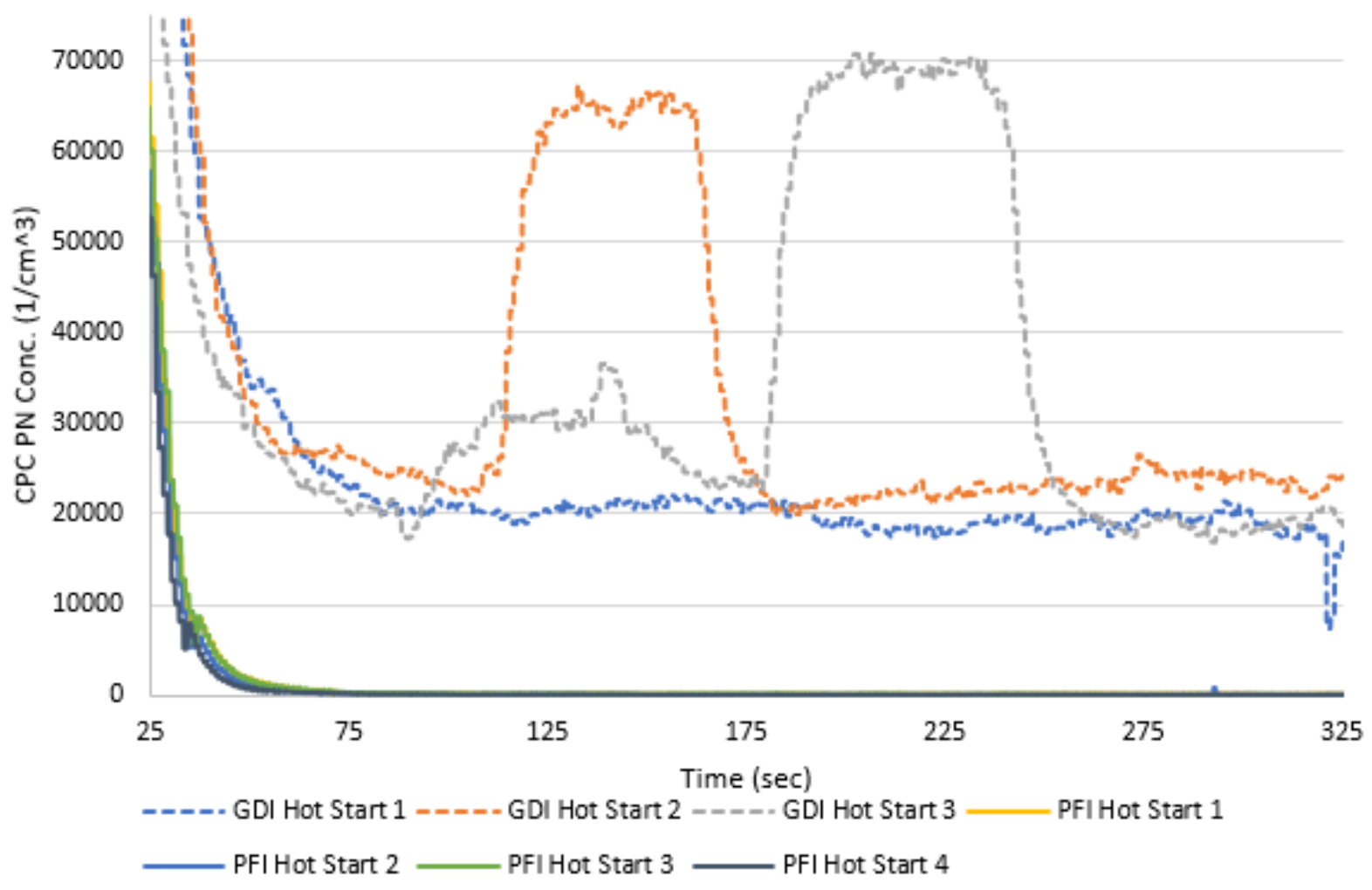

Figure 24: CPC Concentration at DR 1 during City Driving Conditions. 


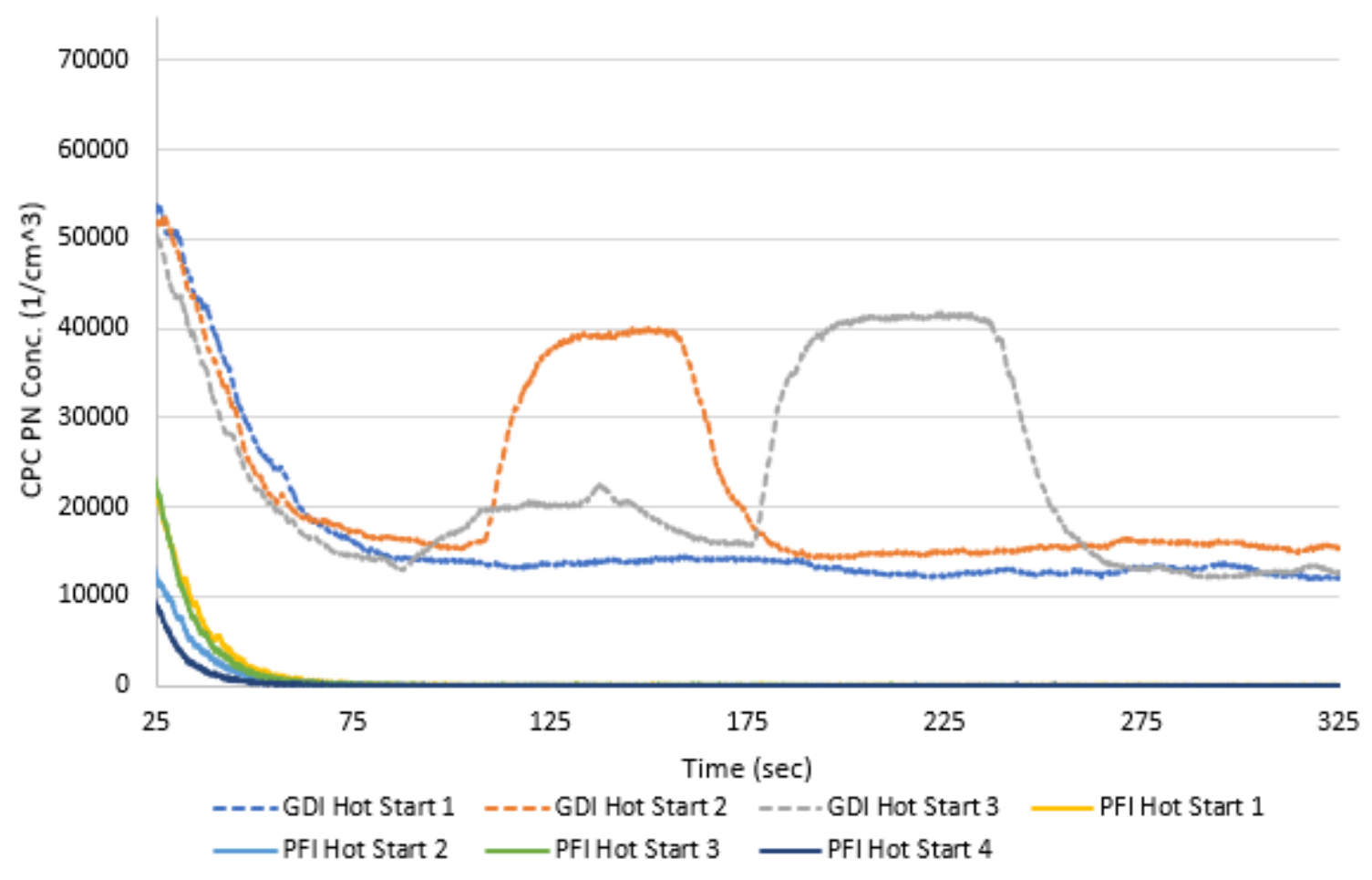

Figure 25: CPC Concentration at DR 2 during City Driving Conditions.

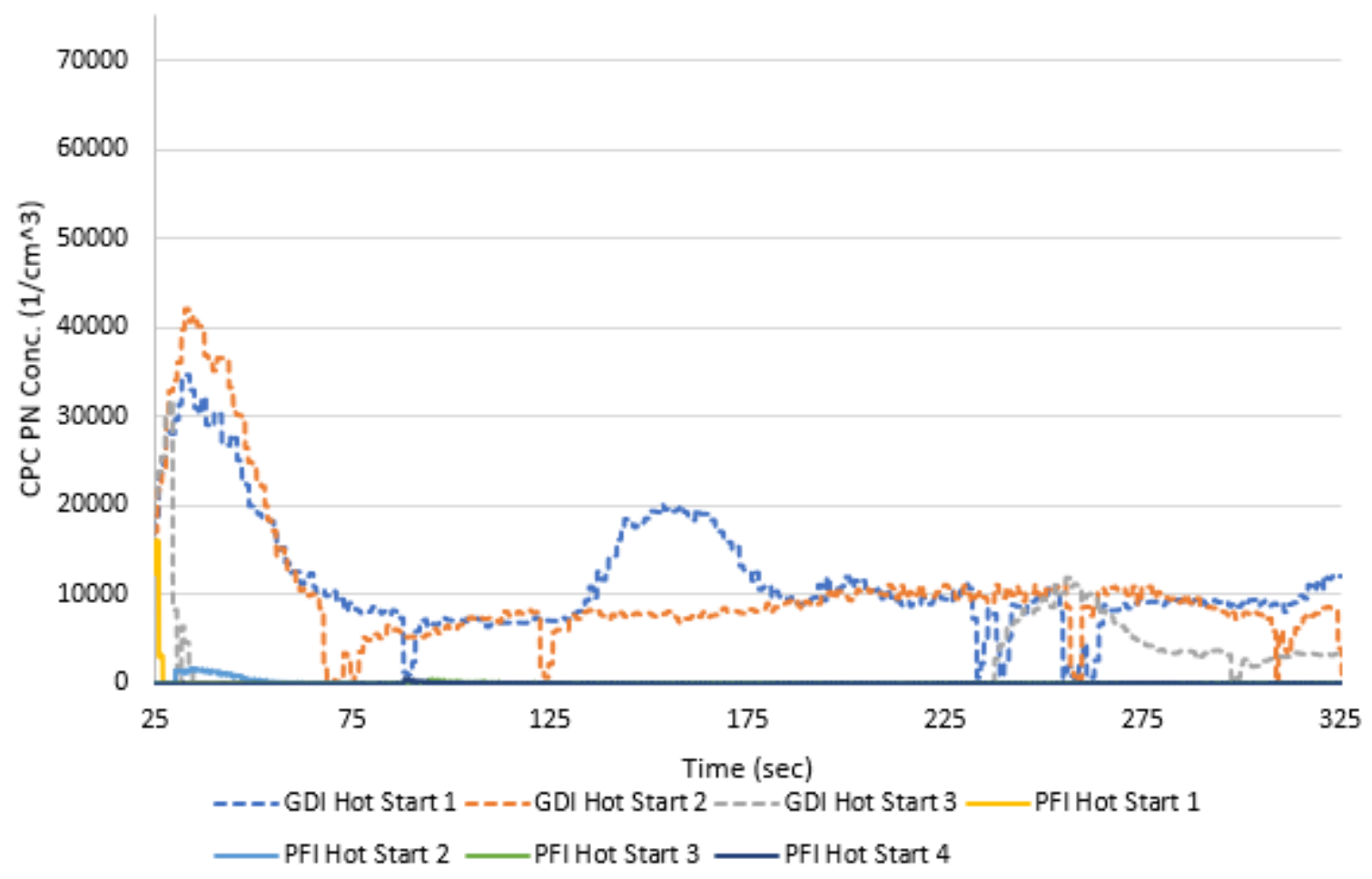

Figure 26: CPC Concentration at DR 3 during City Driving Conditions. 
Figure 27 presents the vehicles normalized vehicle speed and $\mathrm{CO}_{2}$ traces against the DR $1 \mathrm{CPC}$ concentration to identify possible causes for the increase in concentration. Vehicle speed seems to have no effect while $\mathrm{CO}_{2}$ shows minor signs of increasing around the increase in PN and began to decrease shortly before the decrease of PN. This could be a possible sign of the vehicle load increasing as cruise control begins to modulate vehicle speed. This theory is further supported in Figure 28 with the more limited normalized axis to show vehicle speed decrease, hit the set point, and increase. During the setpoint condition is met, the vehicle produces an increased amount of PN.

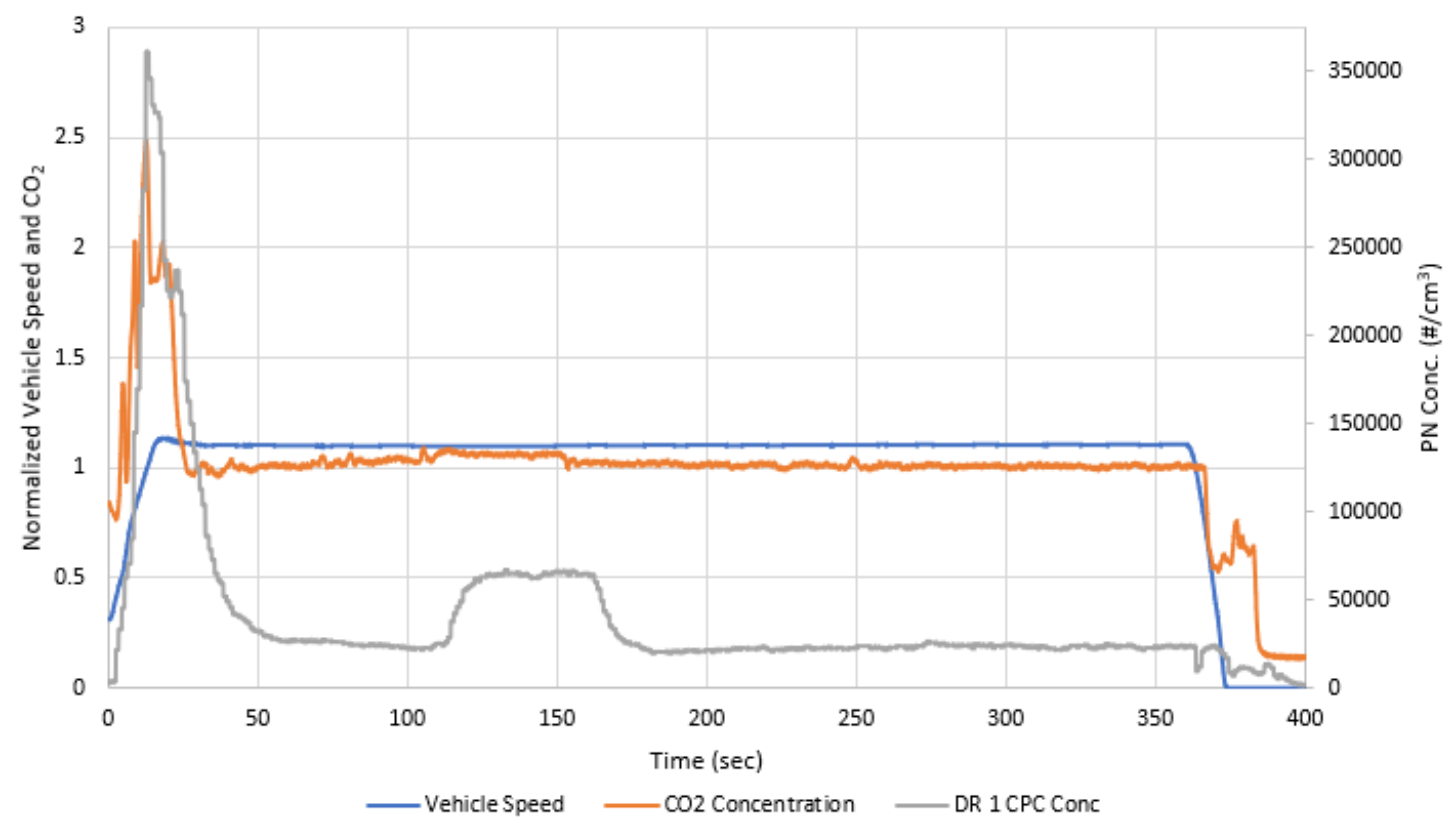

Figure 27: Normalized Vehicle Speed and CO2 against the DR 1 CPC Concentration. 


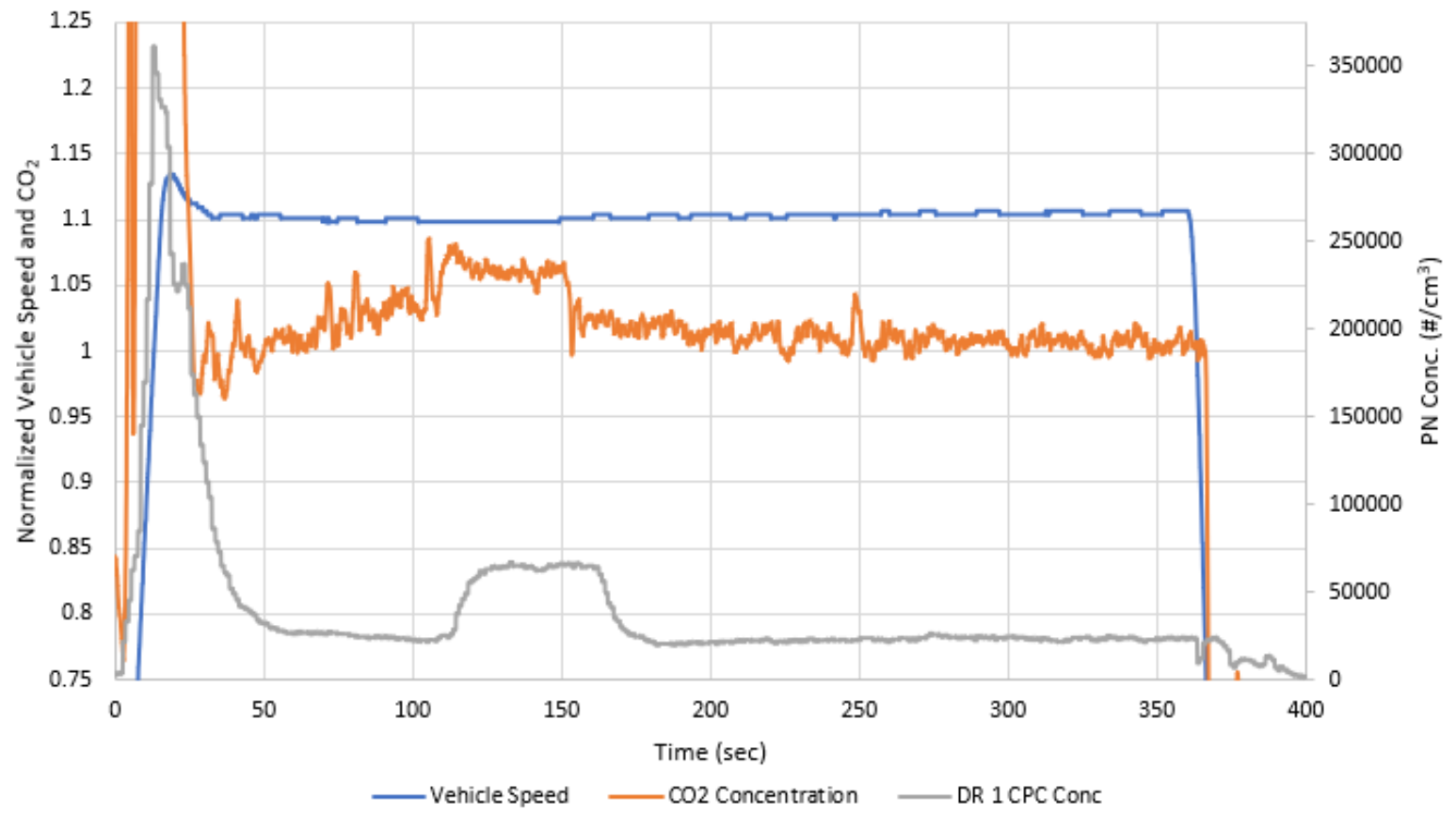

Figure 28: Exploded view of normalized axis of Figure 27.

Figure 29, Figure 30, and Figure 31 show the testing of dilution ratios 1, 2, and 3, respectively, during the Urban driving conditions where the vehicle is held at $45 \mathrm{mph}$ for 5 minutes. The results are similar to the previous results with higher concentrations from the GDI and show the trend of higher concentration with higher vehicle speed. This is to be expected because the vehicle speed has increased, creating a larger load on the vehicle, which should yield a larger particle number count. The GDI hot starts 2 and 3 have PN concentrations with spikes at $110,000 \mathrm{~cm}^{-3}$ and an average concentration of $55,000 \mathrm{~cm}^{-3}$ for the remainder of the cycle. Hot start 1 GDI shows a similar trace to hot starts 2 and 3 but with a 20,000-25,000 $\mathrm{cm}^{-3}$ reduction in particle concentration. The results for the GDI on DR 2 are like DR 1 but at half the concentration. These results reaffirm the dilution ratio in particle concentration and as concentration increases in the higher dilution ratio the detectability increases to involve less variability. The DR 3 results for the GDI are similar to the City condition results with concentrations varying from $5,000-10,000 \mathrm{~cm}^{-3}$. The PFI results remain below a detectable concentration until hot start 4, approximately 1.5 minutes before the end, the PFI begins to emit $6,000-8,000 \mathrm{~cm}^{-3}$ at DR $1,1,000-3,000 \mathrm{~cm}^{-3}$ at DR 2, and $500-1,000 \mathrm{~cm}^{-3}$ at DR 3 . These 
concentrations reflect their dilution ratio with variability enough though the measured concentrations are within the lower portion of the CPCs measurable range.

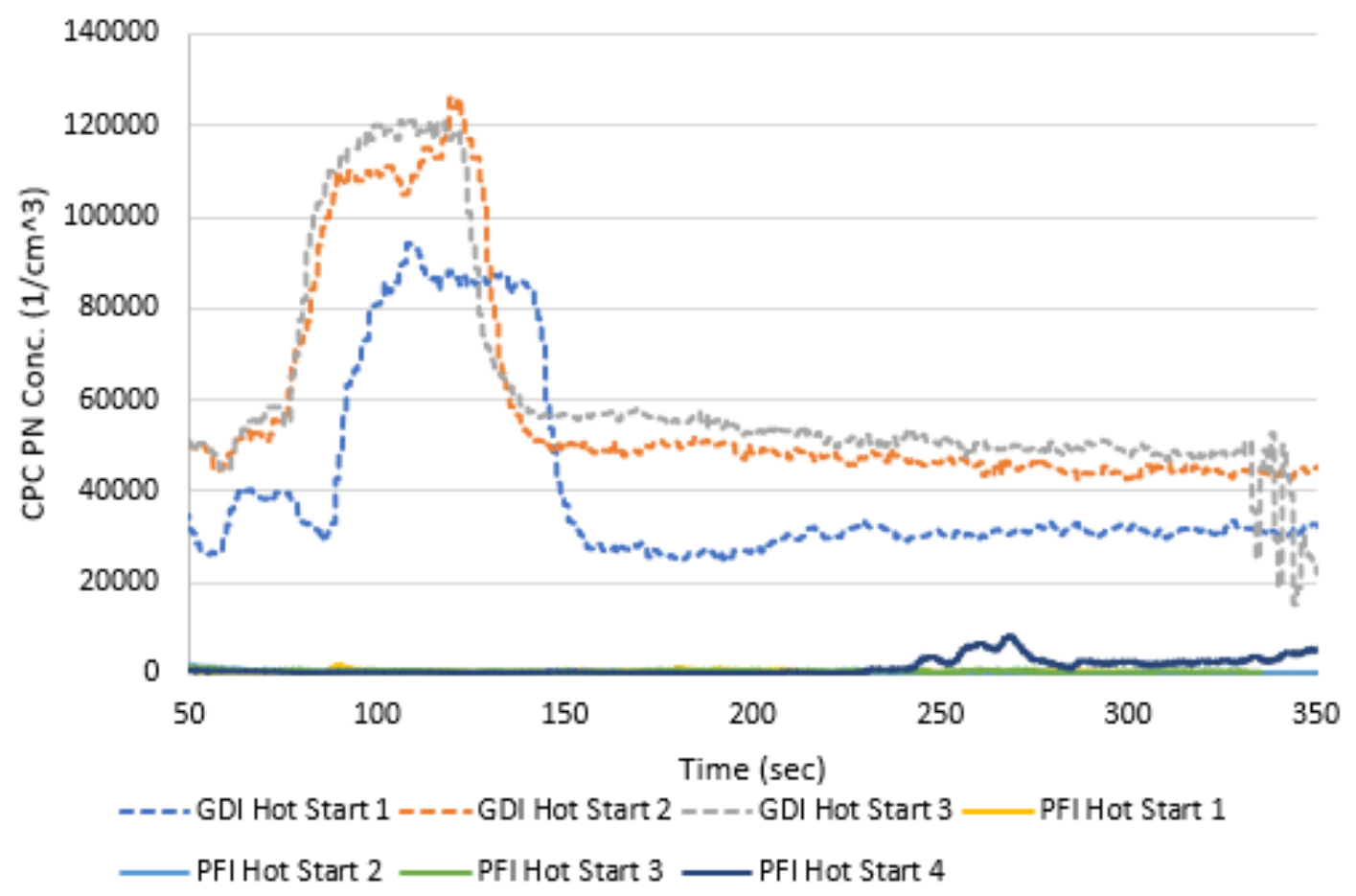

Figure 29: CPC Concentration at DR 1 during Urban Driving Conditions. 


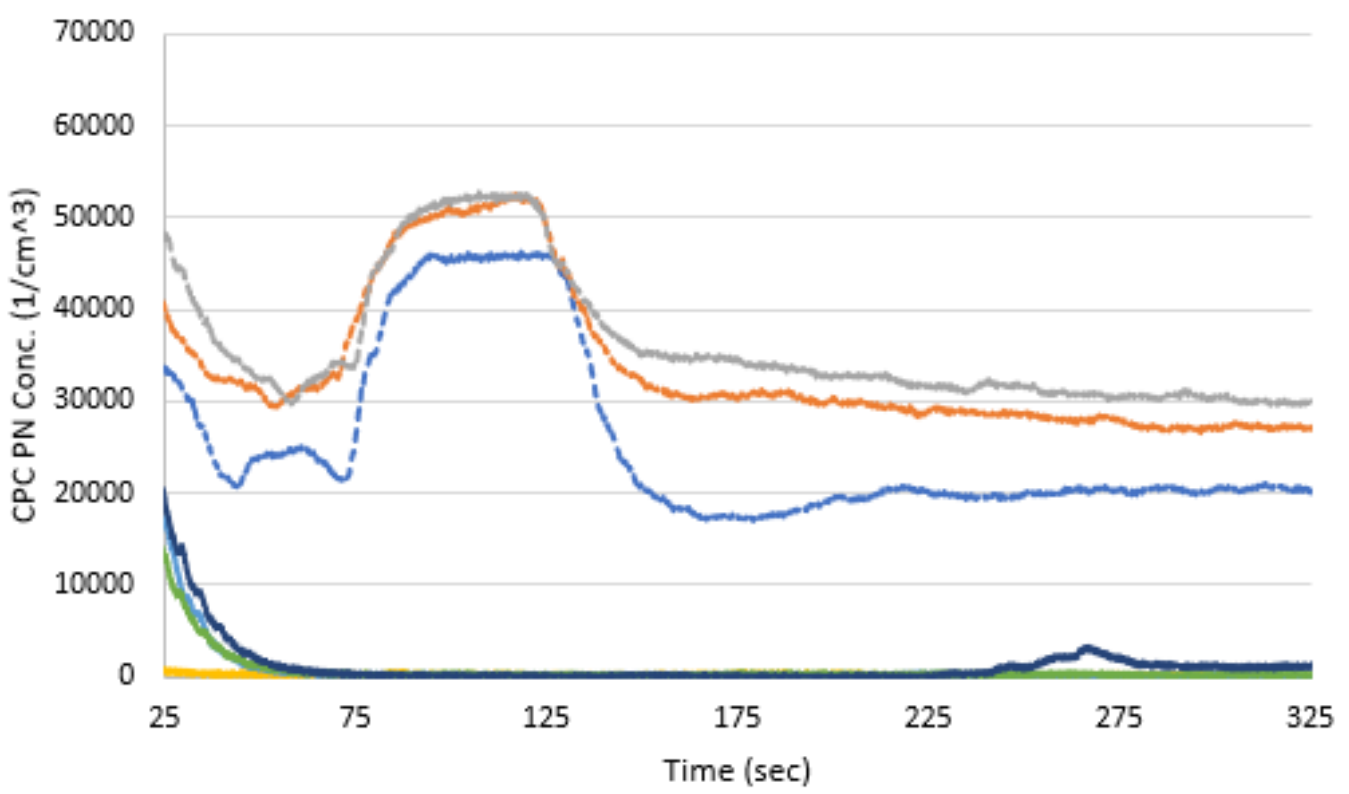

- ---GDI Hot Start 1 - - -- GDI Hot Start 2 -- --GDI Hot Start $3 \_$PFI Hot Start 1

- PFI Hot Start 2 PFI Hot Start 3 - PFI Hot Start 4

Figure 30: CPC Concentration at DR 2 during Urban Driving Conditions.

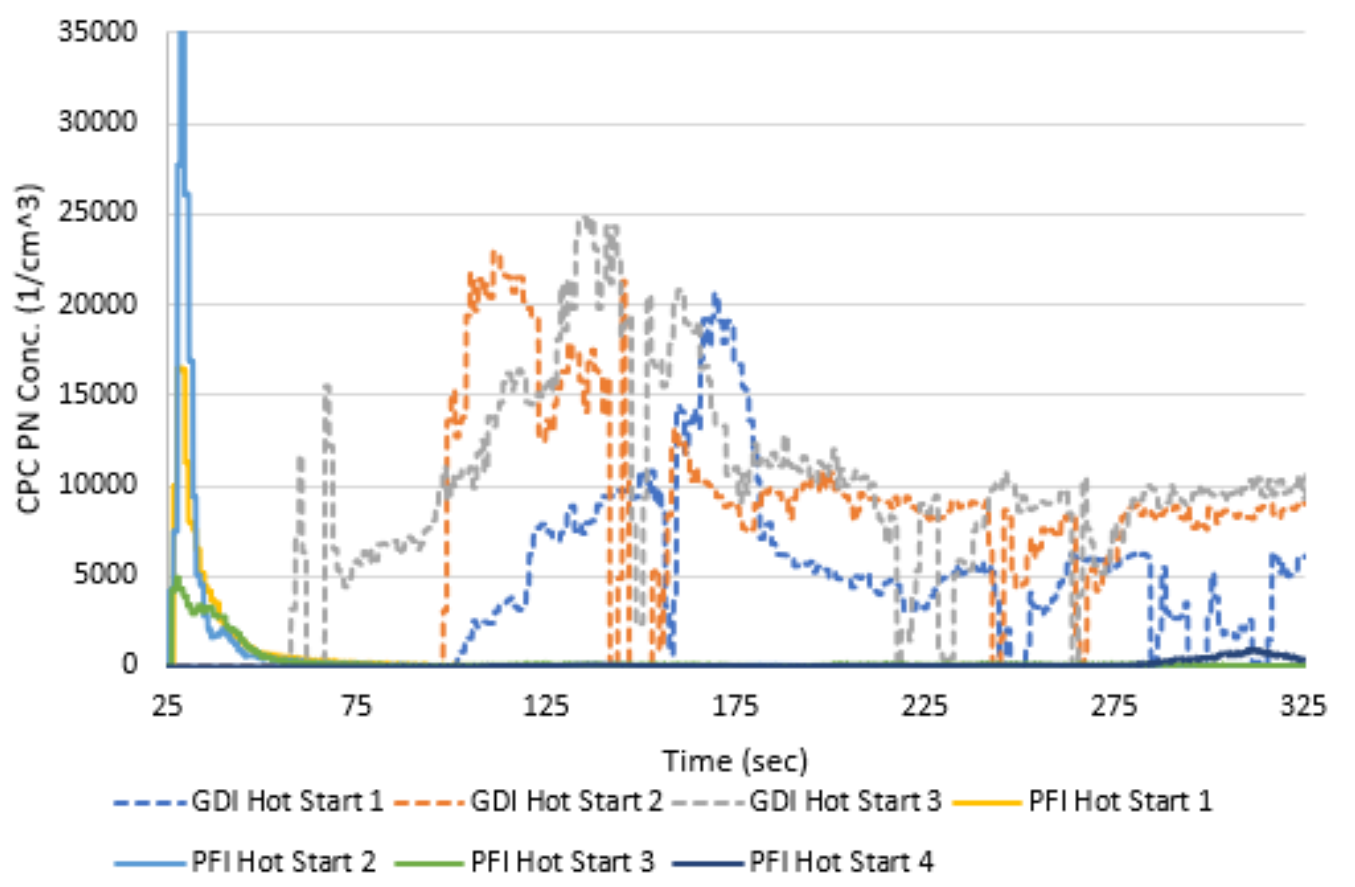

Figure 31: CPC Concentration at DR 3 during Urban Driving Conditions. 
Figure 32, Figure 33, and Figure 34 show the testing of dilution ratios 1, 2, and 3, respectively, during the Highway driving conditions where the vehicle was maintained at $65 \mathrm{mph}$ for 5 minutes. During these cycles both the GDI and PFI were emitting detectable amounts of PN. As this is the highest steady state condition, the largest PN concentration can be expected. While the LA92 transient cycle may produce large spikes, this condition should produce the largest constant production of particles. The GDI PN concentrations are slightly higher from the Urban conditions for DR 1 and 2. DR 1 has a concentration of roughly $60,000 \mathrm{~cm}^{-3}$ for hot starts 1 and 2 for the GDI. Hot start 3 for the GDI has a spike as seen in previous testing conditions and ends the test with a large spike reaching $100,000+\mathrm{cm}^{-3}$, above the equipment's measurable range. The spike is not seen on DR 2 or 3, alluding that the spike is an equipment or system sampling malfunction. DR 2 from the GDI testing shows concentration levels of $35,000 \mathrm{~cm}^{-3}$, slightly over half the DR 1 concentration level. DR 3 results for the GDI produce concentrations of around $12,500 \mathrm{~cm}^{-3}$, slightly under half the concentrations of DR 2. DR 3 PN traces also show a variability in the measurement. The PFI has a low, but detectable concentration level beginning around $10,000 \mathrm{~cm}^{-3}$ and rising to $50,000 \mathrm{~cm}^{-3}$ consistently for the last three tests. Hot start 1 from the PFI has a similar spike to hot start 3 from the GDI with similar results in DR 2 and 3. The spike was not observed in the higher dilution ratios, but the trace for hot start 3 in DR is around $1,000 \mathrm{~cm}^{-3}$ compared to the other concentrations much higher. DR 2 for the PFI shows a PN concentrations ranging from 3,000-20,000 $\mathrm{cm}^{-3}$ for hot start 1, 2, and 4. These tests are seen in DR 3 with concentrations around $1,000-3,000 \mathrm{~cm}^{-3}$. hot start 3 on DR 3 shows PN concentrations two to 10 times higher than the other tests for the PFI. 


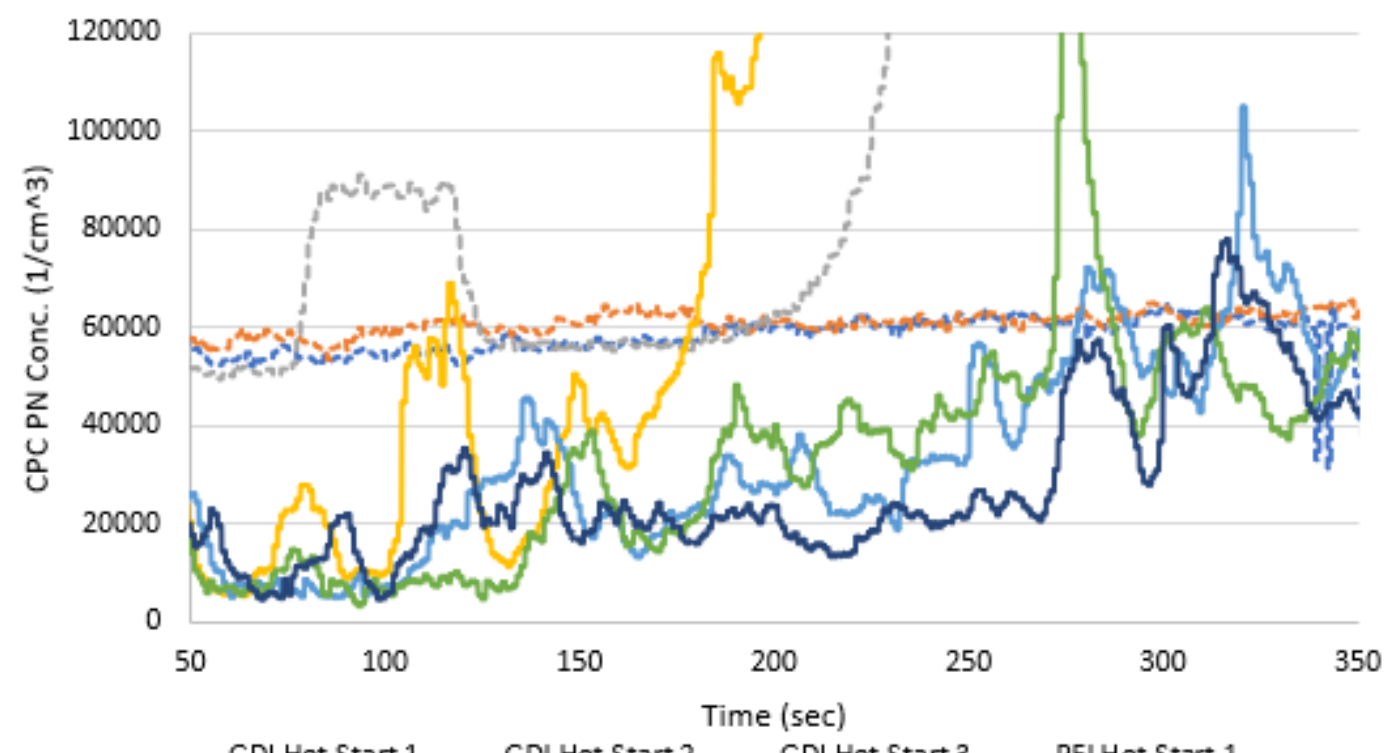

----GDI Hot Start 1 ----GDI Hot Start 2 ----GDI Hot Start 3__ PFI Hot Start 1

PFI Hot Start 2 PFI Hot Start $3-$ PFI Hot Start 4

Figure 32: CPC Concentration at DR 1 during Highway Driving Conditions.

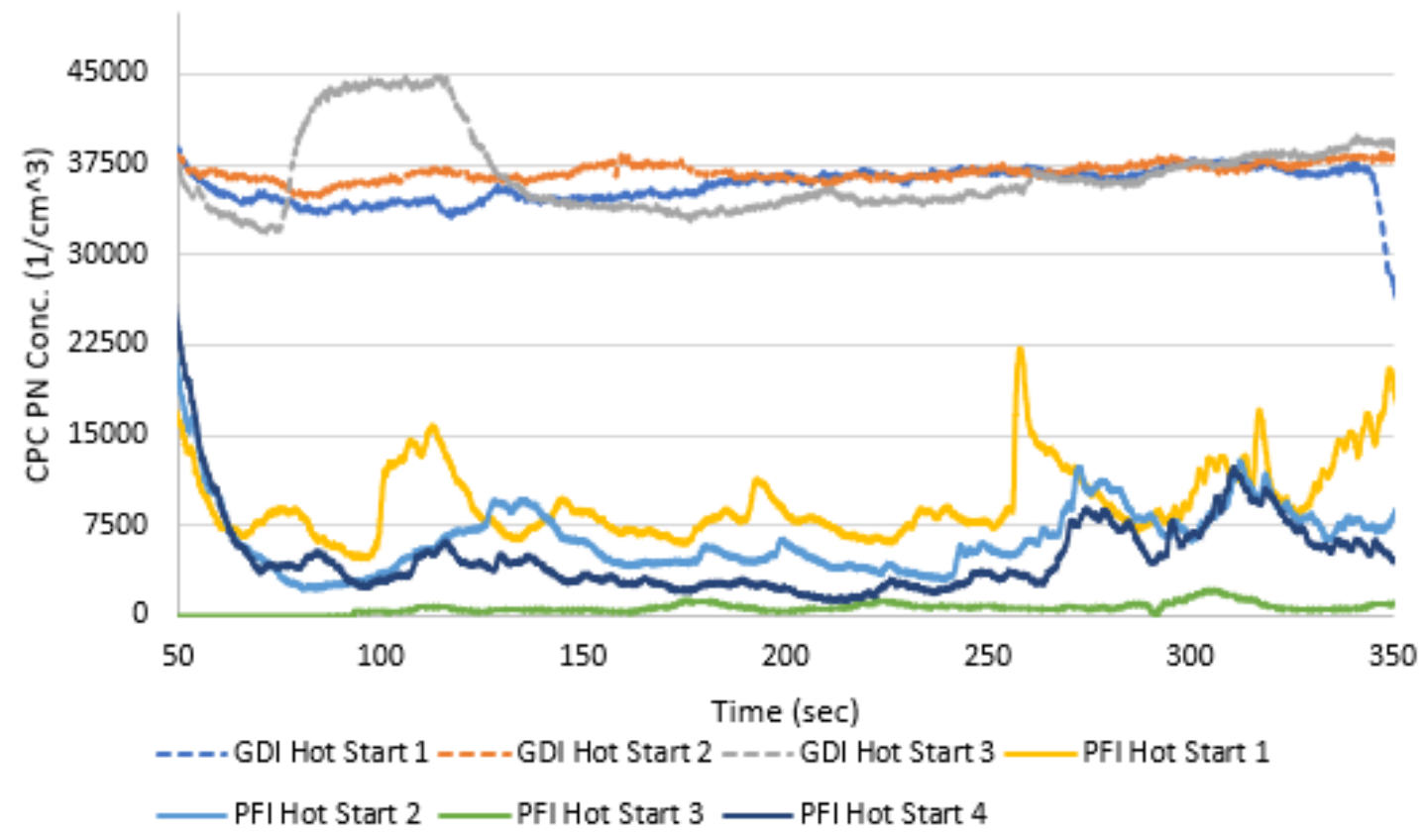

Figure 33: CPC Concentration at DR 2 during Highway Driving Conditions. 


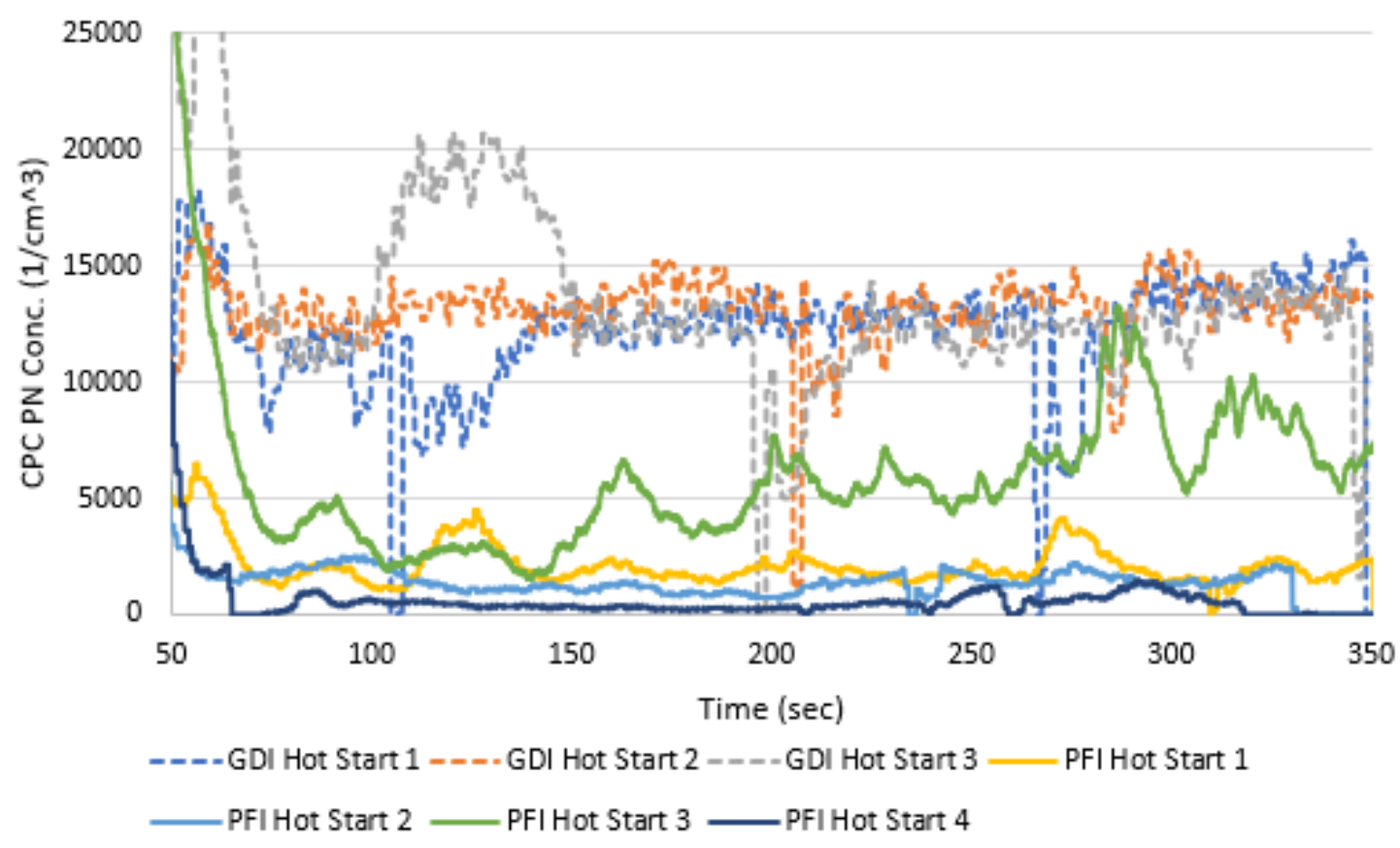

Figure 34: CPC Concentration at DR 3 during Highway Driving Conditions.

Figure 35, Figure 36, and Figure 37 provide the results from the CPCs during the LA92 drive cycle. These three figures used a log scale for PN concentration to reflect the magnitude of particle production more accurately. One test for the GDI was performed while two tests were performed on the PFI to allow for the AVL MSS to be moved from DR2 to DR3. The results of these cycles show spikes in DR1 reaching higher than $250,000 \mathrm{~cm}^{-3}$ and sustained concentrations of 150,000 $\mathrm{cm}^{-3}$ from the GDI. The DR 2 shows slightly under half the concentration of DR 1, while DR 3 shows half of the concentration of DR 2. The spikes are not seen as the resolution of the particle concentration is lost through dilution. A significant observation is that the PFI and GDI have similar concentration levels until the load is sustained. During this period between 300-500 seconds the GDI still produces a large concentration of PN while the PFI may only show a large spike of $600,000 \mathrm{~cm}^{-3}$ (compared to $100,000 \mathrm{~cm}^{-3}$ spikes of the GDI) and back down to 20,000 $\mathrm{cm}^{-3}$. Another instance at 870-960 seconds the PFI produces a series of spikes that over range the CPC. These results are also seen in DR 2 and 3. Particularly in DR 3 at $\sim 900$ seconds and $\sim 1000$ seconds the CPC over ranges as shown in Figure 37 (CPC technical specifications in Table 5). Another observation is the GDI engine producing large spikes of PN concentration under conditions of load during the cycle. When comparing the results from the McCaffery study in Figure 3, there was discussion of a high PN concentration for the Mt. Baldy route (McCaffery, et 
al. 2019). During the cycle, the spray guided GDI vehicle produced four times the PN concentrations of the wall guided. During the LA92 test cycle in this research, the GDI emitted constant levels of PN concentrations under portions of the LA92 cycle that required heavy accelerations. These portions would be similar to the Mt. Badly test route could be a possible correlation in particle emission of spray guided GDI engines under heavy load.

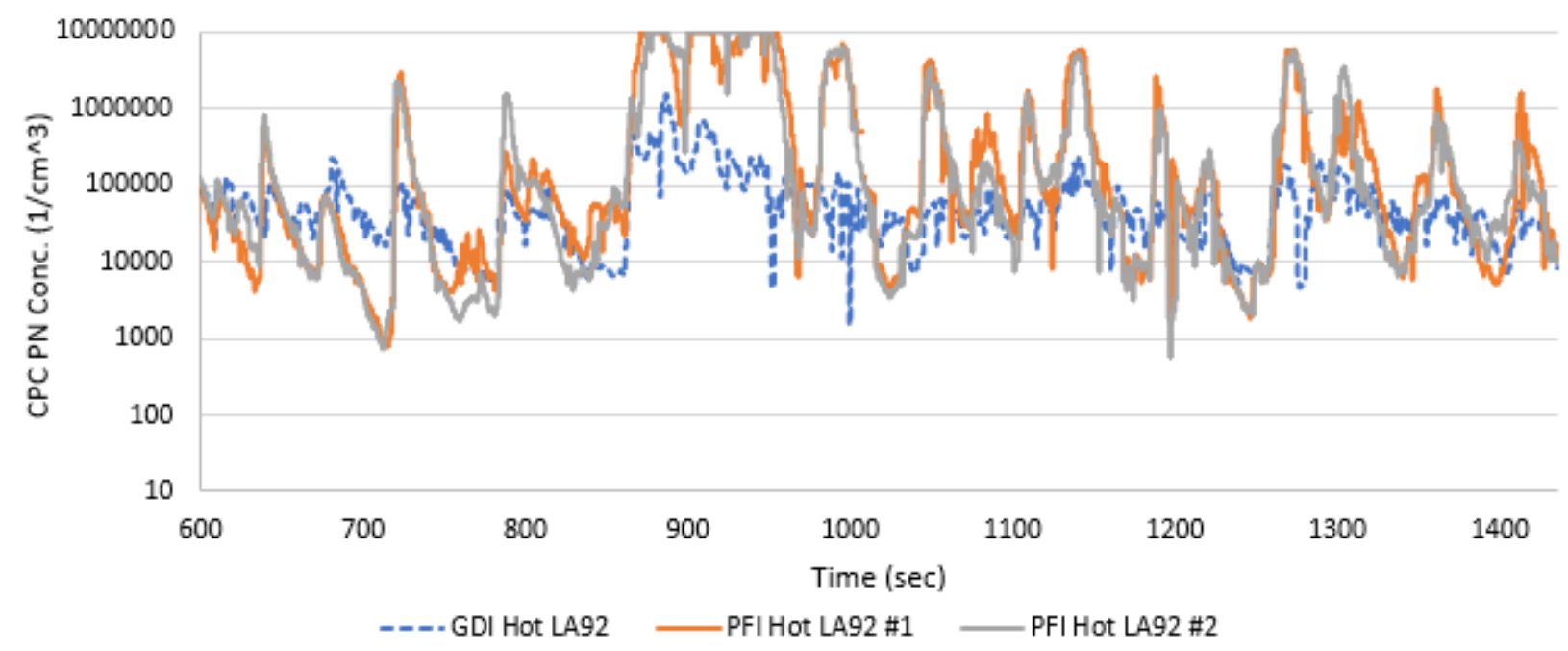

Figure 35: CPC Concentration at DR 1 during LA92 Driving Cycle.

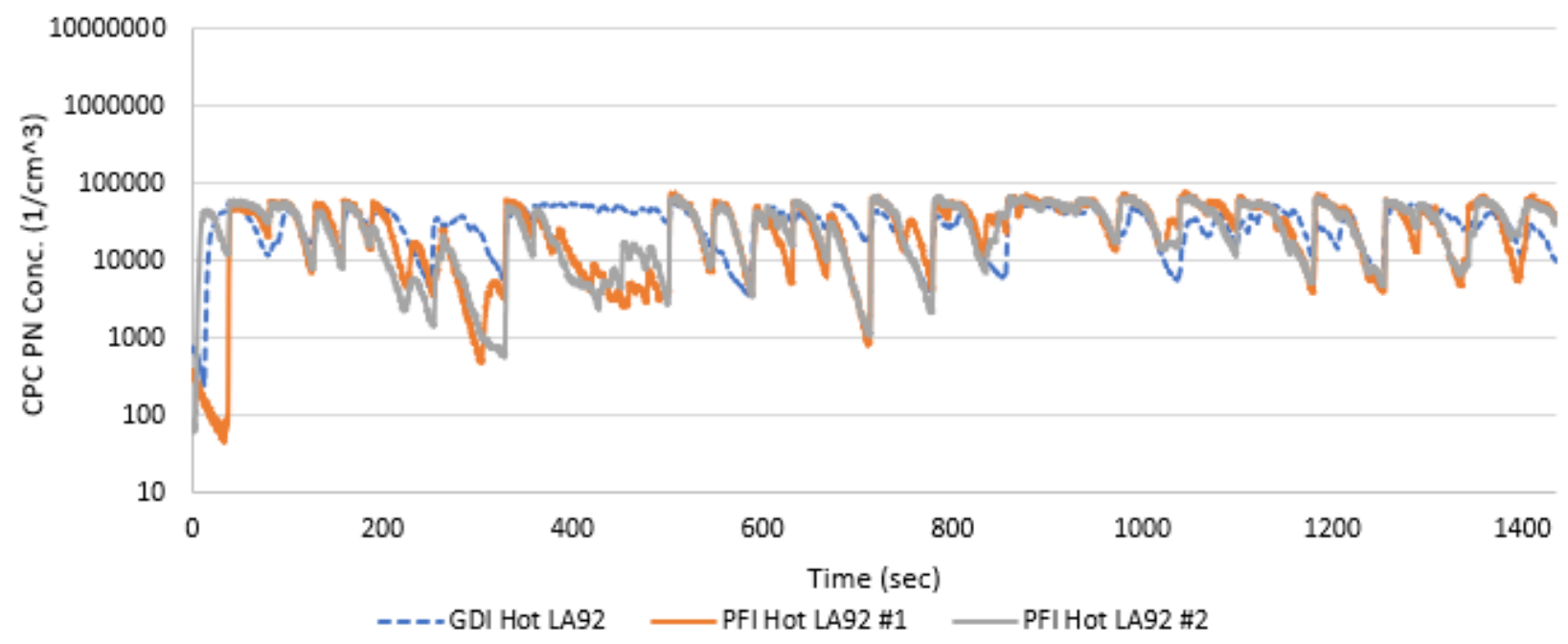

Figure 36: CPC Concentration at DR 2 during LA92 Driving Cycle. 


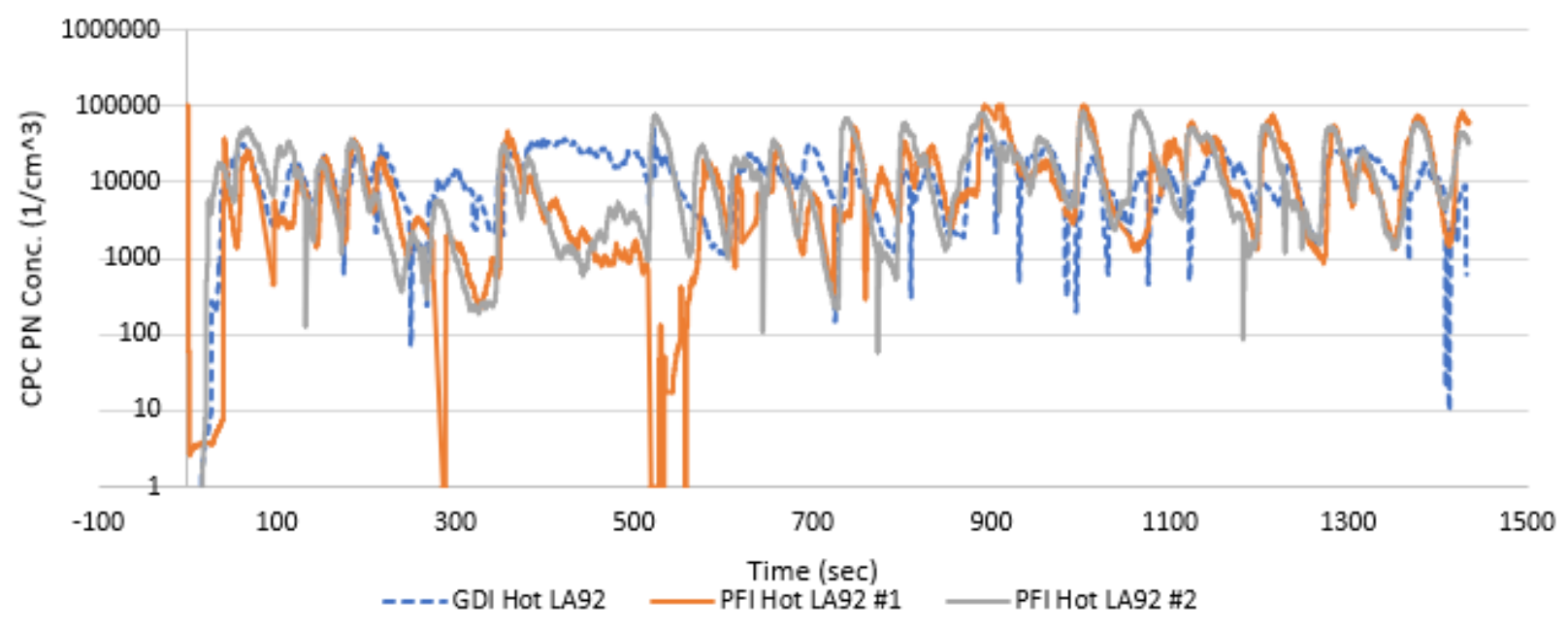

Figure 37: CPC Concentration at DR 3 during LA92 Driving Cycle.

\section{MSS Measurement}

Due to the nature of the test vehicles not emitting high amounts of soot, the equipment had difficulty recording a detectable amount of soot for the PFI for all testing. The AVL MSS and MSS Plus have measuring ranges of $0.001-50 \mathrm{mg} / \mathrm{m}^{3}$ while the AVL M.O.V.E. PEMS has a measuring range of $0.005-50 \mathrm{mg} / \mathrm{m}^{3}$. The AVL M.O.V.E. PEMS was used on DR 1 to measure the higher concentration due to the equipment's higher measuring range. The AVL MSS Plus was used on DR 2 for the GDI testing. The AVL MSS (separate from the MSS Plus) was used for all microsoot measurements during PFI testing and for DR 3 during GDI testing. During the City and Urban steady state testing the microsoot concentration often was near or below detectable limits. Some test performed show a spike similar to the PN results, but no results matched with steady state data due to the lower limit of the measurable range and a detection limit of $0.001 \mathrm{mg} / \mathrm{m}^{3}$. This could allude that due to a notable particle number concentration and lack of soot, the particles being emitted are largely volatile. 


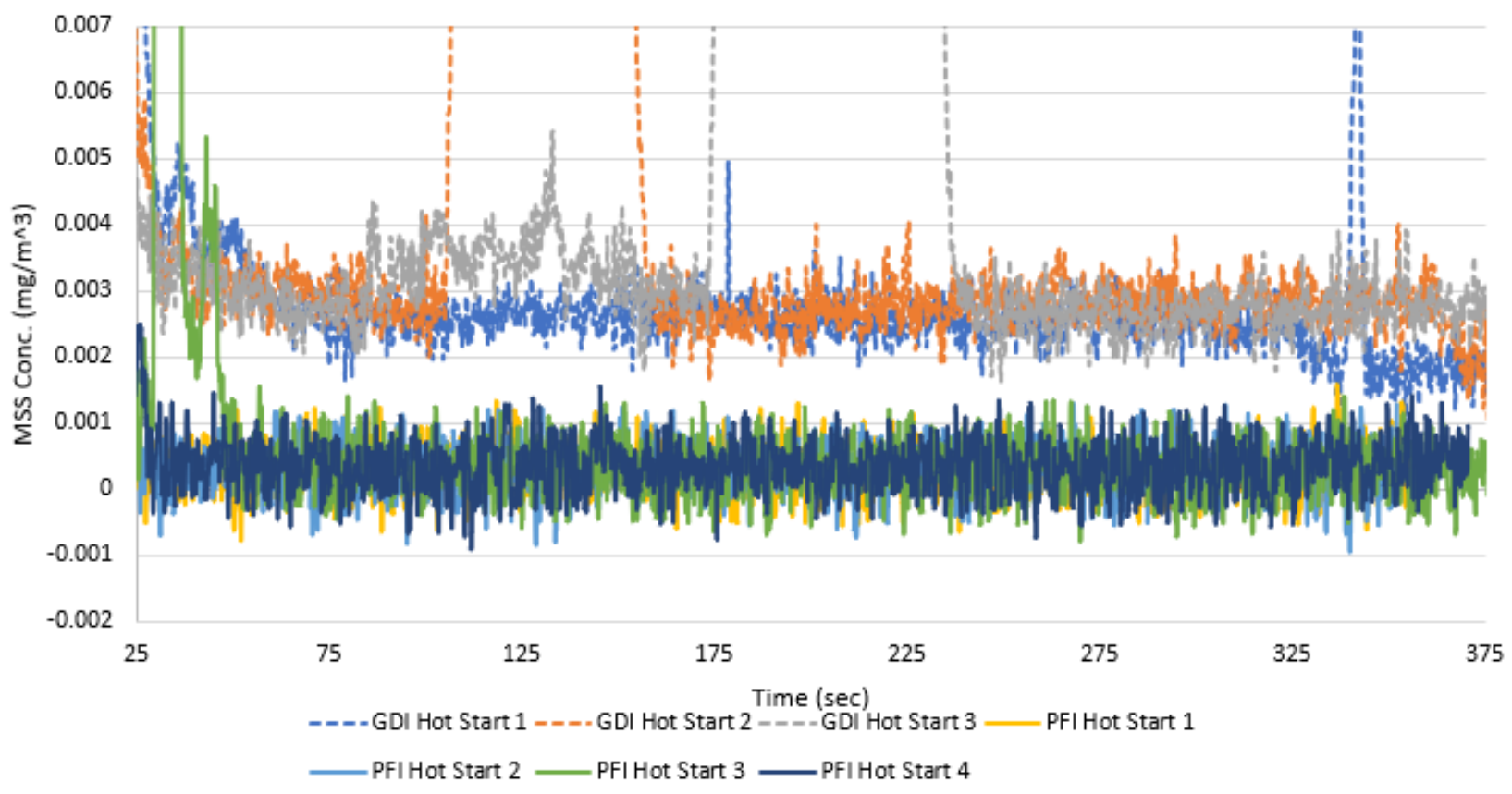

Figure 38: MSS Concentration at DR 1 during City Driving Conditions.

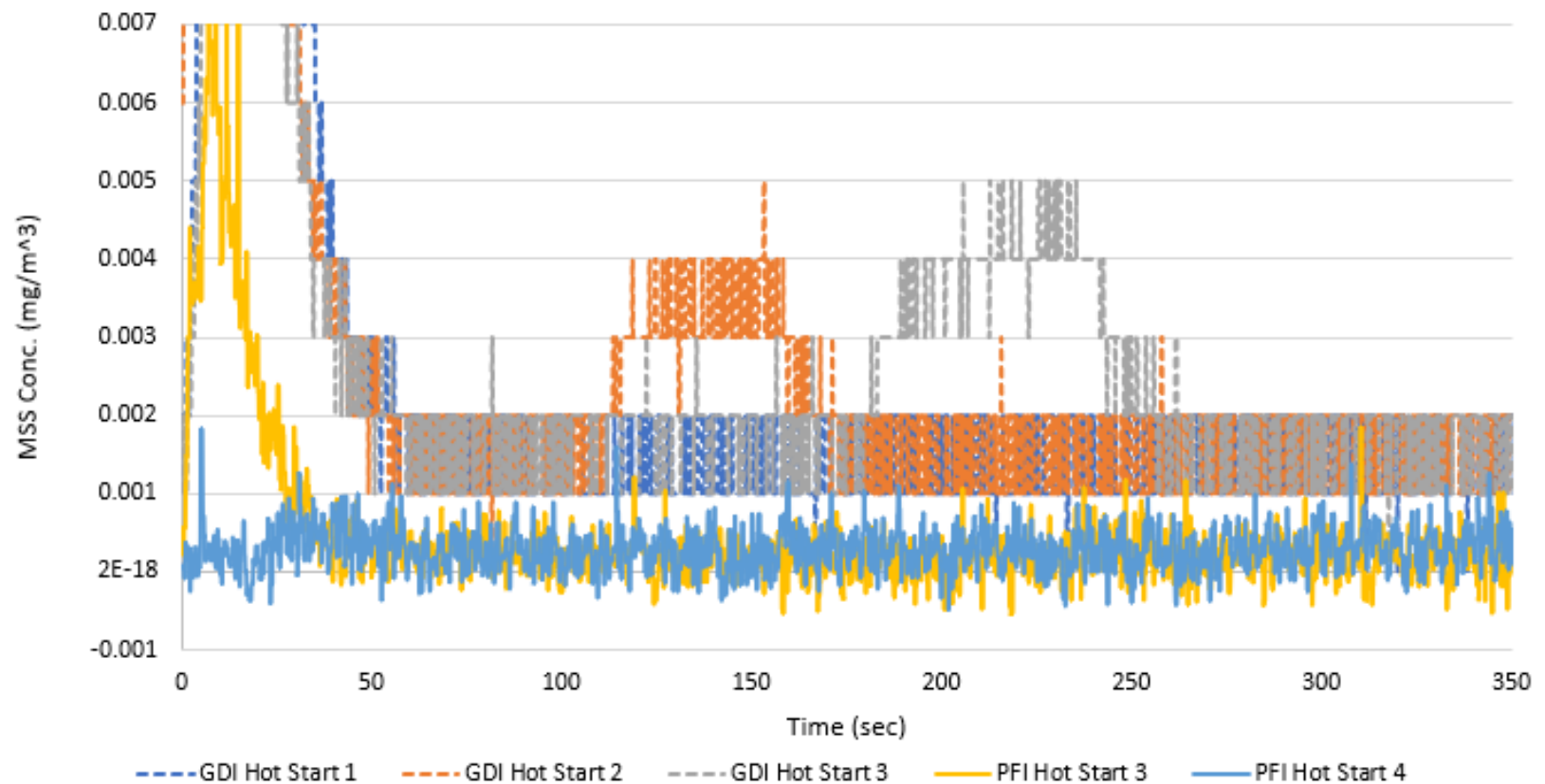

Figure 39: MSS Concentration at DR 2 during City Driving Conditions. 


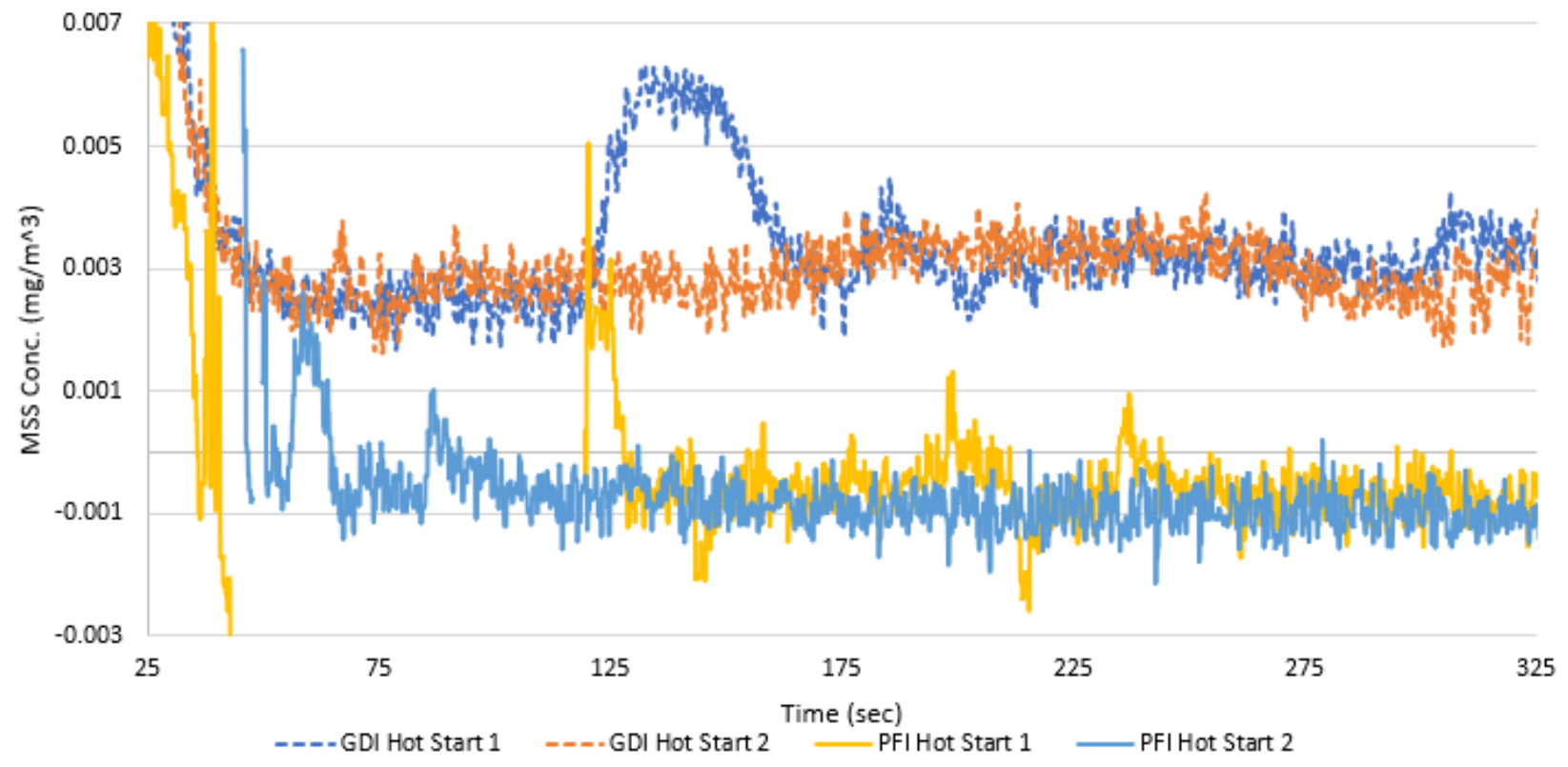

Figure 40: MSS Concentration at DR 3 during City Driving Conditions.

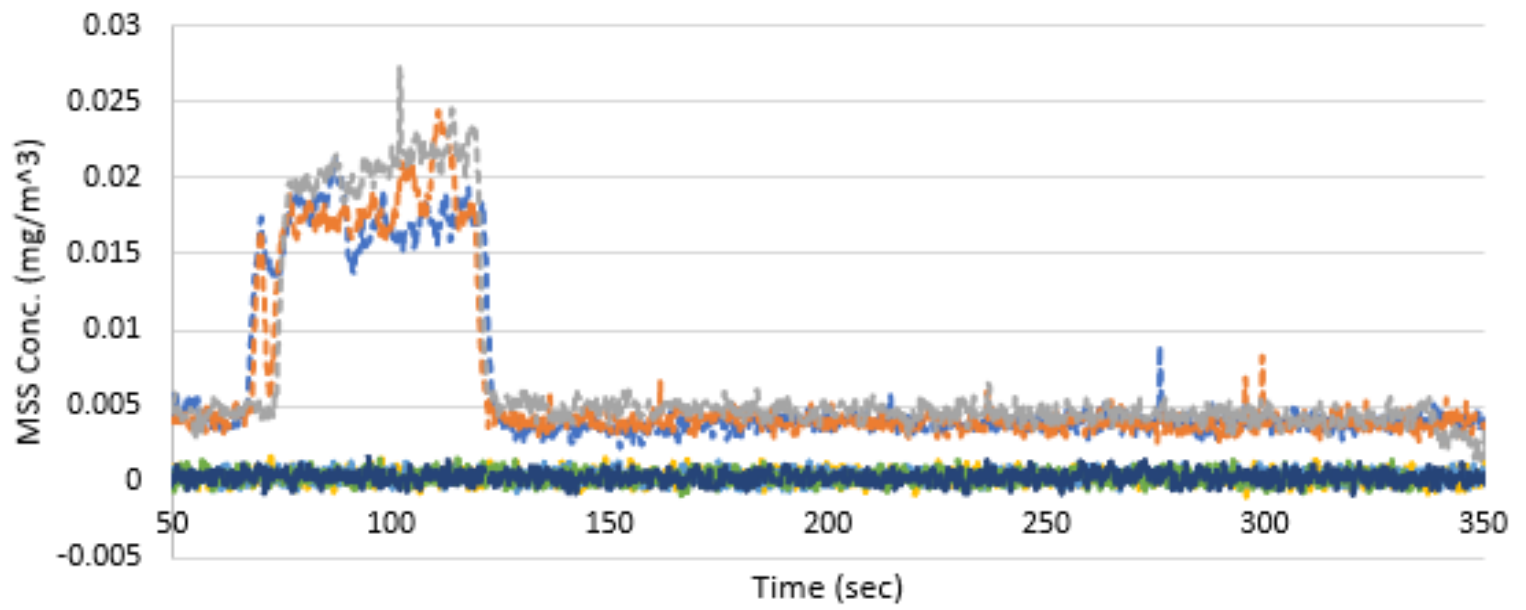

-- --GDI Hot Start 1 ---- GDI Hot Start 2 ----GDI Hot Start 3 _ PFI Hot Start 1

PFI Hot Start 2 PFI Hot Start $3 \longrightarrow$ PFI Hot Start 4

Figure 41: MSS Concentration at DR 1 during Urban Driving Conditions. 


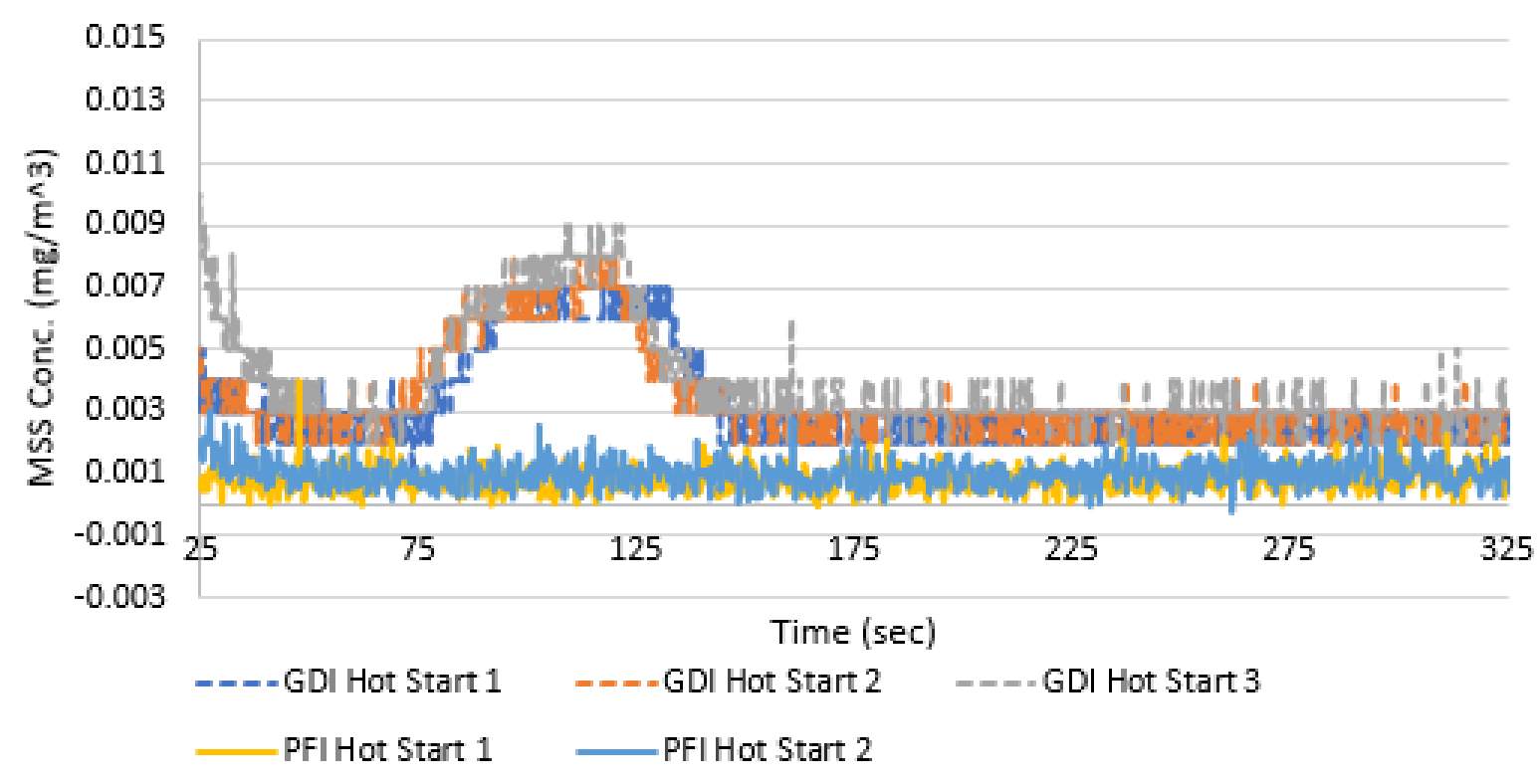

Figure 42: MSS Concentration at DR 2 during Urban Driving Conditions.

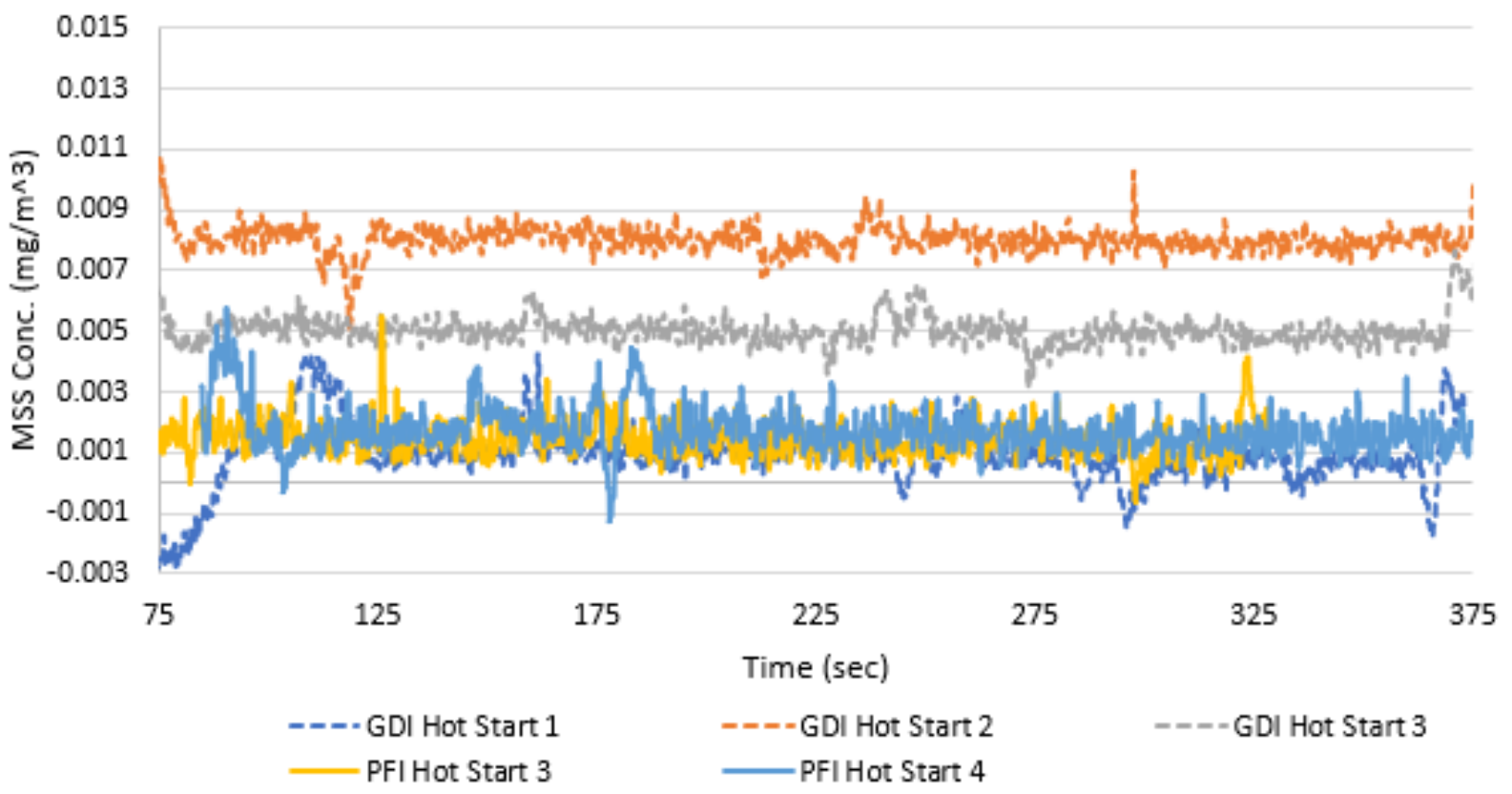

Figure 43: MSS Concentration at DR 3 during Urban Driving Conditions.

The Highway steady state condition shows a average microsoot concentraion of $.01 \mathrm{mg} / \mathrm{m}^{3}$ for the GDI while the PFI produced a concentration below the detectable limit. As previously seen in the PN results, the DR 2 concentration is half of DR 1 . DR 3 shows a concentraion of $0.015 \mathrm{mg} / \mathrm{m}^{3}$ 
where DR 1 showed $0.01 \mathrm{mg} / \mathrm{m}^{3}$. This measurement is inconsistent with CPC PN results and also DR 1 and DR 2 results.

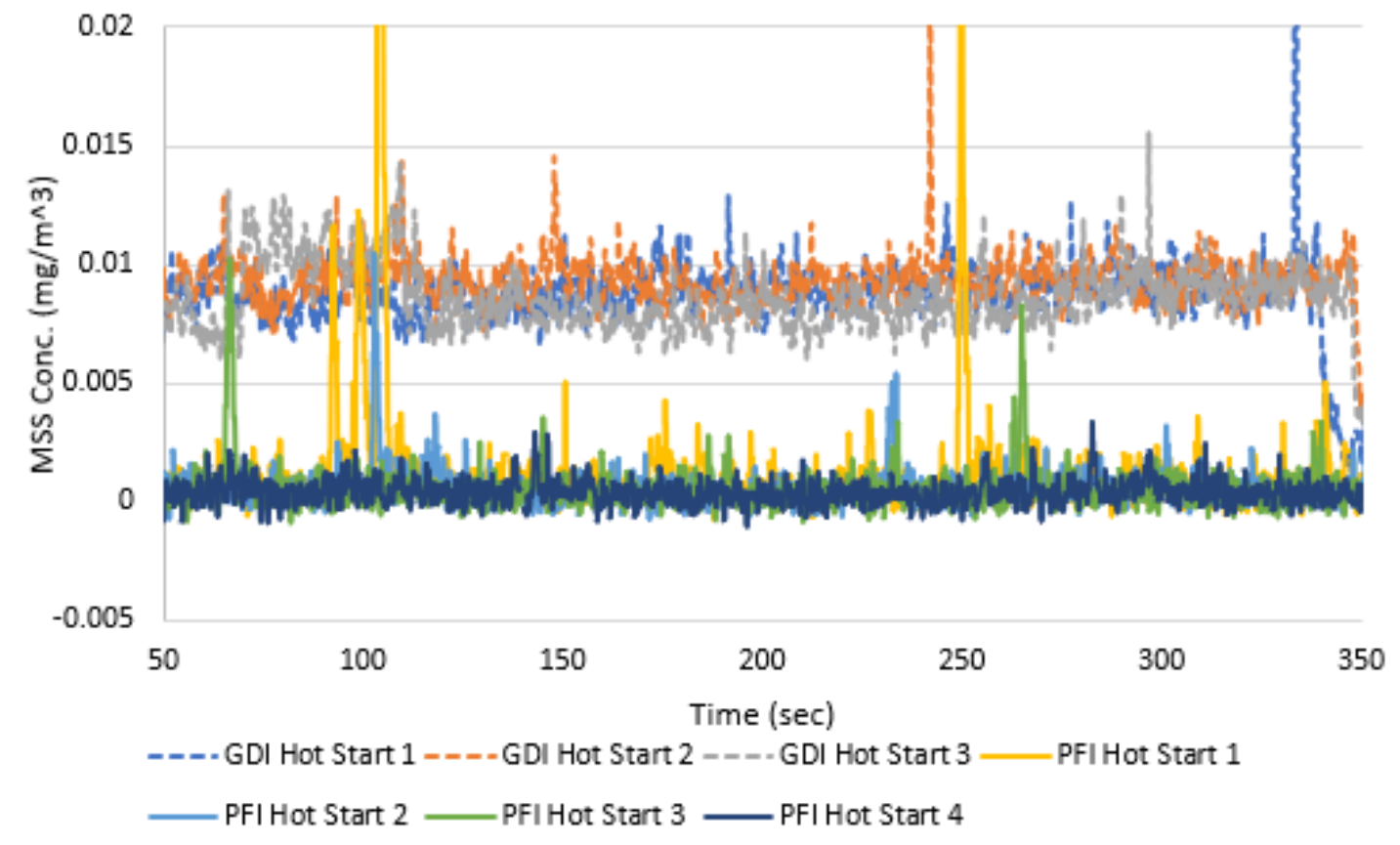

Figure 44: MSS Concentration at DR 1 during Highway Driving Conditions. 


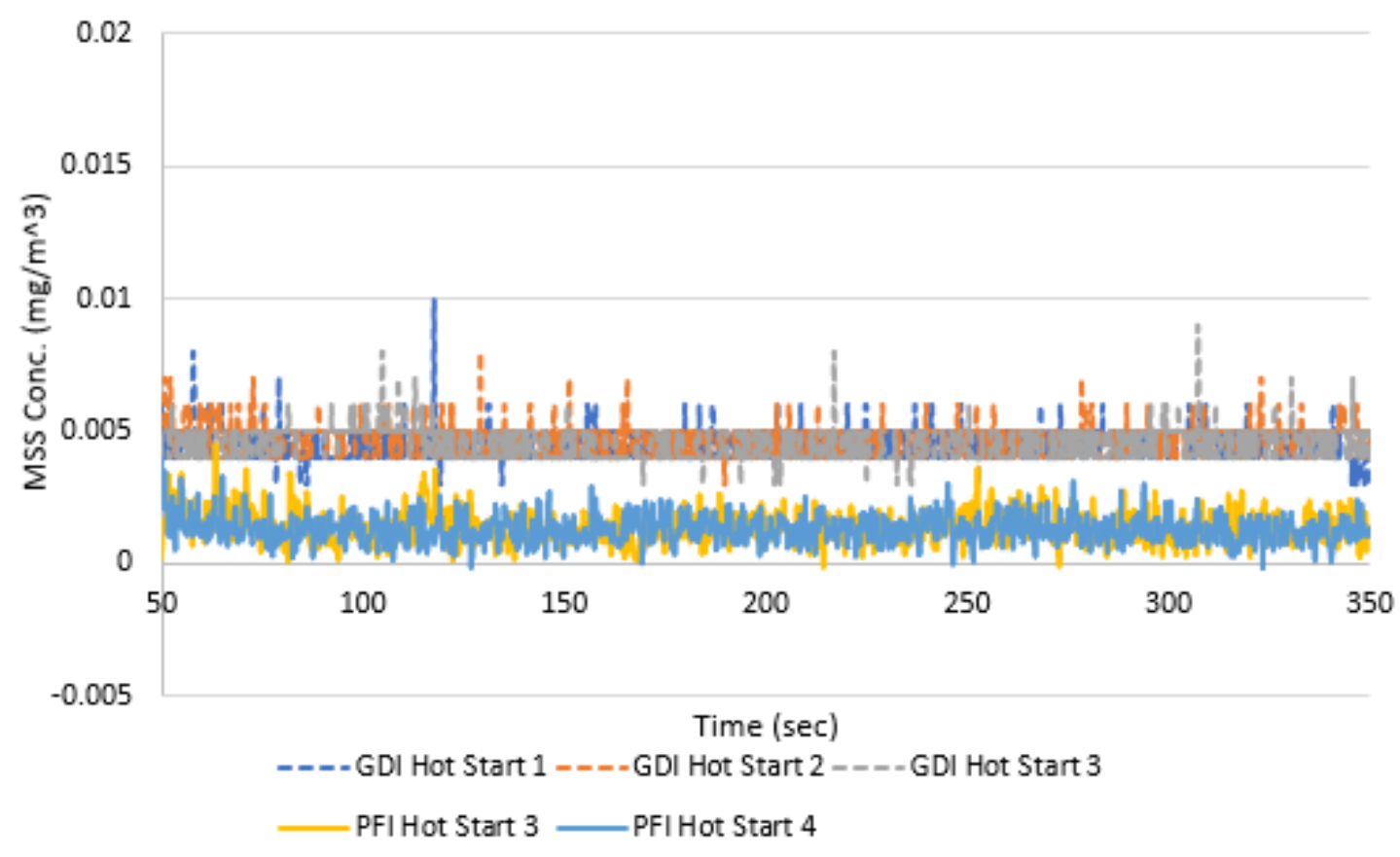

Figure 45: MSS Concentration at DR 2 during Highway Driving Conditions.

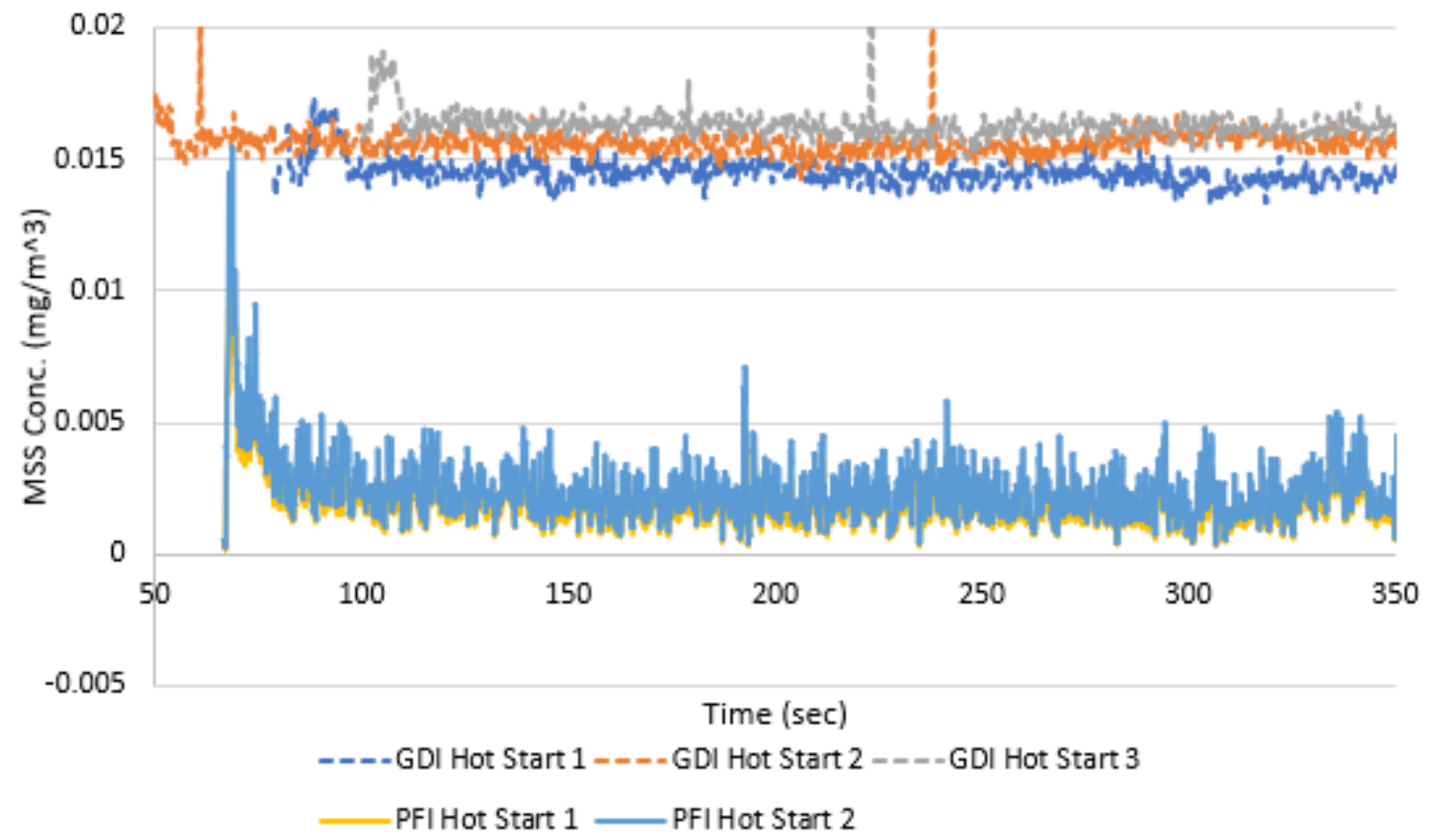

Figure 46: MSS Concentration at DR 3 during Highway Driving Conditions.

MSS results from the LA92 drive cycle on DR 1 show the GDI sustaining higher concentrations in the first half of the cycle while the PFI had large spikes that settled near the detection limit of 
$0.001 \mathrm{mg} / \mathrm{m}^{3}$. Spikes of concentration measured up to $9 \mathrm{mg} / \mathrm{m}^{3}$ at 500 seconds during LA92 of the PFI where the GDI only increased to $0.5 \mathrm{mg} / \mathrm{m}^{3}$. The concentration of microsoot measured from the GDI before and after the spike is an order of 10 to 20 times higher than that of the PFI. This data is presented in Figure 47. During the second half of the LA92 cycle the GDI and PFI microsoot traces remain within $0.005 \mathrm{mg} / \mathrm{m}^{3}$ each other. While the spikes of the PFI remain 10 to 20 higher than the GDI, the concentration settles close to the detection limit when not under load, shown in Figure 48.

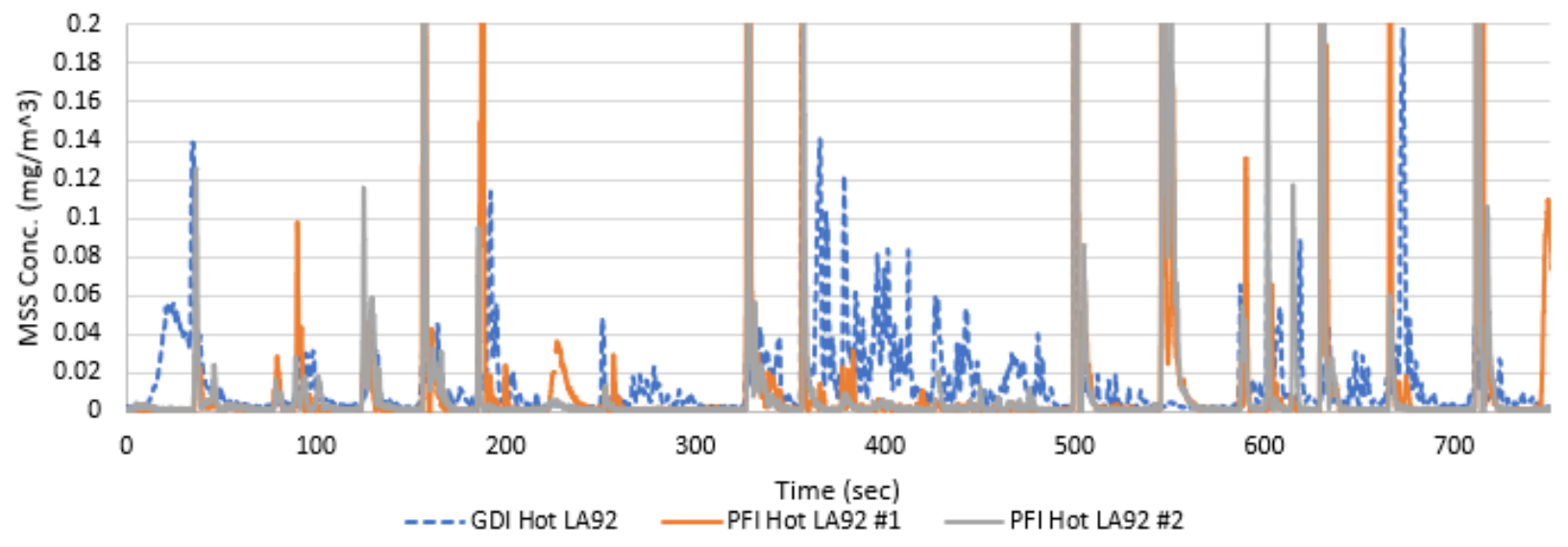

Figure 47: MSS Concentration at DR 1 during the first half of the LA92 Driving Conditions.

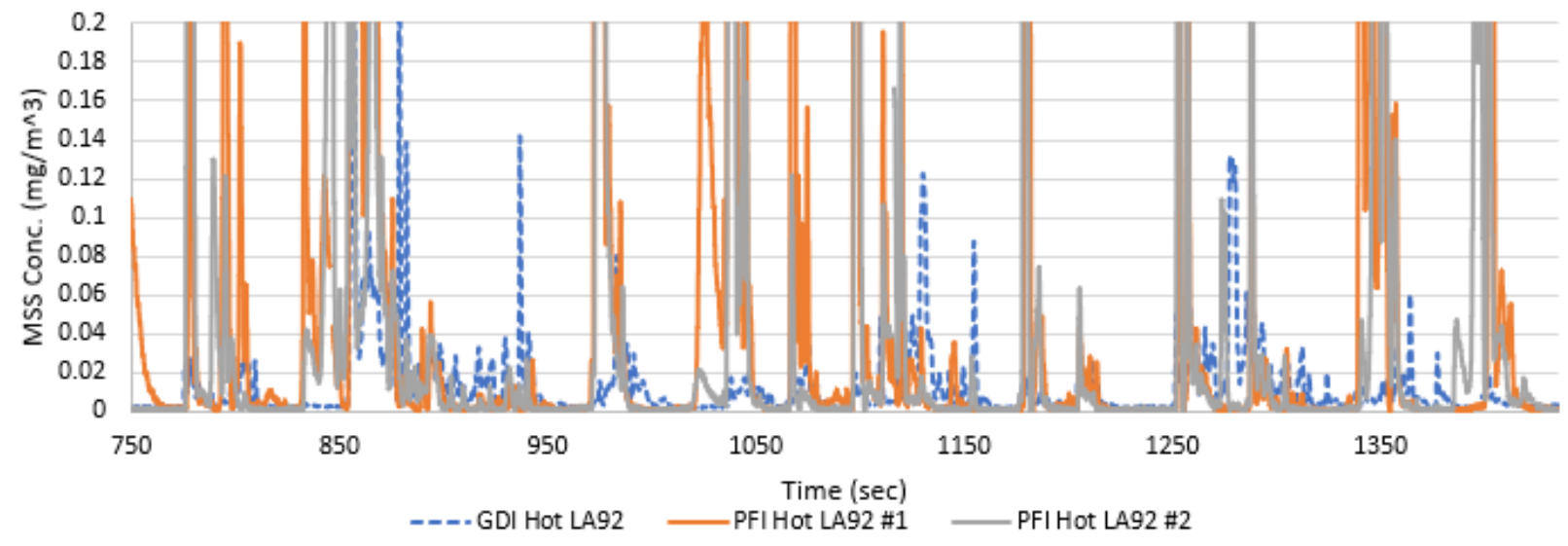

Figure 48: MSS Concentration at DR 1 during the second half of the LA92 Driving Conditions.

The measurement with the MSS at DR 2 is shown over the full cycle in Figure 49 and broken into two halves again in Figure 50 and Figure 51. As seen in Figure 49, the PFI microsoot concentration rises during the spikes seen in Figure 47 and Figure 48. During the spikes it appears the 
concentration lingers and causes the MSS to measure a saturated sample. In Figure 50 at 350 seconds, there is a initial spike and the concentration reduces to low range limit of the MSS for the PFI while the GDI trace remains near $0.005-0.01 \mathrm{mg} / \mathrm{m}^{3}$. This behavior is also seen Figure 35, Figure 36, and Figure 37 measuring PN with the CPCs. The MSS data may be compromised at high dilution ratios due to a saturated sample during high particle mass spikes in the PFI testing.

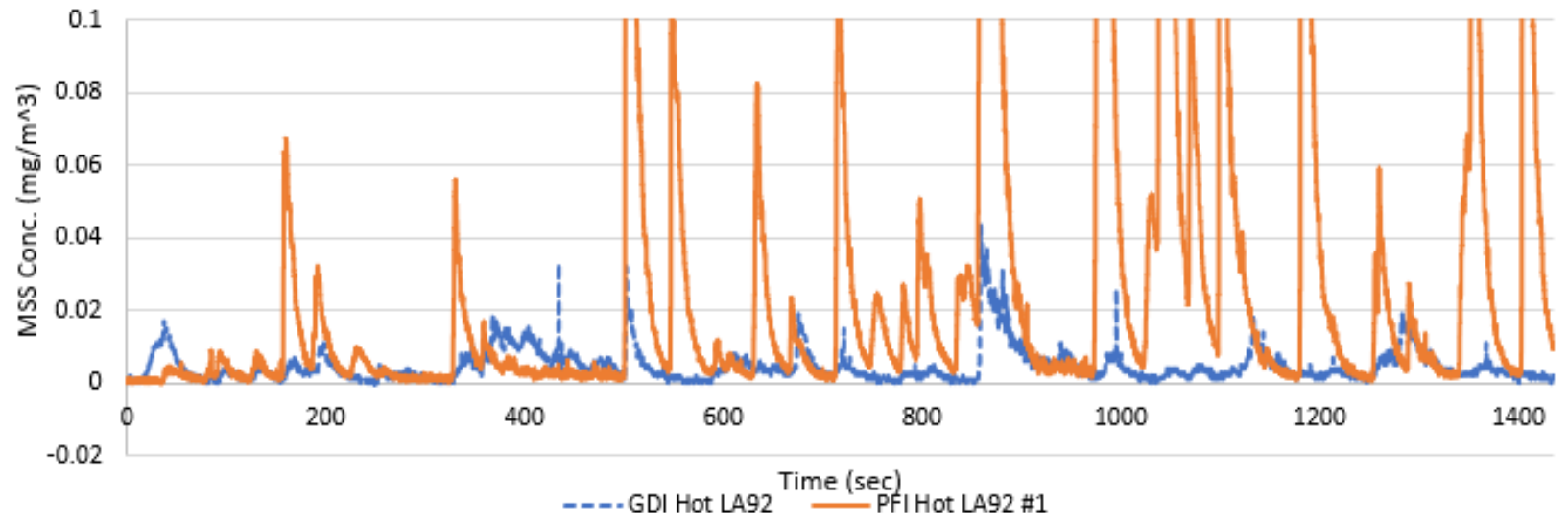

Figure 49: MSS Concentration at DR 2 during the LA92 Driving Conditions.

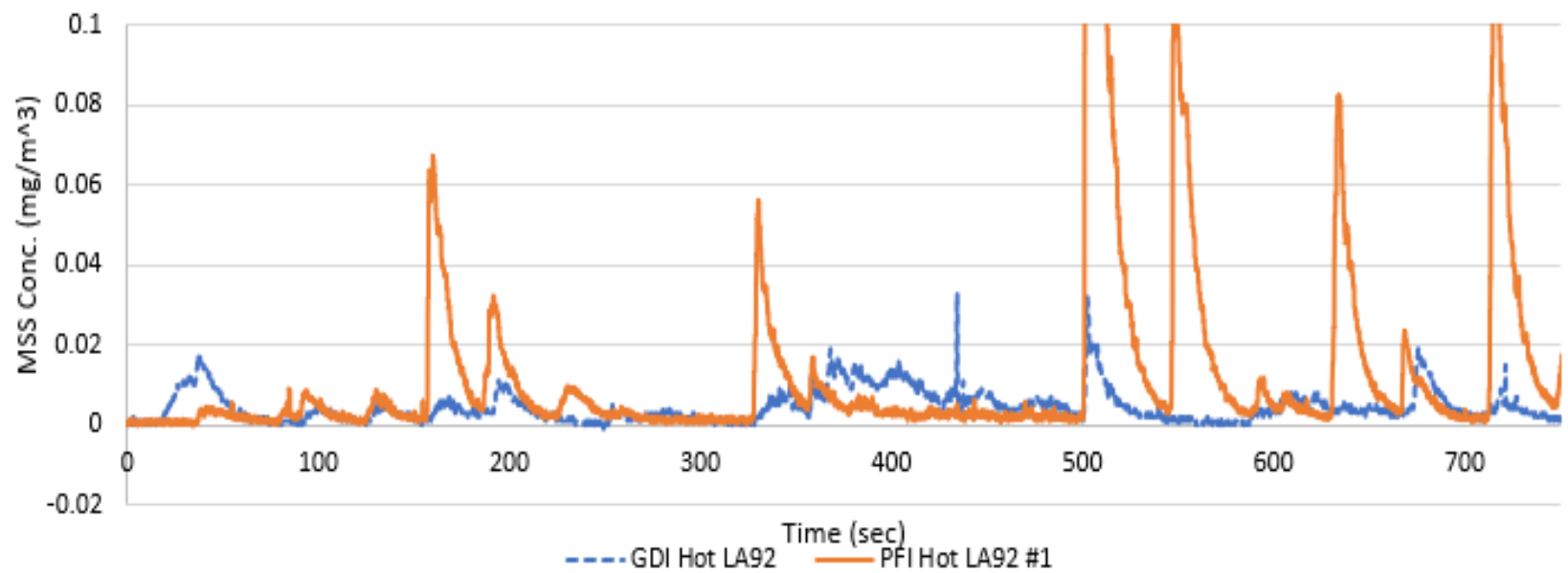

Figure 50: MSS Concentration at DR 2 during the first half of the LA92 Driving Conditions. 


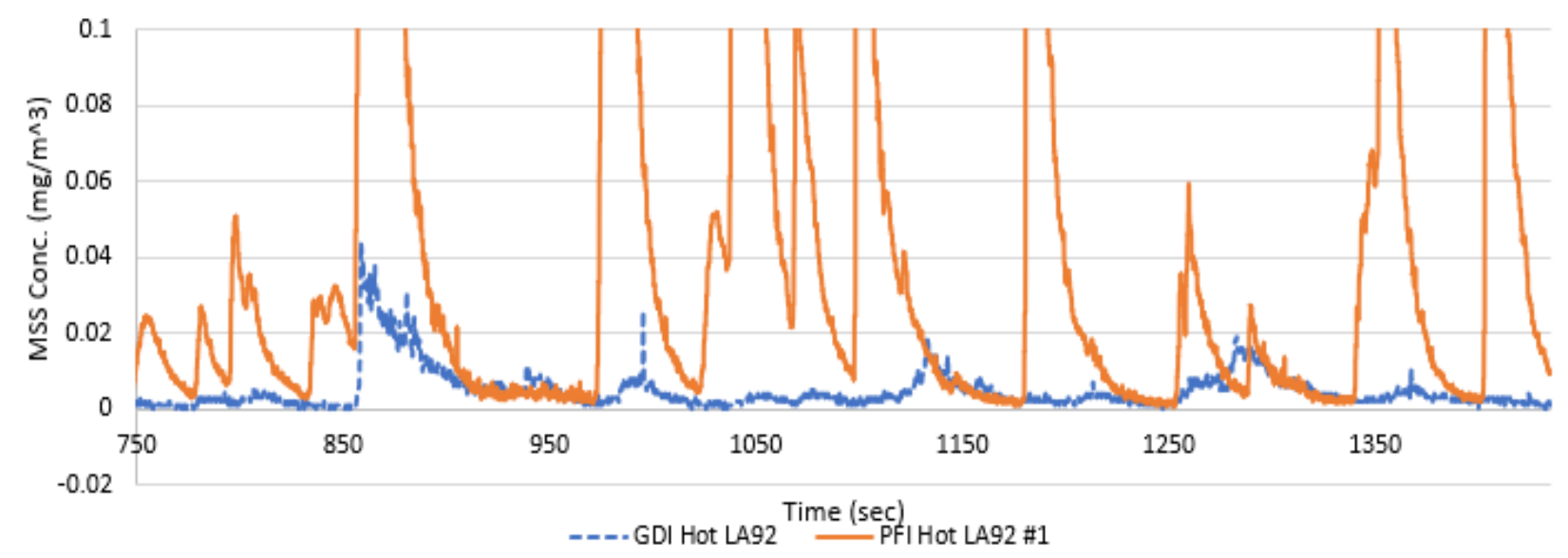

Figure 51: MSS Concentration at DR 2 during the second half of the LA92 Driving Conditions.

Figure 52 shows the results of the MSS during the LA92 cycle at DR 3. This data can be deemed inconclusive because the concentrations are at or below the measurable range of the MSS equipment.

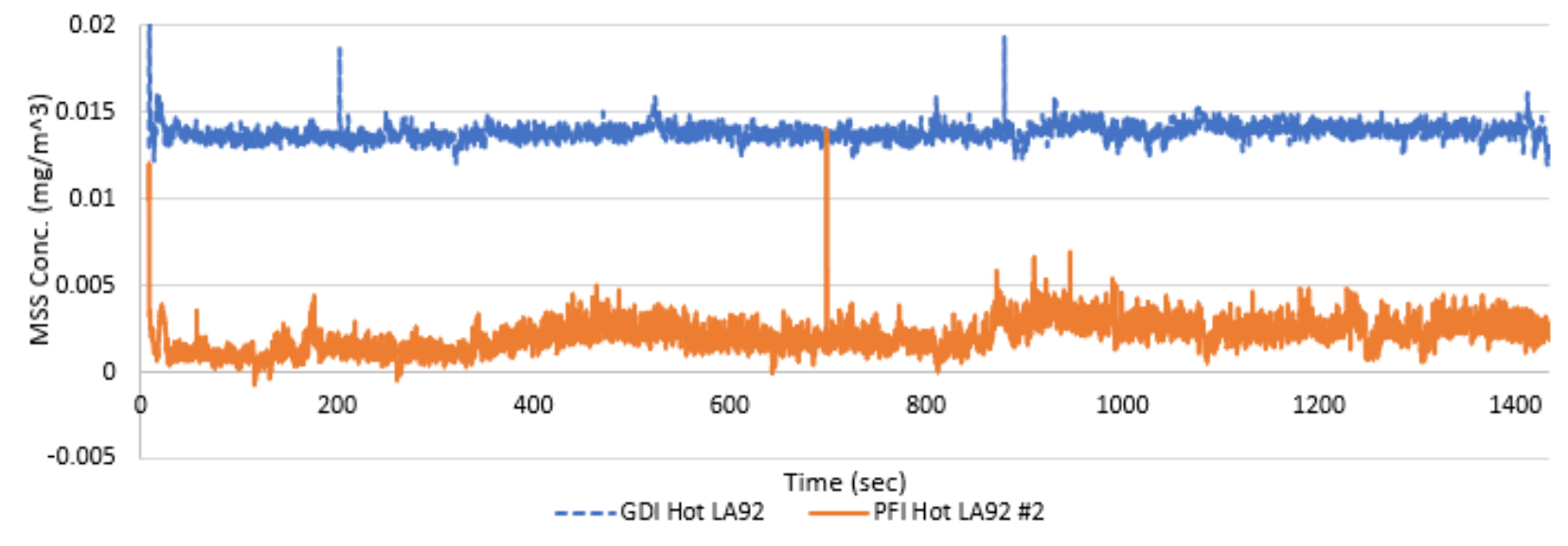

Figure 52: MSS Concentration at DR 3 during the LA92 Driving Conditions.

During the McCaffery study, a comparison was presented in Figure 2 of the soot per mile between the three GDI vehicles (McCaffery, et al. 2019). Similarly, Figure 53 presents the same comparison among the three LA92 transient cycles performed. The GDI engine used for McCaffery was a turbocharged $1.5 \mathrm{~L}$ engine compared to the $2.4 \mathrm{~L}$ naturally aspirated engine of the GDI Hyundai Santa Fe. The results collected during the LA92 transient cycle were collected over 9.8 miles. This is half of the miles driven to collect data for McCaffery for the shortest test route. Another important note is the McCaffery study used PEMS testing with outside ambient air conditions rather than a chassis laboratory with laboratory conditions and equipment. The results of 
McCaffery's study show their spray guided GDI as emitting more than the two wall guided engines. The LA92 cycles performed with the GDI produced less soot per mile than the PFI in both cycles by an average of $0.01 \mathrm{mg} / \mathrm{mile}$. In the comparison to the McCaffery study, the GDI engine produced similar amounts of soot to the spray guided GDI vehicle after the catalyzed GPF was installed.

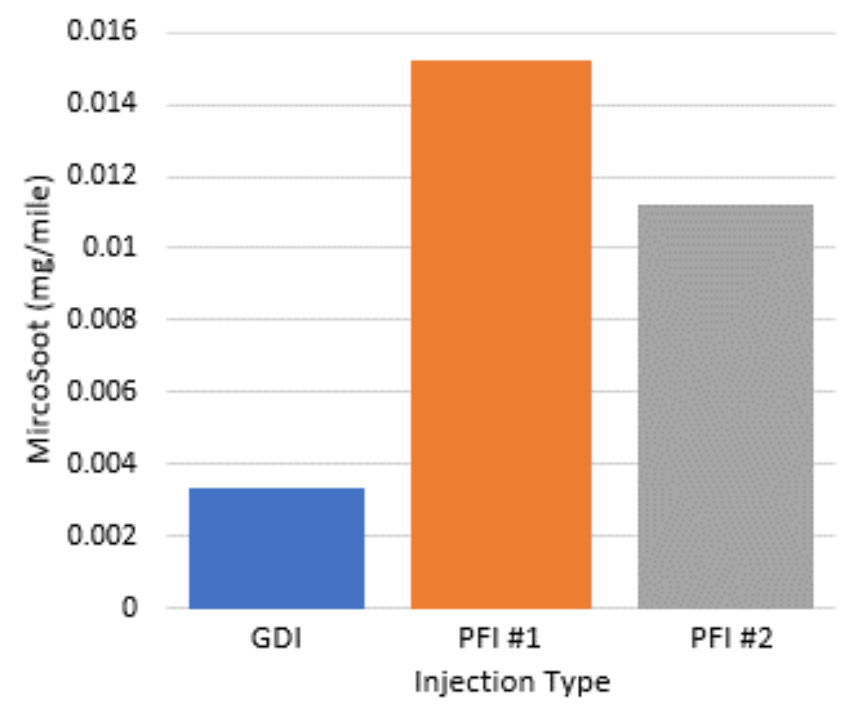

Figure 53: Soot per Mile during the LA92 transient cycle>

\section{PM Collection}

The PM data collection utilized versatile PM equipment that could be used in various sampling systems. The orifices used to control flow were able to achieve the maximum filter face velocity allowed by CFR 40§1065.170(a)(2). This section of the CFR describes the filter flow velocity to be set to $50 \mathrm{~cm} / \mathrm{s}$ but only if the filter loading is exceeding a target of $400 \mu \mathrm{g}$. This design requirement of the PM boxes made gravimetric measurement difficult at high dilution ratios and in sampling environments where PM loading is not significant. The vehicles are regulated to a PM emissions standard of $0.01 \mathrm{~g} / \mathrm{mi}$, deeming them to be a low emitting vehicle and combined with the high dilution ratios the results from the PM collection are inconclusive and do not correlate with the AVL MSS equipment. The results from the testing can be found in the Appendix and recommendations for a repeat test setup will be suggested in the Recommendations. 


\section{Conclusions}

The results showed the PFI engine of the Subaru Legacy tended to emit lower particle concentrations but not soot compared to the GDI engine of the Hyundai Santa Fe. This was shown in the results taken with the CPC and the microsoot sensor measurements. While on average, the GDI vehicle produced more PN concentration and soot during the steady state; the PFI produced a higher average soot/mile during the transient LA92 cycle. During each steady state condition, the GDI produced an average PN concentration of $25,000 \mathrm{~cm}^{-3}$ during the City condition at DR 1 while the PFI's PN concentration was not detectable. During the Urban condition, the GDI produced $35,000-45,000 \mathrm{~cm}^{-3}$ while the PFI consistently produced a spike of $8,000 \mathrm{~cm}^{-3}$ that lowered to $2,000 \mathrm{~cm}^{-3}$ and rose back to $6,000 \mathrm{~cm}^{-3}$ near the end of the cycle at DR 1 . During the Highway condition of the steady state testing at DR 1 the GDI produced $55,000-60,000 \mathrm{~cm}^{-3}$ as the PFI produced $10,000 \mathrm{~cm}^{-3}$ and increased during the cycle to end with $40,000 \mathrm{~cm}^{-3}$ to 60,000 $\mathrm{cm}^{-3}$. The MSS data revealed similar results but with both vehicles yielding concentrations near the lower detection limit (LDL) of the microsoot sensor. The GDI shows a small spike near the beginning of the steady state cycles but both the GDI and the PFI produced soot concentrations too low to make a data supported conclusion. This also explained the results seen with the PM, without any soot being produced, the PM mass failed to yield conclusive results. While there was minimal soot to measure any detectable levels of PN concentration, it could be assumed the majority of the particles produced would be considered volatile. Inconclusive PM mass with repeatable PN measurement is an example why a PN style measurement should be implemented to aid in future emissions standards. During the transient test measuring with CPCs, the GDI engine produced more particles during operation while the PFI engine produced extremely high spikes that would be near the detection limit of the equipment. These spikes caused the PFI engine to produce twice the PN average as the GDI engine. A discrepancy with the CPC data could be the minimum particle size detection. The TSI 3025A had a 50\% detection limit at $3 \mathrm{~nm}$ particle size, the while the TSI 3022A and TSI 3772 had 50\% detection limits at $7 \mathrm{~nm}$ particle size. This could allow for the TSI 3022A to measure more particles than the other CPCs and because TSI 3022A was measuring at DR 1, it could contribute to such high spikes of PN. Another issue is these particles are solid and non-solid. Without an evaporator tube or catalyst to remove non-solid particle, these measurements were elevated compared to a solid particle measurement completed with other equipment. MSS measurements also showed similar results to the CPC. As the dilution 
ratio increased, the measurements tended towards the limiting resolution of the sensors. This is shown during large spikes from the PFI engine at DR1 that is orders of magnitude higher than GDI and when comparing the DR2 traces, the measurement of the PFI and GDI was on the same order of magnitude.

\section{Recommendations}

Recommendations for similar testing include a larger pool of vehicles to evaluate as only a spray guided GDI engine was tested. A wall-guided GDI, a PFI-GDI, and a wall/spray-guided GDI would allow more data to draw conclusions on the injection technologies. Due to low staffing during testing, the drivers for the two vehicles were different and inexperienced. Having a single experienced driver would reduce variability in following the transient speed trace on the dynamometer, producing more consistent results. Another recommendation would be to integrate a TSI EEPS and AVL APC or equivalent equipment at all the sampling locations. Doing this would allow for a measurement of particle distribution for each engine type and how it may or may not change with different dilution ratio environments. The AVL APC could measure a solid particle number concentration at each sample location to better understand how many of the non-solid particles are lost in the transition to each of the dilution ratios. These results could conclude if high dilution sampling would cause too significant losses of amount of particle to be a valid option for particle measurement. For PM sampling, the flow should be increased to target a $400 \mu \mathrm{g}$ loading rather than use a universal PM box. Although increasing sample flow may have various effects on isokinetic flow of the sampling tunnels. Increasing sampling flow may also require an increase in filter size to prevent excessive filter face velocity. Another method to increase loading would be to increase sampling time. This may help for higher vehicle speed conditions, but low speed sampling may still not yield any particulates without extensive data collection periods. From the data collected, once the PFI had achieved the steady state condition it will not produce a PN concentration unless under load. Rather than using a speed condition as a metric, an emphasis on load should be considered. Using longer sampling times would also include back to back cycles for transient cycles. This would give a more meaningful results and could better reinforce a conclusion. Ideally the dilution integration and sampling tunnels would be identical rather than having long sample lines, separate geometries for the mixing tunnels, different equipment with different specifications. 


\section{Appendix}

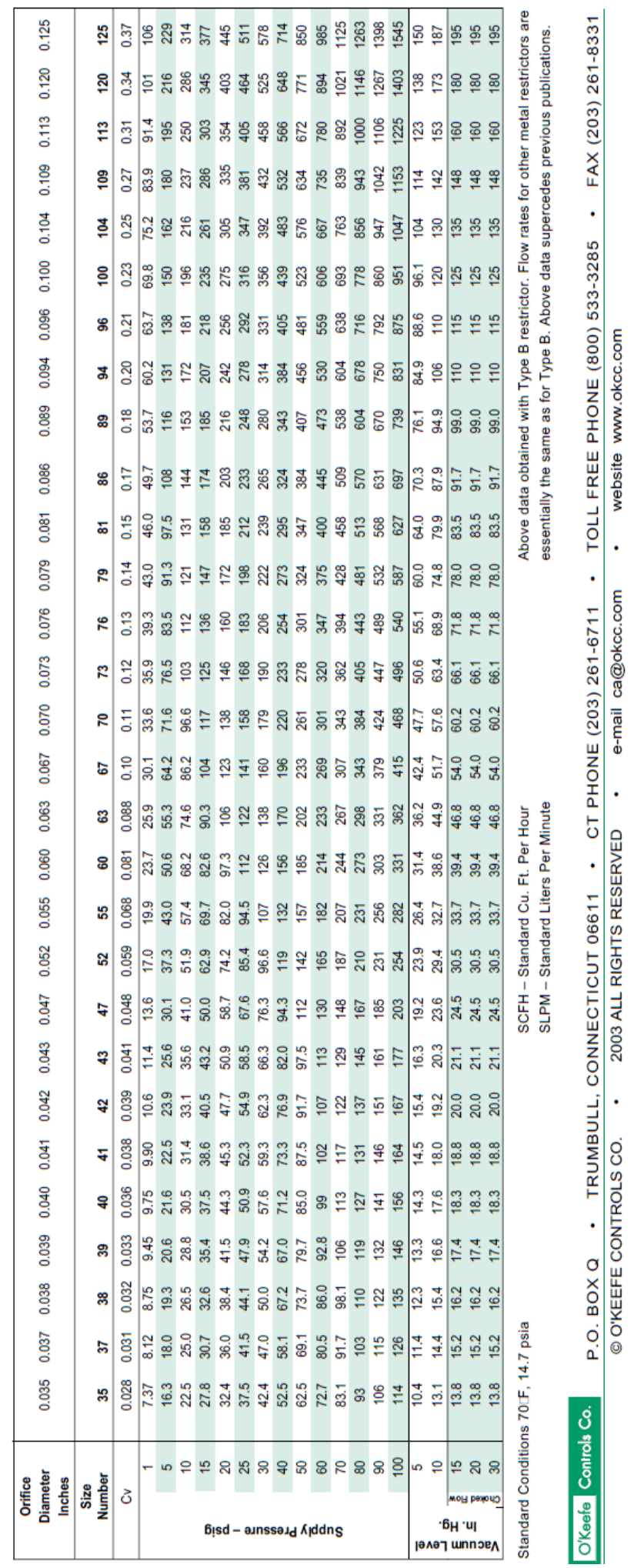

Figure 54: O'Keefe Controls Co. Orifice Data Sheet for Metal Orifice Air Flow in SCFM. 


\begin{tabular}{|c|c|c|c|c|}
\hline \multicolumn{5}{|c|}{ Hyundai } \\
\hline Mode & Filter ID & PRE & Post & Diff \\
\hline 178 & WV12690 & 92.6998 & 92.7108 & 0.01098 \\
\hline 178 & WV12690 & 92.3006 & 92.2858 & -0.01473 \\
\hline 178 & WV12689 & 92.4517 & 92.4615 & 0.00979 \\
\hline 179 & WV12695 & 92.2624 & 92.2601 & -0.00224 \\
\hline 179 & WV12695 & 92.9747 & 92.9876 & 0.01296 \\
\hline 179 & WV12695 & 90.3223 & 90.3544 & 0.03207 \\
\hline 180 & WV12695 & 93.3647 & 93.3791 & 0.01436 \\
\hline 180 & WV12695 & 92.8005 & 92.8092 & 0.00876 \\
\hline 180 & WV12695 & 92.1286 & 92.1408 & 0.01216 \\
\hline 183 & WV12695 & 90.64 & 90.6533 & 0.01327 \\
\hline 183 & WV12695 & 92.0968 & 92.1088 & 0.01197 \\
\hline 183 & WV12695 & 90.4004 & 90.4148 & 0.01437 \\
\hline 184 & WV12695 & 91.1162 & 91.0587 & -0.05745 \\
\hline 184 & WV12694 & 92.6824 & 92.6799 & -0.00253 \\
\hline 184 & WV12694 & 92.1416 & 92.1323 & -0.00933 \\
\hline 185 & WV12694 & 93.3141 & 93.342 & 0.02789 \\
\hline 185 & WV12694 & 92.824 & 92.8419 & 0.01788 \\
\hline 185 & WV12694 & 93.2802 & 93.2864 & 0.00628 \\
\hline 186 & WV12694 & 91.2893 & 91.3025 & 0.01328 \\
\hline 186 & WV12694 & 91.8582 & 91.8796 & 0.02138 \\
\hline 186 & WV12694 & 92.306 & 92.3285 & 0.02249 \\
\hline 187 & WV12694 & 92.6971 & 92.6982 & 0.00108 \\
\hline 187 & WV12694 & - 91.7959 & 91.8137 & 0.01788 \\
\hline 187 & WV12693 & 92.0529 & 92.0628 & 0.00998 \\
\hline 188 & WV12699 & 93.9651 & 93.1634 & -0.80167 \\
\hline 188 & WV12693 & 92.7159 & 92.7383 & 0.02238 \\
\hline 188 & WV12693 & 92.3834 & 92.39 & 0.00657 \\
\hline 191 & WV12696 & 90.8108 & 91.3882 & 0.57739 \\
\hline 191 & WV12696 & 91.5955 & 91.5471 & -0.04837 \\
\hline 191 & WV12696 & 91.519 & 90.8571 & -0.66191 \\
\hline
\end{tabular}

Figure 55: PM Weights from Hyundai Santa Fe Tests. 


\begin{tabular}{|c|c|c|c|c|}
\hline \multicolumn{5}{|c|}{ Subaru } \\
\hline Mode & Filter ID & PRE & Post & Diff \\
\hline 194 & WV12696 & 90.6894 & 90.715 & 0.02556 \\
\hline 194 & WV12696 & 91.1436 & 91.1556 & 0.01196 \\
\hline 194 & WV12696 & 91.1173 & 91.1178 & 0.00045 \\
\hline 195 & WV12697 & 90.3311 & 90.3451 & 0.01405 \\
\hline 195 & WV12697 & 90.6529 & 90.7207 & 0.06778 \\
\hline 195 & WV12697 & 90.9308 & 90.9541 & 0.02326 \\
\hline 196 & WV12697 & 89.973 & 89.9906 & 0.01755 \\
\hline 196 & WV12697 & 91.2646 & 91.1257 & -0.13891 \\
\hline 196 & WV12696 & 91.0907 & 91.1095 & 0.01875 \\
\hline 197 & WV12698 & 93.8816 & 93.8978 & 0.01615 \\
\hline 197 & WV12696 & 93.4285 & 93.4801 & 0.05156 \\
\hline 197 & WV12696 & 90.1609 & 90.168 & 0.00705 \\
\hline 198 & WV12698 & 93.337 & 93.2053 & -0.13171 \\
\hline 198 & WV12698 & 93.7467 & 93.7709 & 0.02426 \\
\hline 198 & WV12697 & 93.7914 & 93.8047 & 0.01335 \\
\hline 199 & WV12697 & 93.2543 & 93.3651 & 0.11079 \\
\hline 199 & WV12697 & 91.0251 & 91.0317 & 0.00665 \\
\hline 199 & WV12697 & 92.1991 & 92.2161 & 0.01696 \\
\hline 200 & WV12699 & 90.6067 & 90.6169 & 0.01016 \\
\hline 200 & WV12698 & 93.2069 & 93.229 & 0.02206 \\
\hline 200 & WV12697 & 90.495 & 90.4997 & 0.00475 \\
\hline 201 & WV12698 & 91.3571 & 91.3612 & 0.00405 \\
\hline 201 & WV12698 & 90.8522 & 90.8646 & 0.01235 \\
\hline 201 & WV12698 & 92.8924 & 92.9059 & 0.01344 \\
\hline 202 & WV12698 & 91.7979 & 91.8162 & 0.01835 \\
\hline 202 & WV12698 & 93.2413 & 93.276 & 0.03475 \\
\hline 202 & WV12698 & 93.1826 & 93.1893 & 0.00664 \\
\hline 203 & WV12699 & 93.4822 & 93.5142 & 0.03205 \\
\hline 203 & WV12699 & 93.7425 & 93.7687 & 0.02625 \\
\hline 203 & WV12699 & 92.0953 & 92.1212 & 0.02585 \\
\hline
\end{tabular}

Figure 56: PM Weights from Subaru Legacy Tests 1 of 2.

\begin{tabular}{|r|r|r|r|r|}
\hline 204 & WV12719 & 94.6698 & 94.7056 & 0.03578 \\
\hline 204 & WV12699 & 92.2344 & 92.2541 & 0.01975 \\
\hline 204 & WV12699 & 91.4829 & 91.5105 & 0.02766 \\
\hline & & & & \\
\hline 205 & WV12699 & 91.6791 & 91.7006 & 0.02145 \\
\hline 205 & WV12699 & 90.3009 & 90.3213 & 0.02045 \\
\hline 205 & WV12699 & 92.0356 & 92.0638 & 0.02825 \\
\hline 208 & WV12719 & 93.9383 & 93.987 & 0.04869 \\
\hline 208 & WV12690 & 94.7157 & 94.8936 & 0.17783 \\
\hline 208 & WV12686 & 92.266 & 92.4011 & 0.13512 \\
\hline & & & & \\
\hline 209 & WV12720 & 92.7583 & 92.9193 & 0.16093 \\
\hline 209 & WV12687 & 95.1203 & 95.2351 & 0.11481 \\
\hline 209 & WV12687 & 94.6434 & 94.6868 & 0.04338 \\
\hline & & & & \\
\hline
\end{tabular}

Figure 57: PM Weights from Subaru Legacy Tests 2 of 2. 


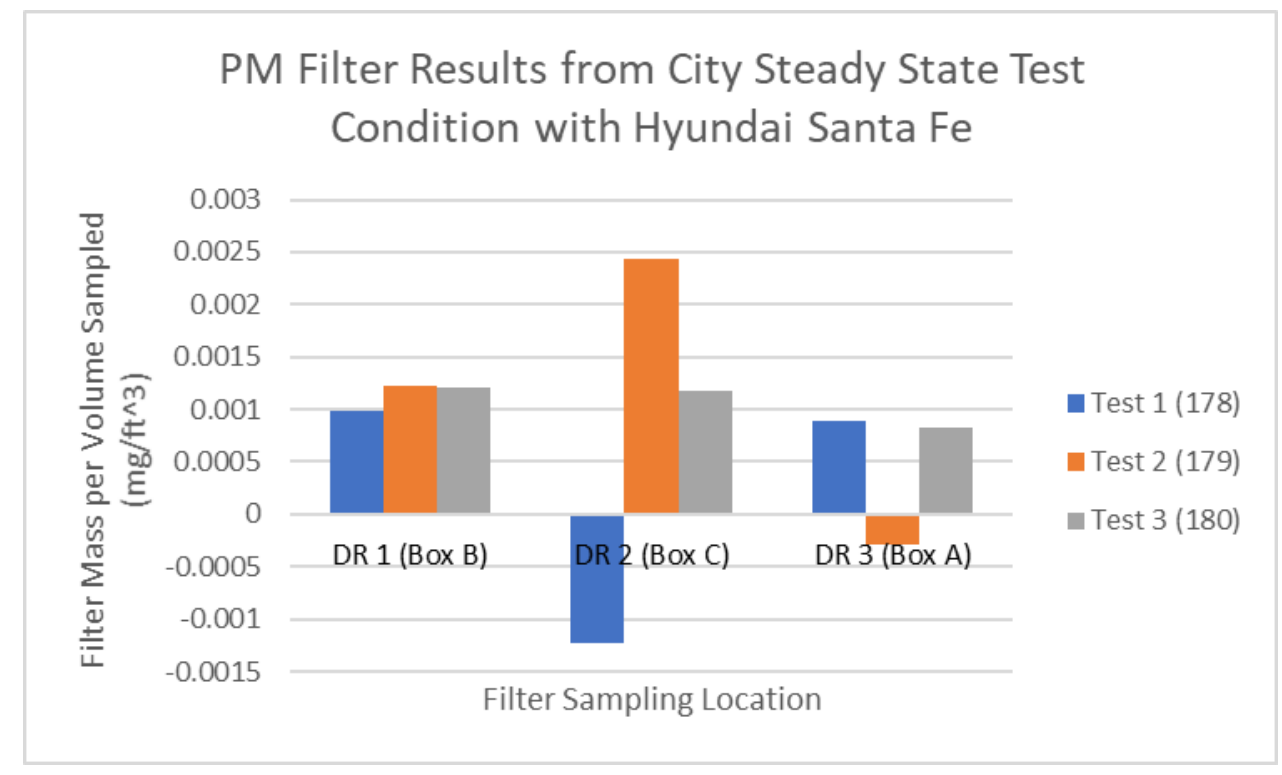

Figure 58: Gravimetric Mass results from City Conditions with the Hyundai.

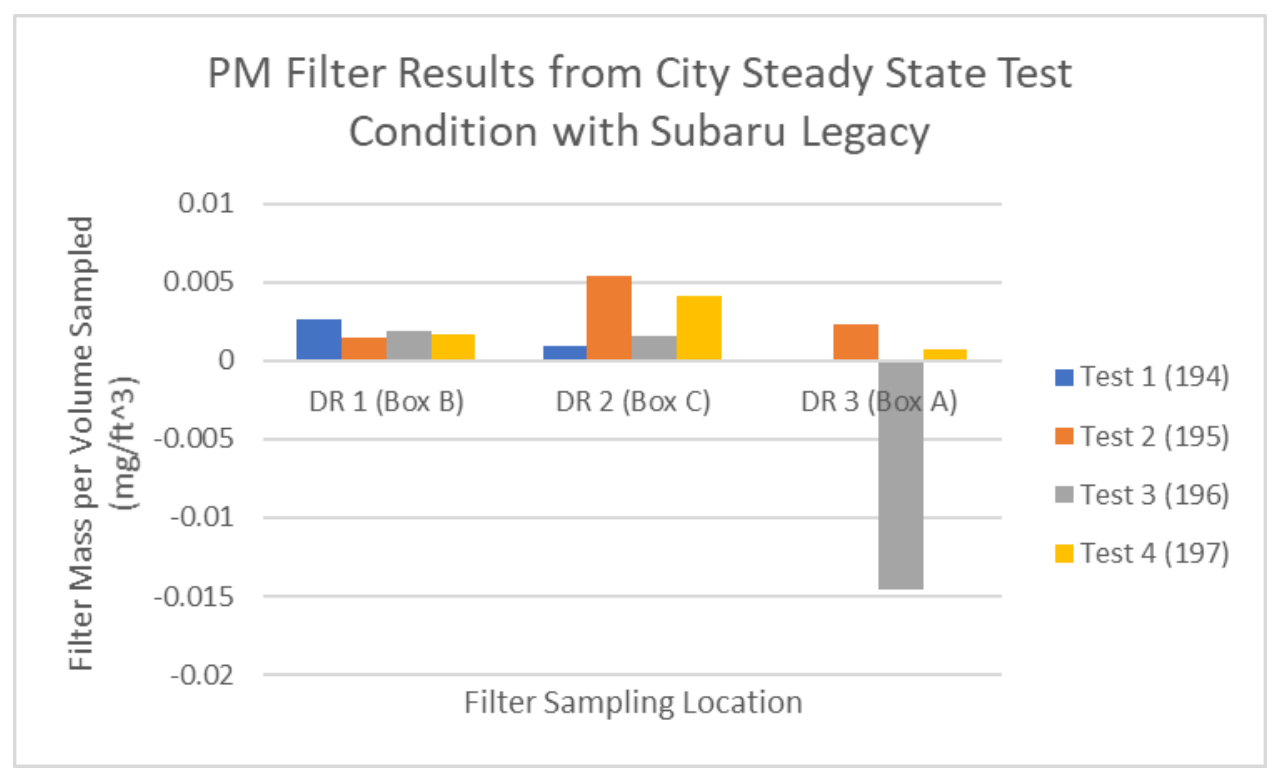

Figure 59: Gravimetric Mass results from City Conditions with the Subaru. 


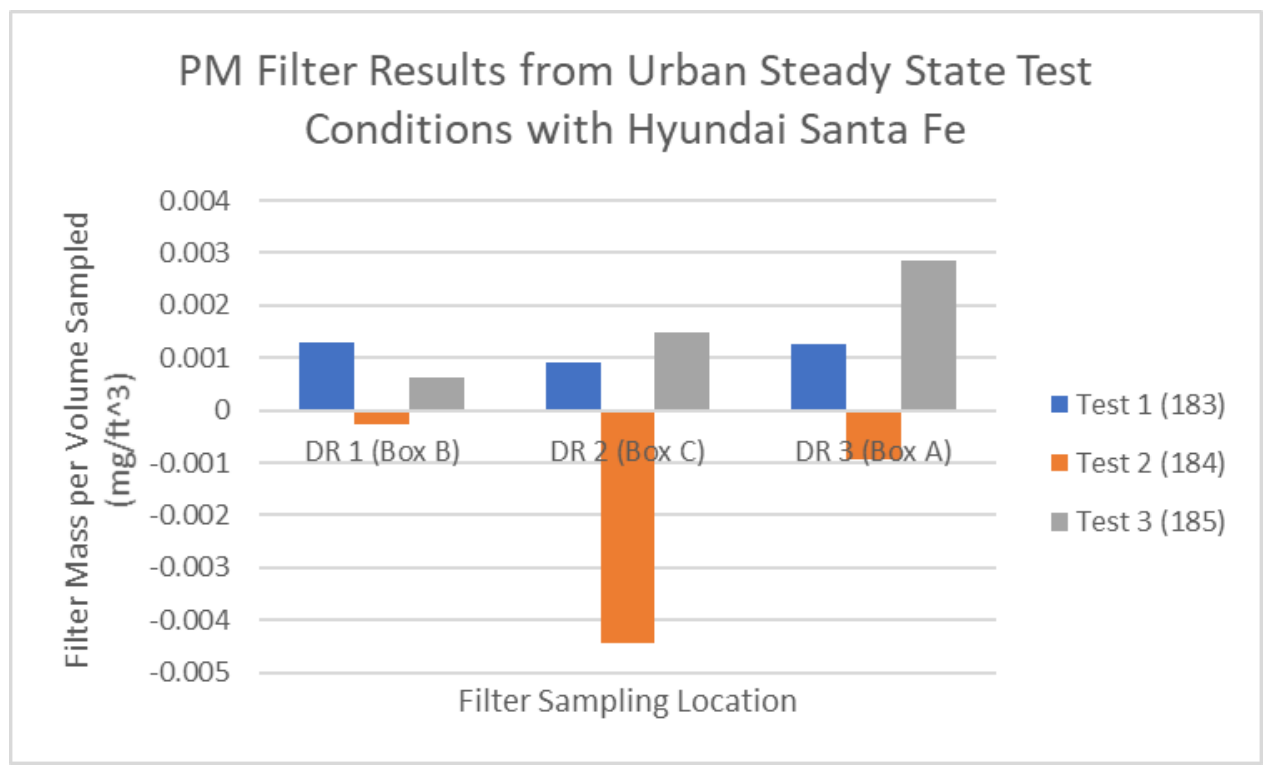

Figure 60: Gravimetric Mass results from Urban Conditions with the Hyundai.

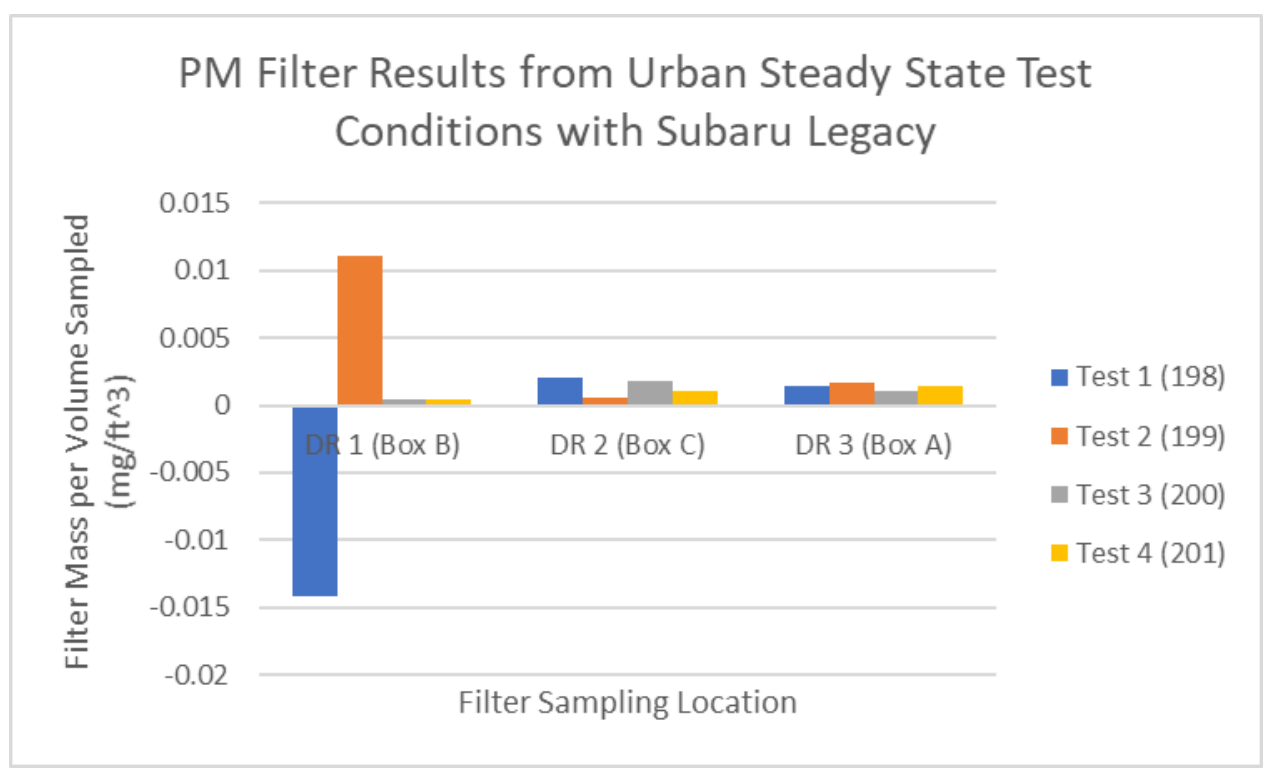

Figure 61: Gravimetric Mass results from Urban Conditions with the Subaru. 


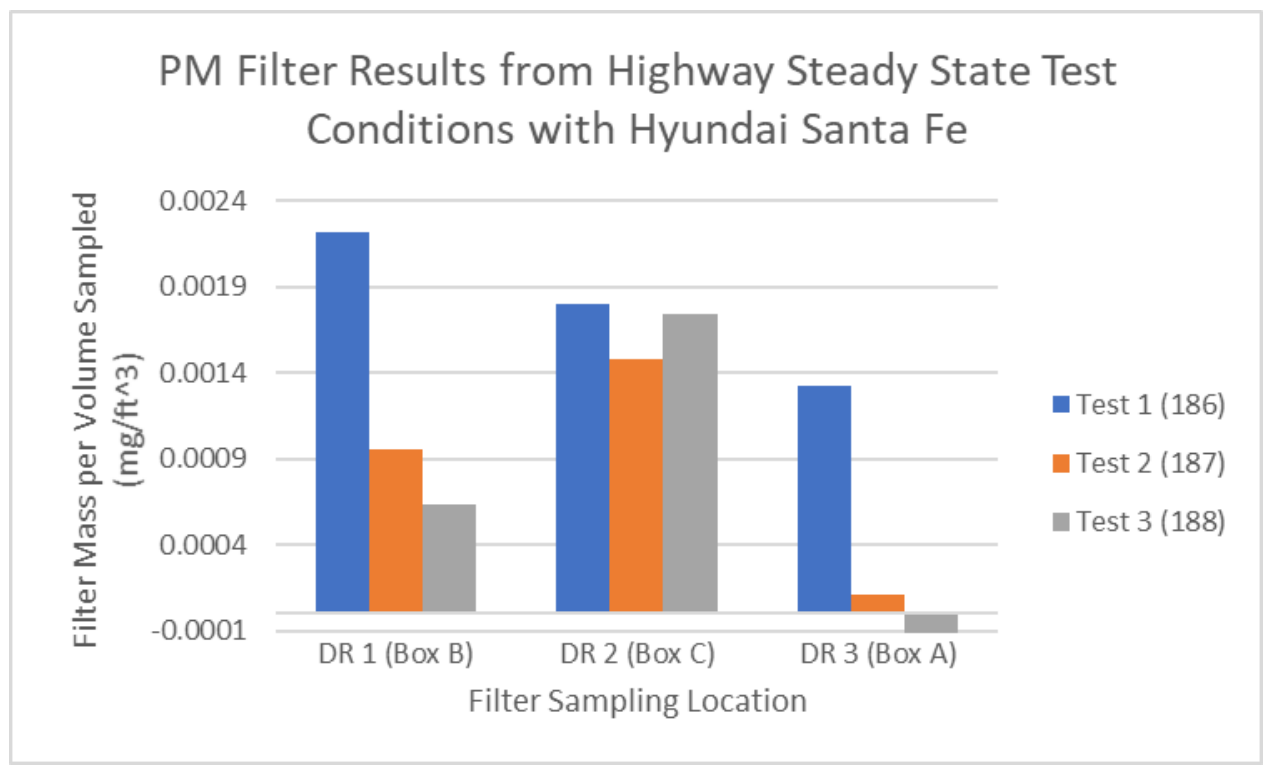

Figure 62: Gravimetric Mass results from Highway Conditions with the Hyundai.

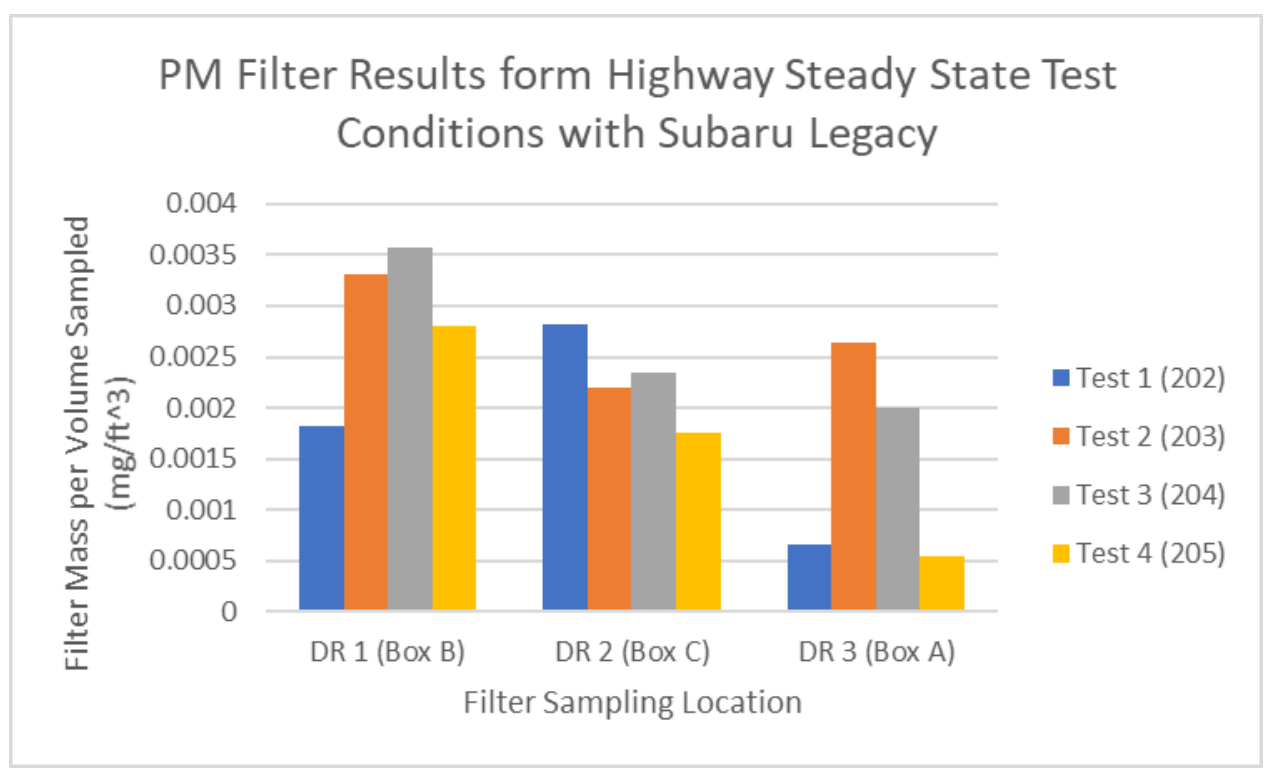

Figure 63: Gravimetric Mass results from Highway Conditions with the Subaru. 


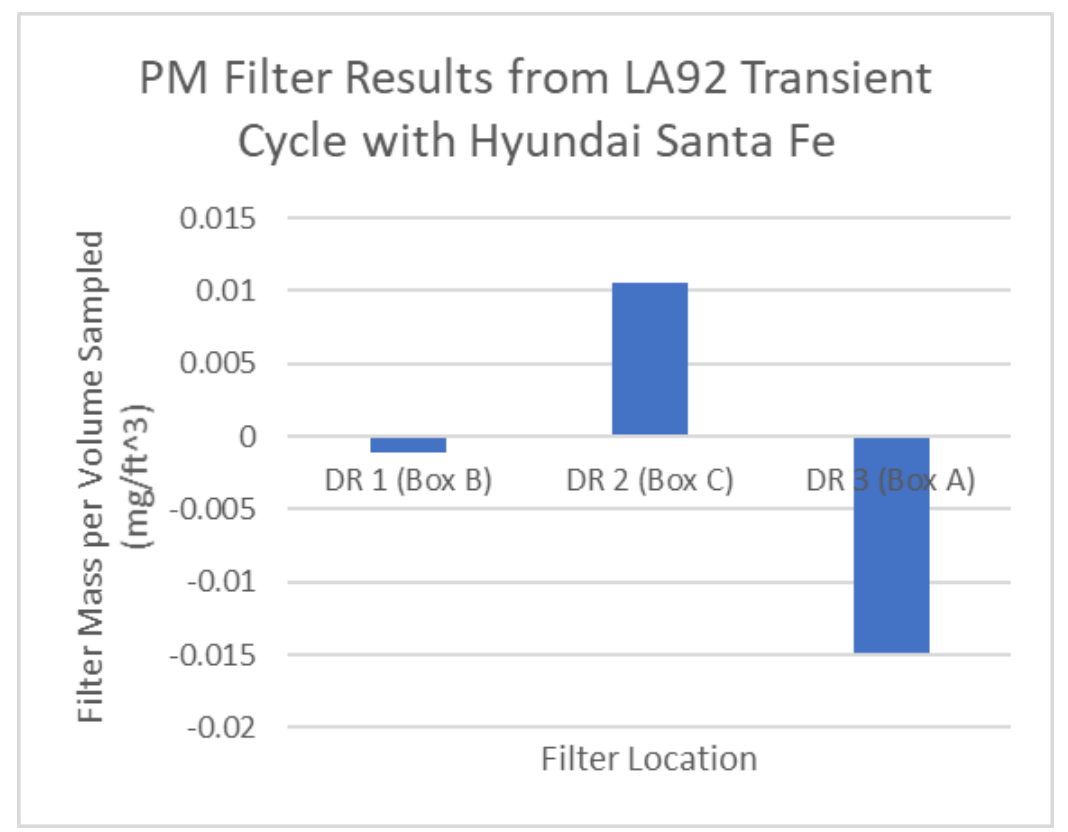

Figure 64: Gravimetric Mass results from LA92 drive cycle with the Hyundai.

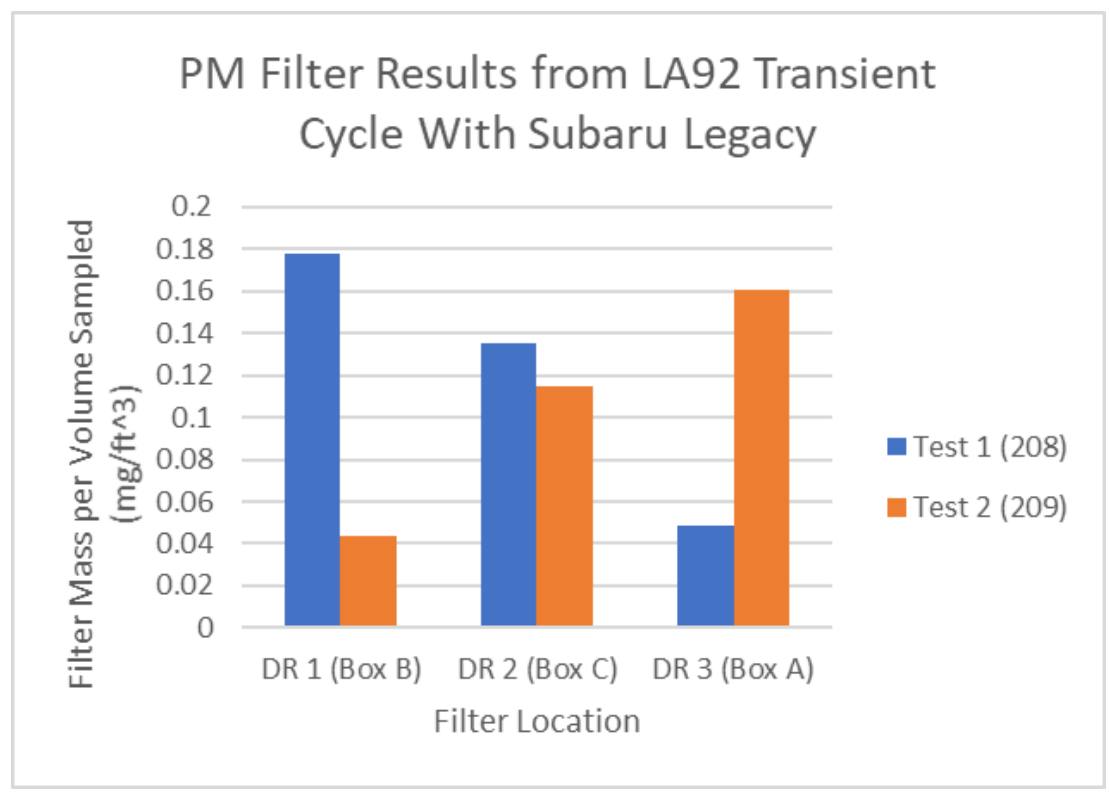

Figure 65: Gravimetric Mass results from LA92 drive cycle with the Subaru. 


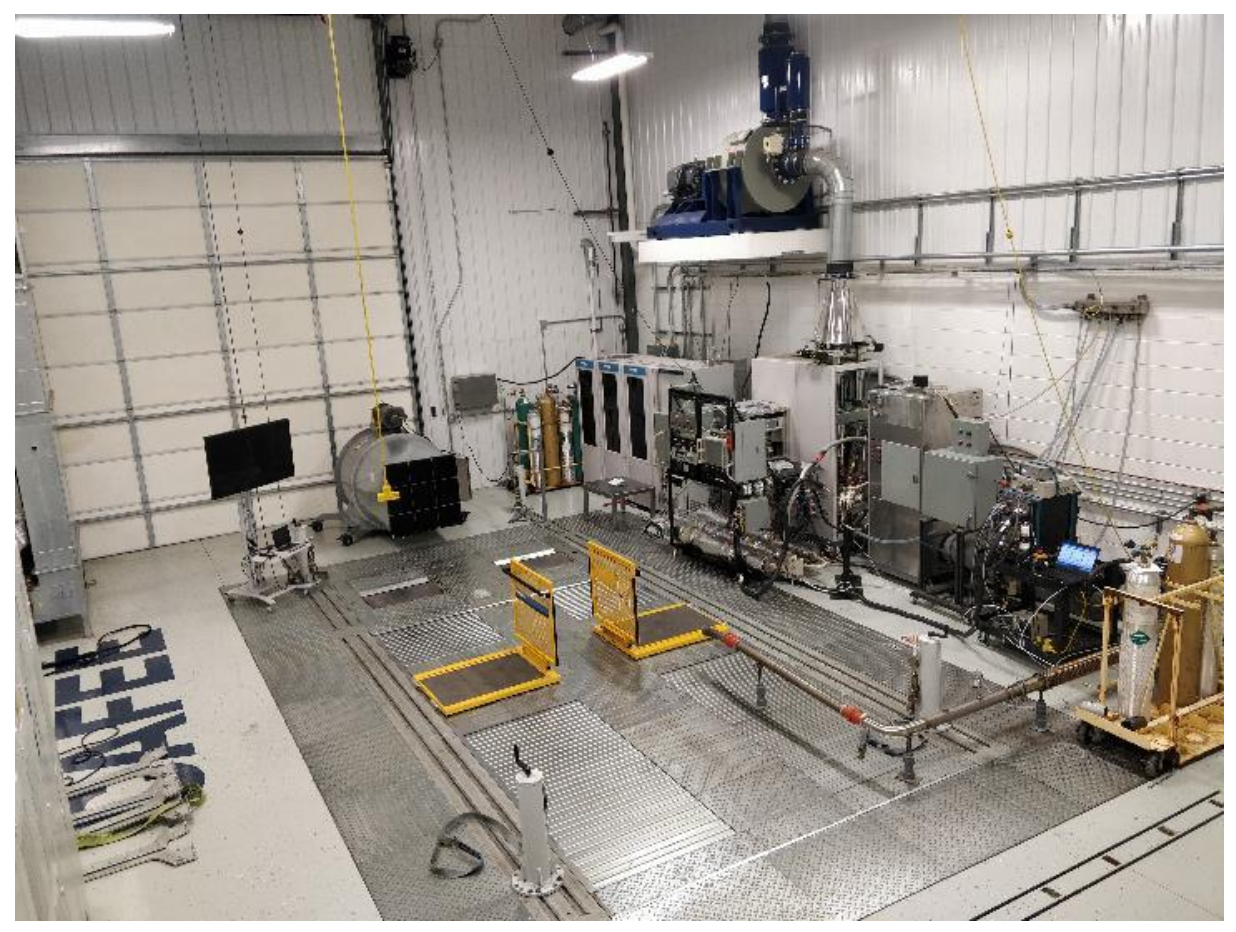

Figure 66: Aerial View Empty Test Cell with Multi-Dilution Setup Installed.

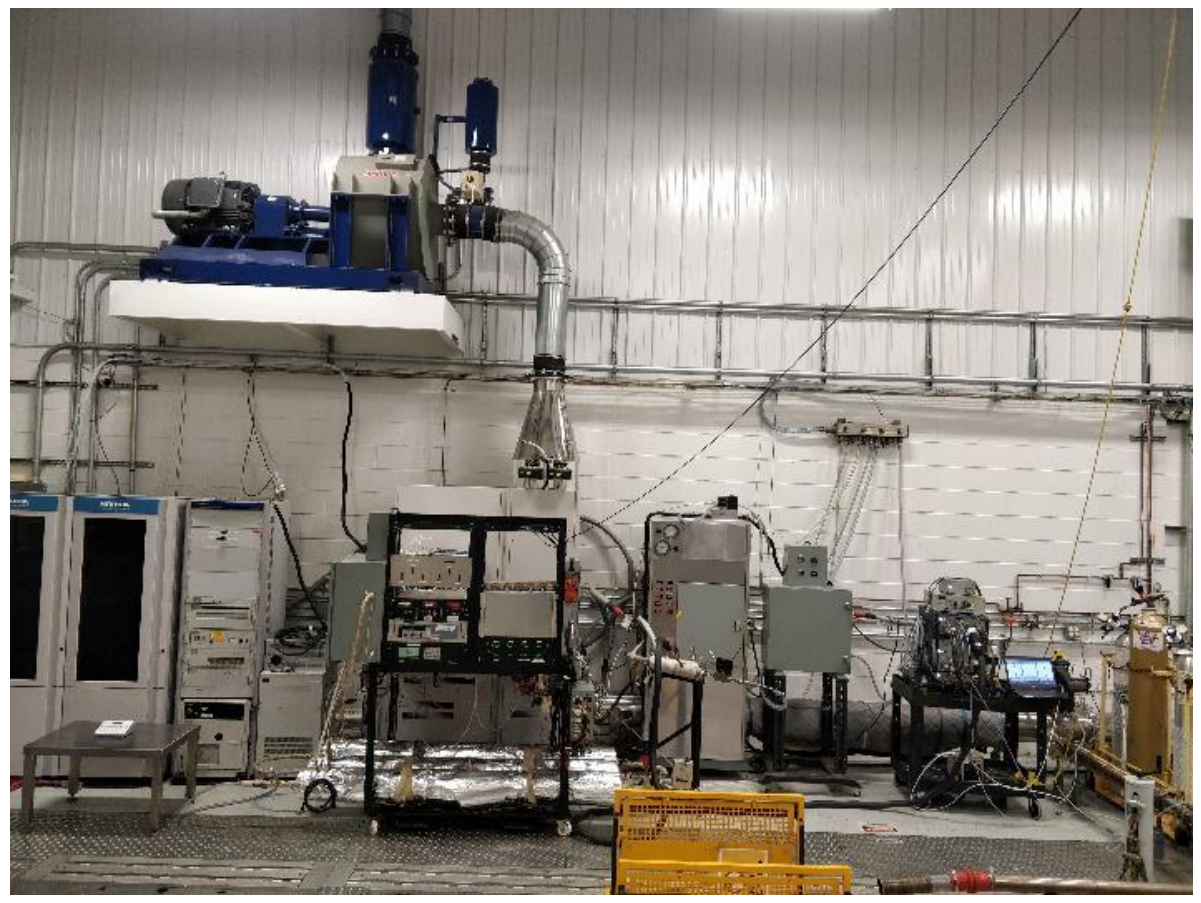

Figure 67: Side View Empty Test Cell with Multi-Dilution Setup Installed \#1. 


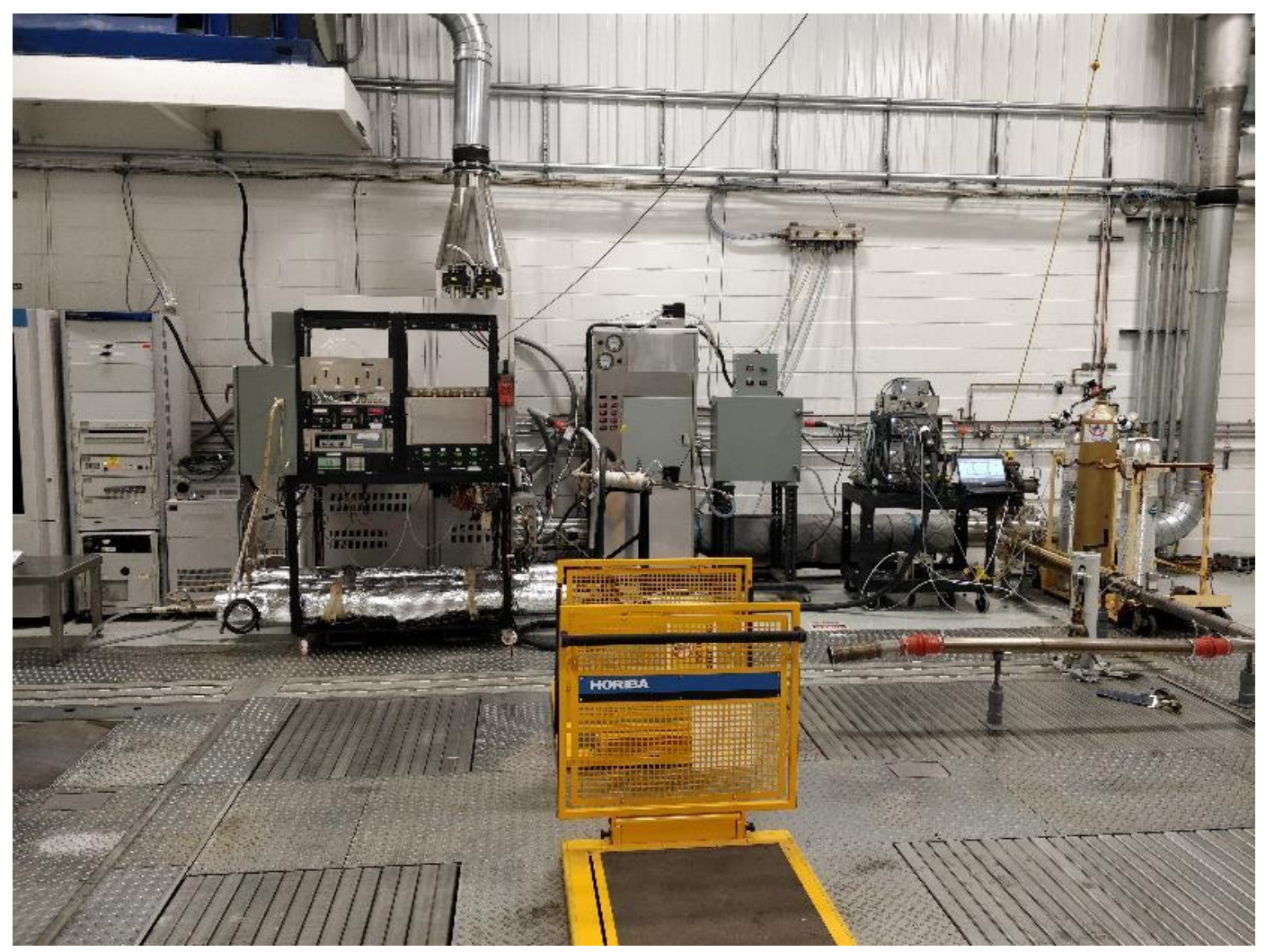

Figure 68: Side View Empty Test Cell with Multi-Dilution Setup Installed \#2.

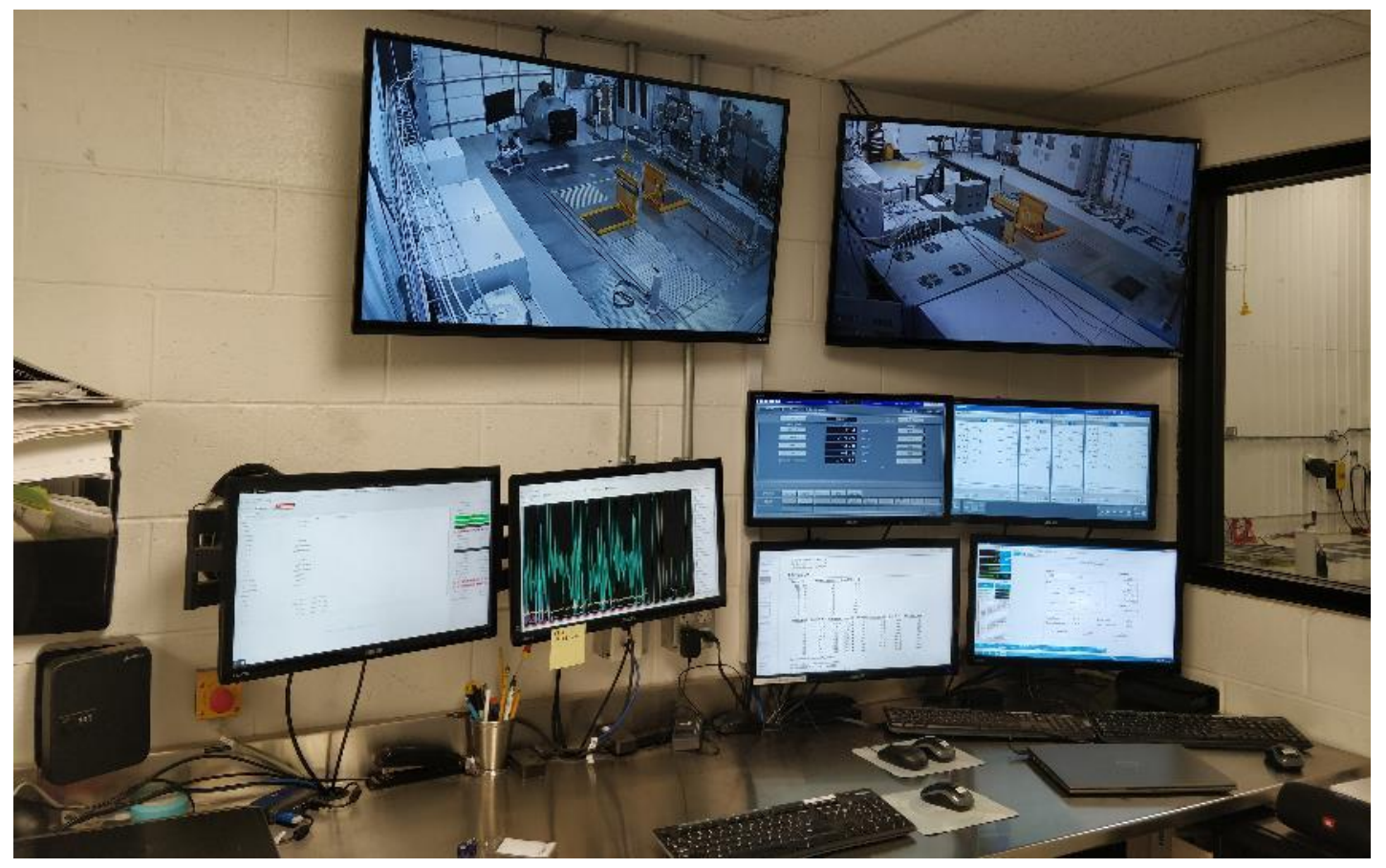

Figure 69: Overview of Control Room for Test Cell. 


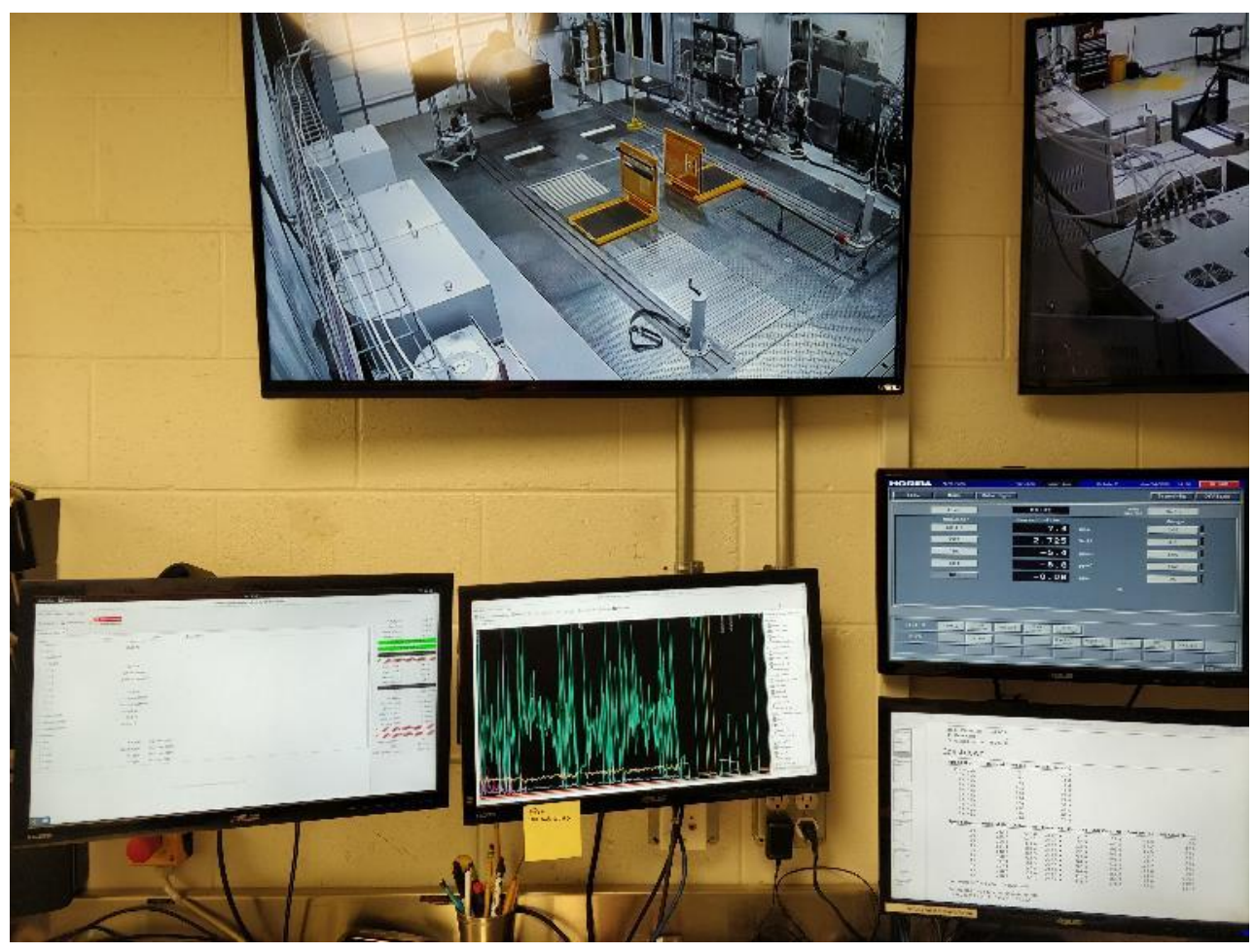

Figure 70: Zoomed Left View of Control Room for Test Cell.

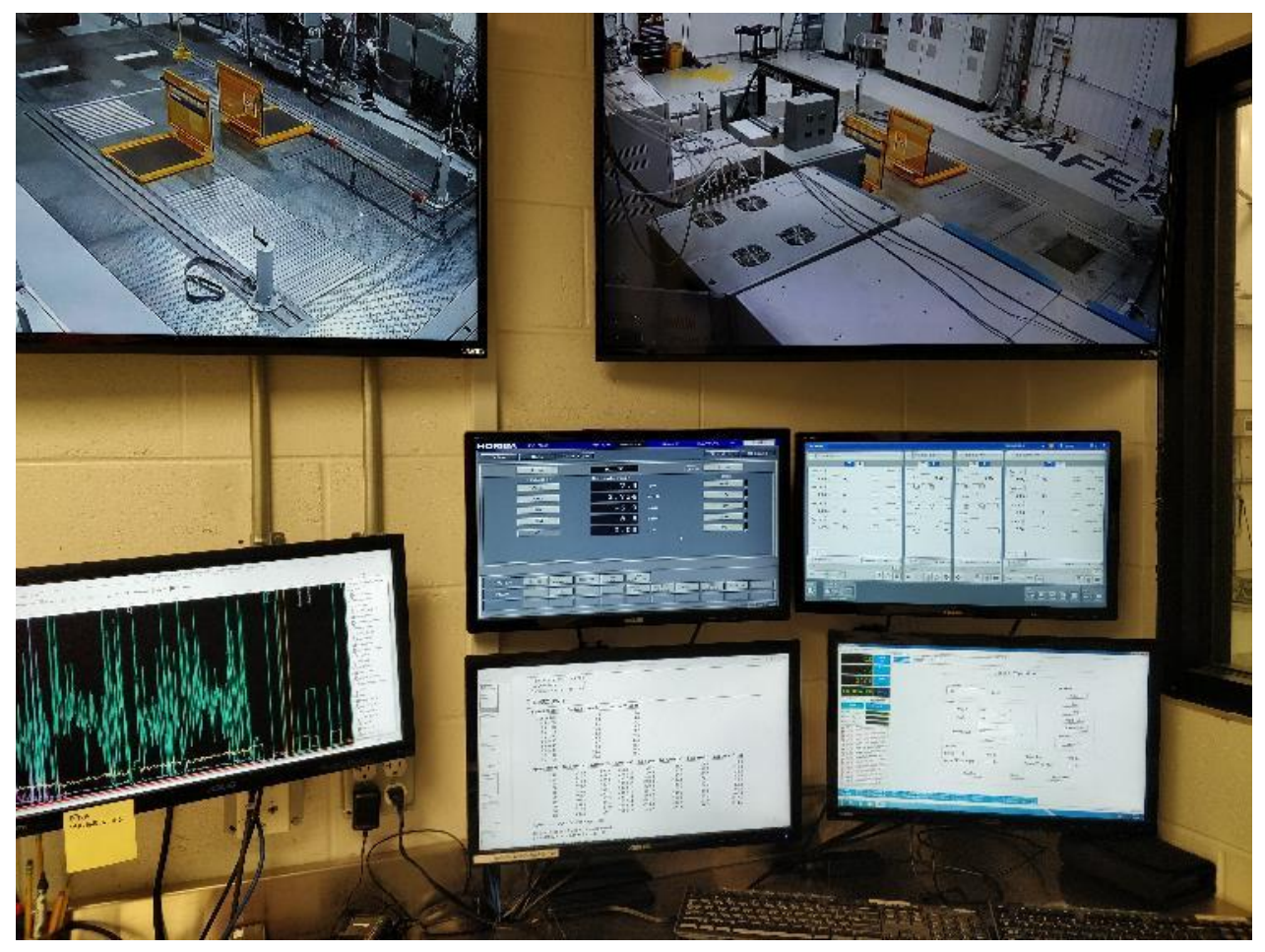

Figure 71: Zoomed Right View of Control Room for Test Cell. 


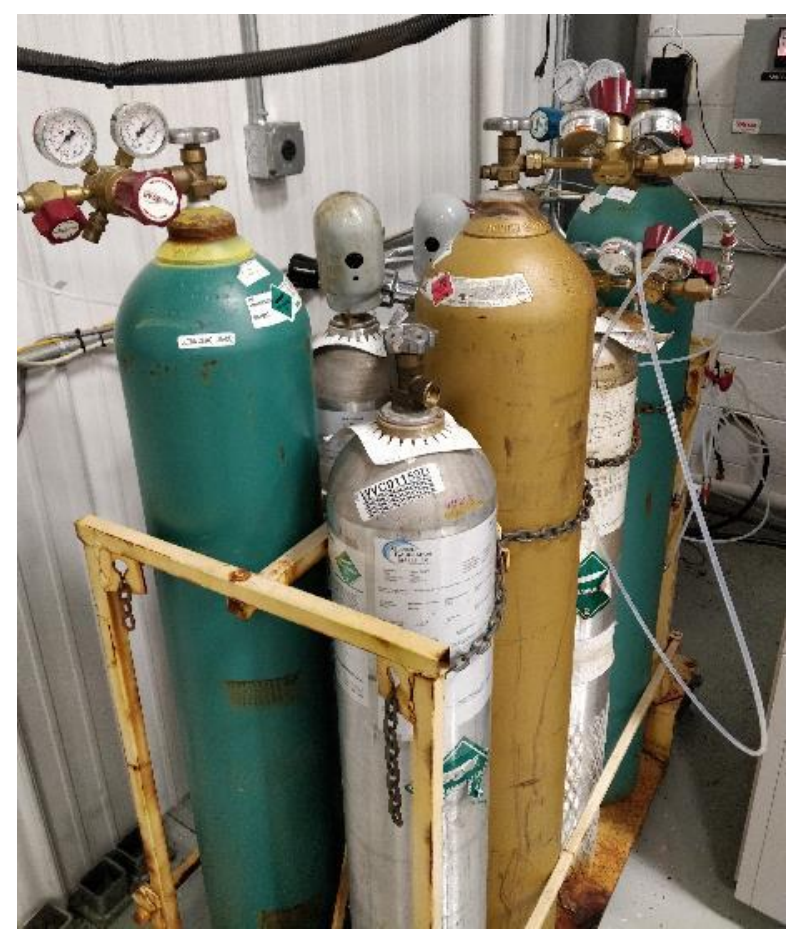

Figure 72: Gas Bottle Rack Containing Span Gases for Analyzers on Test Stand.

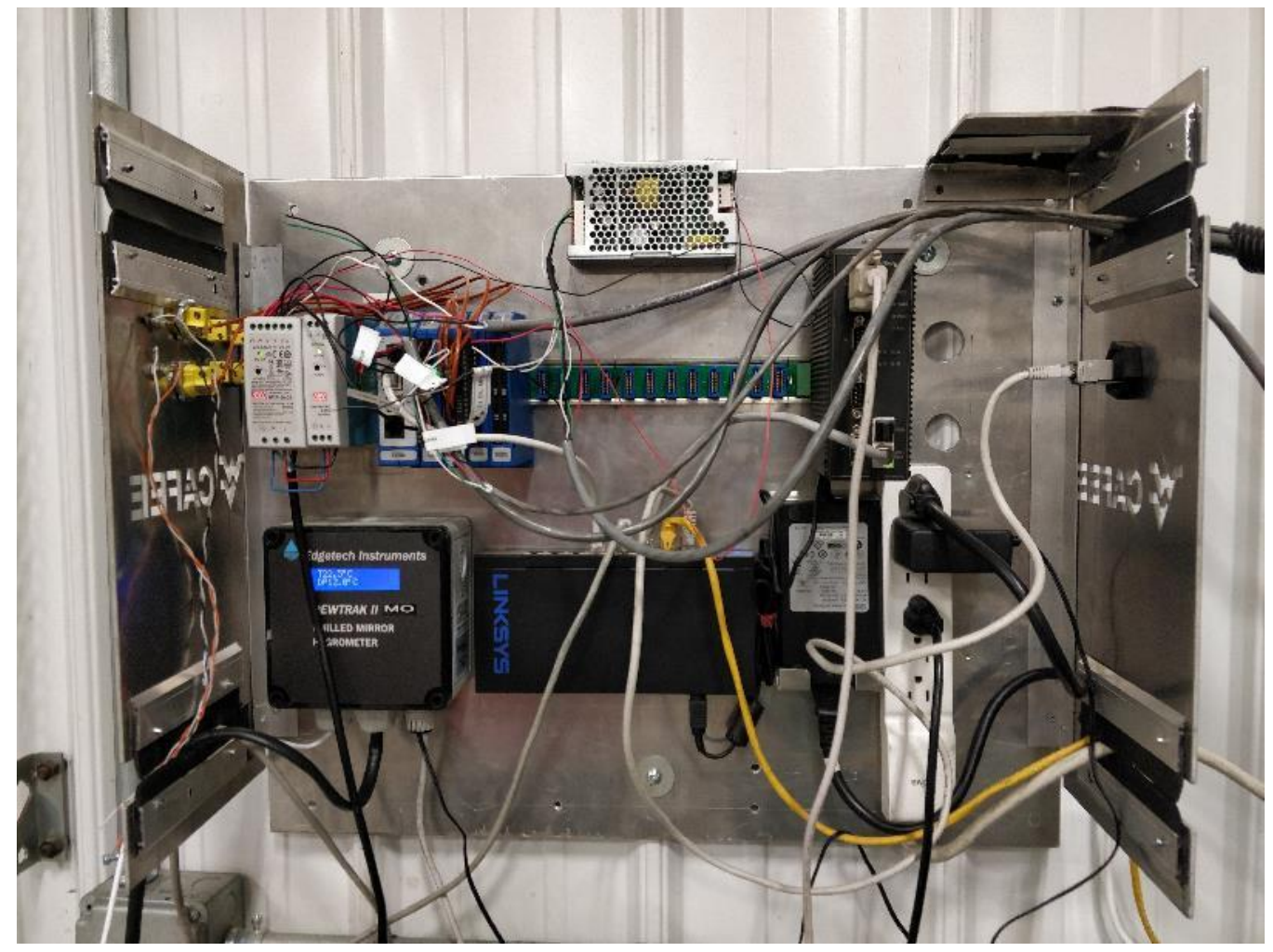

Figure 73: Uncovered View of Wall-Mounted DAQ Box with Test Cell Edgetech Humidity Sensor. 


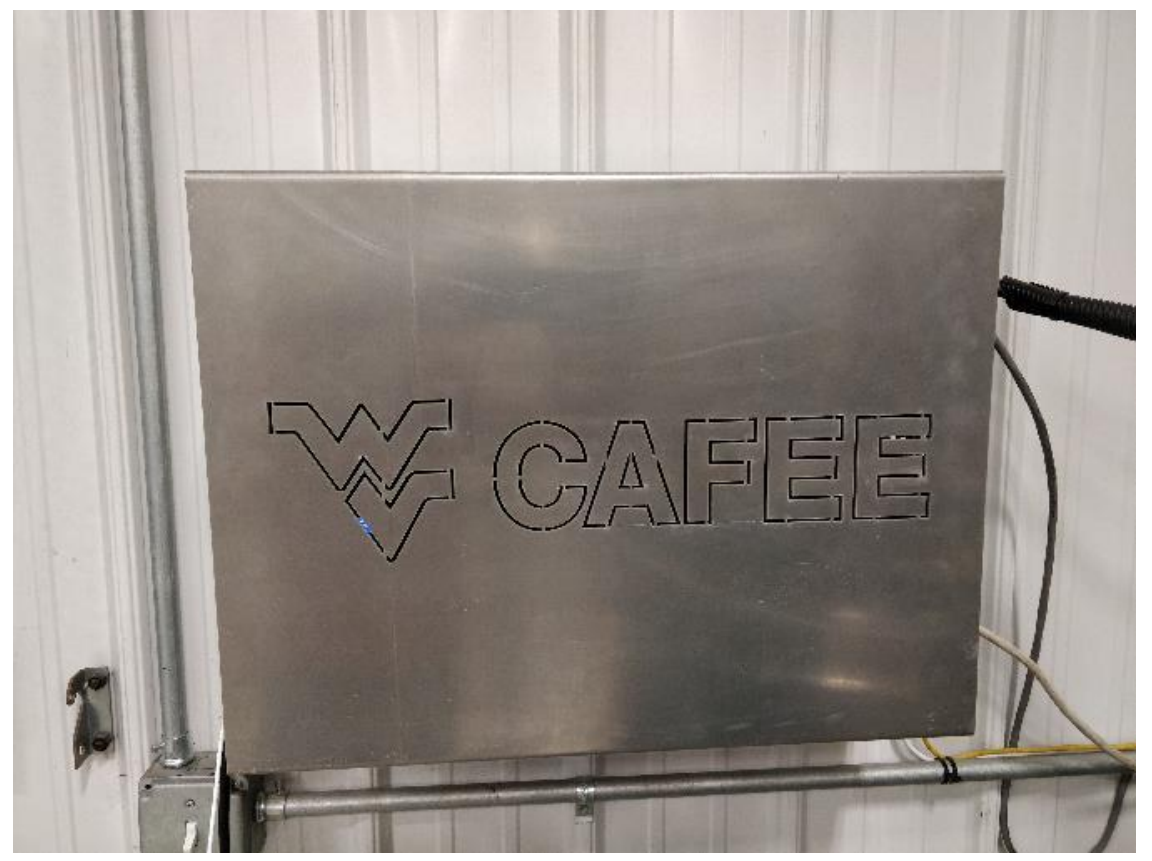

Figure 74: Covered View of Wall-Mounted DAQ Box with Test Cell Edgetech Humidity Sensor.

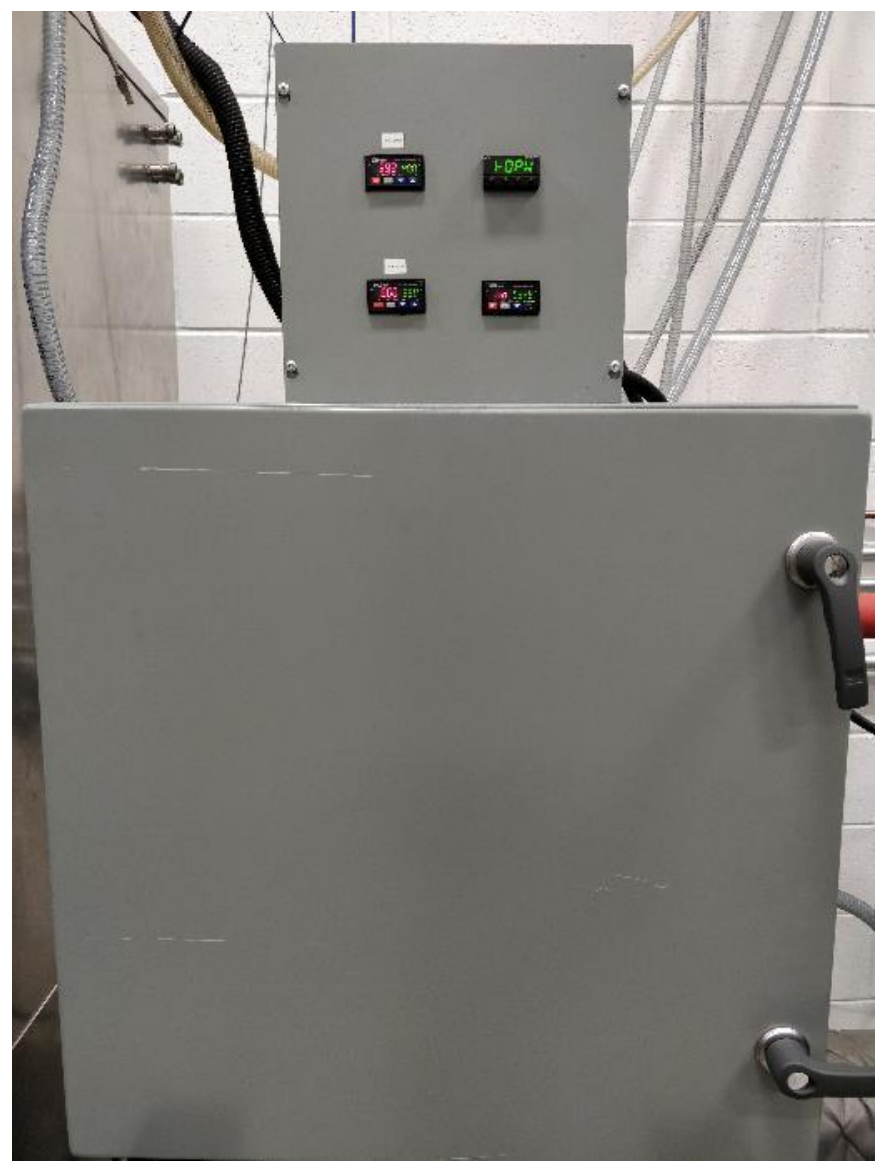

Figure 75: Box B PM Box with door shut. 


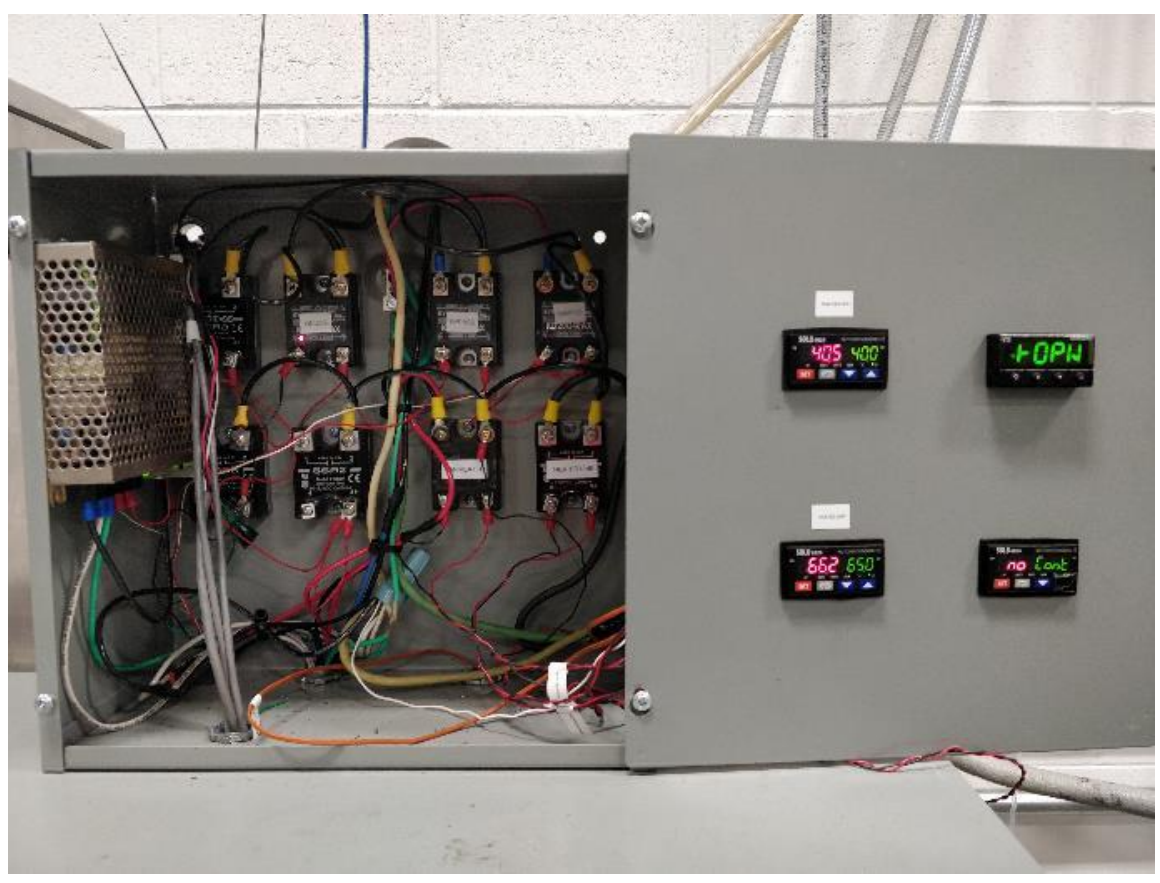

Figure 76: Wiring of the Temperature Controllers for PM Box B.

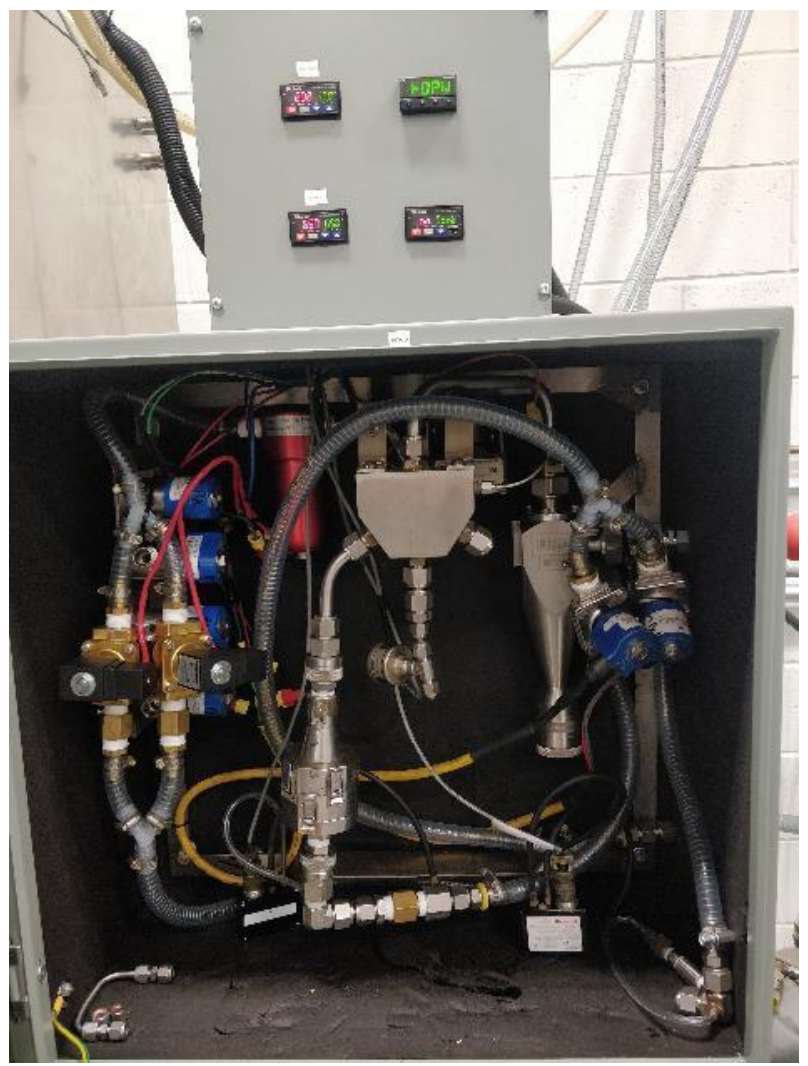

Figure 77: Box B PM Box with door open. 


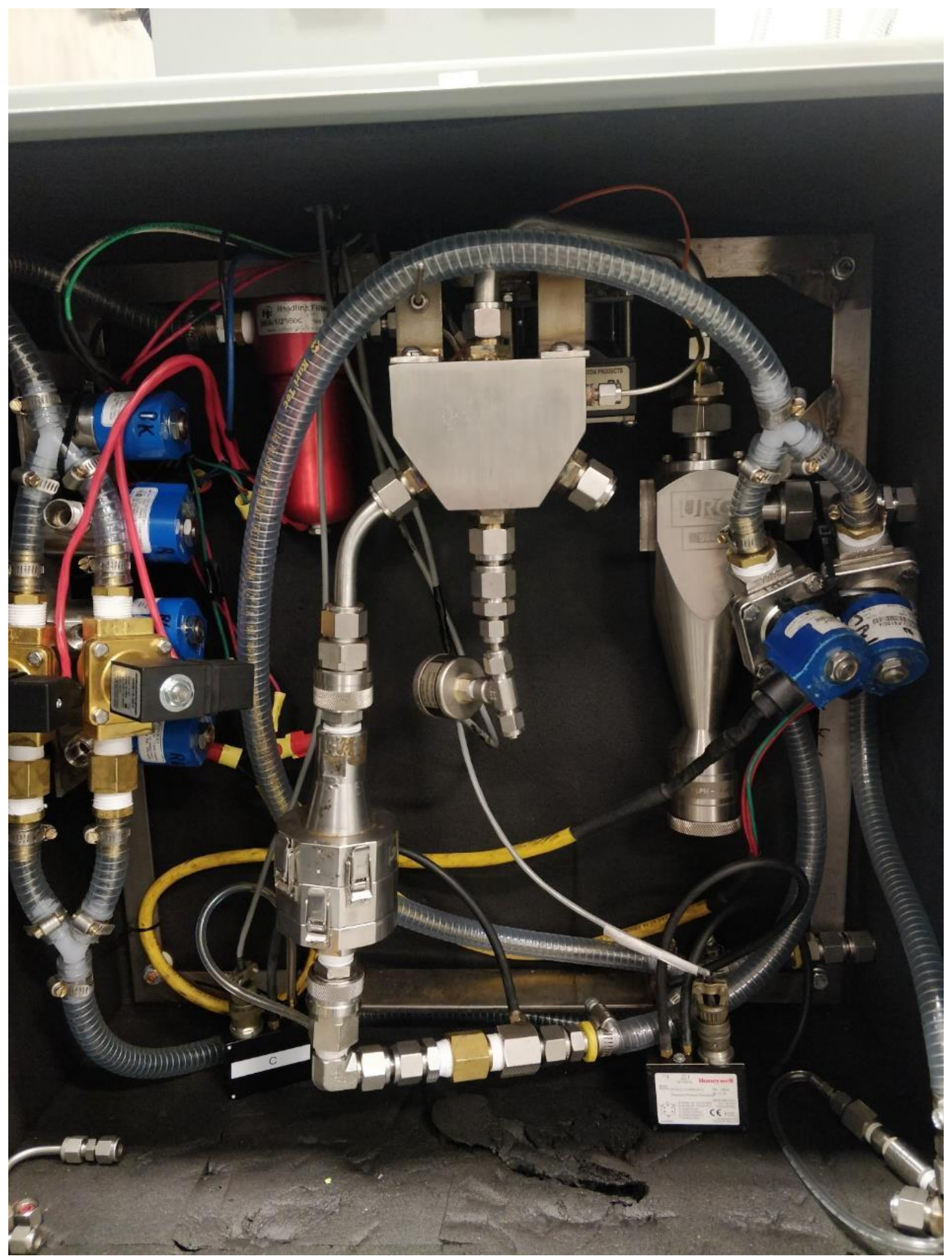

Figure 78: Zoomed in View of the Internals of PM Box B. 


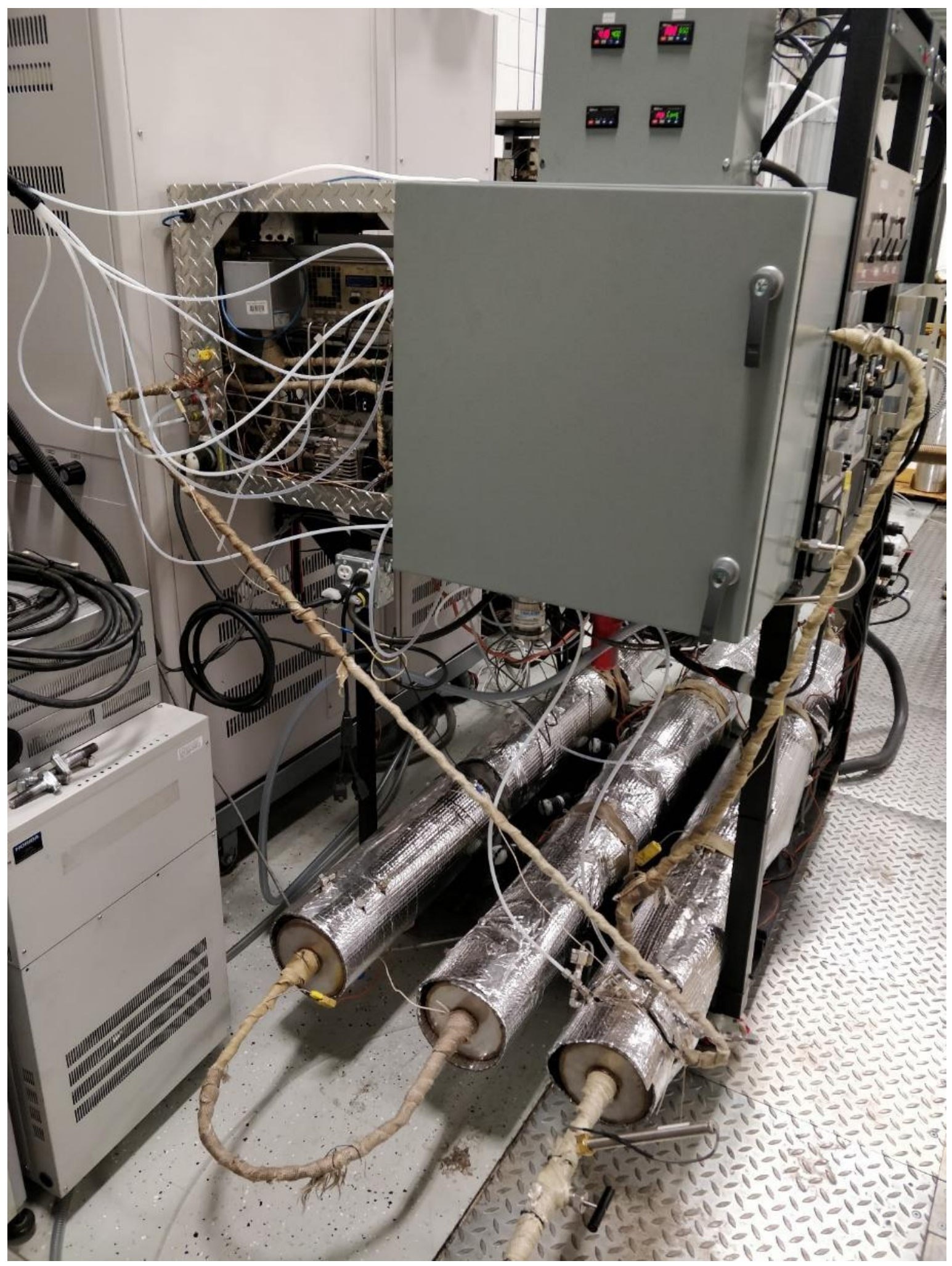

Figure 79: Side View of the Third Dilution Tunnel, DR 3 Analyzer Rack Test Stand, and PM Box A. 


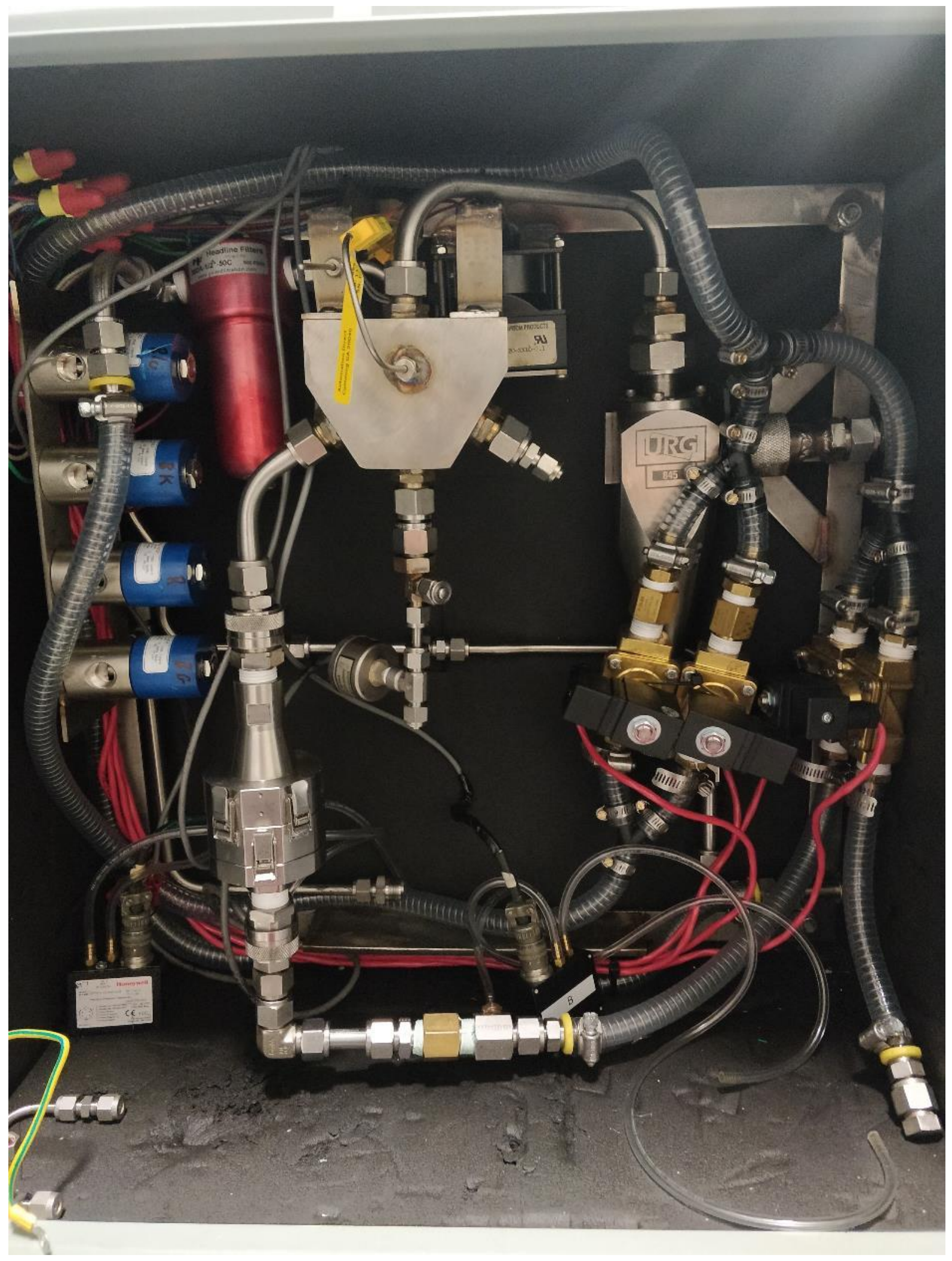

Figure 80: Zoomed in View of the Internals of PM Box A. 


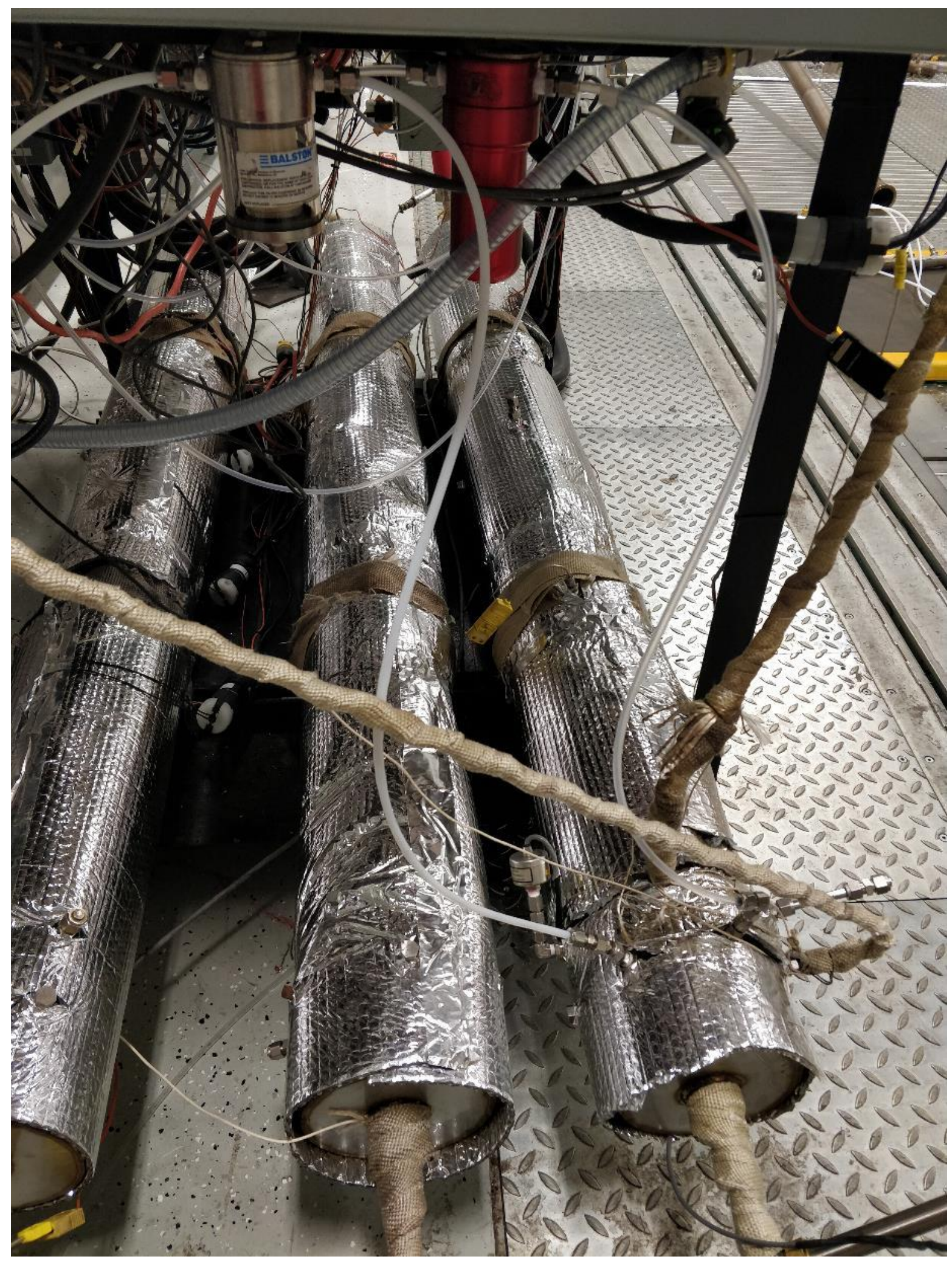

Figure 81: Closer of the DR 3 Dilution Tunnel (most right tunnel). 


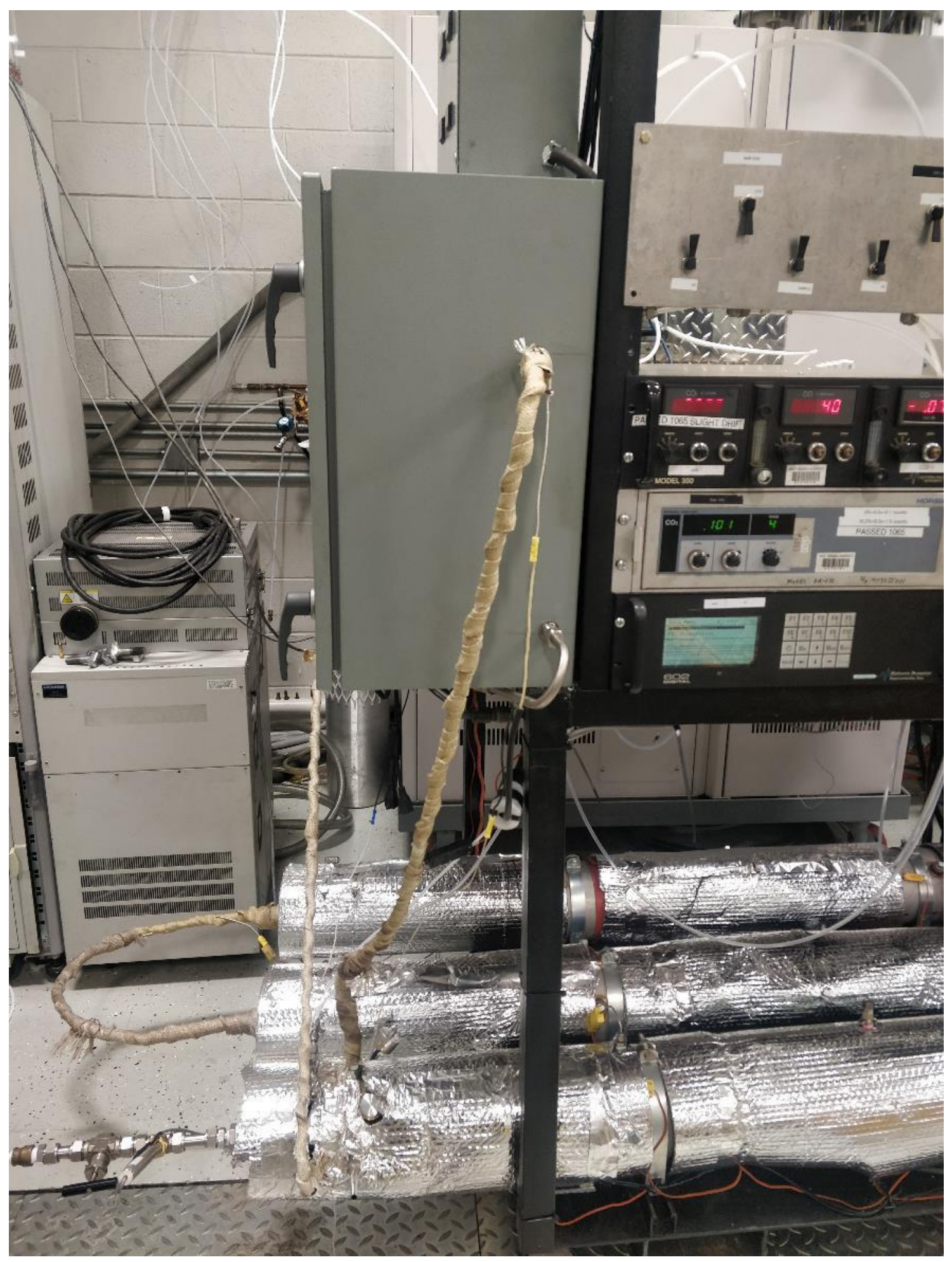

Figure 82: Zoomed Front Left View of the Analyzer Rack Test Stand. 


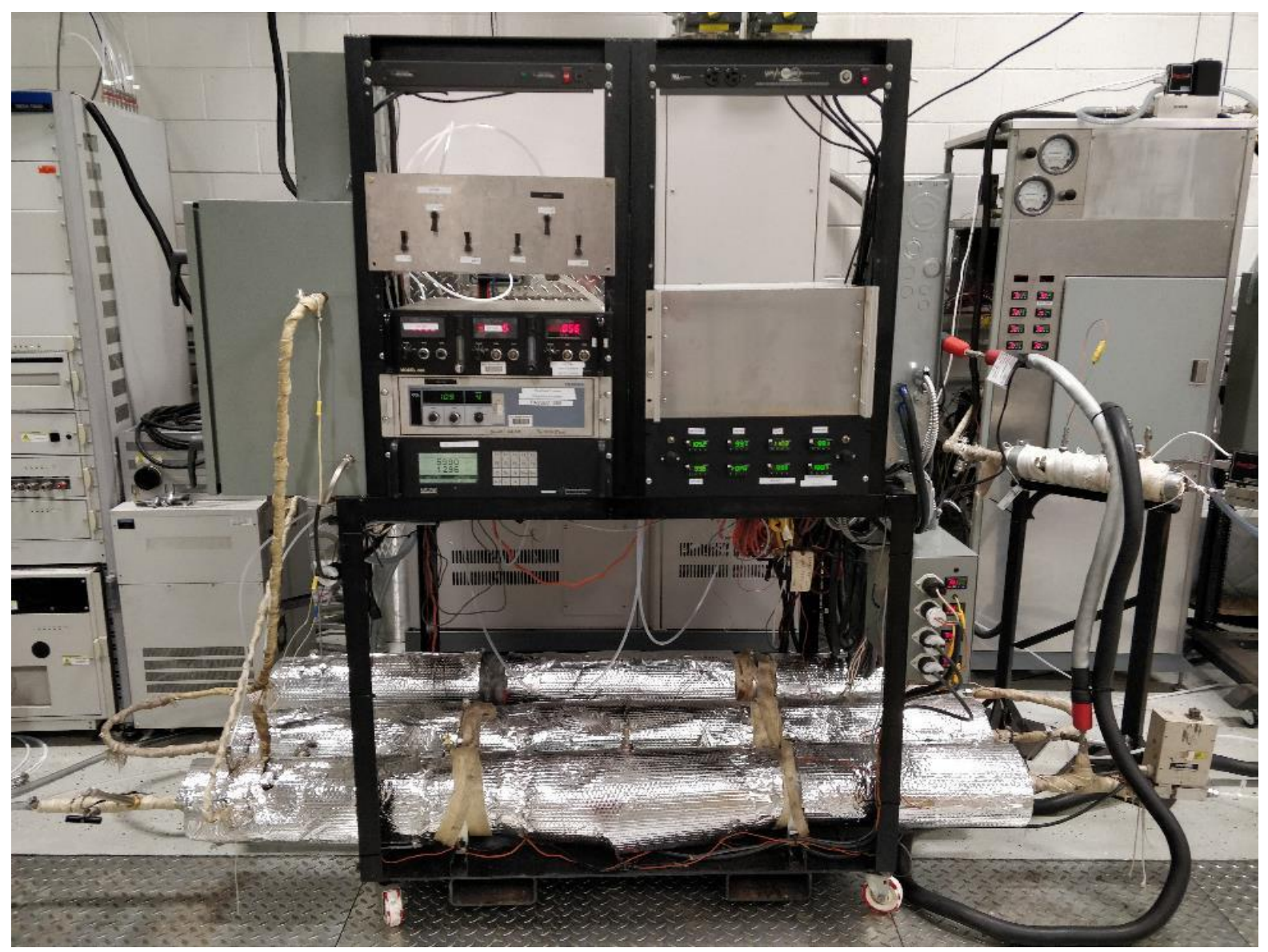

Figure 83: Front View of the Analyzer Rack Test Stand.

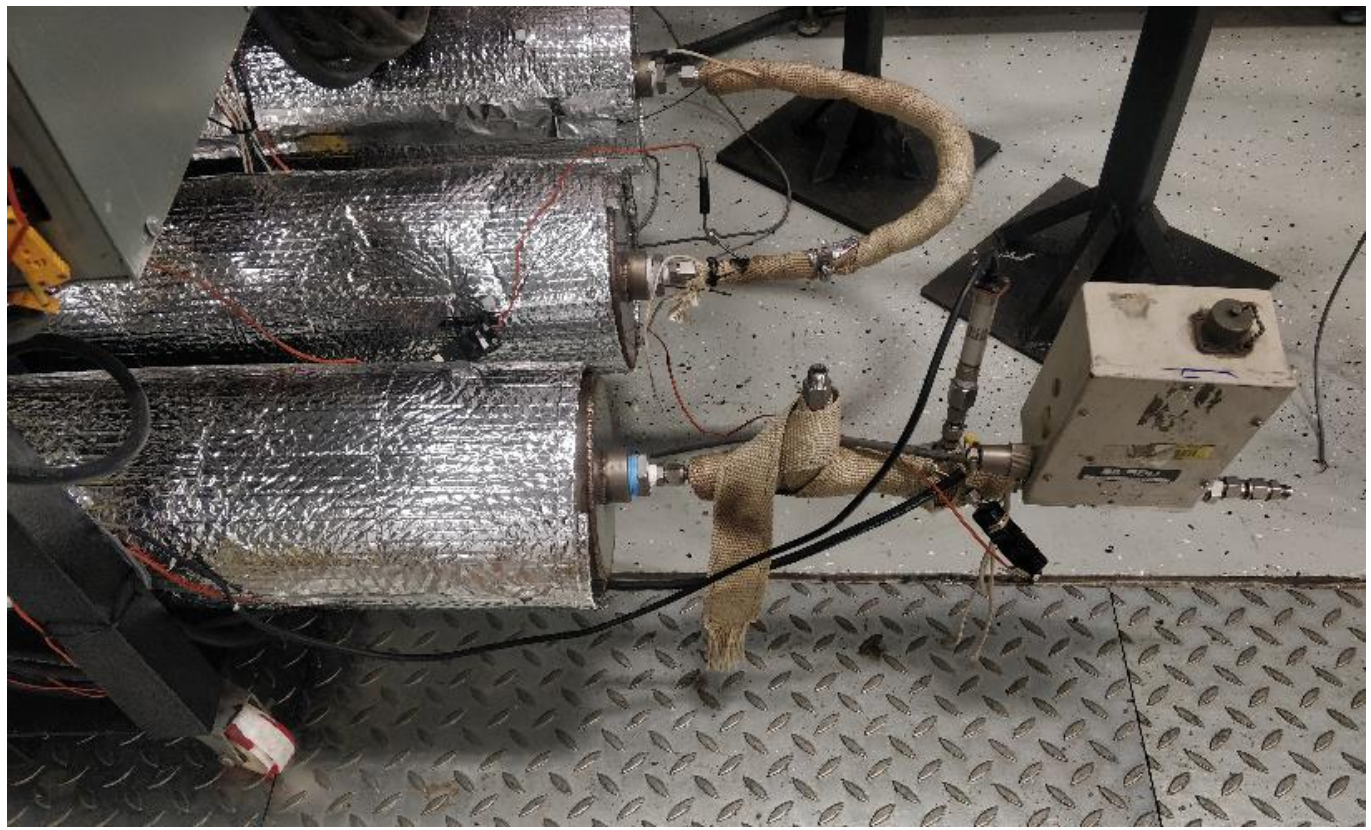

Figure 84: Zoomed View of the DR 3 Ejector Dilutor and Mass Flow Controller. 


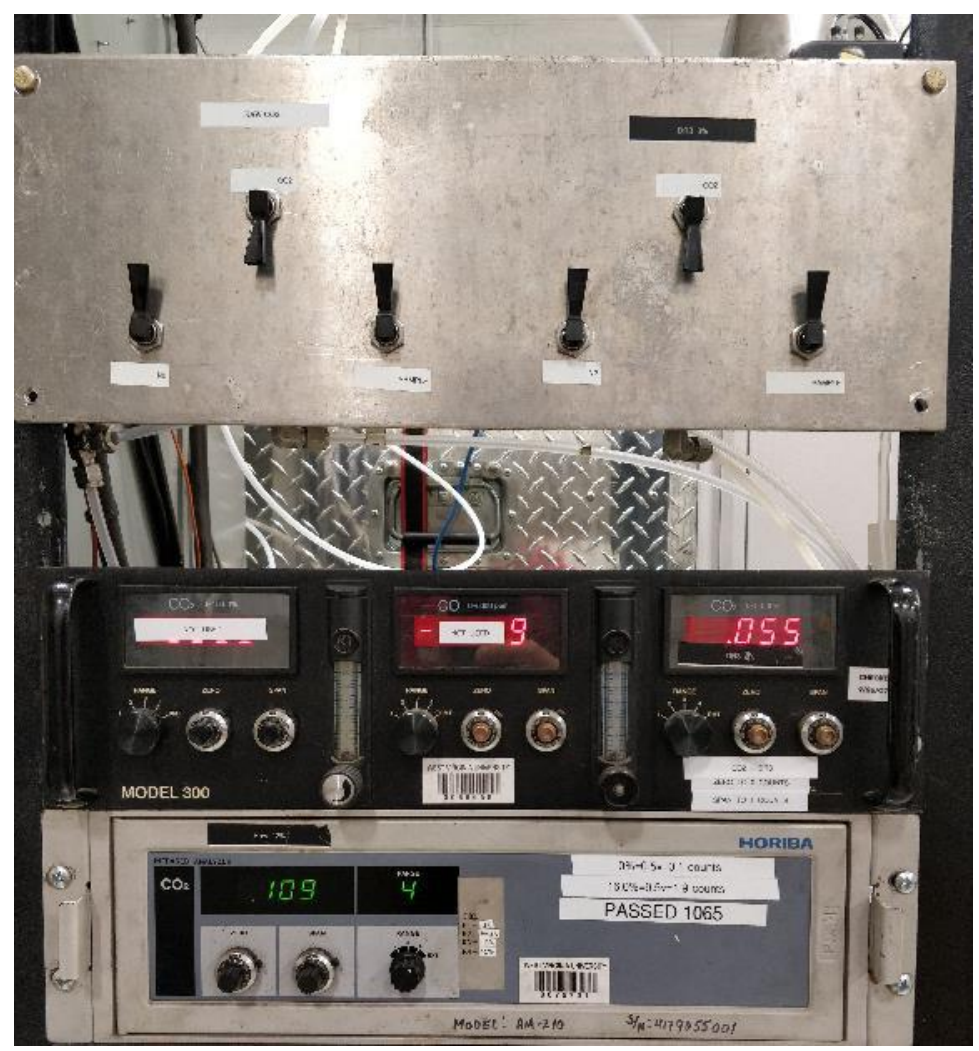

Figure 85: DR 3 and Raw $\mathrm{CO}_{2}$ Analyzers with the Switchboard to Zero/Span/Sample Above.

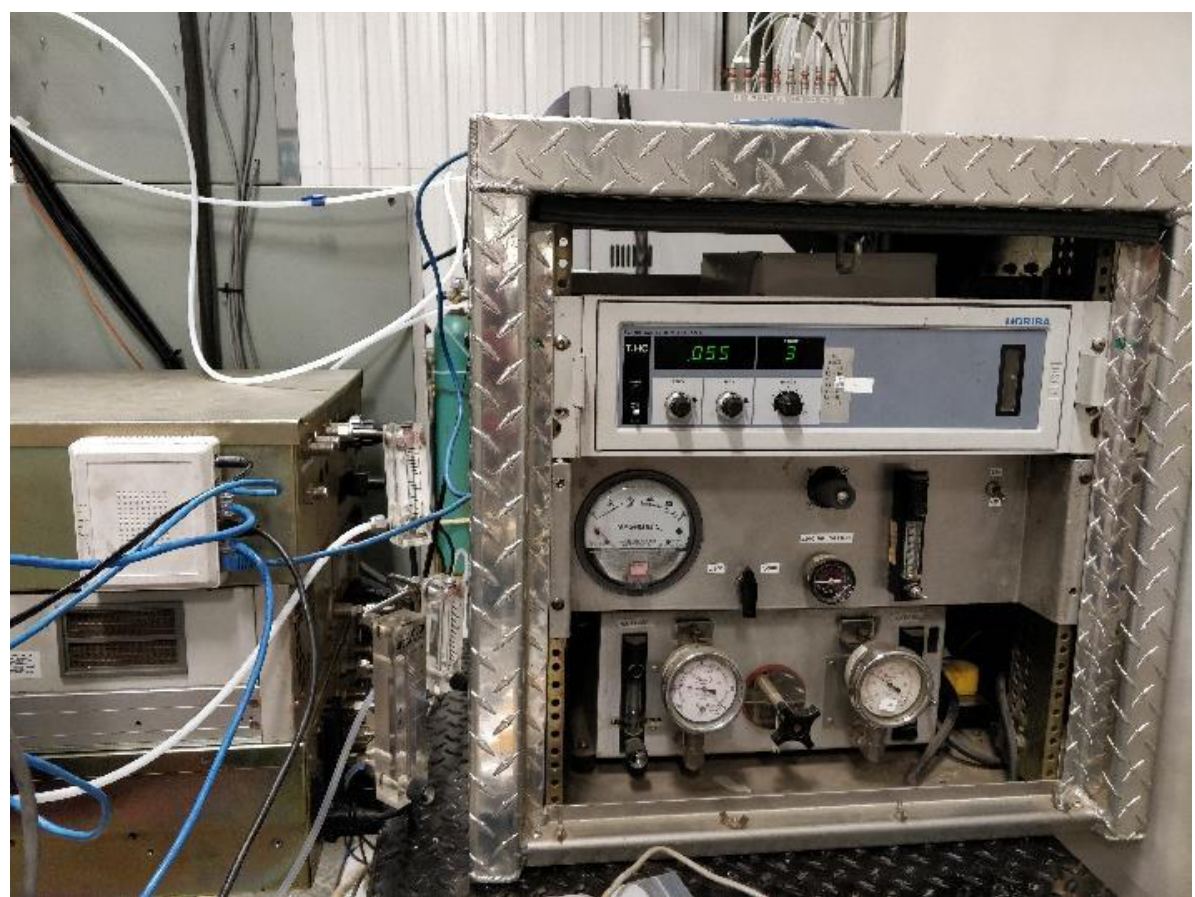

Figure 86: FID Analyzer used to perform Propane Injections for DR 3 Dilution Confirmation. 


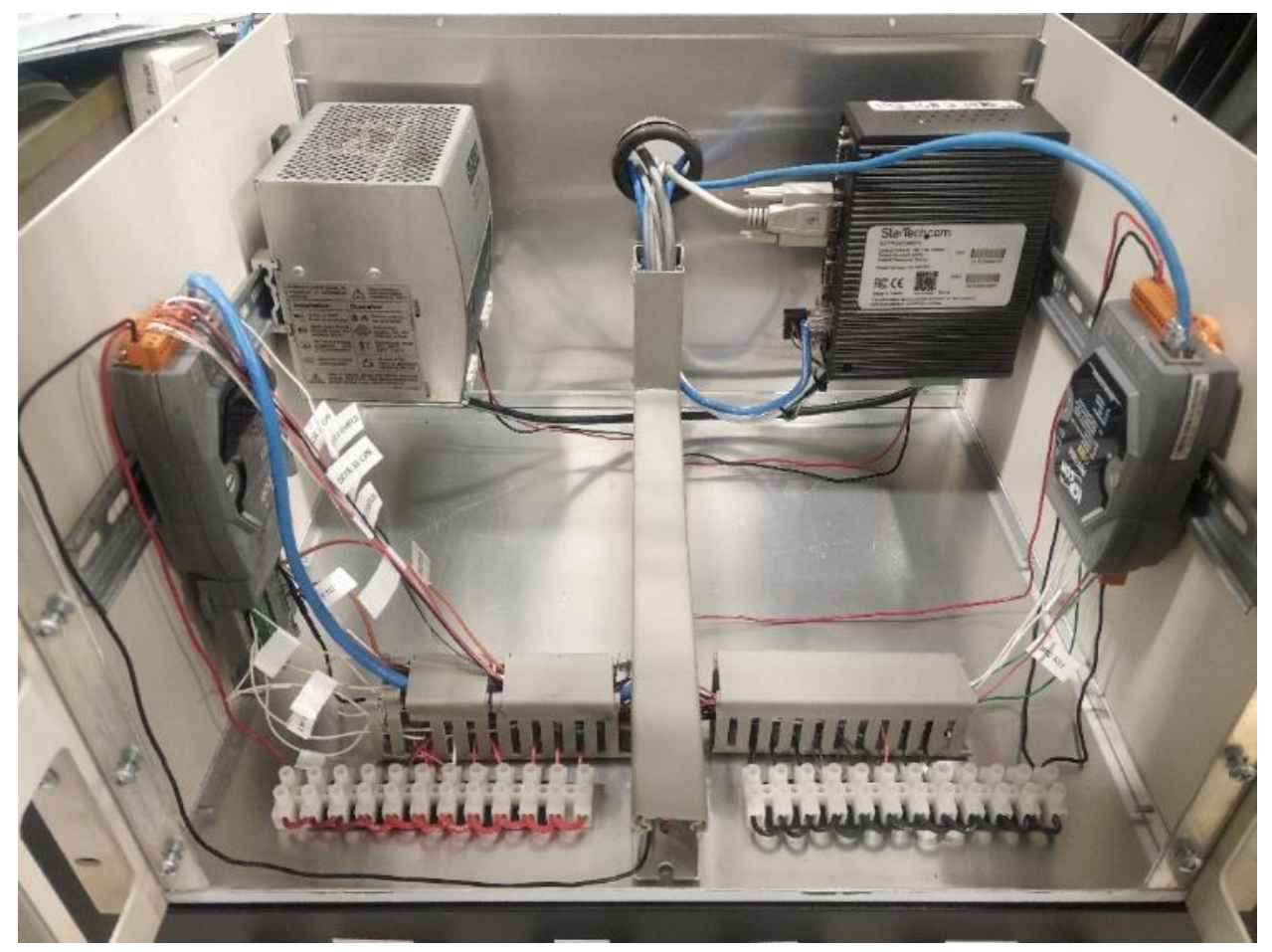

Figure 87: Isotropic View without Cover of the DAQ Box mounted on the Analyzer Rack Test Stand.

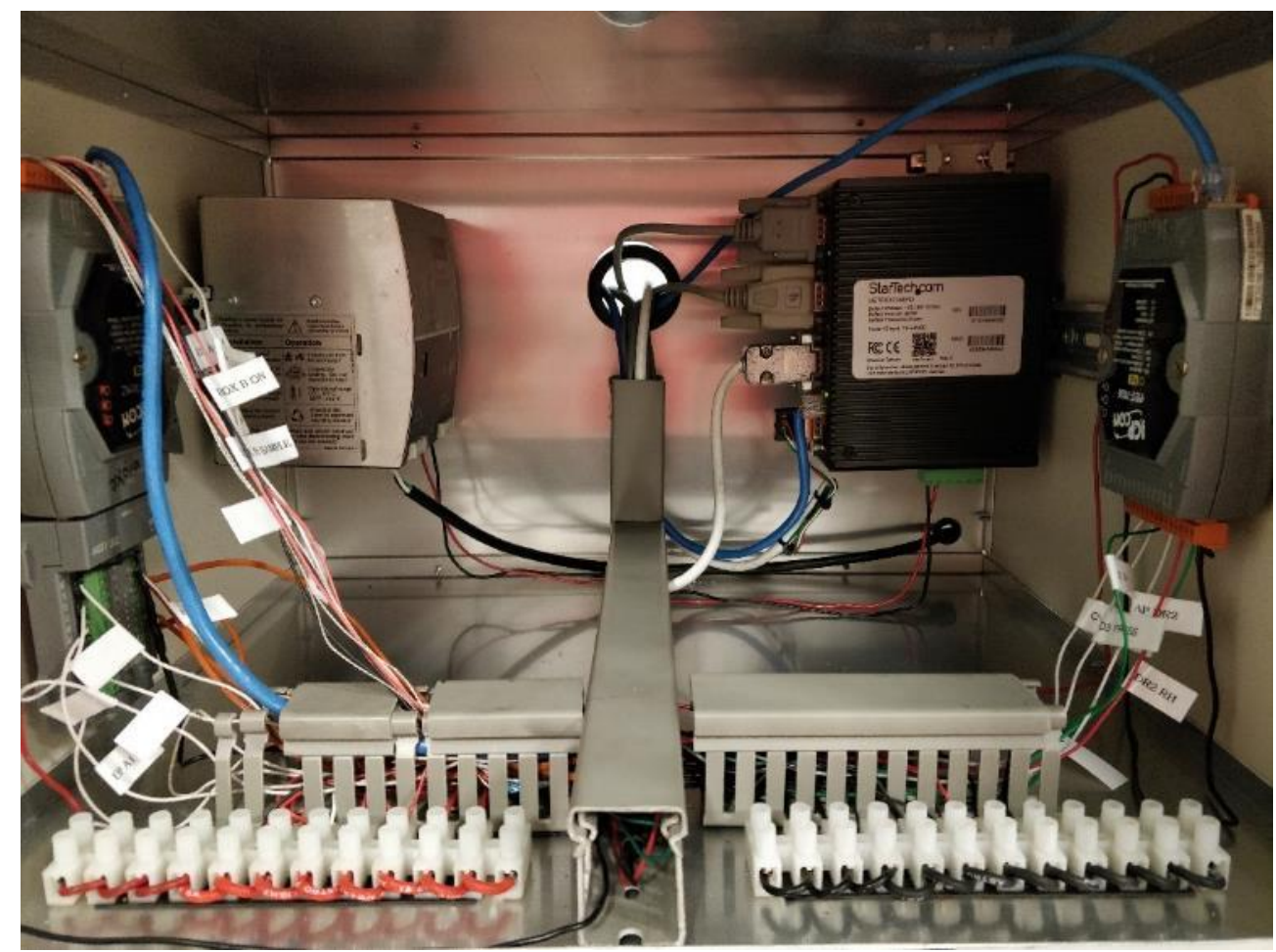

Figure 88: Front View with Cover of the DAQ Box mounted on the Analyzer Rack Test Stand. 


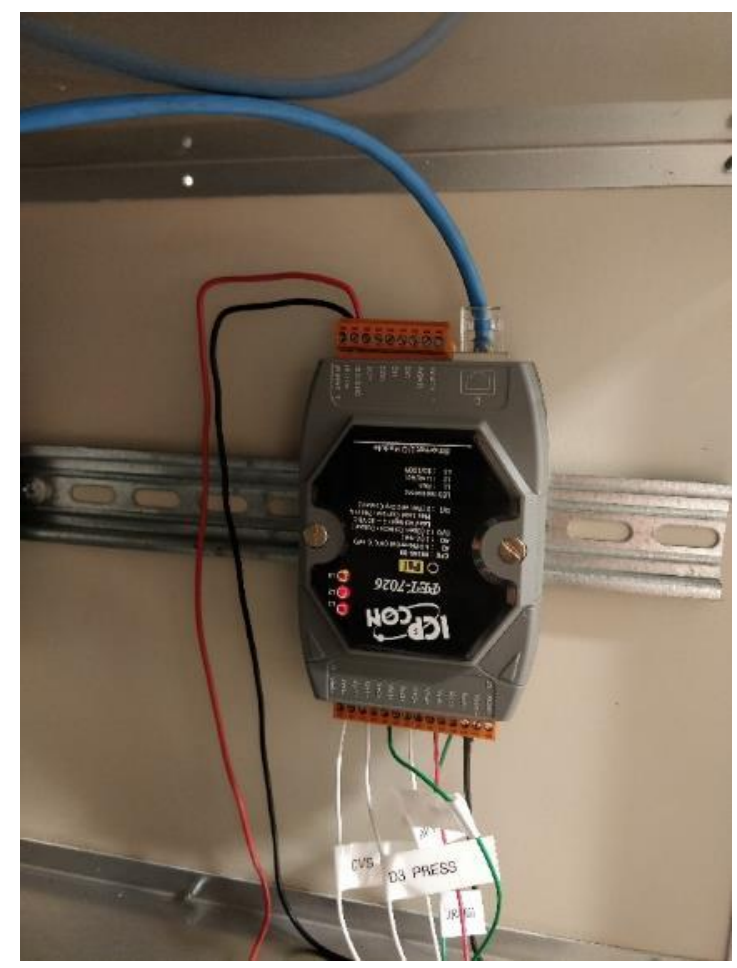

Figure 89: ICP-CON \#2 in DAQ Box mounted on Analyzer Rack Test Stand.

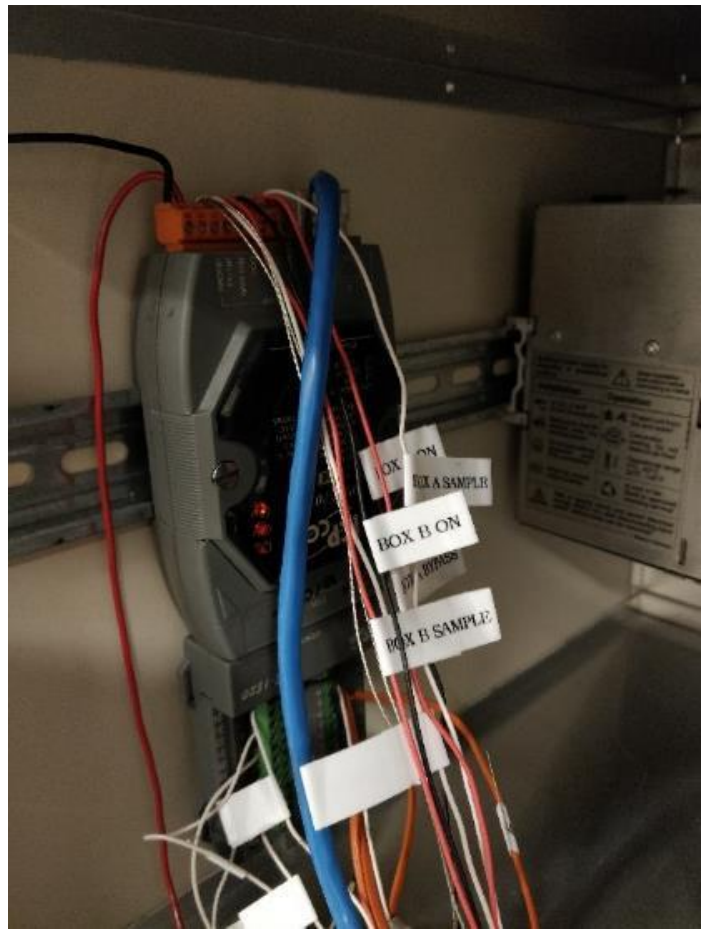

Figure 90: ICP-CON \#1 in DAQ Box mounted on Analyzer Rack Test Stand. 


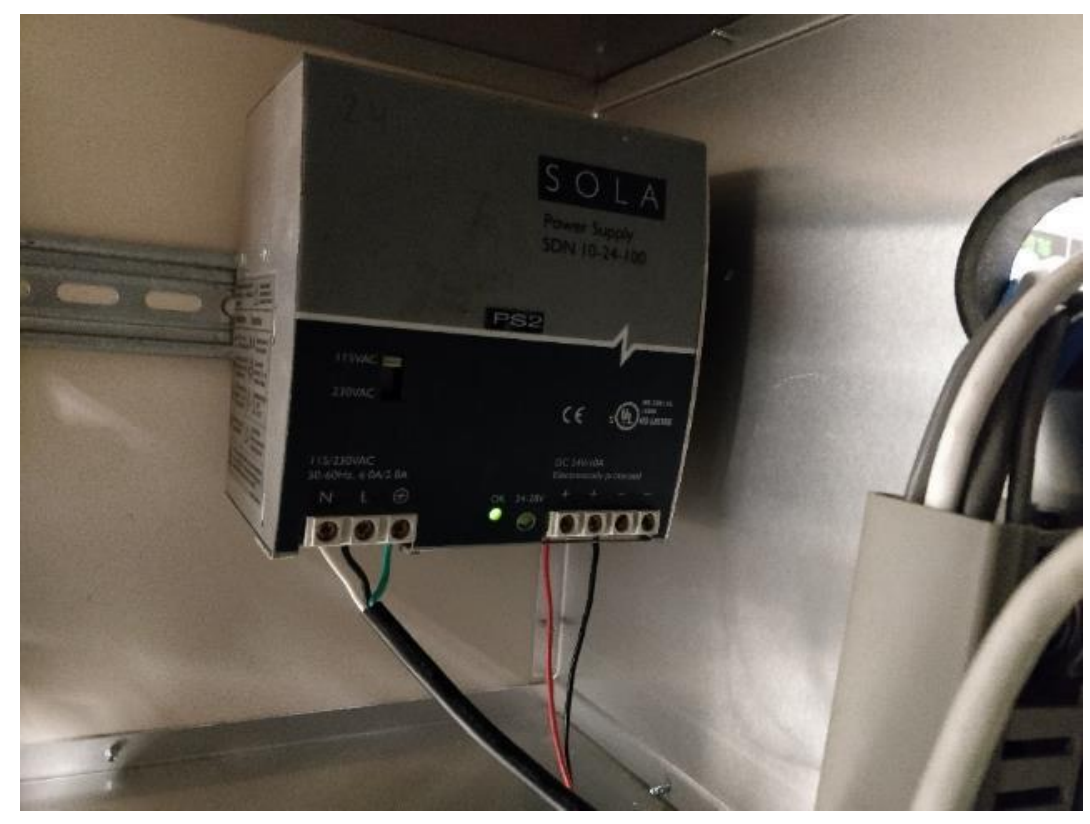

Figure 91: Power Supply for Equipment in DAQ Box on Analyzer Rack Test Stand.

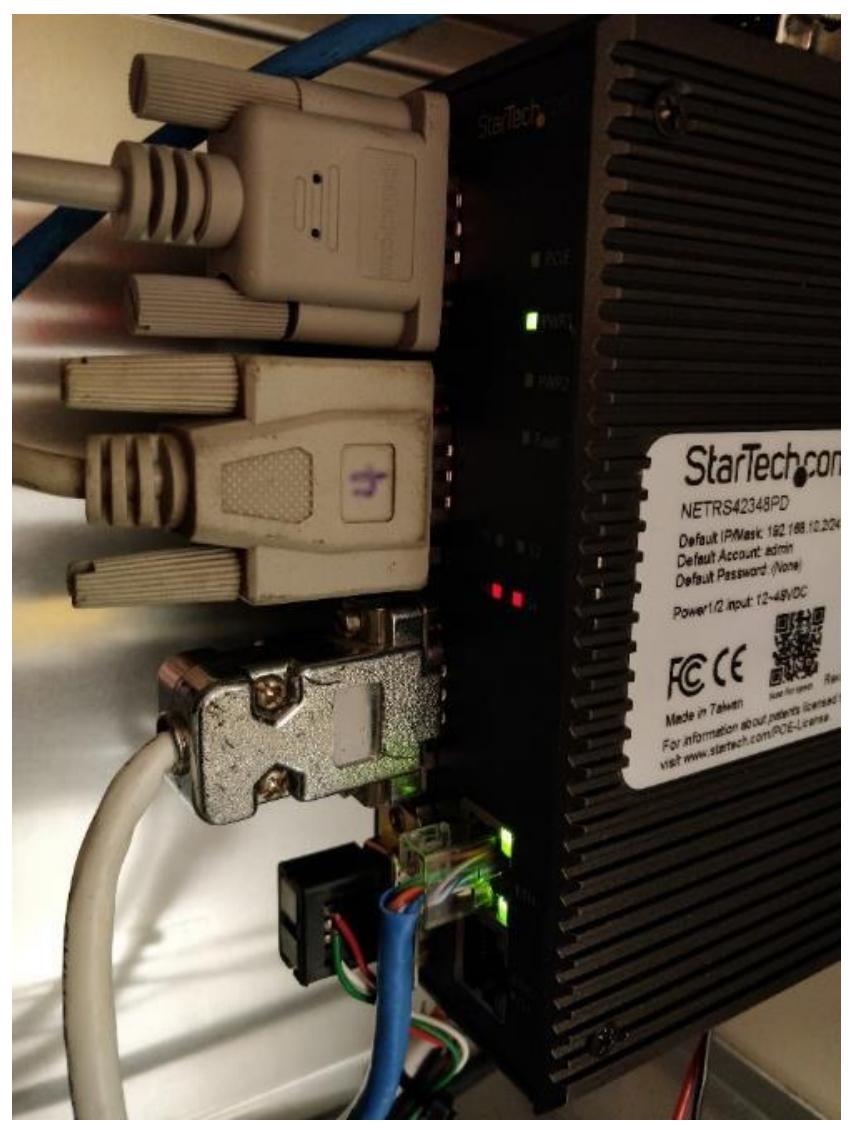

Figure 92: StarTech to connect CPC's, MSS's, and MFC's in DAQ Box on Analyzer Rack Test Stand. 


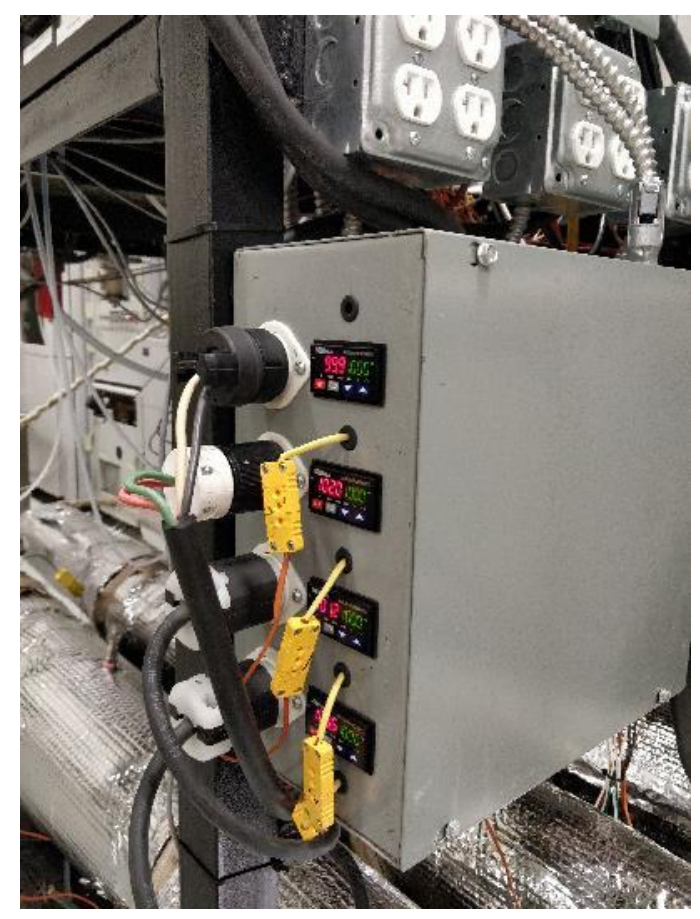

Figure 93: Front View of Temperature Controllers for Experimental Setup (Box \#1).

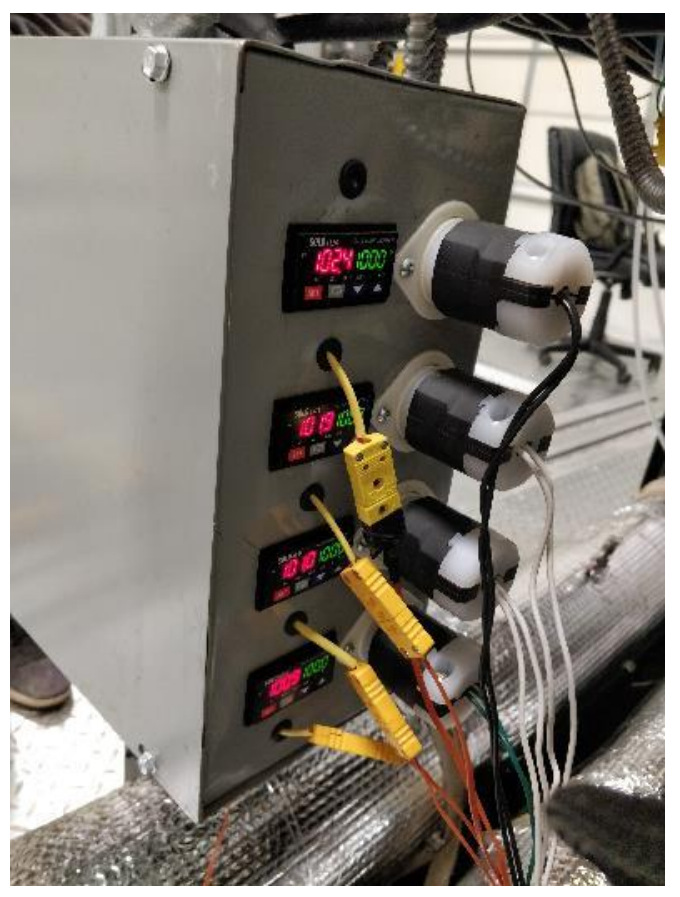

Figure 94: Back View of Temperature Controllers for Experimental Setup (Box \#1). 


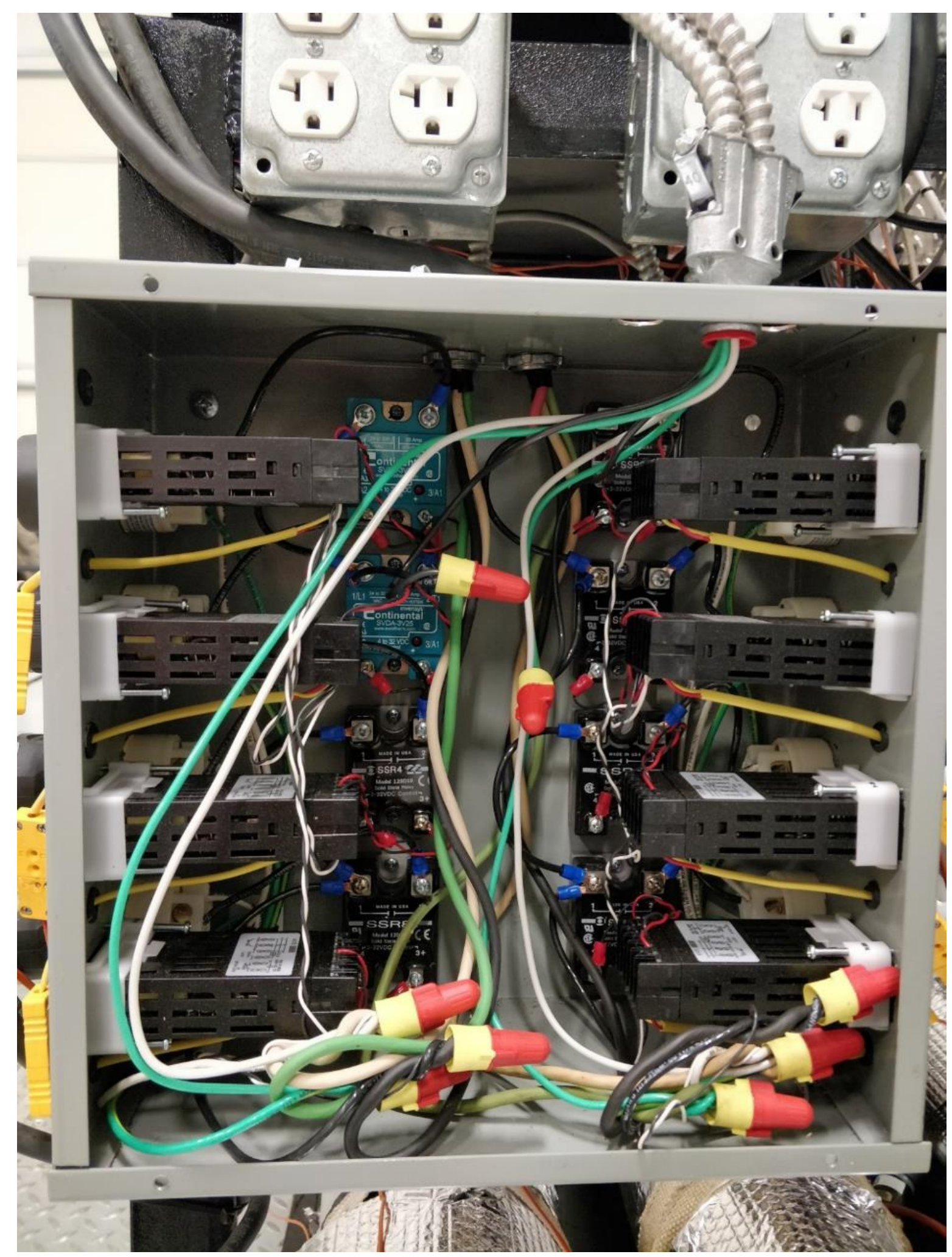

Figure 95: Uncovered Side View of Temperature Controllers for Experimental Setup (Box \#1). 


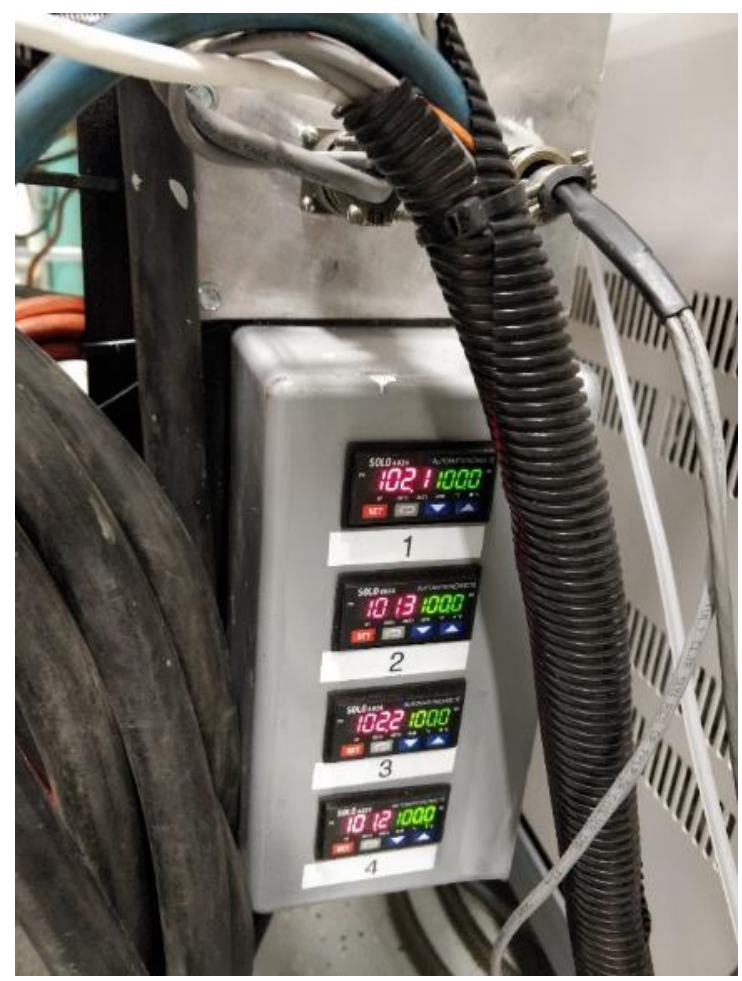

Figure 96: Front View of Temperature Controllers for Experimental Setup (Box \#2).

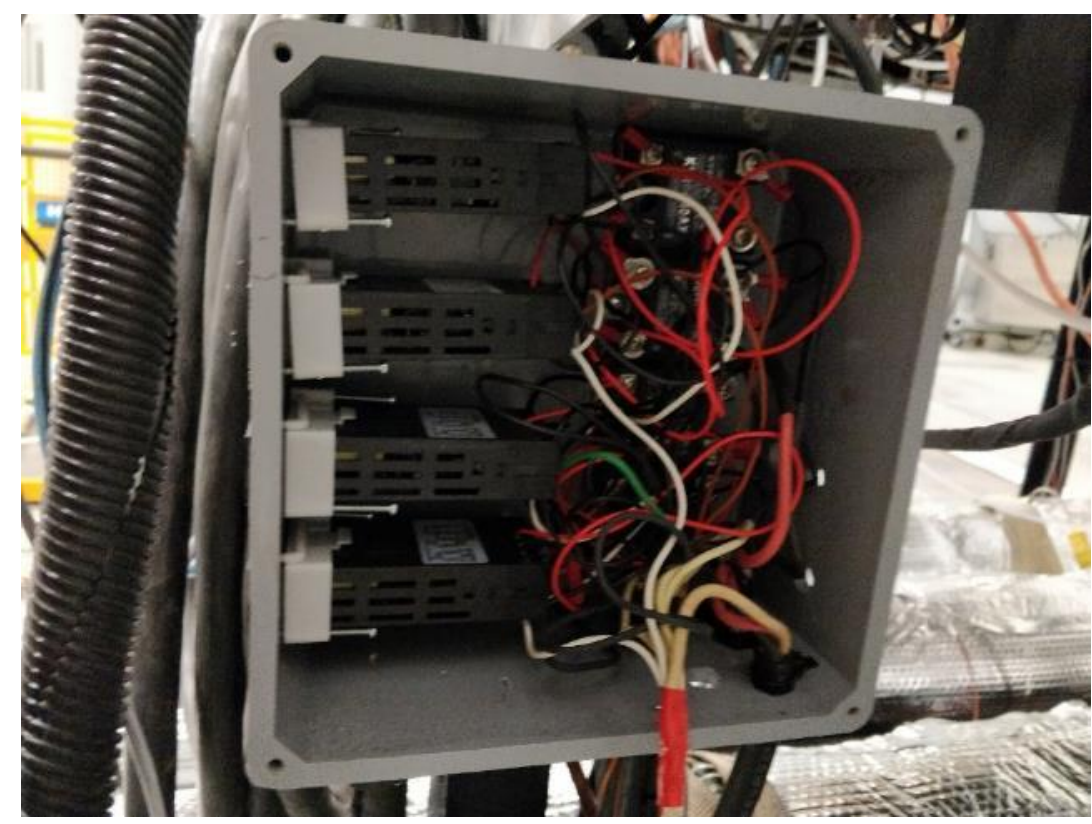

Figure 97: Uncovered Side View of Temperature Controllers for Experimental Setup (Box \#2). 


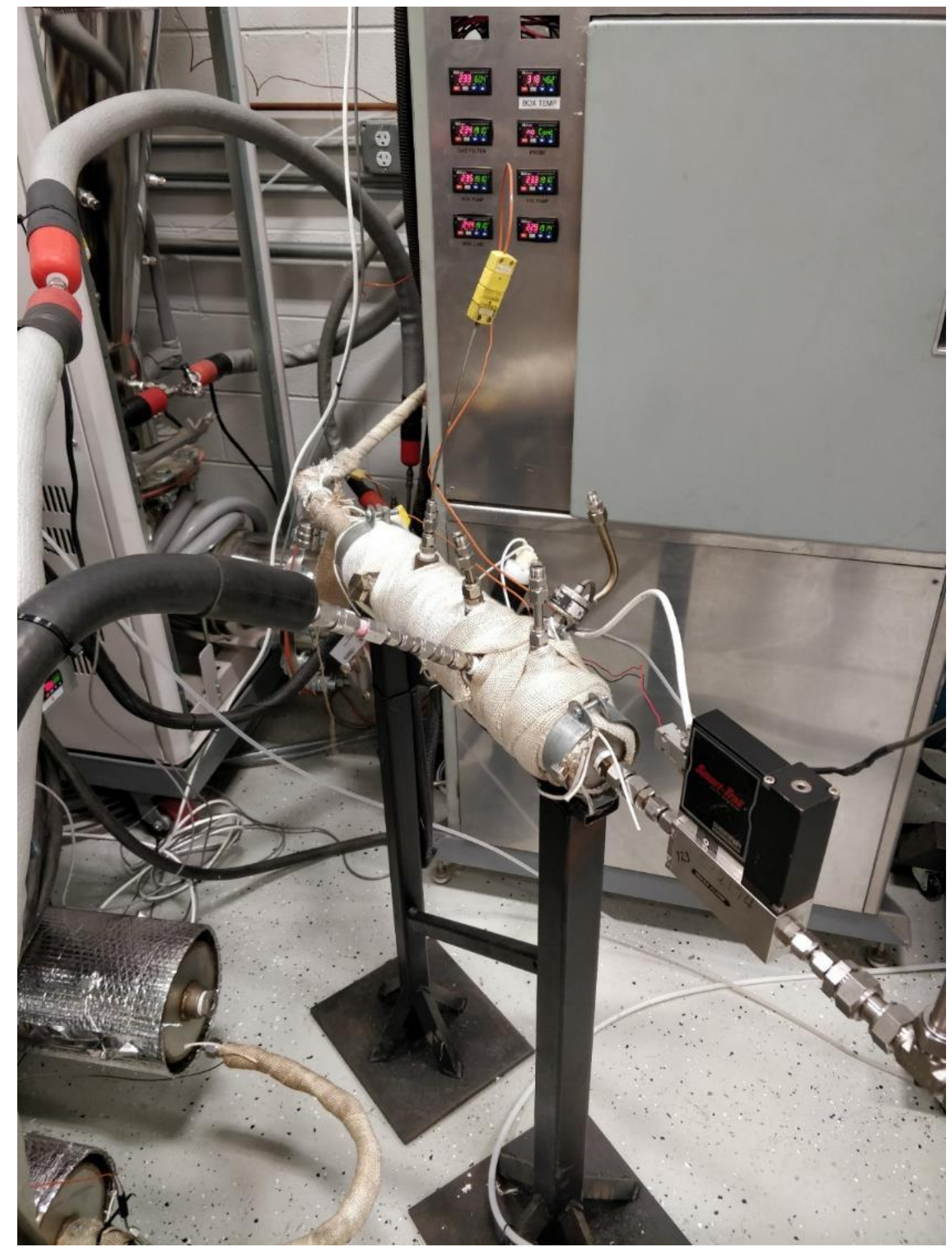

Figure 98: Dilution Tunnel for DR 2 with the DR 2 PM Box (DLMB) in the back. 


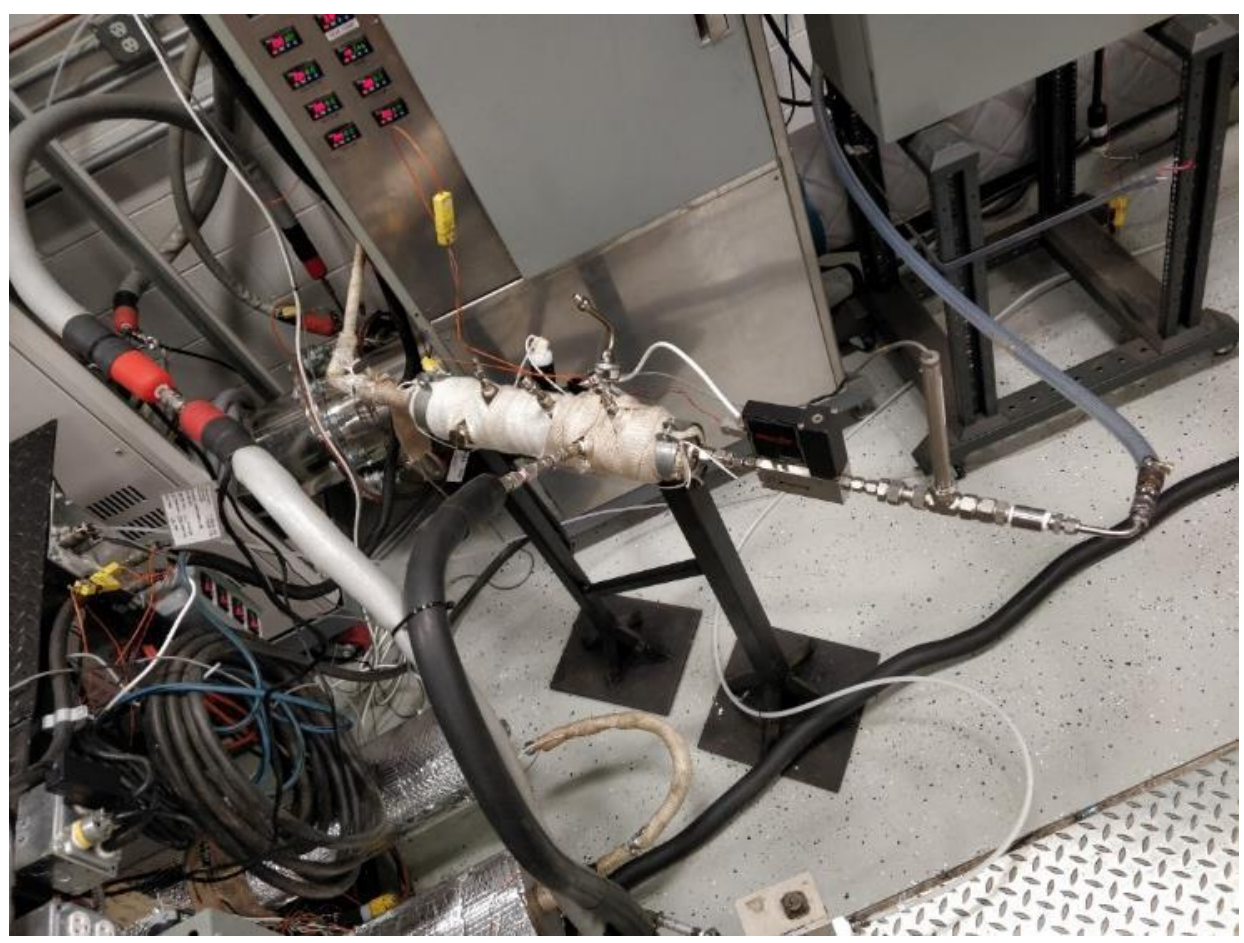

Figure 99: Dilution Tunnel for DR 2, Top View.

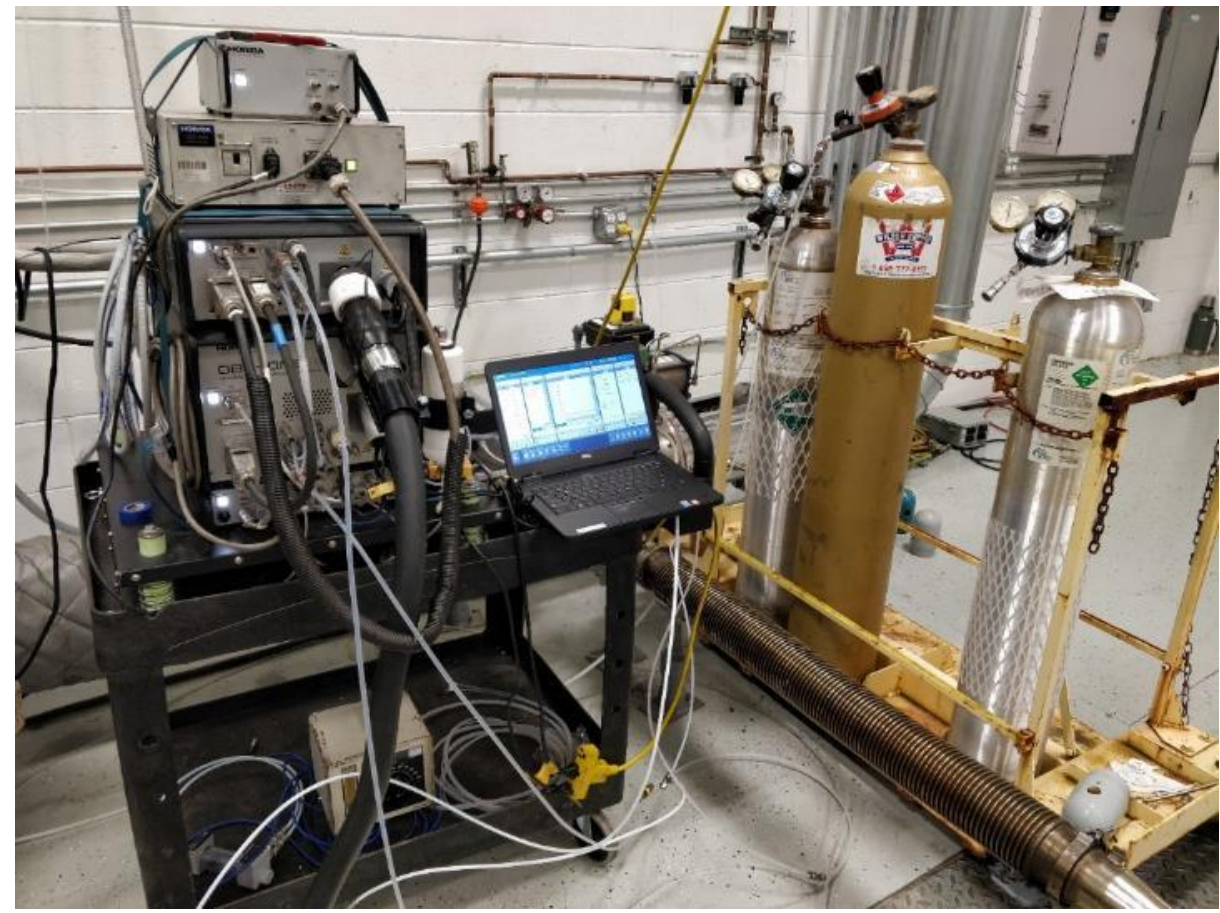

Figure 100: Horiba OBS-ONE used to Sample on DR 2 with Span/Zero Cal Gasses on Bottle Rack. 


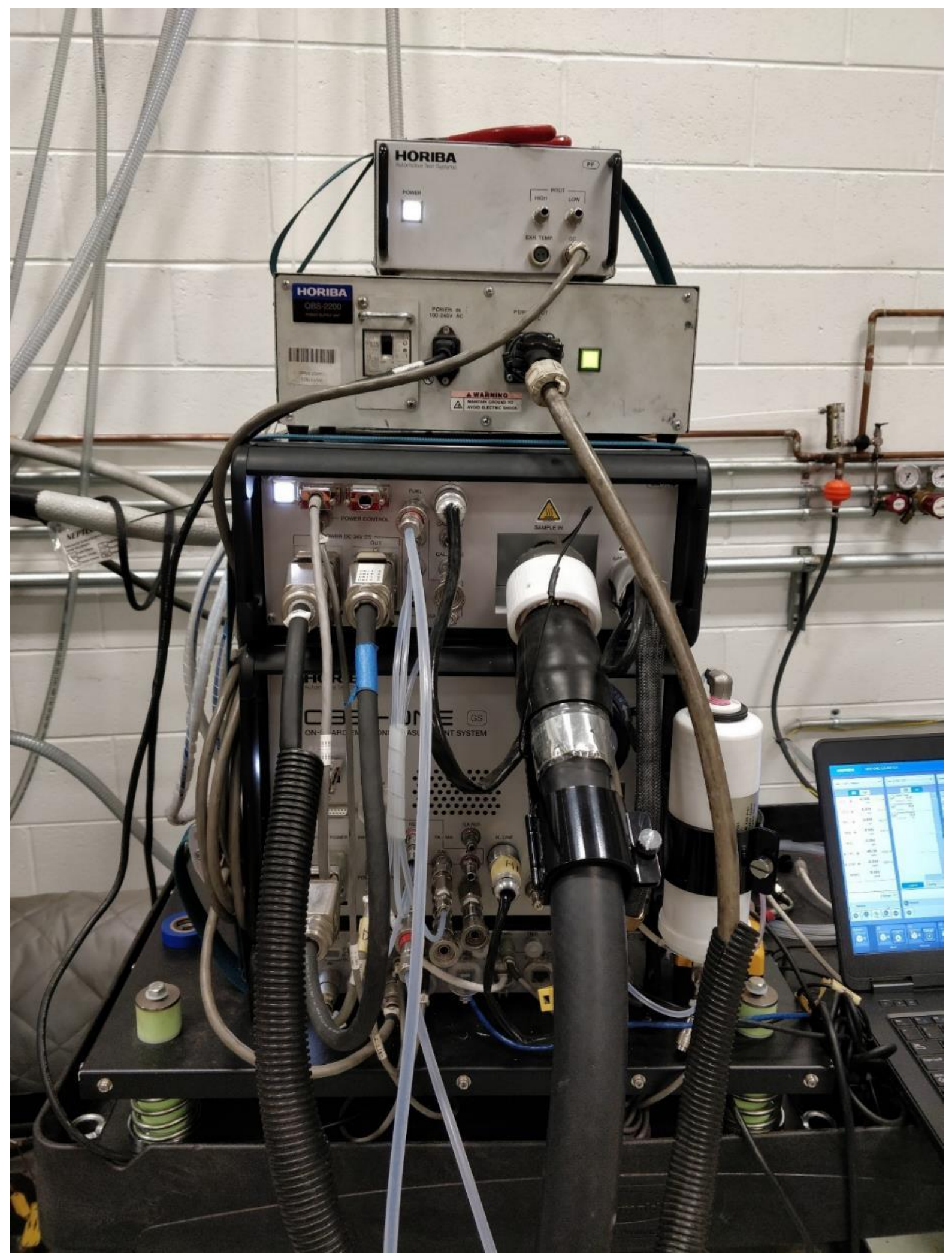

Figure 101: Horiba OBS-ONE Front View. 


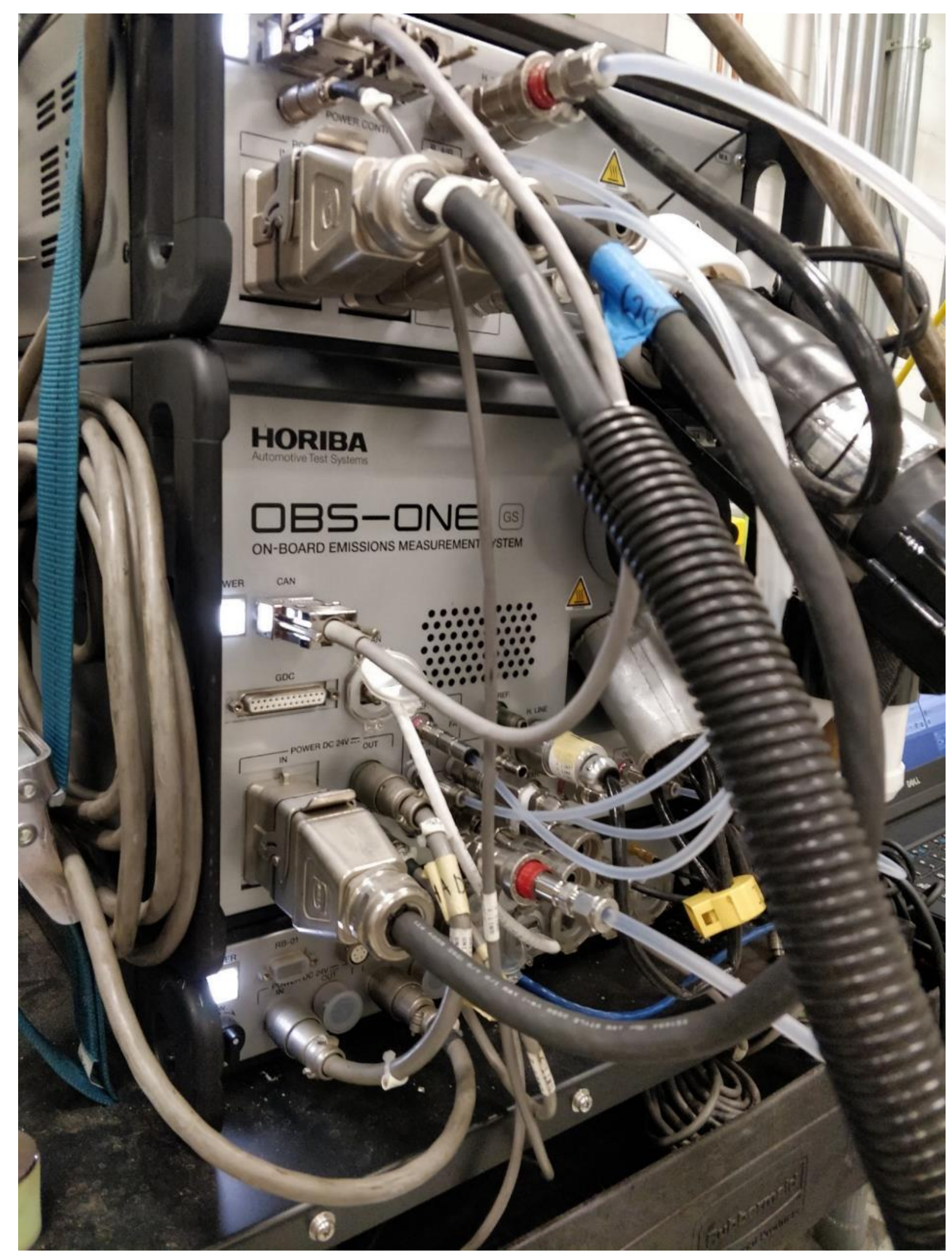

Figure 102: Horiba OBS-ONE Zoomed Side View. 


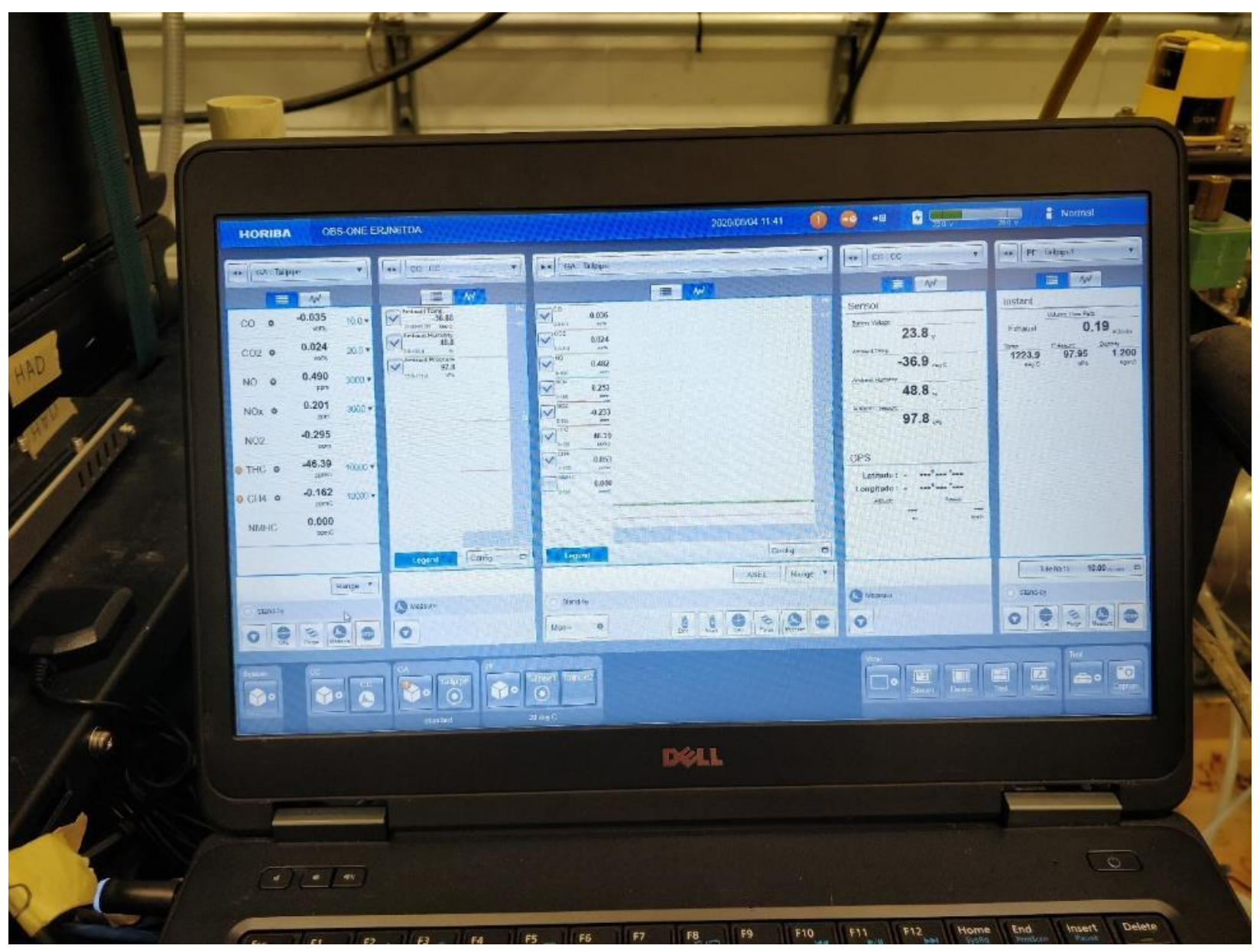

Figure 103: Horiba OBS-ONE Software Computer. 


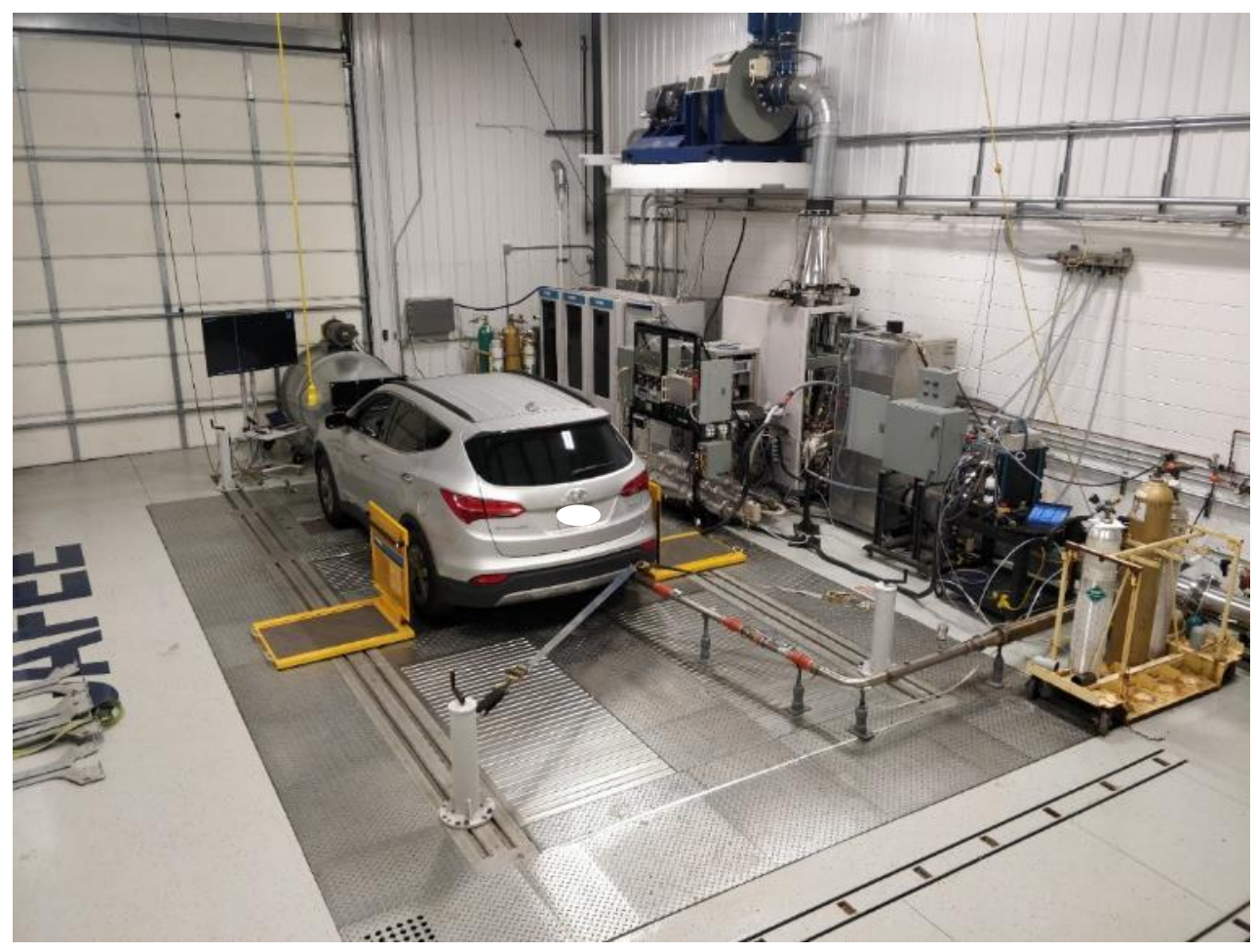

Figure 104: Overview of the Test Cell with the Hyundai Test Vehicle.

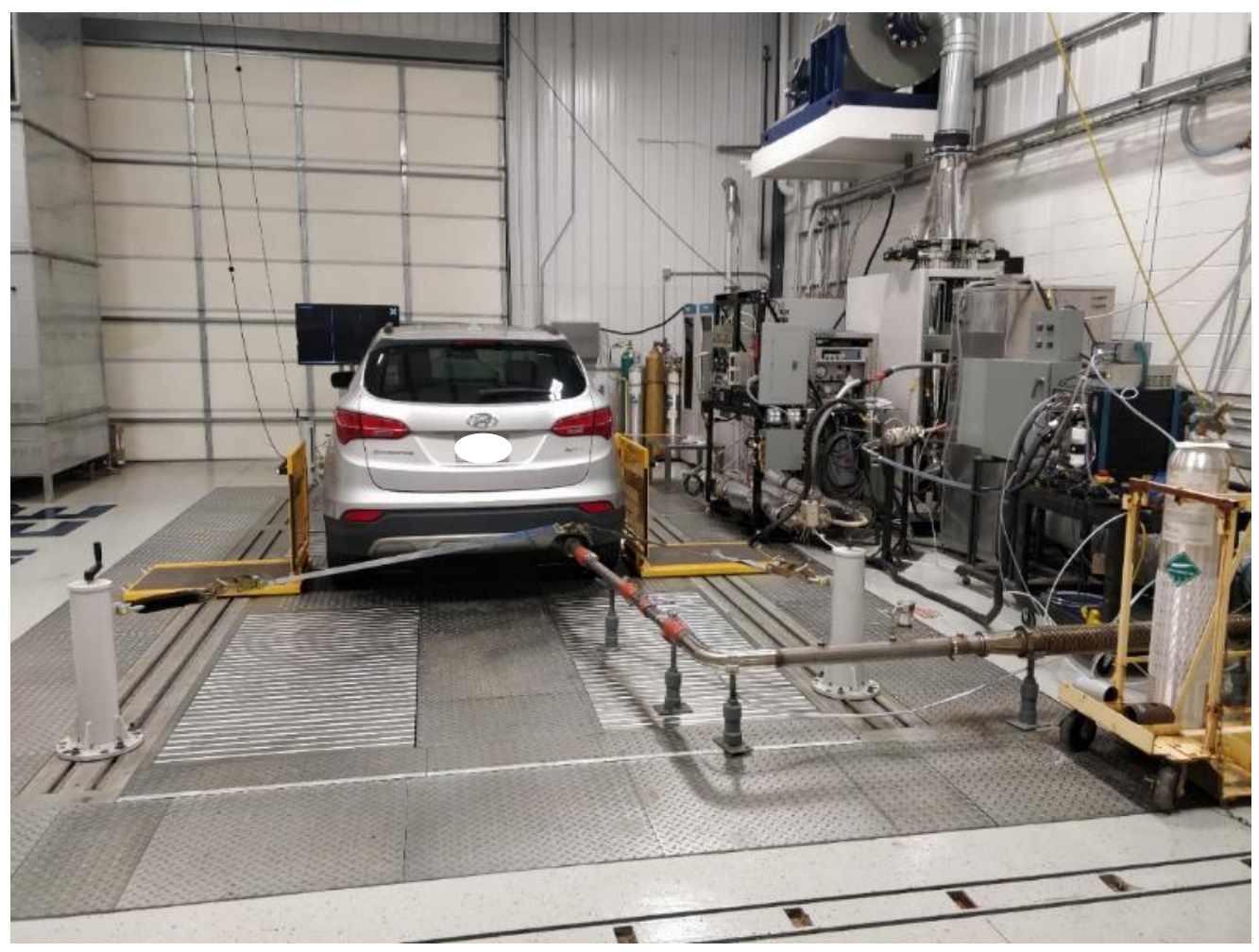

Figure 105: Rear View of the Test Cell with the Hyundai Test Vehicle. 


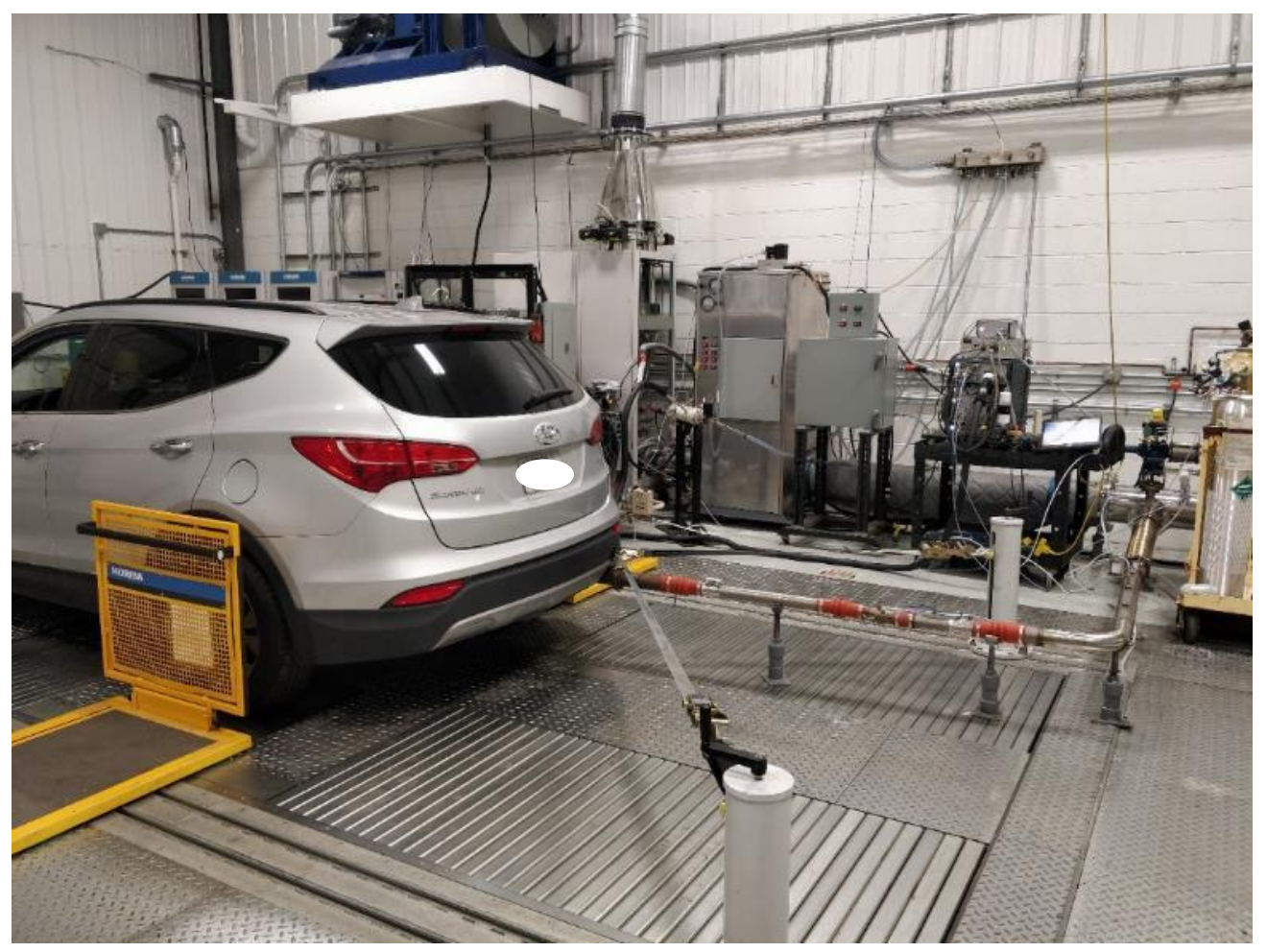

Figure 106: Side Rear View of the Test Cell with the Hyundai Test Vehicle.

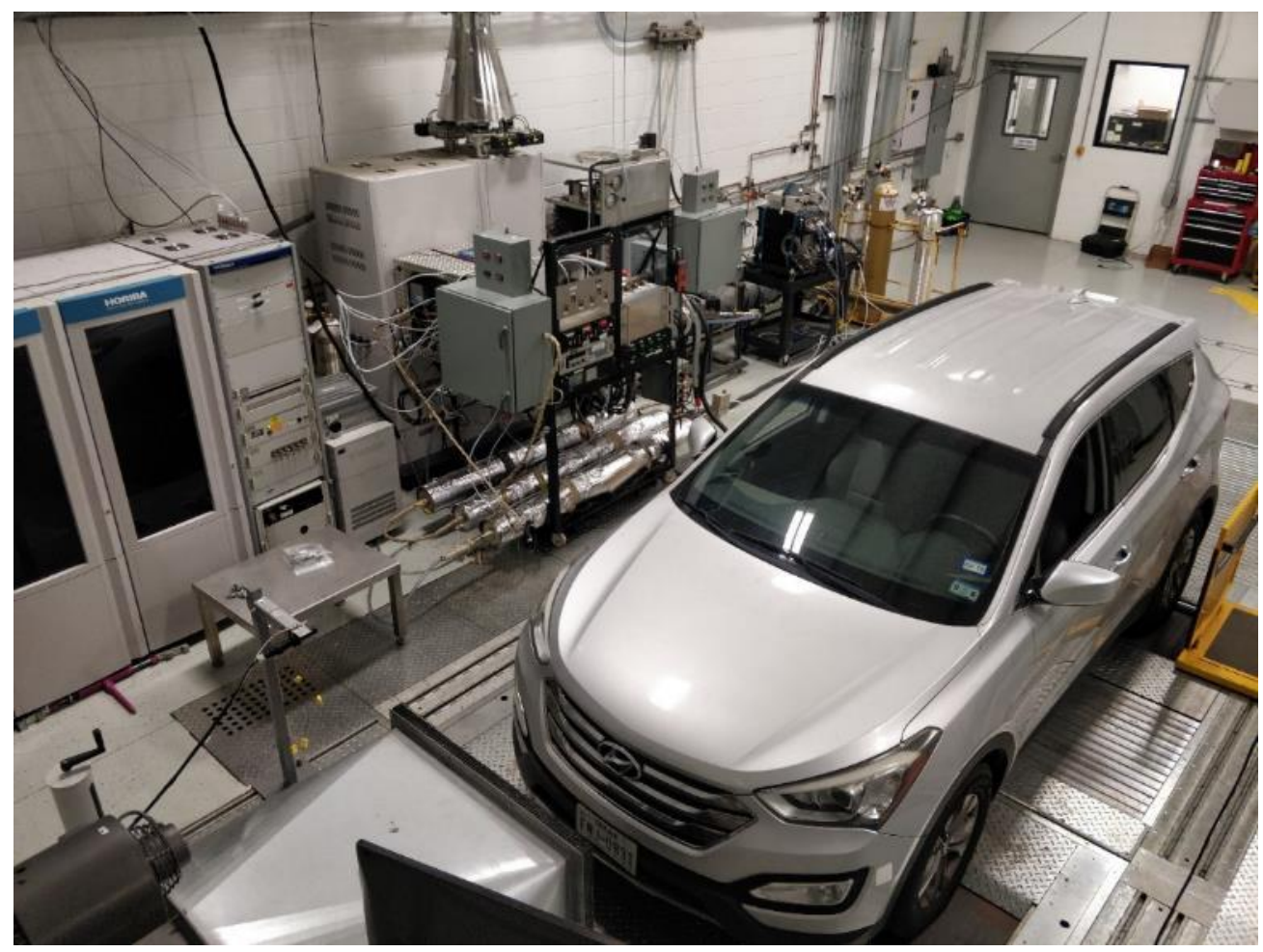

Figure 107: Front Top View of the Test Cell with the Hyundai Test Vehicle. 


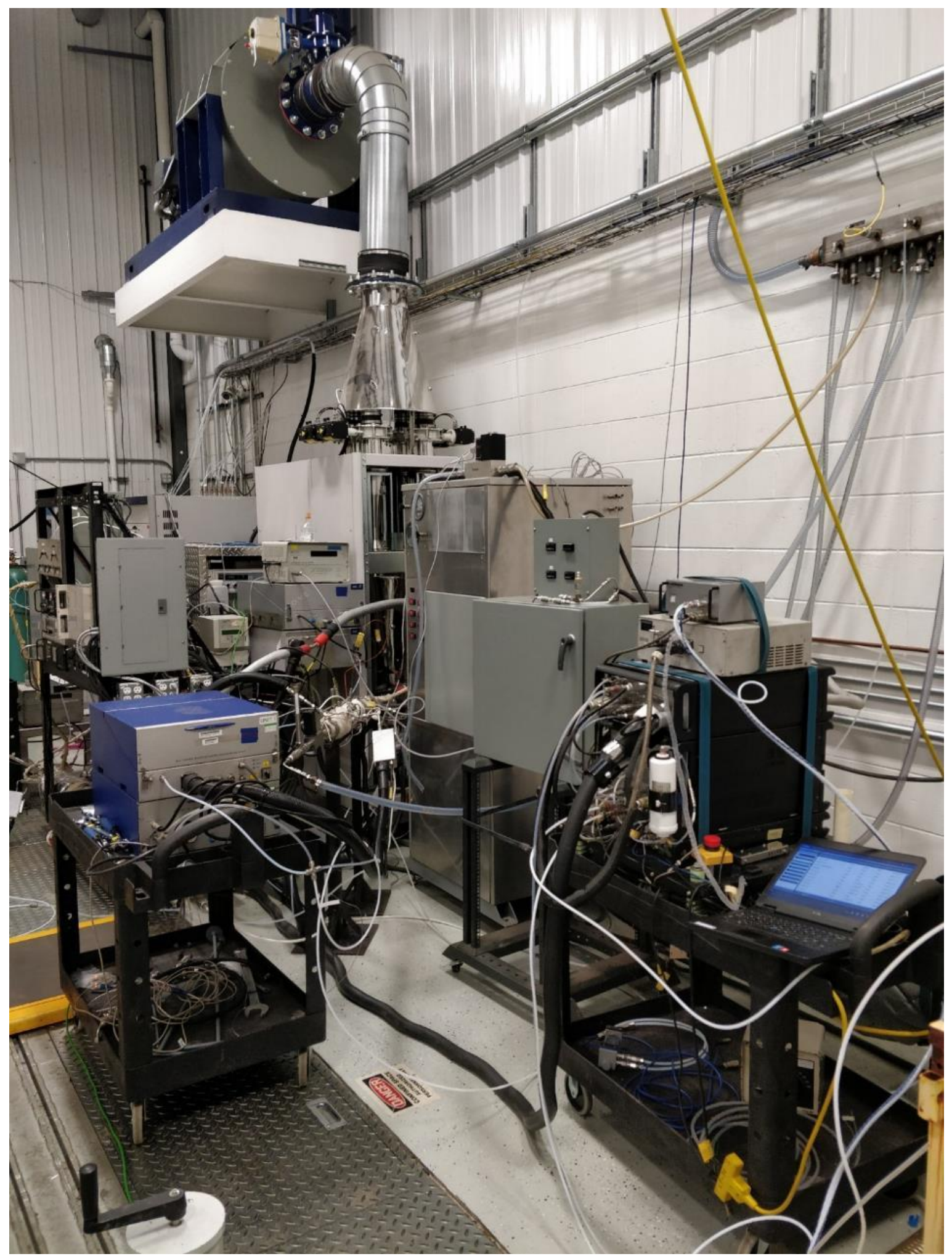

Figure 108: Image \#1 of all Equipment in place during the Hyundai Testing. 


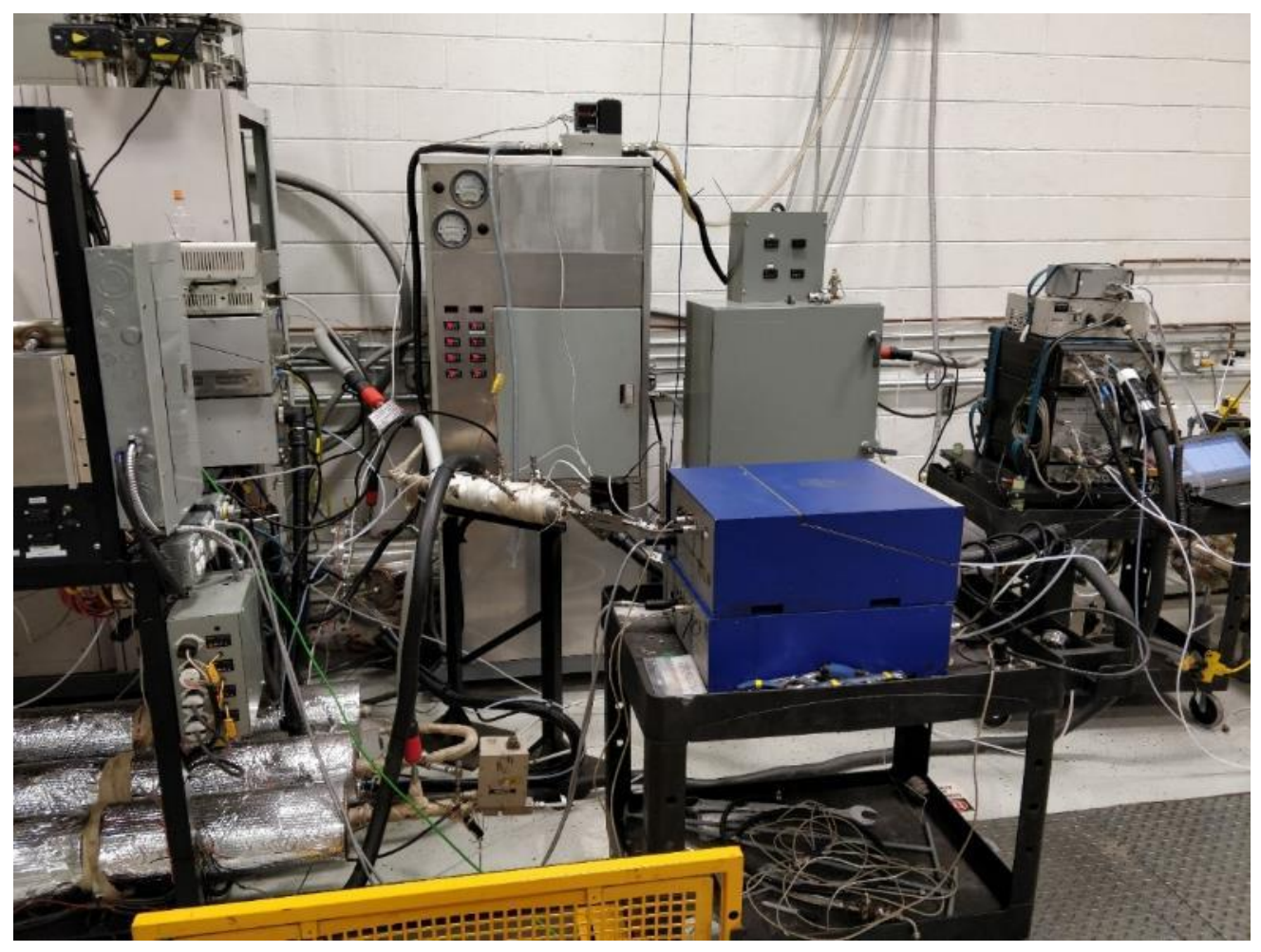

Figure 109: Image \#2 of all Equipment in place during the Hyundai Testing.

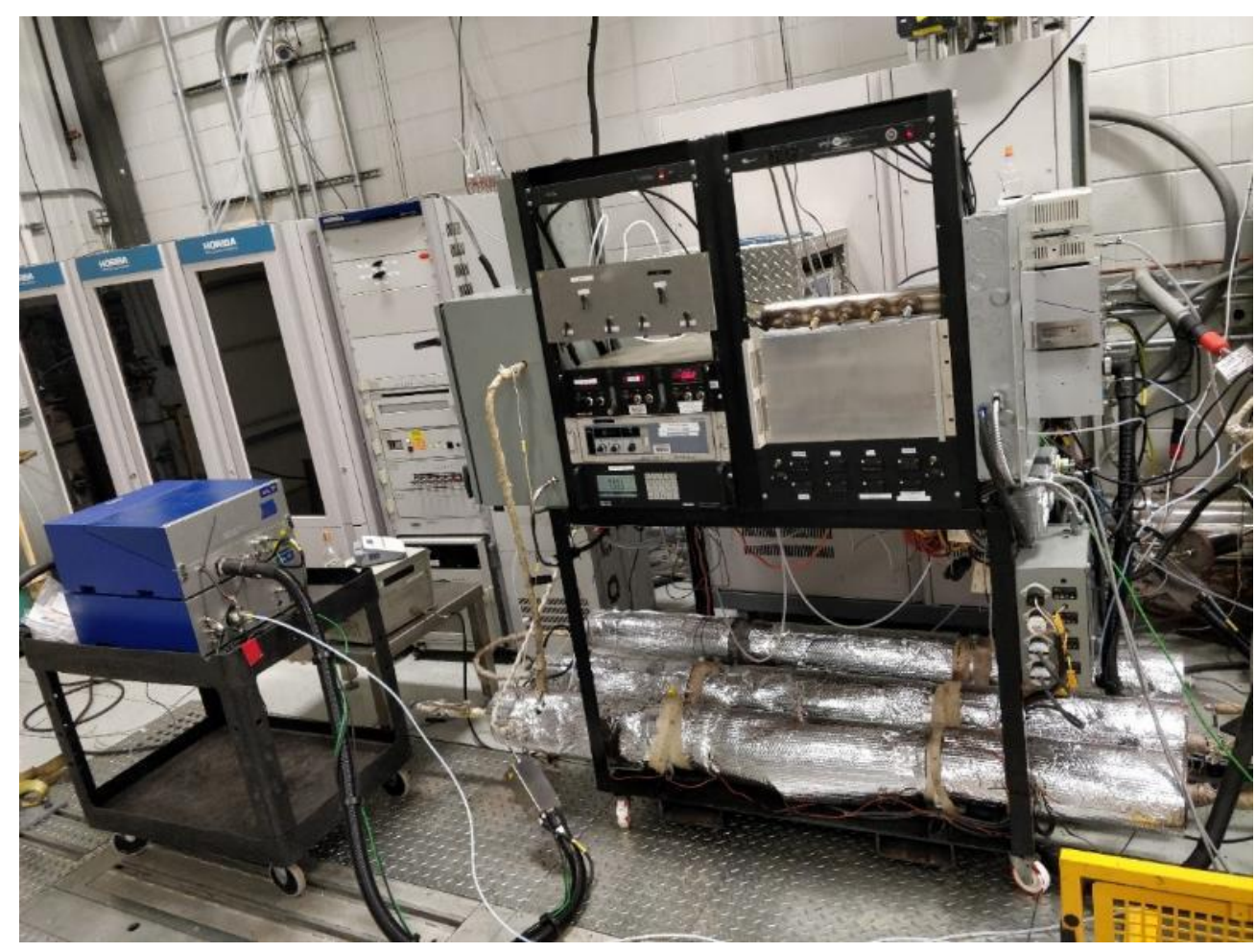

Figure 110: Image \#3 of all Equipment in place during the Hyundai Testing. 


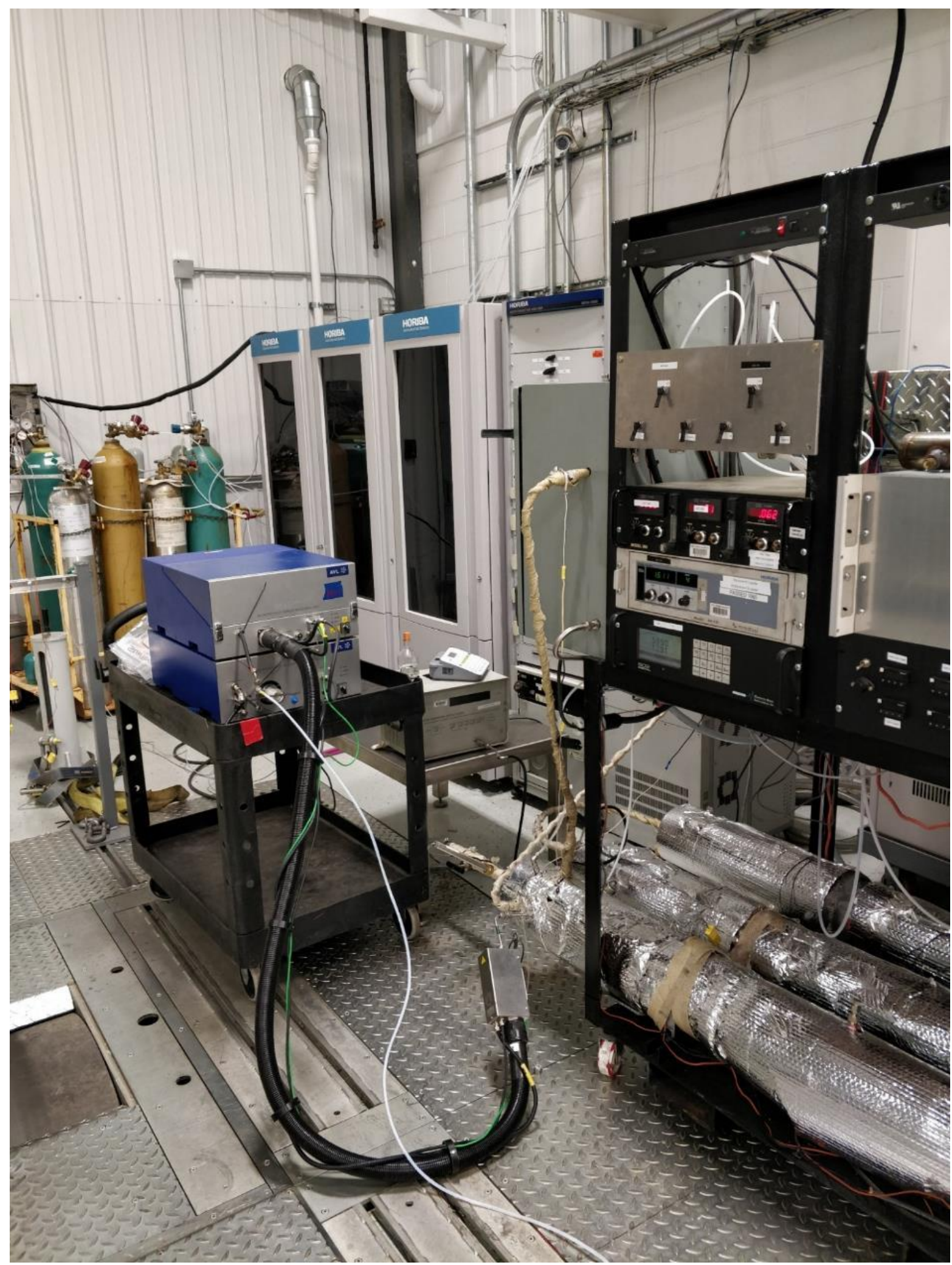

Figure 111: Image \#4 of all Equipment in place during the Hyundai Testing. 


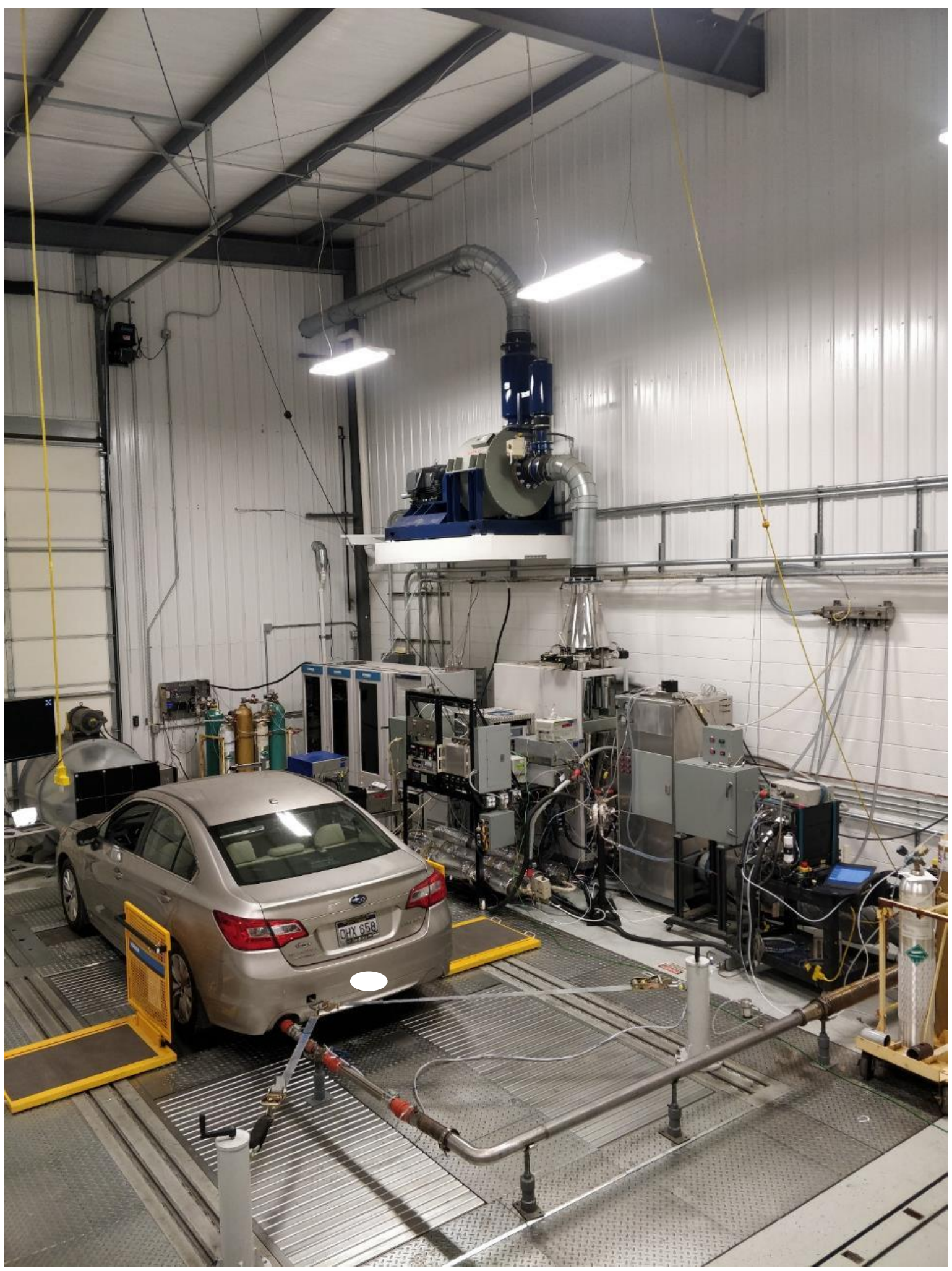

Figure 112: Image \#1 of the Test Cell During the Subaru Testing. 


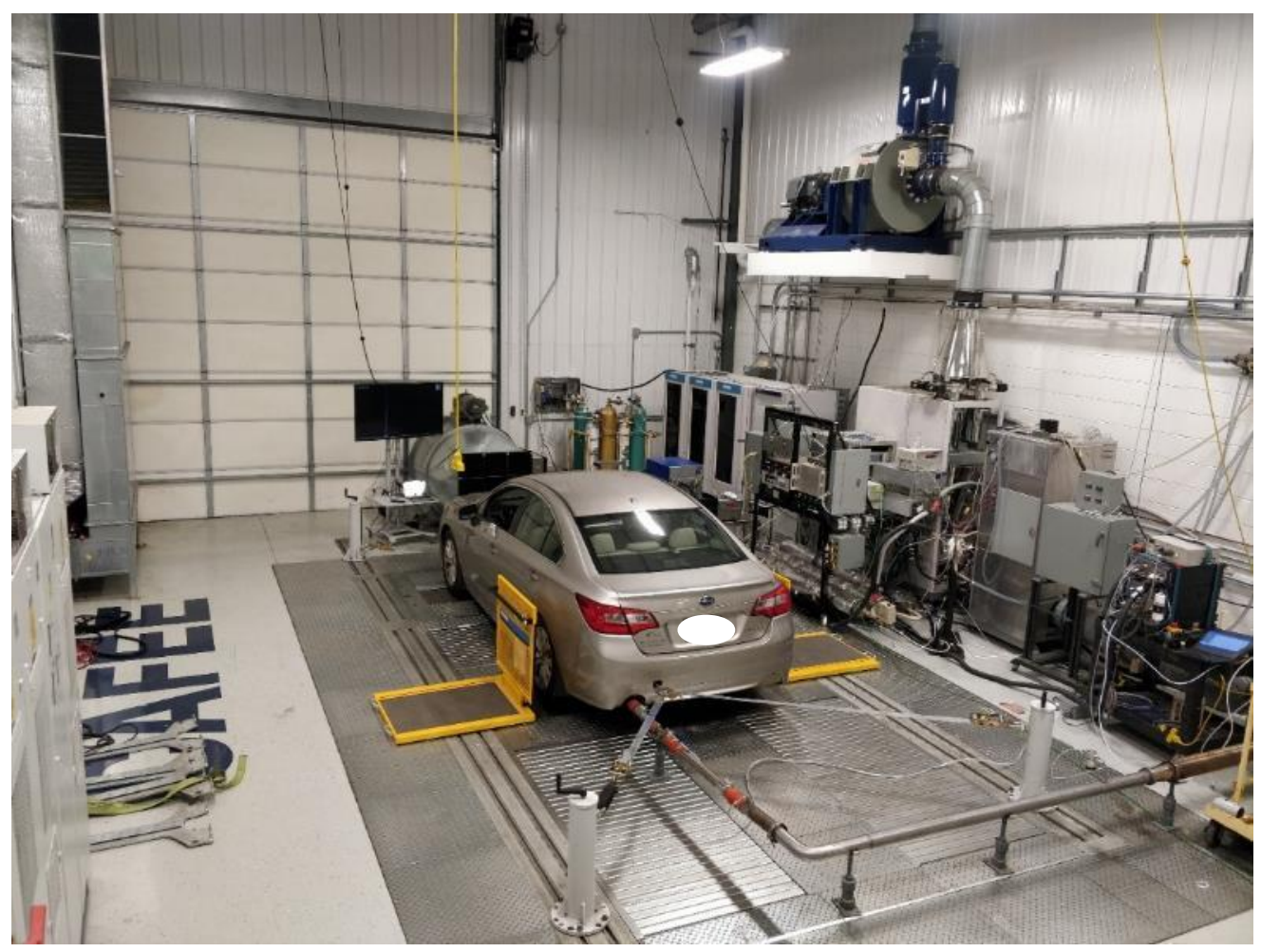

Figure 113: Image \#2 of the Test Cell During the Subaru Testing.

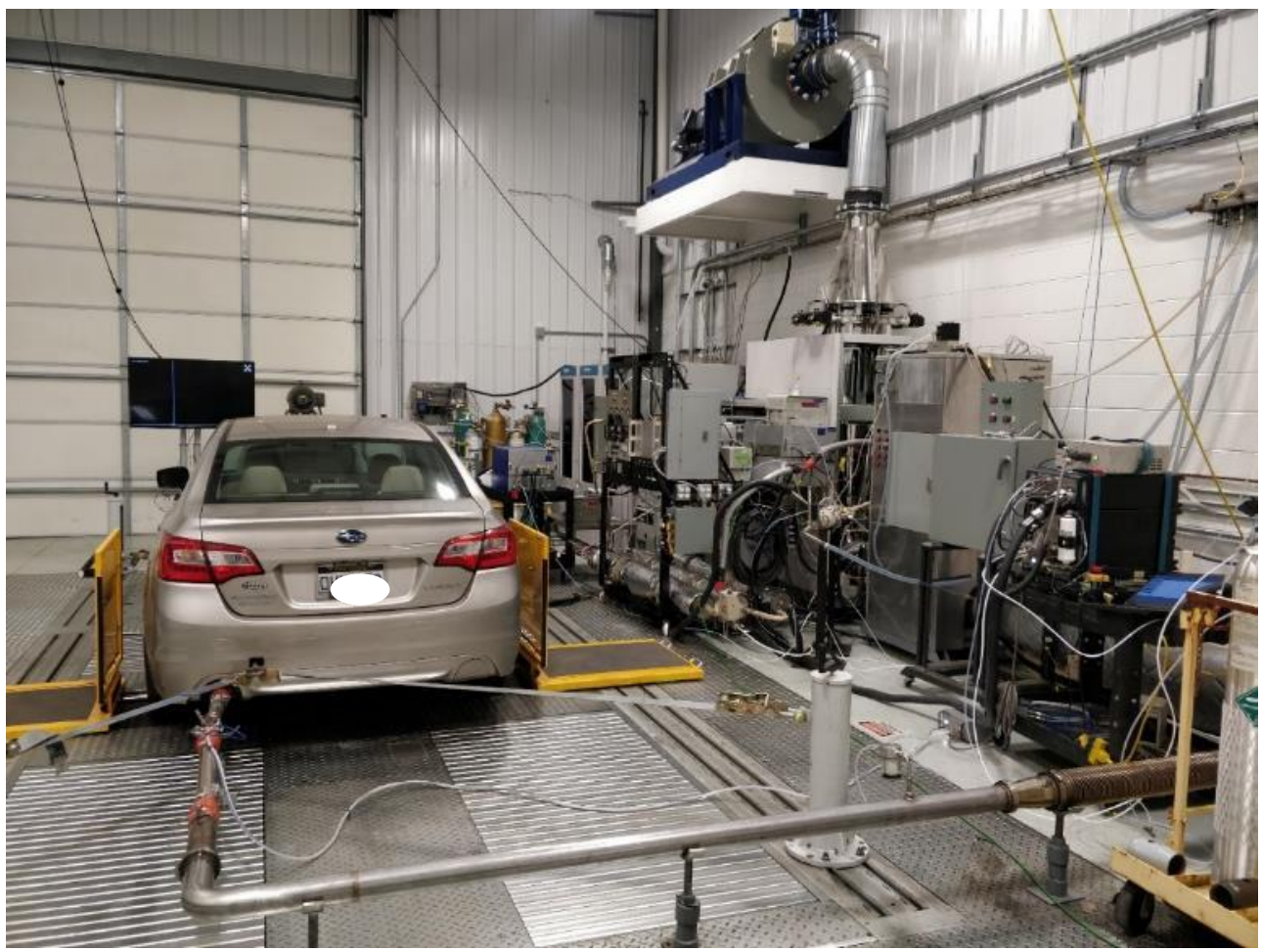

Figure 114: Image \#3 of the Test Cell During the Subaru Testing. 


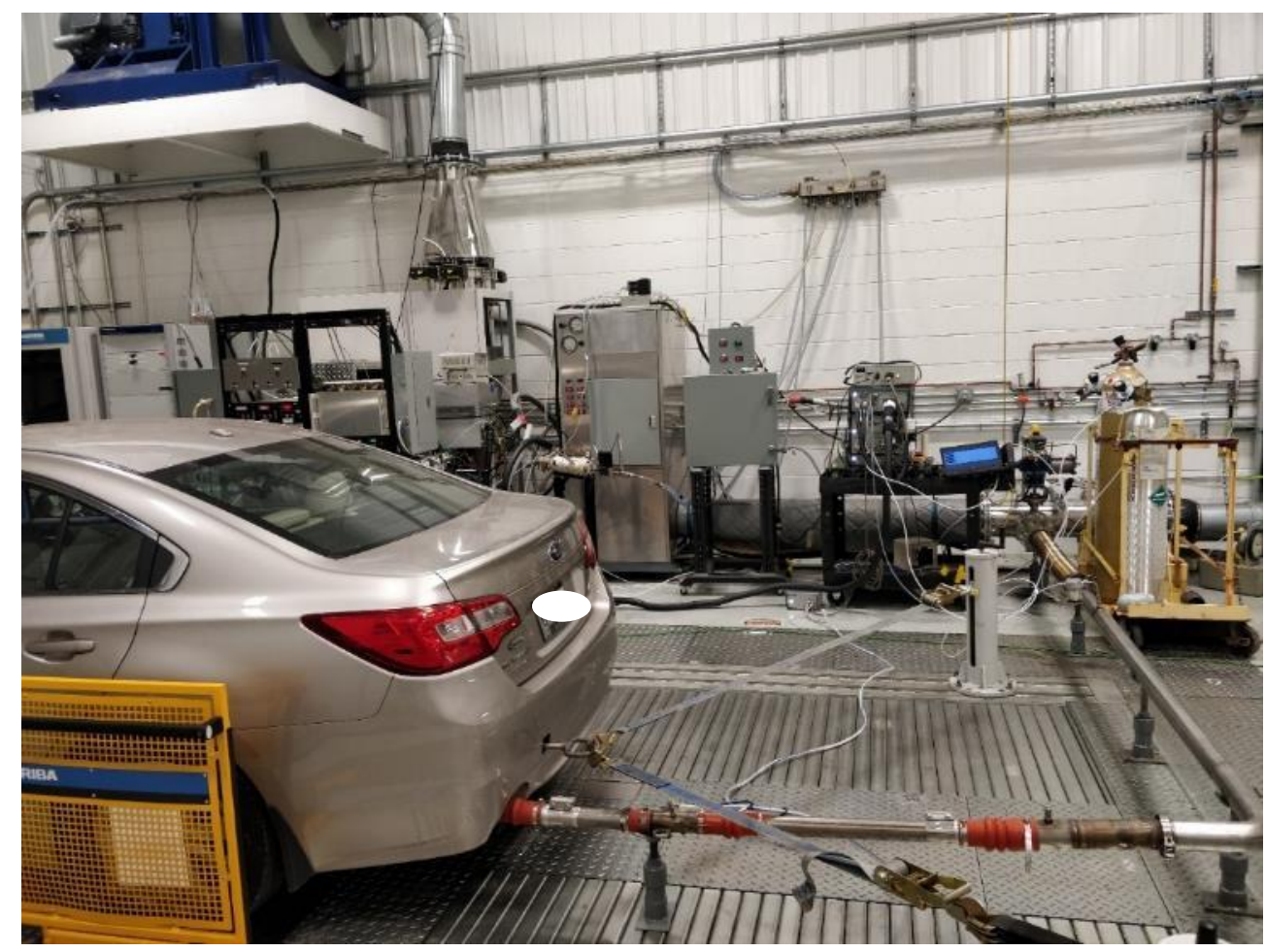

Figure 115: Image \#4 of the Test Cell During the Subaru Testing.

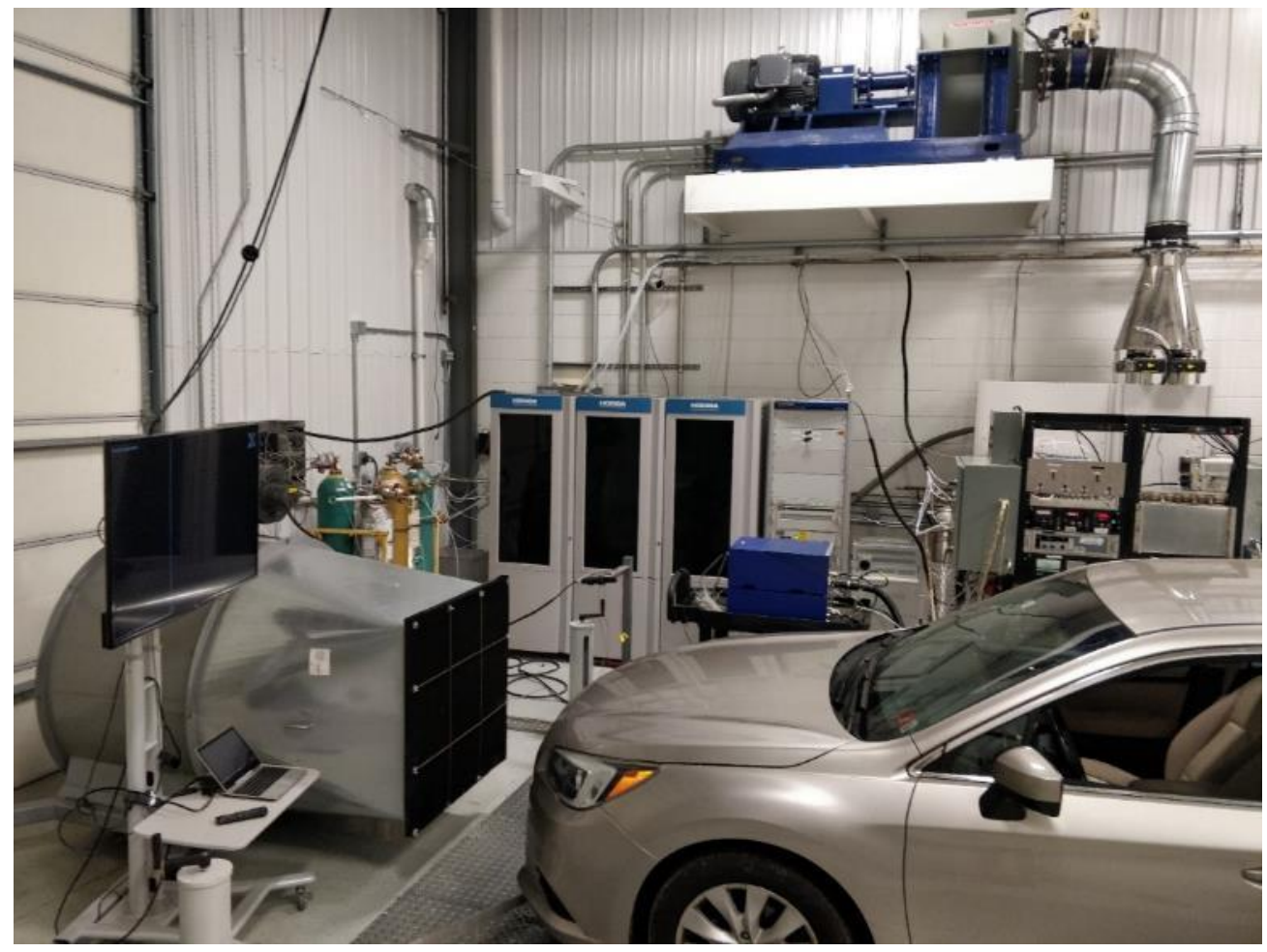

Figure 116: Image \#5 of the Test Cell During the Subaru Testing. 


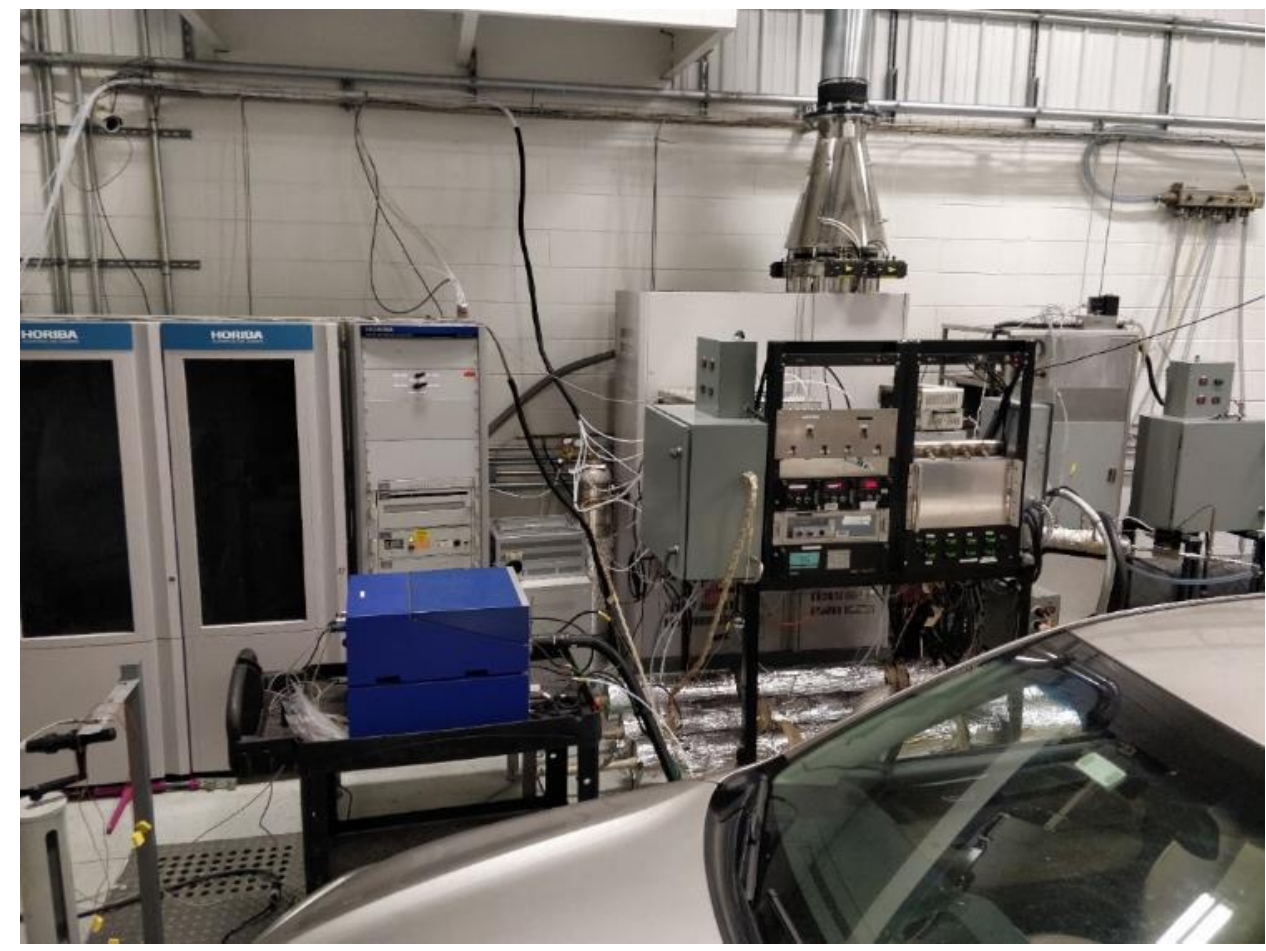

Figure 117: Image \#6 of the Test Cell During the Subaru Testing.

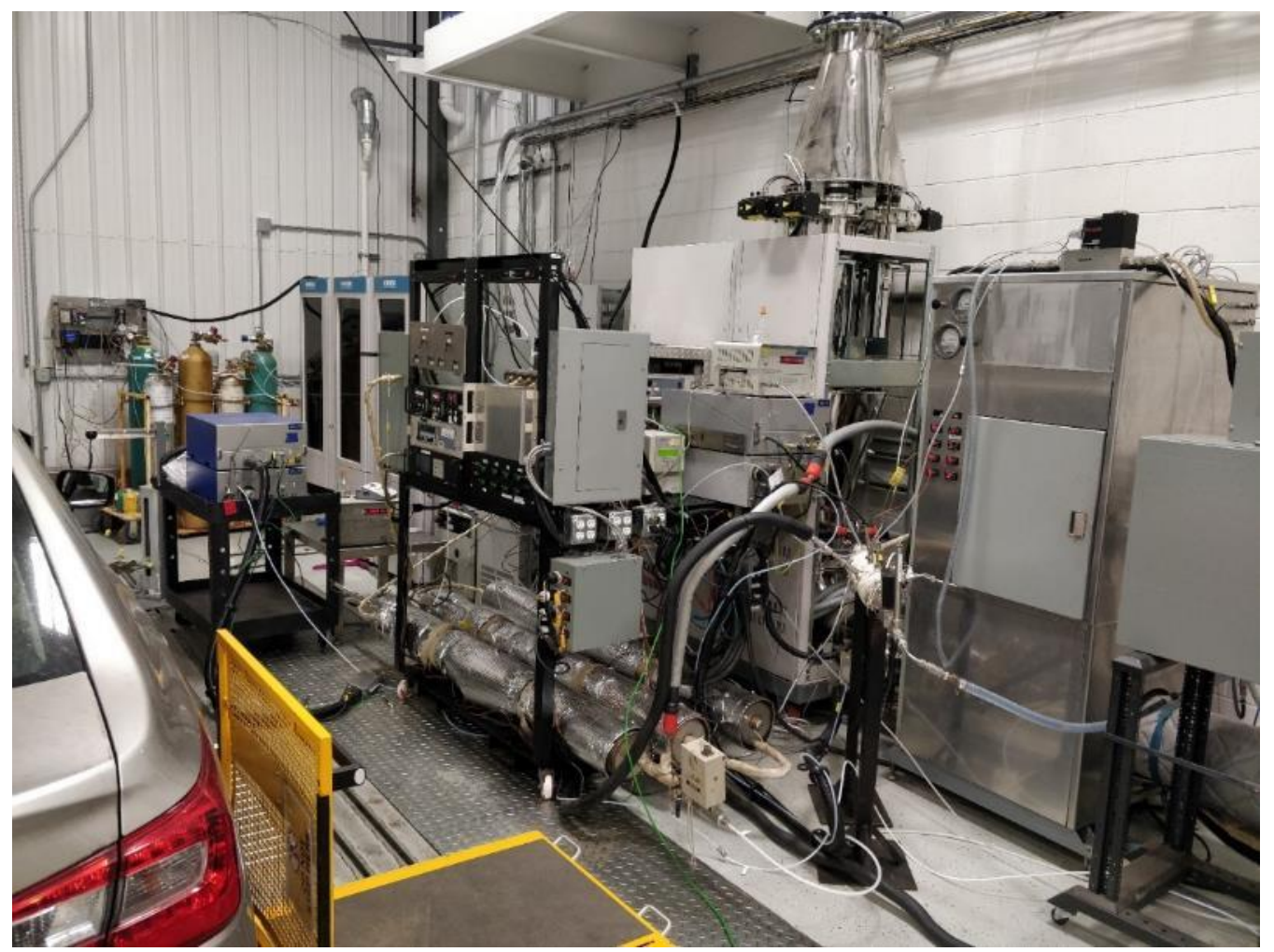

Figure 118: Image \#7 of the Test Cell During the Subaru Testing. 


\section{References}

Air-Vac. 2011. Air-Operated Vacuum Pumps. January 25. Accessed June 3, 2020. https://www.airvacpumps.com/AVstainless.html.

Awad, Omar I., Xiao Ma, Mohammed Kamil, Zhou Zhang Obed Majeed Ali, and Shijin Shuai. 2020. "Particulate emissions form gasoline firect injetion engines: A review of how current emissions regulations are being met by automobile manufacturers." Science of the Total Enviroment 718: 0-17.

Besch, Marc. Cyrill. 2016. In-line, Real-time Particulate Matter Sensors for OBD and Exhaust After-treatment System Control Applicaitons. PhD Disseratation, Morgantown, WV: Departmnet of Mechanical and Aerospace Engineering.

ECE/TRANS/505/Rev.7/Add.48. 2015. "Agreement, Addendum 48: Regulation No. 49, Revision 7."

EPA, Office of Transprotation and Air Quality's. 2020. The 2019 EPA Automotive Trends Report. EPA Automotive Trends Report, Ann Arbor: United States Enviromental Protection Agency.

Eviromental Protection Agency. 2014. "Federal Register." Control of Air Pollution From Motor Vehicles: Tier 3 Motor Vehicle Emissions and Fuel Standards; Final Rule. Vol. 79. National Arcihves and Records Administration, April 28. Accessed May 1, 2020. https://www.govinfo.gov/content/pkg/FR-2014-04-28/pdf/2014-06954.pdf.

GCC. 2006. Mercedes-Benz Premiers New Gasoline Direct Injection System for More Power and Lower Fuel Consumption. Feburary 24. Accessed 5 26, 2020. https://www.greencarcongress.com/2006/02/mercedesbenz_pr.html.

Heywood, John B. 1988. Internal Combustion Engine Fundamentals. McGraw-Hill Publishing Company.

Karavalakis, Georgios, Daniel Short, Diep Vu, Robert L. Russell, Akua Asa-Awuku, Heejung Jung, Kent C. Johnson, and Thomas D. Durbin. 2015. "The impact of ethanol and isobutanol blends on gaseous and particulate emissions from two passenger cars equipped 
with spray-guided and wall-guided direct injection SI (spark ignition) engines." Energy 168-179.

Kittelson, David B. 1998. "Engines and Nano Particles: A Review." Journal of Aerosol Science 575-588.

Ko, Jinyoung, Kangjin Kim, Cha-Lee Myung Wonyong Chung, and Simsoo Park. 2018. "Characteristics of on-road particle number (PN) emissions from a GDIvehicle depending on a catalytic stripper (CS) and a metal-foam gasolineparticulate filter (GPF)." Fuel 363374.

Ko, Jinyoung, Kangjin Kim, Wonyong Chung, Cha-Lee Myung, and Simsoo Park. 2018. "Characteristics of on-road particle number (PN) emissions from a GDI vehicle depending on a catalytic stripper (CS) and a metal-foam gasoline particulate filter (GPF)." Fuel (Elsevier) 363-374.

McCaffery, Cavan, Hanwei Zhu, Chengguo Li, Thomas D. Durbin, Kent C. Johnson, Heejung Jung, Rasto Brezny, Michael Geller, and Georgios Karavalakis. 2019. "On-road gaseous and particulate emissions from GDI vehicles with and without gasoline particulate filters (GPFs) using portable emissions measurement systems (PEMS)." Science of the Total Enviroment.

Meriam. n.d. "User Manual Laminar Flow Elements." https://www.meriam.com/. Accessed 11 30, 2020. https://www.meriam.com/assets/LFE-User-Manual.pdf.

Moon, Seoksu, Tianyun Li, Kiyotaka Sato, and Hideaki Yokohata. 2017. "Governing parameters and dynamics of turbulent spray atomization from modern GDI injectors." Energy 89-100.

O'Keefe Controls Co. 2003. "Precision Metal Orifices - NPT Hex Nipple - Choked Flow of Gases."

O'Keefe Controls Co. Web Site. Accessed June 6, 2020. https://catalog.okeefecontrols.com/viewitems/precision-metal-orifices-nptconnections/precision-metal-orifices-npt-hex-nipple.

—. 2011. "Precision Metal Orifices - NPT Hex Nipple - Technical Considerations." O'Keefe Controls Co. Web Site. Accessed June 6, 2020. 
https://catalog.okeefecontrols.com/viewitems/precision-metal-orifices-nptconnections/precision-metal-orifices-npt-hex-nipple.

Raza, Mohsin, Longfei Chen, Felix Leach, and Shiting Ding. 2018. "A Review of Particle Number (PN) Emissions from Gasoline Direct Injection (GDI) Engines and Their Control Techniques." Energies 1-26.

Saito, Chika, Takahiko Nakatani, Y. Miyairi, Kazuya Yuuki, Mikio Makino, Hiroshi Kurachi, Wolfgang Heuss, et al. 2011. "New Particulate Filter Concept to Reduce Particle Number Emissions." SAE Technical Paper, No. 2011-01-0814.

Shouse, Kate C., and Richard K. Lattanzio. 2020. Clean Air Act: A Summary of the Act and Its Major Requirements. Congressional Research Service.

Sydbom, A., A. Blomberg, S. Parnia, N. Stenfors, T. Sandstorm, and S-E Dahlén. 2001. "Health effects of diesel exhaust emissions." European Respiratory Journal 733-746.

Zhao, Hua. 2009. Advanced Direct Injection Combustion Engine Technologies and Development. Woodhead Publishing. 